\section{TURNING THE TIDE}

\author{
Five Years of \\ Achieving the Dream \\ in Community Colleges
}

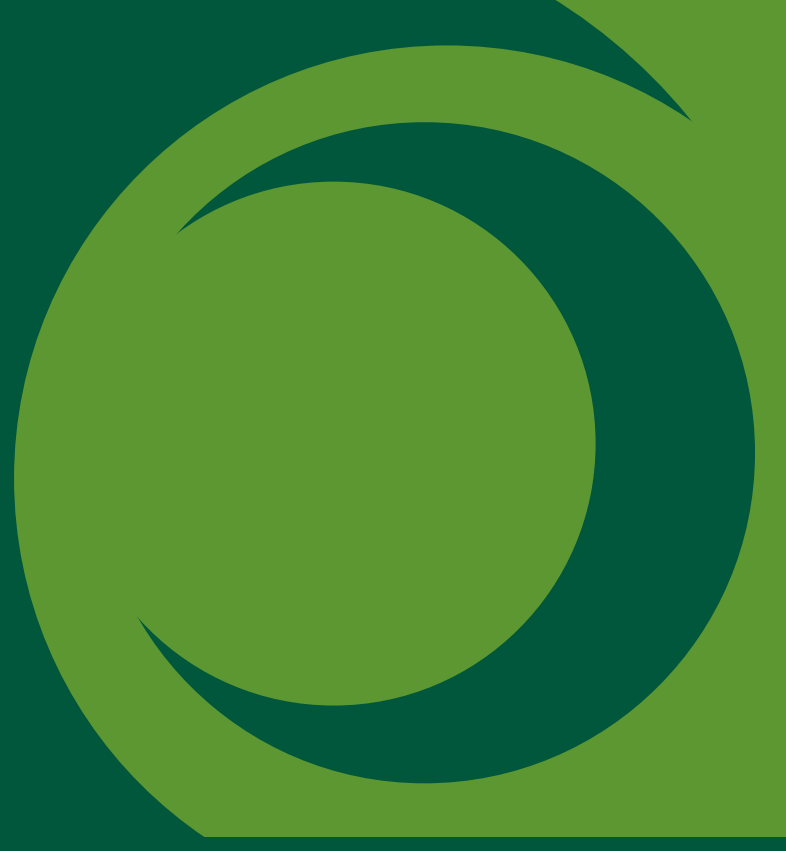





\title{
Turning the Tide \\ Five Years of Achieving the Dream in Community Colleges
}

\author{
Elizabeth Zachry Rutschow \\ Lashawn Richburg-Hayes \\ Thomas Brock \\ Genevieve Orr \\ Oscar Cerna \\ Dan Cullinan \\ (MDRC) \\ Monica Reid Kerrigan \\ (Rowan University and Community College Research Center) \\ Davis Jenkins \\ (Community College Research Center) \\ Susan Gooden \\ Kasey Martin \\ (Virginia Commonwealth University)

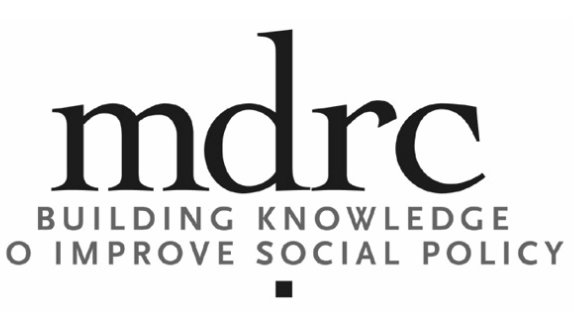

January 2011 
Funding for this report came from Lumina Foundation for Education.

Dissemination of MDRC publications is supported by the following funders that help finance MDRC's public policy outreach and expanding efforts to communicate the results and implications of our work to policymakers, practitioners, and others: The Ambrose Monell Foundation, The Annie E. Casey Foundation, Carnegie Corporation of New York, The Kresge Foundation, Sandler Foundation, and The Starr Foundation.

In addition, earnings from the MDRC Endowment help sustain our dissemination efforts. Contributors to the MDRC Endowment include Alcoa Foundation, The Ambrose Monell Foundation, Anheuser-Busch Foundation, Bristol-Myers Squibb Foundation, Charles Stewart Mott Foundation, Ford Foundation, The George Gund Foundation, The Grable Foundation, The Lizabeth and Frank Newman Charitable Foundation, The New York Times Company Foundation, Jan Nicholson, Paul H. O’Neill Charitable Foundation, John S. Reed, Sandler Foundation, and The Stupski Family Fund, as well as other individual contributors.

The findings and conclusions in this report do not necessarily represent the official positions or policies of the funders.

For information about MDRC and copies of our publications, see our Web site: www.mdrc.org. Copyright (C) 2011 by MDRC. ${ }^{\circledR}$ All rights reserved. 


\section{Overview}

In 2004, Lumina Foundation for Education launched "Achieving the Dream: Community Colleges Count," a national initiative aimed at improving success among community college students, particularly low-income students and students of color. Now encompassing more than 130 institutions in 24 states and the District of Columbia, Achieving the Dream helps community colleges build a "culture of evidence" by using student records and other data to examine students' performance over time and to identify barriers to academic progress. From there, community colleges are expected to develop intervention strategies designed to improve student outcomes; conduct further research on student progress; and bring effective programs to scale. As a result, it is anticipated that colleges will see measurable improvements over time in student outcomes, including increased progress through developmental education and college-level "gatekeeper" (introductory) courses, grades, persistence, and completion of credentials.

This report examines the first 26 colleges to join Achieving the Dream in 2004 (known as the "Round 1 " colleges), and tracks their progress through spring 2009. The key findings are:

- Four out of five Round 1 colleges adopted practices associated with a moderate to strong culture of evidence. These colleges made important enhancements to their institutions, including more sophisticated methods for data analysis and more efficient systems for monitoring their efforts to improve students' achievement. Conversely, about one-fifth of the colleges still struggled to implement many of the initiative's recommended practices, hindered primarily by weak institutional research capacity.

- Colleges that made the greatest strides shared several key characteristics, including broadbased involvement of college administrators, faculty, and staff; strong institutional research departments that produced accessible reports on student achievement; regular evaluations of their programs; and scale-up of successful programs.

- Colleges instituted a wide range of strategies to improve student achievement, but a majority of them remained small in scale. The most popular strategies were tutoring, supplemental instruction, advising, success courses, and learning communities. However, a majority of these reforms reached less than 10 percent of their intended target populations.

- Achieving the Dream had an important influence on most colleges. Representatives from three-fourths of the colleges said that the initiative had at least some influence on their development of a culture of evidence. Other important influences included accreditation systems, grants in addition to those from Achieving the Dream, and visionary college leaders.

- Trends in student outcomes remained relatively unchanged, with a few exceptions. On average, after Achieving the Dream was introduced, colleges saw modest improvements in the percentage of students completing gatekeeper college English courses and courses completed. In contrast, students' persistence and the percentage of students completing developmental math, developmental English, developmental reading, and gatekeeper math courses remained substantially the same.

A final report on the Round 1 colleges, with a follow-up on the trends in student outcomes, is planned for 2012-2013. 



\section{Contents}

Overview iii

List of Tables, Figures, and Boxes vii

Preface $\quad$ xi

Acknowledgments xiii

Executive Summary $\quad$ ES-1

\section{Chapter}

1 Introduction 1

A Brief History of Achieving the Dream 5

The Achieving the Dream Model and Theory of Change 9

Characteristics of Students at the Achieving the Dream Colleges at Baseline 13

Research Methods and Data Sources $\quad 15$

$\begin{array}{ll}\text { Organization of the Report } & 16\end{array}$

2 Leadership Commitment 19

Levers for Change in Achieving the Dream 22

Leadership Commitment to Student Success $\quad 23$

Leadership Commitment to Reducing Achieving Gaps 28

Senior Leaders' Exposure to Student Outcomes Data 32

Usefulness of Achieving the Dream's Inputs 34

Summary $\quad 35$

3 Use of Data to Prioritize Actions 37

Levers for Change in Achieving the Dream 40

Colleges' Data Capacity 41

Usefulness of Achieving the Dream's Inputs 47

$\begin{array}{ll}\text { Summary } & 51\end{array}$

$4 \quad$ Broad Engagement 53

Levers for Change in Achieving the Dream $\quad 55$

Engagement of Faculty and Staff $\quad 57$

$\begin{array}{ll}\text { Engagement of Students } & 64\end{array}$

$\begin{array}{ll}\text { Engagement of External Stakeholders } & 67\end{array}$

$\begin{array}{ll}\text { Summary } & 69\end{array}$

$5 \quad$ Intervention Strategies $\quad 71$

Achieving the Dream Framework for Strategy Implementation 72

$\begin{array}{ll}\text { Levers for Change in Achieving the Dream } & 74\end{array}$

$\begin{array}{ll}\text { Type and Reach of Strategies } & 75\end{array}$

Colleges' Use of Data to Inform Strategy Development and Refinement 93

$\begin{array}{ll}\text { Summary } & 95\end{array}$ 
$6 \quad$ Establishing a Culture of Continuous Improvement 97

Colleges' Development of a Systemic Institutional Improvement Process 99

The Influence of Achieving the Dream on Colleges' Systemic Institutional
Improvement Processes

$\begin{array}{lr}\text { Summary } & 108\end{array}$

7 Institutionalizing Change: Progress in Building a Culture of Evidence 111

$\begin{array}{ll}\text { Colleges' Overall Progress in Developing a Culture of Evidence } & 112\end{array}$

$\begin{array}{ll}\text { Summary } & 119\end{array}$

$8 \quad$ Trends in Academic Performance $\quad 121$

$\begin{array}{ll}\text { Methodology } & 124\end{array}$

Trends in Student Outcomes Among the Round 1 Colleges 125

$\begin{array}{ll}\text { Summary } & 142\end{array}$

9 Instituting Large-Scale Reform: Achieving the Dream in Context 145

Improvements to the Leadership Model in Achieving the Dream 146

Improvements to the Data Analysis Model in Achieving the Dream 151

Improvements to the Broad Engagement Model in Achieving the Dream 152

Recommendations for Policy Change 154

$\begin{array}{lr}\text { Conclusion } & 156\end{array}$

\section{Appendix}

A Methodology for Survey of Faculty and Administrators at Achieving the Dream Colleges

B Technical Appendix

References

Earlier MDRC Publications on Achieving the Dream 


\section{List of Tables, Figures, and Boxes}

Table

ES.1 Culture of Evidence at Achieving the Dream Round 1 Colleges, Spring 2006 and Spring 2009

ES-6

ES.2 Influence of Achieving the Dream on the Culture of Evidence at Round 1 Colleges and Progress Made from Spring 2006 to Spring 2009

ES-9

$1.1 \quad$ Round 1 Colleges, Academic Years 2004-2005 and 2008-2009 4

1.2 Founding Investor and Partners in the Achieving the Dream Initiative 6

1.3 Average Characteristics of Entering Students at the 26 Round 1 Colleges in Achieving the Dream, Fall 2002

7.1 Culture of Evidence at Achieving the Dream Round 1 Colleges, Spring 2006 and Spring 2009

7.2 Influence of Achieving the Dream on the Culture of Evidence at Round 1 Colleges and Progress Made from Spring 2006 to Spring 2009

8.1 Change in Average Two-Year Performance Indicators at Achieving the Dream Round 1 Colleges, 2002-2004 Cohorts Compared with 2007 Cohort

8.2 Change in Average Two-Year Performance Indicators at Achieving the Dream Round 1 Colleges, by Pell Grant Status, 2002-2004 Cohorts Compared with 2007 Cohort

8.3 Change in Average Two-Year Performance Indicators at Achieving the Dream Round 1 Colleges, by Race/Ethnicity, 2002-2004 Cohorts Compared with 2007 Cohort $\quad 140$

B.1 Alternative Trend Breaks in Interim Performance Indicators

\section{Figure}

ES.1 States and Colleges Involved in Achieving the Dream, 2004 to $2010 \quad$ ES-2

1.1 States and Colleges Involved in Achieving the Dream, 2004 to 2010

1.2 Achieving the Dream's Five-Step Process for Improving Student Success 11

2.1 Leadership Commitment to Improving Student Success Among Presidents, Senior Administrators, and Faculty Leaders in Achieving the Dream Colleges, Spring 2009 


\section{Figure}

2.2 Influence of Achieving the Dream on College Presidents', Senior Administrators', and Faculty Leaders' Self-Reported Commitment to Improving Student Success, Spring 2009

2.3 Involvement of Presidents, Senior Administrators, and Faculty Leaders in Student Success Reforms at the Round 1 Colleges in Achieving the Dream, Spring 2009

2.4 Frequency with Which Administrators Used Student Outcomes Data, by Type of Data, 2007 to 2008

2.5 Frequency with Which Administrators Used Data Disaggregated by Race and Income, 2007 to 2008

3.1 Progress of Achieving the Dream Round 1 Colleges in Developing Data and Research Capacity, Spring 2006 to Spring 2009

3.2 Development of Diversified Data Activities at Achieving the Dream Round 1 Colleges, Spring 2009

3.3 Evaluation of Strategies for Improving Student Success at Achieving the Dream Round 1 Colleges, Spring 2009

3.4 Contributions of Achieving the Dream Inputs to Use of Data Among Round 1 Colleges, Spring 2009

4.1 Faculty and Staff Involvement in Student Success Reforms at the Achieving the Dream Round 1 Colleges, Spring 2009

4.2 Frequency with Which Faculty Members Used Student Outcomes Data, by Type of Data, 2007 to 2008

4.3 Frequency with Which Faculty Members Used Data Disaggregated by Race and Income, 2007 to 2008

4.4 Number of Achieving the Dream Round 1 Colleges with at Least Some Involvement from Students in the Institutional Improvement Process, Spring 2009

4.5 Number of Achieving the Dream Round 1 Colleges with at Least Some Involvement from External Stakeholders in the Institutional Improvement Process, Spring 2009

5.1 Step 4 of the Achieving the Dream Institutional Improvement Process: Implement, Evaluate, and Improve Strategies

5.2 Popularity of Direct Program and Service Strategies: Percentage of Round 1 Colleges That Implemented Each Type of Strategy Under Achieving the Dream 


\section{Figure}

5.3 Popularity of Direct Program and Service Strategies: Percentage of Achieving the Dream Strategies Focused on Each Type of Target Population

5.4 Proportion of Direct Program and Service Strategies Operating at Small, Medium, and Large Scale at the Round 1 Achieving the Dream Colleges, Spring 2009

5.5 Proportion of Direct Program and Service Strategies Operating at Small, Medium, and Large Scale at the Round 1 Achieving the Dream Colleges, by Strategy Intensity, Spring 2009

6.1 Aspects of Systemic Institutional Improvement Processes in Place at the Achieving the Dream Round 1 Colleges, Spring 2009

6.2 Influence of Achieving the Dream on Systemic Institutional Improvement Processes in Round 1 Colleges

8.1 Trends in Developmental Math and Developmental English Completions Among Students Referred to Any Developmental English or Math Course, 2002 2007:

Two-Year Outcomes for Achieving the Dream Round 1 Colleges

8.2 Trends in Completion of Gatekeeper Math and English Courses Among All Students, 2002-2007: Two-Year Outcomes for Achieving the Dream Round 1 Colleges

8.3 Trends in Course Completion, 2002-2007: Two-Year Outcomes for Achieving the Dream Round 1 Colleges

8.4 Distribution of Pre-Initiative and Post-Initiative Differences in Completion of Gatekeeper English at Achieving the Dream Round 1 Colleges, 2002-2007

8.5 Distribution of Pre-Initiative and Post-Initiative Differences in Fall-to-Fall

Persistence at Achieving the Dream Round 1 Colleges, 2002-2007

8.6 Distribution of Institution-Level Changes in Two-Year, Interim Performance Indicators at Achieving the Dream Round 1 Colleges, 2002-2004 Compared with 2007

\section{Box}

ES.1 "Star" Colleges in Achieving the Dream: Institutions that Made Solid Progress in Building a Culture of Evidence

2.1 Principles and Practices for Increasing Student Success Through Institutional Improvement: Practices Associated with Principle 1,Committed Leadership 


\section{Box}

2.2 Spearheading a Focus on Equity: Case Studies of Four Colleges 30

3.1 Principles and Practices for Increasing Student Success Through Institutional Improvement: Practices Associated with Principle 2, Use of Evidence to Improve Policies, Programs, and Services

3.2 Using Data to Build Interventions: Case Studies of Three Colleges 48

4.1 Principles and Practices for Increasing Student Success Through Institutional Improvement: Practices Associated with Principle 3, Broad Engagement 55

4.2 Promising Practices for Promoting Faculty and Staff Engagement 59

4.3 Bringing Adjunct Faculty on Board: Promising Models from Two Round 1 Colleges 65

5.1 Promising Approaches for Scaling Up Strategies 85

5.2 Types of Policy Change Strategies Implemented Under the Auspices of Achieving the Dream

5.3 Types of Professional Development Strategies Implemented Under the Auspices of Achieving the Dream

5.4 Types of Externally Oriented Strategies Implemented Under the Auspices of Achieving the Dream

6.1 Principles and Practices for Increasing Student Success Through Institutional Improvement: Practices Associated with Principle 4, Systemic Institutional Improvement

6.2 The Costs of Undertaking Broad-Scale Institutional Reform 102

6.3 Intensive Professional Development 106

7.1 "Star" Colleges in Achieving the Dream: Institutions that Made Strong Progress in Building a Culture of Evidence

8.1 MDRC's Achieving the Dream Impact Studies 


\section{Preface}

Today, more students than ever are enrolling in community college, but nearly half of them never go on to earn a degree or certificate. Until recently, most community colleges did not have the capacity or the incentives to gather information about their students' performance over time and the possible barriers to their success. Traditionally focused on increasing access to postsecondary education, particularly for low-income students, community colleges are now turning more attention to improving the academic success of their students. But without concrete evidence to illuminate how and why their students are underperforming, colleges have been hard-pressed to take steps to help them improve.

Enter "Achieving the Dream: Community Colleges Count," an ambitious national initiative launched by Lumina Foundation for Education in 2004, with support from a number of other philanthropies and organizations. The initiative helps community colleges learn how to collect and analyze student performance data in order to build a "culture of evidence" - a culture in which colleges routinely use solid evidence to develop institutionwide reform strategies that are aimed at helping their students succeed academically. Achieving the Dream has grown into a national movement; more than 130 community colleges are now participating.

This interim report takes stock of the experiences among the first 26 colleges from five states to join the initiative (the "Round 1" colleges). It offers a look at the influence of the initiative in its early stages, while its practices and supports were still evolving. The study shows that after five years in Achieving the Dream, four out of five of the 26 Round 1 colleges had adopted some or all of the practices associated with a culture of evidence. While the colleges instituted a wide range of strategies to help their students succeed, increasing student achievement and persistence levels in the colleges remains a huge challenge.

What are we to make of Achieving the Dream at this juncture? On the one hand, it represents an unprecedented effort to help community colleges change their institutional cultures so they can continuously pinpoint where, how, and why their students are underperforming, and then implement reforms to help them improve. Achieving the Dream was at the vanguard, anticipating — and helping spur - the growing national focus on institutional accountability in community colleges. After five years in the initiative the first two years of which were spent planning and setting up strategies for reform - a majority of the Round 1 colleges are collecting data on their students' performance and are committed to using those data to design and implement effective reforms. On the other hand, trends in student outcomes - such as course completion, persistence, maintaining good grades, and earning college credentials - have remained relatively unchanged at these colleges, underscoring the depth of the challenge facing all community colleges.

One lesson from Achieving the Dream is that simply understanding the problems is not enough to solve them. Nevertheless, Achieving the Dream has provided a better sense of where the colleges have to go to improve and how to get there, creating an infrastructure through which change can occur. What remains is 
for colleges to harness the potential power of that infrastructure - and for Achieving the Dream itself to further refine its approach in order to better help colleges focus systematically on the issues that affect student achievement.

Achieving the Dream is not a static intervention, but a living, organic process - and many of the Round 1 colleges are now moving into the next stage of that process. A final report on the Round 1 colleges is planned for 2012-2013, by which time they will have had more time to institutionalize their reforms.

Gordon Berlin

President 


\section{Acknowledgments}

The Achieving the Dream evaluation is made possible by the support of Lumina Foundation for Education. We are grateful for Lumina's generous and steadfast support for this evaluation, as one component of Achieving the Dream's effort to improve outcomes for community college students.

MDRC and the Community College Research Center (CCRC) appreciate the cooperation of the colleges represented in this report: Alamo Community College District, Brookhaven College, Broward College, Central New Mexico Community College, Coastal Bend College, Danville Community College, Durham Technical Community College, El Paso Community College, Galveston College, Guilford Technical Community College, Hillsborough Community College, Houston Community College, Martin Community College, Mountain Empire Community College, New Mexico State University-Doña Ana, Patrick Henry Community College, Paul D. Camp Community College, Santa Fe Community College, South Texas College, Southwest Texas Junior College, Southwestern Indian Polytechnic Institute, Tallahassee Community College, Tidewater Community College, University of New Mexico-Gallup, Valencia Community College, and Wayne Community College. We are especially grateful for the openness of the college administrators, faculty, staff, board members and students who generously gave their time to be interviewed for this report.

We also thank the larger Achieving the Dream family. Our national partners were kind enough to read and critique the report with care. We are particularly grateful for written comments received from Bill Trueheart, Carol Lincoln, and Katie Loovis of Achieving the Dream;

Nushina Mir and Mary Williams of Lumina Foundation for Education; and Maggie Shelton of MDC, Inc. In addition, the coaches and data facilitators working on Achieving the Dream offered invaluable support in arranging and facilitating our field visits to the college campuses.

The ambitious work of the Achieving the Dream evaluation represents a collaborative effort between CCRC and MDRC. The research team that conducted interviews with us at the 26 sites included Melissa Boynton, Erin Coghlan, and Christian Geckeler of MDRC; and Katherine Boswell, Aaron Doyle, Todd Ellwein, and John Wachen of CCRC. At MDRC, early report drafts benefited from careful review by Gordon Berlin, Thomas Bailey, John Hutchins, and Robert Ivry. Alice Tufel edited the report, and David Sobel and Stephanie Cowell prepared it for publication.

The Authors 



\section{Executive Summary}

Across the United States, enrollments at community colleges are soaring. In fall 2009, approximately 8 million students took courses for credit - nearly a 17 percent increase from two years before. ${ }^{1}$ Community colleges tend to be welcoming and accessible institutions, particularly for nontraditional, low-income, and minority students. But while community colleges do a good job of helping students get a foothold in higher education, close to half of the students who begin at community colleges with the intention of earning a certificate or degree do not achieve their goal and are not enrolled in any college or university after six years. ${ }^{2}$ A growing number of policymakers and educators are calling upon community colleges to do better.

"Achieving the Dream: Community Colleges Count" is a national initiative that was launched in 2004 and was designed to increase the academic success of community college students, with a special emphasis on low-income students and students of color. Its approach is to help community colleges build a "culture of evidence" by using student records and other data to examine how students are performing over time and to identify barriers to academic progress. From there, community colleges are expected to develop intervention strategies designed to improve student outcomes, conduct further research on student progress, and bring effective programs to scale. Lumina Foundation for Education launched Achieving the Dream and was its principal funder, with a large group of philanthropies and other organizations joining Lumina to support the initiative. Today, more than 130 community colleges in 24 states and the District of Columbia are involved in Achieving the Dream (see Figure ES.1).

MDRC - a nonprofit, nonpartisan education and social policy research organization — and the Community College Research Center (CCRC) are evaluating the work of the first 26 colleges to join the initiative from Florida, New Mexico, North Carolina, Texas, and Virginia (called the "Round 1" colleges here). This report covers a five-year period, beginning in the 2004-2005 academic year. Because the process of building a culture of evidence is envisioned as a long-term effort, a future report will examine trends in student achievement after the colleges have had more time to institutionalize reforms that began under Achieving the Dream.

Overall, the report concludes that:

\footnotetext{
${ }^{1}$ American Association of Community Colleges (AACC), Community College Enrollment Survey: An Analysis of Estimated Fall 2009 Headcount Enrollments at Community Colleges (Washington, DC: AACC, 2009).

${ }^{2}$ Stephen Provasnik and Michael Planty, Community Colleges: Special Supplement to the Condition of Education 2008, NCES 2008-033 (Washington, DC: National Center for Education Statistics, Institute of Education Sciences, U.S. Department of Education, 2008).
} 
Figure ES.1

States and Colleges Involved in Achieving the Dream, 2004 to 2010

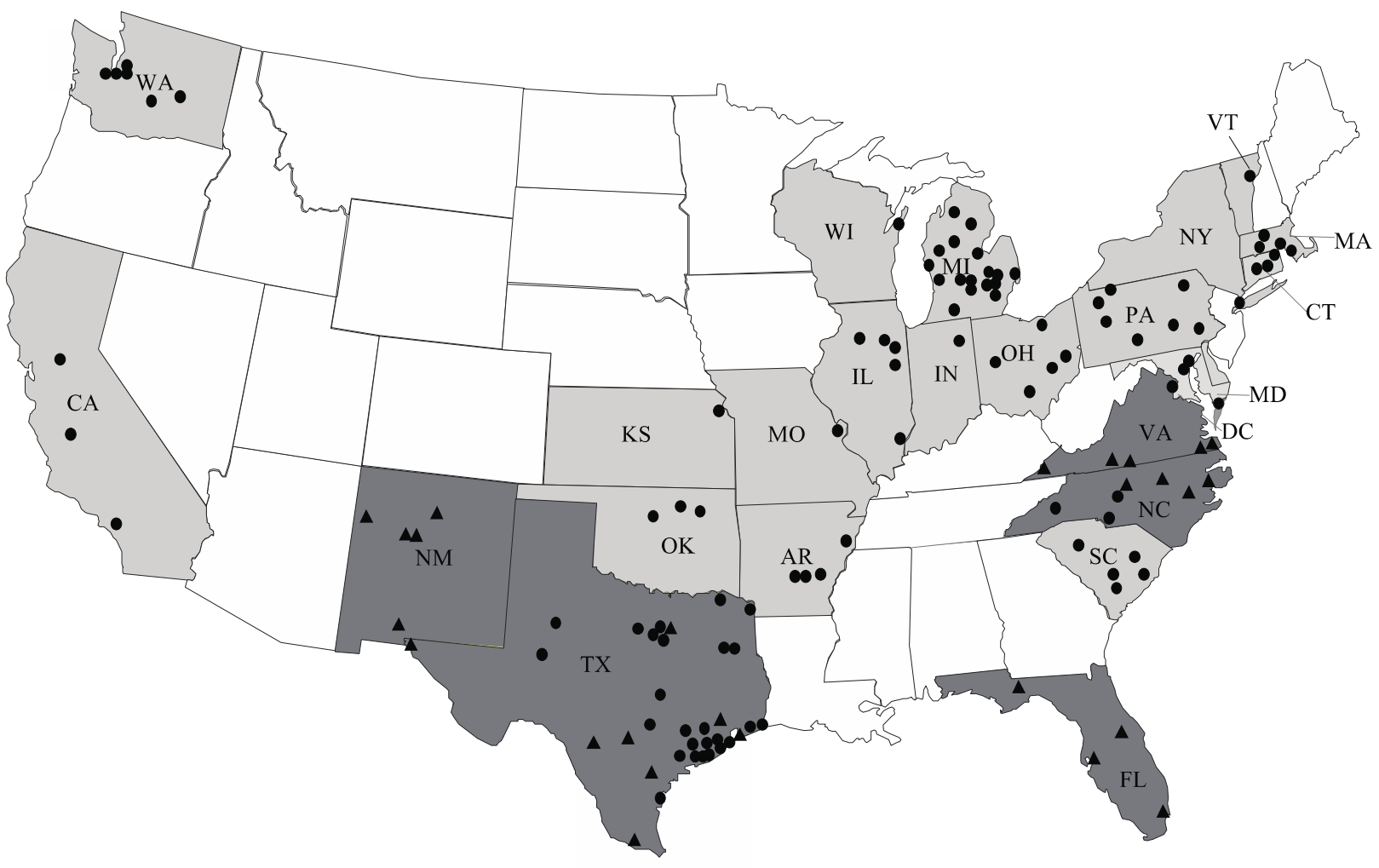

Round 1 Achieving the Dream states (joined in 2004-2005)

Achieving the Dream states that joined after 2005

A Round 1 Achieving the Dream colleges (joined in 2004-2005)

- Colleges that joined Achieving the Dream after 2005

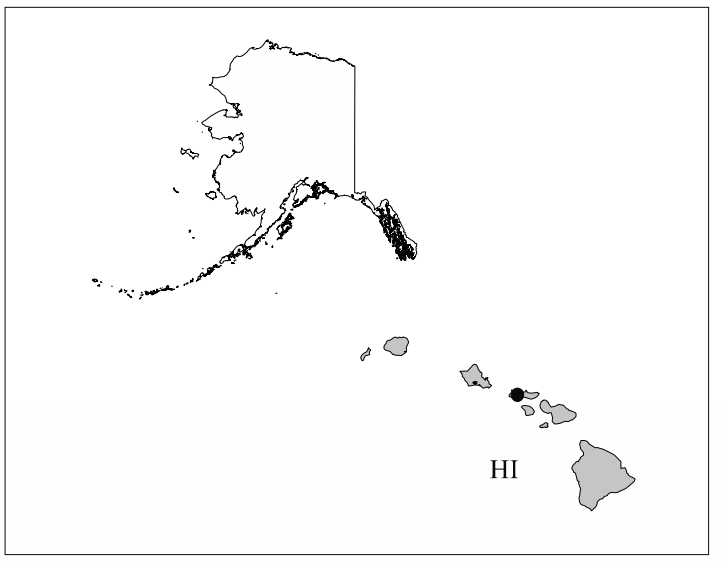

NOTE: Multi-college districts are represented with one dot on this map. 
- Many Round 1 colleges made important strides in building a stronger culture of evidence during their five-year participation in the initiative. In particular, colleges enhanced their leadership commitment to student success, increased their research capacity, and developed a number of interventions aimed at improving their students' achievement.

- By spring 2009, four out of five Round 1 colleges had adopted a number of practices associated with a strong culture of evidence, with one-fifth of the colleges still facing major challenges in undertaking this work.

- While colleges instituted a wide range of strategies to improve student achievement under the auspices of Achieving the Dream, a majority of these reforms reached less than 10 percent of their intended target populations - likely too few to make demonstrable progress on improving student achievement overall.

- Other forces besides Achieving the Dream sometimes helped the colleges build a culture of evidence, including accreditation processes and grants other than those from the initiative. However, about three-fourths of the colleges indicated that Achieving the Dream had at least some influence in helping them develop a culture of evidence.

- Trends in student outcomes remained relatively unchanged, except for modest improvements in gatekeeper (introductory) college English courses and the completion of courses attempted within the first two years.

\section{The Theory of Action Behind Achieving the Dream}

From the earliest conversations, it was clear that Lumina Foundation and the partners had big ambitions for Achieving the Dream. They spoke about fostering fundamental changes in the culture and operations of community colleges - changes that would lead to measureable and lasting improvements in student outcomes. They also spoke about changing the context in which community colleges operate - everything from the rules governing their accreditation and funding to public awareness and support for community colleges.

On the ground, participating colleges were expected to enact a five-step process of institutional reform, which included (1) securing leadership commitment; (2) using data to prioritize actions; (3) engaging stakeholders; (4) implementing, evaluating, and improving intervention strategies; and (5) establishing a culture of continuous improvement. To help colleges institute their reforms, Achieving the Dream provided them with both monetary and technical support. The Round 1 colleges were awarded an initial year-long planning grant of $\$ 50,000$ each, followed by annual grants of $\$ 100,000$ for four years $(\$ 450,000$ total). In addition, the colleges 
were aided by two consultants: a data facilitator, who helped them perform the data collection and analysis and interpret the results; and a coach, who helped them set priorities, build consensus, and implement strategies for improvement. The initiative also sponsored a Kick-off Institute and annual Strategy Institutes for all the Achieving the Dream colleges, where they learned more about the Achieving the Dream process, made plans for their own campuses, and shared ideas and lessons with other colleges on how to help students be more successful. Colleges also received technical assistance from the initiative's eight founding partner organizations, led by MDC, Inc., the managing partner of Achieving the Dream.

All Achieving the Dream colleges were asked to try to "move the needle" on five measures of student success: (1) completion of developmental courses and progression to creditbearing courses; (2) completion of so-called gatekeeper courses, including introductory college courses in English and math; (3) completion of attempted courses with a grade of " $\mathrm{C}$ " or better; (4) persistence from semester to semester and from year to year; and (5) attainment of college credentials. Colleges were expected to track these outcomes for each fall cohort of entering students and to make comparisons with past cohorts to determine whether the outcomes improved over time. As noted above, colleges were also expected to break down the results for subgroups of students defined by race, ethnicity, and income.

Throughout the history of Achieving the Dream, there was some tension between those who believed that gains in student outcomes should come quickly and those who believed it was a long-term process. The initiative's "Integrated Action Plan" was vague on this point, indicating that colleges should see "measurable improvement in success rates" after four years and have "achieved their long-term targets for student success" after eight years. What was clear was that the five-step process was iterative, so any improvements in student outcomes depended on the colleges' ability to master the initial steps. Even if colleges did all that was asked of them, it could still take time for improvements to show up in the data, given the longitudinal nature of the measures. Some of the partners cited the oft-used metaphor of turning a ship to describe the work of Achieving the Dream. On the one hand, they firmly believed that the initiative would set community colleges on a better course; on the other hand, they recognized that changes would likely occur only gradually and might not be fully apparent for several years' time.

In analyzing the work and progress of the Round 1 colleges, it is also important to note that these schools began their work in Achieving the Dream as the initiative was still evolving. Indeed, since its beginning in 2004, the initiative has expanded, modified, and codified many of its practices and supports, with the Round 1 colleges receiving less intensive versions of these messages during the early phases of their implementation. As such, the Round 1 colleges' progress should be seen as offering a look at the initiative's influence during its early development, while its practices and supports were still being solidified. 
The Round 1 colleges are diverse in size, location, and student characteristics. The largest institution is Houston Community College, which had a full-time equivalent 12-month enrollment of over 32,000 students in 2008-2009. The smallest institution is Martin Community College in North Carolina, which had a full-time equivalent enrollment of 410 students. The colleges are located in large and midsize cities, suburbs, and small towns. White students make up a majority or plurality of students at most of these institutions, but nearly all the colleges enrolled substantial numbers of African American, Hispanic, or Native American students.

\section{How Was the Research Conducted at the Round 1 Colleges?}

A research team comprising MDRC and CCRC staff studied the Round 1 colleges over several years to learn how they implemented Achieving the Dream and whether they made progress in developing a culture of evidence on campus. The team visited each of the 26 colleges two times: once during the first year of implementation, in spring 2006, and again during the last year of implementation, either in fall 2008 or spring 2009. The visits lasted two to three days and included interviews with the administrators, faculty members, and institutional research staff, among others. The research team also conducted a survey of college administrators and faculty at 23 of the 26 colleges in 2007-2008. In addition, the research team reviewed annual reports that the colleges submitted to Achieving the Dream, as well as reports prepared by the coaches and data facilitators. Finally, the research team analyzed student records data that the colleges submitted to the Achieving the Dream database, which allows researchers to track student performance over time. The analysis examines student outcomes at the institutional level for students who began college each fall between 2002 and 2007 (three years before the initiative began and three years after its implementation). Each entering cohort is tracked for two years.

\section{Have the Round 1 Colleges Created a Culture of Evidence?}

The bulk of this report assesses the Round 1 colleges' success between spring 2006 and spring 2009 in developing a culture of evidence - that is, their progress in instituting the five main steps of the Achieving the Dream model, described above.

As Table ES.1 shows, most of the Round 1 colleges made substantial progress in developing more evidence-based systems aimed at improving student success during their participation in Achieving the Dream. Eighty-one percent (21) of the Round 1 colleges improved their culture of evidence over the course of their five-year participation in the initiative, and 19 percent (five) of the colleges continued to have major challenges implementing the initiative's model for institutional improvement. Indeed, most of the Round 1 colleges made a number of enhancements to their institutions, including the use of more sophisticated methods for data 
Achieving the Dream: Community Colleges Count

Table ES.1

\section{Culture of Evidence at Achieving the Dream Round 1 Colleges, Spring 2006 and Spring 2009}

\begin{tabular}{lrrrr}
\hline & \multicolumn{2}{c}{ Spring 2006 } & & \multicolumn{2}{c}{ Spring 2009 } \\
\cline { 2 - 3 } \cline { 5 - 5 } Culture of Evidence Rating & $\begin{array}{r}\text { Number of } \\
\text { Round 1 Colleges }\end{array}$ & $\begin{array}{r}\text { Percentage of } \\
\text { Round 1 Colleges }\end{array}$ & $\begin{array}{r}\text { Number of } \\
\text { Round 1 Colleges }\end{array}$ & $\begin{array}{r}\text { Percentage of } \\
\text { Round 1 Colleges }\end{array}$ \\
\hline $\begin{array}{l}\text { Strong or very strong } \\
\text { culture of evidence }\end{array}$ & 6 & 23 & 11 & 42 \\
$\begin{array}{l}\text { Some culture of evidence } \\
\begin{array}{l}\text { Weak or very weak } \\
\text { culture of evidence }\end{array}\end{array}$ & 5 & 19 & 10 & 38 \\
\hline Total & 15 & 58 & 5 & 19 \\
\hline
\end{tabular}

SOURCE: Information collected from faculty, staff, and administrators during two rounds of implementation research across all 26 Round 1 colleges, cross-referenced against reports submitted by college representatives, Achieving the Dream coaches, and data facilitators.

NOTE: Percentages may not add to 100 because of rounding.

analysis, numerous interventions aimed at increasing students' success, and more efficient systems for monitoring their efforts to improve students' achievement. The colleges can be divided into three categories, based on their success in institutionalizing a culture of evidence.

\section{Strong Culture of Evidence}

Eleven Round 1 colleges (42 percent) had implemented most of the practices that are associated with a strong culture of evidence by the end of their five-year participation in Achieving the Dream. These colleges had excelled at building or further strengthening all five aspects of the initiative's institutional improvement model - that is, they (1) had strong leadership systems committed to improving student success; (2) had well-developed institutional research departments that conducted intensive, in-depth analyses of their students' achievement; (3) involved faculty, staff, students, and external stakeholders in multiple aspects of their reform agenda; (4) had used well-developed strategies, with one or more strategies reaching substantial proportions of their target population; and (5) had instituted multiple processes for strategic planning and program review, and made financial and programmatic decisions based on evidence of improved student achievement. As described in Box ES.1, the colleges that made the greatest strides in developing an evidence-based approach to improving student achievement shared several important characteristics, including the broad-based involvement of college administrators, faculty, and staff; strong institutional research departments that produced reports on student achievement that people could readily understand; regular evaluations of interven- 


\section{Box ES.1}

\section{"Star" Colleges in Achieving the Dream: Institutions that Made Solid Progress in Building a Culture of Evidence}

Four of the 26 Round 1 colleges stood out because they had a weak culture of evidence at the start of the initiative and made great strides in building up their culture over five years. These colleges made changes that set them apart from the other colleges that made less progress, including:

- Multiple senior administrators who were deeply involved in the colleges' reforms. Each college had a cadre of senior leaders, including the vice presidents of instruction and student services and the head of institutional research (IR), leading its Achieving the Dream work. Two colleges also had presidents who were very involved.

- Active IR departments that produced accessible reports on students' achievement. Each school focused sharply on increasing IR capacity by hiring new IR staff and upgrading its data management system, which allowed it to better manage multiple IR demands. Each school also produced institutional- or department-specific reports on students' success, with clearly delineated target goals for students' achievement.

- Regular evaluations of their interventions to improve student success. Each college systematically tracked its interventions, often comparing students who were participating in a particular program with nonparticipants. These findings were disseminated widely throughout the school, with a number of faculty and staff commenting on the results.

- Strong faculty and staff leaders who played an active role in leading the colleges' reforms and interventions. Each of the four colleges had strong participation from faculty and staff, who were involved in leadership and policymaking committees at their colleges and led the implementation of numerous strategies that were aimed at improving students' success.

- Integrated committee structures that allowed for regular communication among administrators, faculty, and staff. Each of the four schools developed numerous standing committees to monitor its reform efforts. These committees brought faculty, staff, and administrators together through regular communication, providing a clear and consistent voice in their colleges' larger policy- and institutional decision-making.

- Consistent attention to financial supports for strategy scale-up and numerous strategies operating at scale. Each of these college developed systematic ways to support broad-scale reforms, often by using federal or state grants to support the additional costs. All four colleges had strategies that were reaching substantial proportions of their remedial students or students who were in college for the first time.

- Heavy investment in professional development. Each of the four schools dedicated significant funds to training faculty and staff. 
tions to improve student success; and attention to scaling up program strategies that helped students be more successful.

\section{Some Culture of Evidence}

Ten Round 1 colleges (38 percent) had instituted many of the aspects of Achieving the Dream's suggested improvement process in their schools, though not to the same degree as the colleges described above. Most schools had built (or started with) relatively capable institutional research departments, and most undertook longitudinal analyses of student outcomes and tracked the progress of at least some of their student success interventions. However, they also continued to have limitations in their data capacity that hindered their ability to undertake broader-based analyses. Other stakeholders, such as faculty and staff, also reported increased awareness of student achievement or had some exposure to reports on students' success in particular interventions. Faculty and staff were also generally involved in some aspects of the reform agenda at many of these schools, most often around implementing the colleges' student success strategies, although their participation tended to be more limited than at colleges that had a better-developed culture of evidence. Finally, most colleges had some form of strategic planning process in place, which at times used student achievement data to inform decisionmaking, though the use of data was not consistent across these colleges.

\section{Weak Culture of Evidence}

As observed earlier, five colleges (19 percent) were still struggling to implement a number of Achieving the Dream's recommended practices by spring 2009. Very weak institutional research departments were the primary difficulty hindering most of these schools' ability to institute a broad data-driven culture. Most of these schools did not employ an institutional researcher continuously during their time in the initiative, relying instead on outside consultants or other, less well-trained staff to fill these positions. Sometimes these challenges were the result of a poor economic situation, which kept the college from being able to attract good technical support. Some schools also had difficulty implementing Achieving the Dream across multiple campuses and providing sustained leadership to bring these disparate groups together.

\section{How Much Did Achieving the Dream Influence the Round 1 Colleges?}

Many of the Round 1 colleges attributed their improvements to Achieving the Dream. As can be seen in Table ES.2, 19 out of 26 (73 percent) of the Round 1 colleges reported that Achieving the Dream had at least some influence on their development of a culture of evidence. However, they also noted other systems that were important in helping them develop a culture

of evidence. For instance, a number of the schools discussed how their accreditation processes 


\section{Achieving the Dream: Community Colleges Count}

Table ES.2

\section{Influence of Achieving the Dream on the Culture of Evidence at Round 1 Colleges and Progress Made from Spring 2006 to Spring 2009}

\begin{tabular}{|c|c|c|c|}
\hline Number of Colleges & $\begin{array}{r}\text { Spring } 2006 \\
\text { Culture of } \\
\text { Evidence }^{\mathrm{a}} \\
\end{array}$ & $\begin{array}{r}\text { Spring } 2009 \\
\text { Culture of } \\
\text { Evidence } \\
\end{array}$ & $\begin{array}{r}\text { Progress Made } \\
\text { from Spring } 2006 \\
\text { to Spring } 2009^{\mathrm{b}} \\
\end{array}$ \\
\hline \multicolumn{4}{|c|}{ Heavy influence: 8 colleges } \\
\hline 3 colleges & Strong & Very strong & +1 \\
\hline 1 college & Some & Strong & +1 \\
\hline 3 colleges & Weak & Strong & +2 \\
\hline 1 college & Very weak & Strong & +3 \\
\hline \multicolumn{4}{|c|}{ Some influence: 11 colleges } \\
\hline 2 colleges & Strong & Very strong & +1 \\
\hline 1 college & Very weak & Some & +2 \\
\hline 6 colleges & Weak & Some & +1 \\
\hline 2 colleges & Very weak & Weak & +1 \\
\hline \multicolumn{4}{|c|}{ Little influence: 7 colleges } \\
\hline 1 college & Strong & Very strong & +1 \\
\hline 1 college & Weak & Some & +1 \\
\hline 2 colleges & Some & Some & 0 \\
\hline 1 college & Very weak & Very weak & 0 \\
\hline 2 colleges & Some & Weak & -1 \\
\hline
\end{tabular}

SOURCE: Information collected from faculty, staff, and administrators during two rounds of implementation research across all 26 Round 1 colleges, cross-referenced against reports submitted by college representatives, Achieving the Dream coaches, and data facilitators.

NOTES: While some of the colleges in the "Little influence" category made progress in developing their cultures of evidence, they did not consider Achieving the Dream to be a primary motivator for these changes.

${ }^{\text {aSpring }} 2006$ culture of evidence ratings are based on implementation findings from MDRC and CCRC's baseline report on the Round 1 Achieving the Dream colleges (Brock et al., 2007, pp. 9697).

'Progress ratings reflect changes in colleges' cultures of evidence between spring 2006 and spring 2009 , as measured by movement across the following rating scale: very weak, weak, some, strong, very strong. For example, a college that received a "very weak" rating in spring 2006 and a "very strong" rating in spring 2009 would receive a progress rating of "+4," indicating that it had progressed 4 levels in the rating scale. 
or grants other than those from Achieving the Dream, such as federal Title V or TRIO grants, were the main drivers of the reforms at their colleges. Achieving the Dream was seen as "complementing" or "reinforcing" this agenda, but not necessarily as the primary inspiration for the colleges' efforts to improve student achievement or to use data. Additionally, a few colleges said that the motivation for their reforms stemmed from an internal push to increase student achievement, often from a strong leader who was already committed to improving student success.

\section{What Program Strategies Were Developed for Students, and to What Effect?}

Colleges can expect real changes in student outcomes only when they extend meaningfully improved programs and services to significant numbers of students. In other words, a strategy will make an observable impact on institutional performance only if it (1) improves academic outcomes among the students who are served, and (2) reaches enough students to "move the needle" on collegewide measures.

Overall, the Round 1 colleges implemented a large number of strategies under the auspices of Achieving the Dream. Most of those strategies involved the implementation of direct programs and services that were designed to improve students' college success. While the strategies ranged widely, from light-touch orientation activities to more intensive curricular reforms, several common themes emerged across the 26 colleges:

- A large majority of strategies were designed to increase academic and social support systems for students, while only about one-fourth changed the content and delivery of classroom instruction itself.

- Nearly half of the colleges' strategies targeted developmental education students, and one-third focused on students in their first year of college. Very few strategies targeted students based on their race, ethnicity, or economic status, though some colleges addressed achievement gaps indirectly through programs aimed at a broader group of students.

- Despite colleges' notable efforts to scale up their programs and services, the majority of strategies reached less than 10 percent of their intended target populations. Intensive strategies, such as curricular reforms or intensive advising, which were defined by longer periods of contact time with students, were particularly unlikely to reach large numbers of students. Student success courses (courses aimed at introducing students to college life and enhancing their study skills) were the sole high-intensity strategy to reach a 
large number of students at a majority of colleges. This finding suggests that colleges often faced a trade-off between the intensity and scale of their interventions.

Most colleges had several additional strategies that did not reach students directly, but rather through (1) changes in college policies, and (2) collaborative relationships with external stakeholders, including local school districts and community members.

Besides improving upon the programs, services, and policies that affect students, Achieving the Dream colleges are expected to leverage engagement among faculty and staff and improve their skills as part of the effort to increase student success. Indeed, the initiative highlights the importance of professional development in creating more systemic changes in community colleges' improvement efforts. This proved to be an important area of college activity under Achieving the Dream, with every college reporting at least one professional development strategy and several reporting that this was a key focus of their work. Findings from an MDRC cost study of Achieving the Dream further highlight the centrality of this work: investments in professional development averaged $\$ 654,000$ across the five Round 1 colleges in the study, representing an important share of colleges' spending on activities related to the initiative. ${ }^{3}$

On average, each college implemented seven strategies, with all 26 colleges implementing over 200 strategies in total, representing an enormous investment of time and work by college personnel. Also, even though, as already noted, most strategies reached less than 10 percent of their intended target, the colleges made noteworthy progress toward scale-up, as nearly all succeeded at expanding at least one direct strategy to reach at least 25 percent of its intended target population. However, a majority of strategies across the Round 1 colleges remained small in scale, particularly when they involved the kind of intensive contact that might be expected to meaningfully influence students' performance. The result is that the benefits of promising interventions were frequently extended to only a fraction of the students who were in need of more intensive assistance.

It should not be surprising then, that the trends in student outcomes across the Round 1 colleges remained relatively unchanged across the pre-initiative and post-initiative periods. The analysis suggests that the average rates of persistence and graduation as well as the rates for completion of developmental math, developmental English, developmental reading, and gatekeeper math courses remained substantially the same throughout the pe-

\footnotetext{
${ }^{3}$ Elizabeth Zachry and Erin Coghlan with Rashida Welbeck, Investing in Change: How Much Do Achieving the Dream Colleges Spend - and from What Resources - to Become Data-Driven Institutions? (New York: MDRC, 2010).
} 
riod, with modest improvements over time in the rates for completion of gatekeeper English and completion of coursework.

In addition, few changes were seen in the outcomes of specific college and student subgroups. For instance, a separate analysis of the outcomes for several colleges that made the most progress in building a culture of evidence during their time in Achieving the Dream revealed no significant differences from the trends of the Round 1 colleges overall. Similarly, few changes were seen in the achievement gaps by race, ethnicity, and income. Though African American students showed some improvements in course completions and white students showed improvements in both course completions and gatekeeper English pass rates, those improvements over time were not large enough to close the achievement gap between the two groups.

While these descriptive trends seem to suggest that Achieving the Dream had few positive effects on student outcomes, the results must be interpreted with caution. While the lack of movement in student outcomes may occur largely because the interventions affected a small proportion of students in a cohort, the stability of student indicators over time may also reflect the short time span over which outcomes were analyzed. That is, the analysis of two-year outcomes for students may not provide a long enough window to adequately reflect the changes in institutional capacity and the implementation of specific strategies given the very low levels of student achievement that most colleges faced initially.

\section{Conclusion}

While community colleges are a prominent part of the national conversation today, few organizations were concentrating on these institutions before 2004, and even fewer were devoting substantial funds toward their improvement. Moreover, before Lumina Foundation for Education launched Achieving the Dream, few colleges or other postsecondary organizations focused on community college students' success; rather, they focused more often on providing open access to postsecondary education.

In 2010, Achieving the Dream became an independent nonprofit entity, and it is undergoing a marked shift in its leadership and organization as a result, seeking to involve an even wider range of community colleges in its work. In a change from the past, community colleges will have to pay to participate in Achieving the Dream, though it is expected that some institutions may find sponsors. Many of the core activities that Achieving the Dream provides - such as coaching, data facilitation, and annual Strategy Institutes - will also be subsidized so that colleges do not have to cover the full cost of participation. 
As Achieving the Dream moves into this new phase, the initiative, like its participating institutions, may need to refine its approach to make a stronger impact on students' success. For instance, outside of implementing colleges' strategies, the faculty and staff at many of the Round 1 colleges tended to be less involved than administrators in the colleges' overall improvement work. Similarly, only a handful of colleges made attempts to engage their part-time faculty and staff, who most often lead the developmental and gatekeeper courses that are so important to students' ultimate success in college. Additionally, while most colleges had expanded at least one strategy, the majority of strategies at these schools remained small in scale, leaving large proportions of students relatively untouched by the colleges' Achieving the Dream work.

These issues represent important challenges to Achieving the Dream's vision for improved student achievement; however, they should also be placed in the context of the overall struggles facing the U.S. education system as a whole. Elementary and secondary schools have long faced an uphill battle in their efforts to improve students' achievement, with only a relative few achieving large-scale reforms that successfully increased students' academic skills or graduation rates. Far more have been mired in many of the same struggles that Achieving the Dream colleges face, including students with major academic challenges, poor funding streams, and a lack of faculty or staff engagement in larger school reform efforts. Indeed, school systems working with adolescents, such as middle and high schools, tend to have the most struggles with large-scale reform, mirroring many of the key challenges that community colleges are facing.

As Achieving the Dream continues to expand, it might look to revise its framework for action by drawing on some of the lessons from efforts by K-12 stakeholders to improve students' outcomes. Some of these steps include a more rigorous focus on changing the practices that are most likely to affect students - namely, the interactions that occur between students and instructors in the classroom. As K-12 schools have learned, changing such practices can be difficult and often requires heavy engagement with faculty and staff, strong and continuous professional development, and a carefully researched plan detailing how new practices will affect students' achievement. Given this scenario, Achieving the Dream might look toward more definitive ways to involve larger proportions of faculty and staff in the change process while also aiming to develop a larger evidence base about what practices work to increase community college students' achievement. Similarly, the initiative might also seek to incorporate classroombased measures of learning, which more clearly document students' attainment of particular skills and practices, in its model for institutional improvement. Such measures might help bridge the gap in Achieving the Dream's theory of action, which currently focuses on broad institutional changes in student outcomes that may take many years to manifest.

While larger changes in students' achievement may not yet have been realized, Achieving the Dream has begun an unprecedented movement toward helping colleges improve their student outcomes and develop systems to sustain those efforts. Bringing faculty and staff voices 
more concretely into colleges' reform work and focusing more directly on improvements to classroom instruction and services may reap benefits for the next stage of the initiative's work. Given the successes they have already had, the initiative and its participating colleges stand poised to move forward with this agenda and make the changes needed to help more community college students accomplish their goals. 


\section{Chapter 1}

\section{Introduction}

Across the United States, enrollments at community colleges are soaring. In fall 2009, approximately 8 million students took courses for credit - nearly a 17 percent increase from two years before. ${ }^{1}$ The rising demand is a result of many factors, including the weak economy. In such an environment, community colleges may help job seekers be more competitive. Community colleges are also more affordable than most alternatives; average annual tuition and fees are less than half those at public four-year colleges and universities, and one-tenth of those at private four-year colleges and universities. Finally, community colleges tend to be welcoming and accessible institutions. Probably for all these reasons, much larger percentages of nontraditional, low-income, and minority students enroll in community colleges than in four-year colleges and universities. ${ }^{2}$

The figures above indicate that community colleges do a good job of helping students get a foothold in higher education. Unfortunately, after students enroll, far too many seem to slip. National studies reveal that close to half of all students who begin at community colleges with the intention of earning a certificate or degree do not achieve their goal and are not enrolled in any college or university after six years. ${ }^{3}$ And despite the economic and cultural diversity at community colleges, students from higher-income families are much more likely to persist and earn diplomas than are students from lower-income families; similarly, white or Asian students are more apt to finish than black or Hispanic students. ${ }^{4}$ There are many explanations for these patterns, including the fact that many community college students are not ready to perform college-level work when they enter and may be juggling the demands of work and family while trying to go to school. Nevertheless, a growing number of policymakers and educators are calling upon community colleges to do better.

"Achieving the Dream: Community Colleges Count" is a national initiative that was designed to increase the academic success of community college students, with a special emphasis on low-income students and students of color. Its approach is to help community colleges build a "culture of evidence" by using student records and other data to examine how students are performing over time and to identify barriers to their academic progress. From this analysis,

\footnotetext{
${ }^{1}$ American Association of Community Colleges (2009); Kente Phillipe (Associate Vice President for Research and Student Success, American Association of Community Colleges), personal communication, July 9, 2010.

${ }^{2}$ Provasnik and Planty (2008).

${ }^{3}$ National Center for Education Statistics (2002).

${ }^{4}$ Berkner, He, and Cataldi (2002).
} 
community colleges are expected to develop intervention strategies that are designed to improve student outcomes, conduct further research on student progress, and bring effective programs to scale. Participating colleges received multiyear grants and technical assistance to help them meet the initiative's goals. Lumina Foundation for Education launched Achieving the Dream and is its principal funder, though a large group of philanthropies and other organizations have joined Lumina to support the initiative. As of December 2010, more than 130 community colleges in 24 states and the District of Columbia are involved in Achieving the Dream (see Figure 1.1).

This report examines the accomplishments and lessons from the first group of $26 \mathrm{com}-$ munity colleges to join the initiative. ${ }^{5}$ The "Round 1" colleges, as they are known, are located in Florida, New Mexico, North Carolina, Texas, and Virginia (see Table 1.1). Drawing on a combination of field visits, surveys of college administrators and faculty, program documents, and student achievement data, the report answers the following major questions:

- To what extent did the Achieving the Dream colleges succeed in building a culture of evidence? What factors facilitated or hindered their efforts? What influence did Achieving the Dream have in changing college practices?

- What strategies did the colleges put in place to improve student outcomes? What was the scale of those strategies? What did colleges learn about the effectiveness of their strategies through their own evaluations?

- What were the trends in student achievement at participating colleges? Are those trends similar to or different from trends of a comparison group of colleges that did not participate in Achieving the Dream?

The report covers a five-year period, beginning in the 2004-2005 academic year (when the first group of colleges joined Achieving the Dream) and ending in the 2008-2009 academic year (at the conclusion of their grants from Lumina Foundation). In analyzing the work and progress of the Round 1 colleges, it is important to note that these schools began their work in Achieving the Dream as the initiative was still evolving. Indeed, throughout the past several years, the initiative has expanded, modified, and codified many of its practices and supports, with the Round 1 colleges receiving less intensive versions of these messages during the early phases of their implementation. As such, the progress of the Round 1 colleges offers a look at the influence of the initiative during its early development, while its practices and supports were still being solidified. Additionally, because the process of building a culture of evidence is envisioned as a long-term effort, a future report will examine trends in student achievement over a longer

\footnotetext{
${ }^{5}$ There were originally 27 colleges in the initiative, but one college withdrew after the first year, leaving 26 colleges in Round 1. Additionally, some multicampus districts, such as Alamo Community College District, are counted as one college.
} 
Achieving the Dream: Community Colleges Count

Figure 1.1

States and Colleges Involved in Achieving the Dream, 2004 to 2010

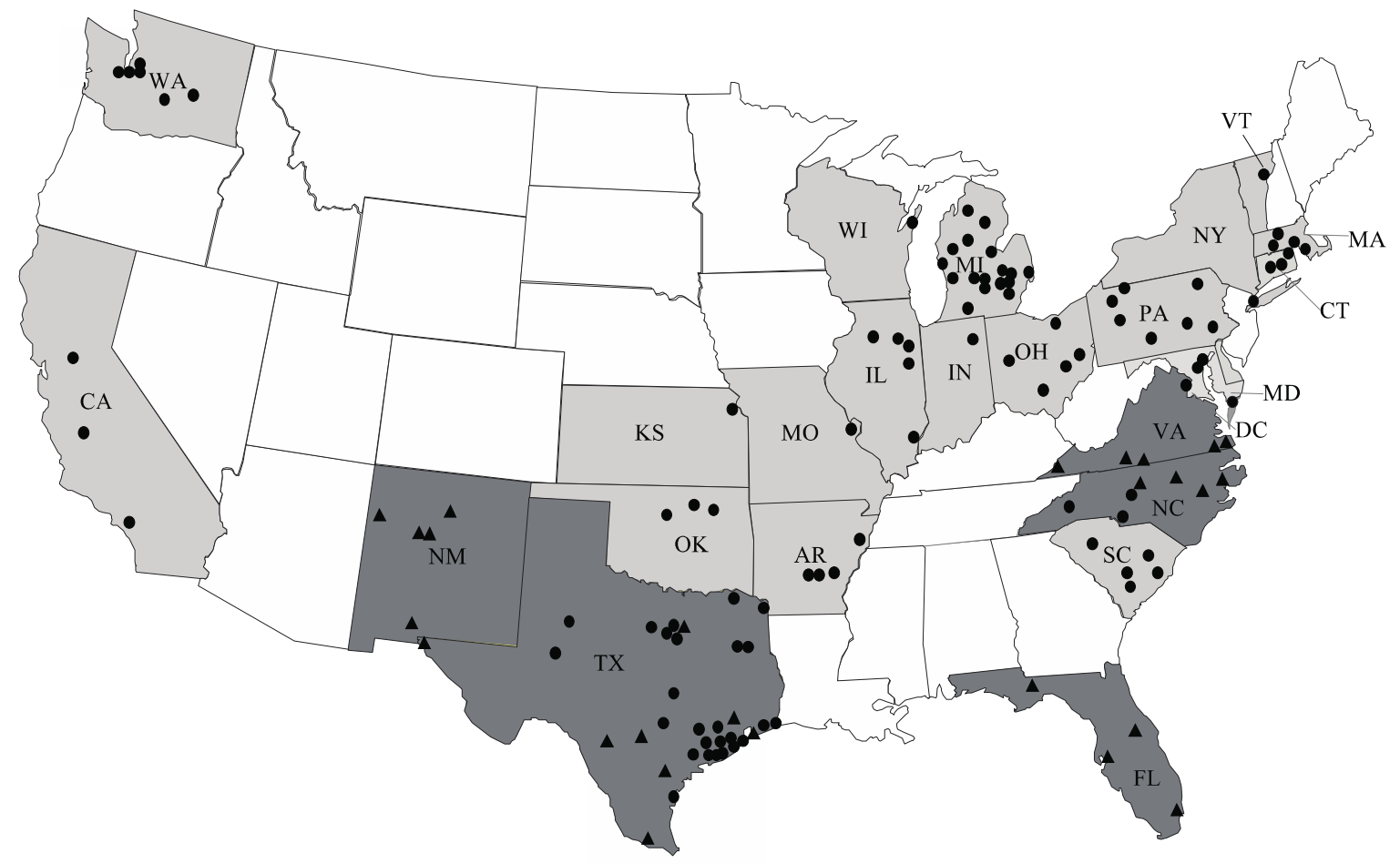

Round 1 Achieving the Dream states (joined in 2004-2005)

Achieving the Dream states that joined after 2005

$\Delta$ Round 1 Achieving the Dream colleges (joined in 2004-2005)

- Colleges that joined Achieving the Dream after 2005

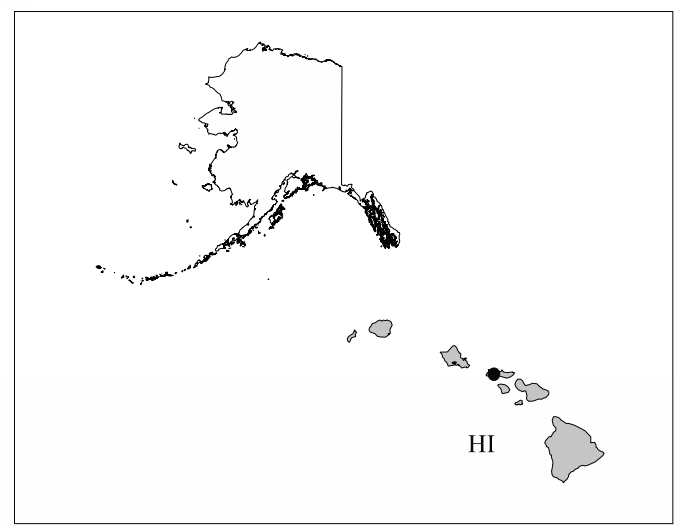

NOTE: Multi-college districts are represented with one dot on this map. 
Achieving the Dream: Community Colleges Count

Table 1.1

Round 1 Colleges, Academic Years 2004-2005 and 2008-2009

\begin{tabular}{|c|c|c|c|}
\hline State/College & Location & $\begin{array}{r}2004-2005 \\
\text { Enrollment }^{\mathrm{a}} \\
\end{array}$ & $\begin{array}{r}2008-2009 \\
\text { Enrollment }^{\mathrm{a}}\end{array}$ \\
\hline \multicolumn{4}{|l|}{ Florida } \\
\hline$\overline{\text { Broward College }}$ & Ft. Lauderdale & 22,540 & 24,634 \\
\hline Hillsborough Community College & Tampa & 16,157 & 18,321 \\
\hline Tallahassee Community College & Tallahassee & 9,819 & 10,947 \\
\hline Valencia Community College & Orlando & 20,727 & 26,230 \\
\hline \multicolumn{4}{|l|}{ New Mexico } \\
\hline$\overline{\text { Central New Mexico Community College }}$ & Albuquerque & 14,955 & 16,930 \\
\hline New Mexico State University-Doña Ana & Las Cruces & 3,656 & 4,872 \\
\hline Santa Fe Community College & Santa Fe & 2,307 & 2,132 \\
\hline Southwestern Indian Polytechnic Institute & Albuquerque & 699 & 536 \\
\hline University of New Mexico-Gallup Campus & Gallup & 1,814 & 1,757 \\
\hline \multicolumn{4}{|l|}{ North Carolina } \\
\hline Durham Technical Community College & Durham & 4,028 & 3,819 \\
\hline Guilford Technical Community College & Jamestown & 7,513 & 9,969 \\
\hline Martin Community College & Williamston & 717 & 410 \\
\hline Wayne Community College & Goldsboro & 2,911 & 2,954 \\
\hline \multicolumn{4}{|l|}{ Texas } \\
\hline \multicolumn{4}{|c|}{ Alamo Community College District Central Office ${ }^{b}$} \\
\hline Northwest Vista College & San Antonio & 3,448 & 12,866 \\
\hline Palo Alto College & San Antonio & 3,416 & 8,622 \\
\hline San Antonio College & San Antonio & 9,027 & 24,812 \\
\hline St. Philips College & San Antonio & 5,521 & 12,060 \\
\hline Brookhaven College & Farmers Branch & 6,629 & 6,818 \\
\hline Coastal Bend College & Beeville & 2,893 & 2,438 \\
\hline El Paso Community College & El Paso & 17,084 & 14,884 \\
\hline Galveston College & Galveston & 1,583 & 1,306 \\
\hline Houston Community College System & Houston & 26,341 & 32,362 \\
\hline South Texas College & McAllen & 11,478 & 14,162 \\
\hline Southwest Texas Junior College & Uvalde & 3,488 & 3,341 \\
\hline \multicolumn{4}{|l|}{ Virginia } \\
\hline$\overline{\text { Danville }}$ Community College & Danville & 2,470 & 2,503 \\
\hline Mountain Empire Community College & Big Stone Gap & 1,846 & 1,932 \\
\hline Patrick Henry Community College & Martinsville & 2,242 & 2,194 \\
\hline Paul D. Camp Community College & Franklin & 821 & 915 \\
\hline Tidewater Community College & Norfolk & 15,078 & 18,312 \\
\hline
\end{tabular}

SOURCE: U.S. Department of Education, National Center for Education Statistics, Integrated Postsecondary Education Data System (IPEDS).

NOTES: aFull-time equivalent (FTE) 12-month enrollment numbers are shown.

${ }^{b}$ Four colleges in the Alamo Community College District are particpating in Achieving the Dream. The district is the recipient of the Achieving the Dream grant. 
time period, when colleges will have had more time to institutionalize reforms that began under Achieving the Dream.

Overall, research on the implementation of Achieving the Dream at these colleges revealed that many institutions had made important strides in building a stronger culture of evidence during their five-year participation in the initiative. In particular, colleges had enhanced their leadership commitment to student success, increased their research capacity, and developed a number of interventions that are aimed at improving their students' achievement. By spring 2009, 81 percent of the Round 1 colleges had adopted a number of practices associated with a strong culture of evidence, with only 19 percent of colleges still facing major challenges undertaking this work. The research also revealed a number of areas for improvement for the initiative, including the need for an increased focus on faculty and staff engagement, particularly among adjunct or part-time faculty; further definition of the initiative's efforts to reduce achievement gaps by race, ethnicity, and income level; and a more systematic effort to help colleges expand and institutionalize their student success efforts.

The remainder of this chapter is organized as follows: The next two sections provide a brief history of Achieving the Dream and describe the model and underlying theory. Those sections are followed by a description of the characteristics of students attending the Round 1 colleges at baseline (that is, before the initiative began). The penultimate section describes the research methods and data sources that were used for the Achieving the Dream evaluation. The chapter concludes with an outline for the remainder of the report.

\section{A Brief History of Achieving the Dream}

The mission of Lumina Foundation is to help people achieve their potential by expanding access to and success in education beyond high school. In an internal document prepared in 2002 - just two years after the foundation was created - staff identified community colleges as a "high-need area" that was ripe for systemic reform and direct assistance. ${ }^{6}$ The foundation convened a meeting with community college experts and stakeholders from all over the country to vet ideas and solicit feedback on a grantmaking strategy that would increase the attainment and academic success of community college students, including those who are first-generation students, students of color, low-income students, and adult learners. After requesting that interested parties submit a statement of their qualifications, Lumina selected a group of organizations to help it design and operate what became Achieving the Dream: Community Colleges Count (see Table 1.2). The initiative was formally launched in 2004, and MDC, Inc. - a

\footnotetext{
${ }^{6}$ Lumina Foundation for Education (2002).
} 


\section{Achieving the Dream: Community Colleges Count}

Table 1.2

\section{Founding Investor and Partners in the Achieving the Dream Initiative}

Organization
American Association of Community Colleges
www.aacc.nche.edu
Community College Leadership Program,
University of Texas
www.utexas.edu/academic/cclp
Community College Research Center,
Columbia University
http://ccrc.tc.columbia.edu

Jobs for the Future www.jff.org

Lumina Foundation for Education http://www.luminafoundation.org/

MDC, Inc.

www.mdcinc.org

MDRC

www.mdrc.org

Public Agenda

www.publicagenda.org

\author{
Primary Responsibilities in Achieving the Dream
}

Helps recruit and select colleges, houses Achieving the Dream Web site, establishes Web-based data tools, cohosts annual Strategy Institute, co-leads national policy work, and helps disseminate lessons from Achieving the Dream to the higher education community

Hires coaches, manages coaching activities, co-leads Kick-off Institute for new colleges joining the initiative, and leads trustee institutes in select states

Conducts research on a variety of issues related to community college students' success, leads knowledge development activities for the initiative, and works in partnership with MDRC on the evaluation

Coordinates state policy work, develops strategies to align state laws and administrative procedures with Achieving the Dream goals, selects and supports state lead organizations, develops portfolio of promising state policies, and co-leads national policy work

Made founding investment in Achieving the Dream and has invested a total of over $\$ 67$ million into the initiative

Manages and coordinates the overall initiative, hires and manages data facilitators, oversees communications, helps implement strategies to build community support and connect Achieving the Dream with other initiatives, chairs cross-organizational structural inequity team, and co-leads annual Strategy and Kick-off institutes ${ }^{\mathrm{a}}$

Leads the evaluation of the initiative, develops and conducts a comprehensive evaluation plan that assesses the implementation of the overall initiative and the impacts of specific programs at select colleges

Works with select colleges to increase public awareness of campus issues; creates tool kits and provides technical assistance to help colleges engage various internal and external stakeholders; conducts focus groups with faculty, students, and community residents

NOTE: ${ }^{a} \mathrm{MDC}$ is currently providing consultation, program services, and administrative support to Achieving the Dream as it makes the transition from a demonstration initiative to a sustainable nonprofit entity. 
nonprofit organization dedicated to expanding opportunity and advancing equity — was chosen to manage it.

From the earliest conversations, it was clear that Lumina Foundation and the partners had big ambitions for Achieving the Dream. They spoke about fostering fundamental changes in the culture and operations of community colleges - changes that would lead to measureable and lasting improvements in student outcomes. They also spoke about changing the context in which community colleges operate - everything from the rules governing their accreditation and funding to public awareness and support for community colleges. Over a series of meetings, the partners developed an "Integrated Action Plan" that called for coordinated work on several fronts: ${ }^{7}$

- Inside community colleges, by increasing their capacity to gather and analyze data on the academic needs and progress of their students and to use those data to inform decisions on how to strengthen classroom teaching, student services, and other college programs to raise academic achievement

- In public policy, by encouraging state lawmakers and higher education officials to adopt policies that could help community colleges serve their students more effectively, and to build consensus on state reporting requirements and measures of student success

- In research, by supporting investigation into factors that contribute to or impede the success of community college students and on effective programs to boost achievement

- Among the public at-large, by increasing awareness of the work that community colleges do and engaging more people in supporting their mission

- Among national organizations that represent, support, and study community colleges, by promoting regular meetings, information sharing, and collaboration

Each of the partner organizations was assigned specific roles, as shown in Table 1.2. For example, the American Association of Community Colleges had primary responsibility for planning annual conferences ("Strategy Institutes") that involved all the partners and community colleges participating in Achieving the Dream. Similarly, Jobs for the Future took the lead on state policy work. The Integrated Action Plan helped to ensure that the partners understood each

${ }^{7}$ MDC, Inc. (2008). 
other's roles and that their work was mutually reinforcing. Ultimately, all efforts were geared toward increasing the capacity of community colleges to improve student outcomes.

From the beginning, Lumina Foundation and the partners envisioned Achieving the Dream as a national initiative that would involve many states and institutions. Rather than spread resources too thinly, however, Lumina and the partners agreed to concentrate on particular regions of the country and to expand gradually. They also believed that it would be advantageous to create a "critical mass" of institutions within certain states that could work together on state budget issues and other legislative priorities. Florida, New Mexico, North Carolina, Texas, and Virginia were chosen for the first round of Achieving the Dream efforts, largely because those states were perceived as having favorable climates for policy change, including stable funding and high-level support for community colleges. The initiative was also particularly concerned about promoting an equity-based agenda and including institutions with high concentrations of low-income students, students of color, and nontraditional students. Using data compiled by the U.S. Department of Education, the partners identified community colleges in each of those states that served the largest proportion of students of color and/or low-income students. ${ }^{8}$ A Request for Proposals (RFP) was sent out to those institutions to invite them to apply for grants. Of the 105 institutions that received RFPs, 60 applied and 27 were selected to participate. ${ }^{9}$ One college subsequently withdrew, leaving 26 Round 1 institutions.

The Round 1 colleges are diverse in size, location, and student characteristics. The largest institution is Houston Community College, which had a full-time equivalent (FTE) enrollment of over 32,000 students in 2008-2009. The smallest institution is Martin Community College in North Carolina, which had an FTE enrollment of 410 students. The colleges were located in large and midsize cities, suburbs, and small towns. White students made up a majority or plurality of students at most institutions, but nearly all the colleges enrolled substantial numbers of African American, Hispanic, or Native American students. ${ }^{10}$

Over the next several years, the partners held true to their vision of making Achieving the Dream a national initiative. As noted earlier, more than 130 institutions in 24 states and the District of Columbia have gotten involved, representing nearly 1 million students across the country. In addition, a group of 20 funders have joined Lumina Foundation in supporting the

\footnotetext{
${ }^{8}$ To be eligible for Achieving the Dream, Round 1 colleges had to have at least one-third of their students identify themselves as African American, Hispanic, or Native American, or at least half of their students had to be receiving federal Pell Grants (a proxy for low income). Eligibility criteria were modified for later rounds.

${ }^{9}$ Representatives from the partner organizations and several independent reviewers scored the colleges' proposals based on four criteria: (1) the strength of the personnel that the colleges proposed would lead the initiative on their campuses; (2) the colleges' commitment to the goals of the initiative; (3) a description of at least three programs or strategies to increase student achievement; and (4) the colleges' vision for how participation in the initiative would lead to improvements in student outcomes.

${ }^{10}$ For more detail on the characteristics of individual colleges when they entered Achieving the Dream, see Brock et al. (2007), Appendix A.
} 
work at individual colleges and partner organizations. Following another extensive planning process that began in 2008, Achieving the Dream became an independent nonprofit entity in 2010. In a marked shift from the past, community colleges will have to pay to participate in Achieving the Dream, though it is expected that some institutions may find sponsors. ${ }^{11}$ Many of the core activities provided by Achieving the Dream, such as coaching, data facilitation, and annual Strategy Institutes, will also be subsidized so that colleges do not have to cover the full cost of participation.

Achieving the Dream was at the forefront of national efforts to improve student outcomes in community colleges and to hold institutions accountable for their performance. While there is no community college equivalent of No Child Left Behind - the federal law that requires states to establish proficiency standards in reading and math for students in public primary and secondary schools, and to conduct annual testing - most state governments require community colleges to report on student retention, graduation, transfer to other colleges and universities, and sometimes job placement rates. Some states are also beginning to use the budget process to reward or penalize community colleges for institutional performance. ${ }^{12}$

Regional accreditation agencies are also pushing community colleges in the direction of increased accountability. For example, the Southern Association of Colleges and Schools requires colleges to develop a Quality Enhancement Plan that identifies an area for improvement; establishes specific, measurable goals; and engages in an ongoing assessment of progress toward meeting the plan. Similarly, the North Central Association of Schools and Colleges asks colleges to identify and undertake three "action projects" for improvement as part of its Academic Quality Improvement Program. ${ }^{13}$ Many community colleges either want to or are required to participate in these efforts, and are hungry for guidance. Achieving the Dream provides these institutions with a framework, guidance from outside professionals, and a network of institutions with similar goals and relevant experience.

\section{The Achieving the Dream Model and Theory of Change}

Achieving the Dream aspires to nothing less than to change the way community colleges "do business." By gathering and analyzing data on student performance, college administrators and faculty are expected to gain a better understanding of where students are having academic difficulty and what might be needed to make students more successful. From this research, colleges are expected to implement strategies to improve student performance, evaluate the effectiveness of those strategies, and scale up those strategies that lead to improve-

\footnotetext{
${ }^{11}$ Such changes were instituted as part of Achieving the Dream's new sustainability model, which is focusing on diversifying the funding base and becoming less dependent on philanthropy.

${ }^{12}$ Dougherty and Hong (2006).

${ }^{13}$ Biswas (2006).
} 
ment in student outcomes - and refine or eliminate those that do not. As shown in Figure 1.2, the Achieving the Dream model involves five steps:

- Step 1: Leadership commitment. The college's president and senior executives, with support from the board of trustees and faculty leaders, commit to making the changes in policy and resource allocation that are necessary to improve student outcomes. They also organize a team representing administrators, faculty, and other members of the community to guide the process.

- Step 2: Use of data to prioritize actions. The college mines student transcripts and other data to understand how students are performing over time - for example, whether students are progressing through developmental courses and into college-level courses, and whether students are returning in subsequent semesters. Colleges are also expected to analyze data by race or ethnicity, income, and other background characteristics to identify groups that may be in need of extra support or intervention. Colleges are encouraged to identify a manageable set of problems to ensure that they focus their resources to the greatest effect.

- Step 3: Stakeholder engagement. The college engages faculty, staff, and other internal and external stakeholders in developing strategies for overcoming barriers to student achievement based on a diagnosis of the causes and a review of lessons gleaned from prior attempts to address such problems.

- Step 4: Implementation, evaluation, and improvement of strategies. The college implements strategies for addressing priority problems, which may include such things as revamping college orientation and testing procedures, adopting new instructional practices, or making improvements in student advising programs. The college evaluates whether the strategies lead to improvements in student outcomes and uses the results to make decisions about whether to continue with the strategies or make further improvements.

- Step 5: Establishment of a culture of continuous improvement. The college takes steps to institutionalize effective policies and practices. Particular attention is given to how resources can be used to sustain and expand proven strategies. Program review, planning, and budgeting are driven by evidence of what works best for students. Colleges are also encouraged to provide professional development for faculty and staff to advance their efforts to improve student achievement.

In addition to these five steps, Achieving the Dream also placed an important emphasis on equity and overcoming achievement gaps, particularly among students of color and lowincome students. The initiative initially made this component a cornerstone of its work by 


\section{Achieving the Dream: Community Colleges Count}

Figure 1.2

\section{Achieving the Dream's Five-Step Process for Improving Student Success}

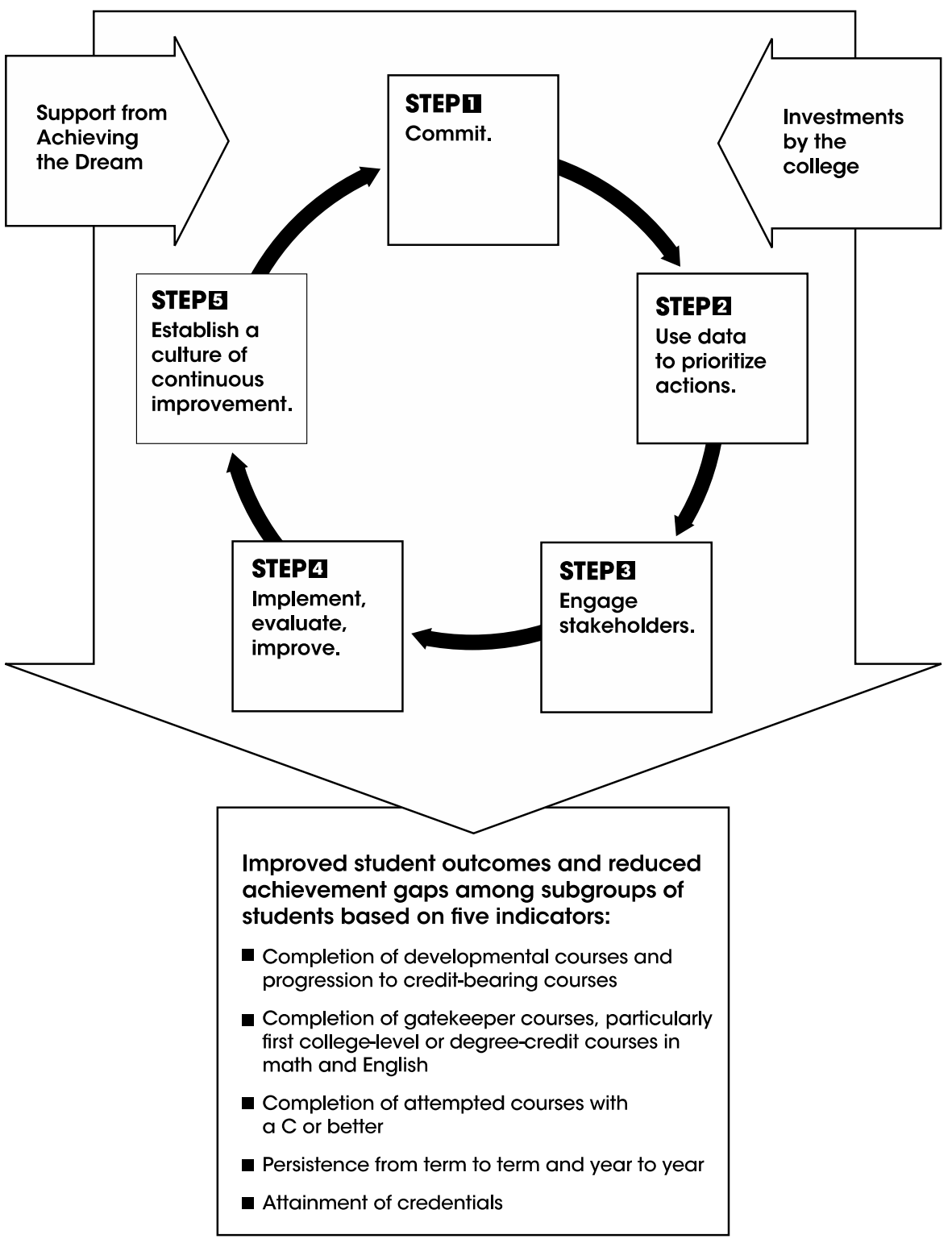

SOURCE: Field Guide for Improving Student Success (2009), p.11, from the Achieving the Dream: Community Colleges Count initiative. Copyright 2009 by Lumina Foundation for Education. Reprinted with permission. Available online at www.achievingthedream.org/docs/Field_Guide_for_Improving_Student_Success.pdf. 
recruiting colleges with high proportions of low-income students or students of color. As Achieving the Dream grew and a more diverse group of institutions joined, the initiative continued to push this agenda by encouraging colleges to analyze the performance of these students and develop interventions aimed at increasing their success.

To help colleges institute their reforms, Achieving the Dream provided both monetary and technical support to the participating institutions. The Round 1 colleges were awarded an initial year-long planning grant of $\$ 50,000$ each, followed by annual grants of $\$ 100,000$ for four years $\left(\$ 450,000\right.$ total). ${ }^{14}$ In addition, the colleges were aided by two consultants: a data facilitator, who helped them perform the data collection and analysis and interpret the results, and a coach, who helped them set priorities, build consensus, and implement strategies for improvement. These consultants spent 12 days each at their assigned colleges during the planning year and the first year of implementation, and then gradually reduced their time to three days each during the final year. Additionally, the initiative sponsored a kick-off conference and annual Strategy Institutes for all the Achieving the Dream colleges. Each institution sent teams of administrators and faculty to these events, where they learned more about the Achieving the Dream process, made plans for their own campuses, and shared ideas and lessons with other colleges on how to help students be more successful.

The initiative also provided some supports that were aimed at helping colleges focus on achievement gaps between students by racial, ethnic, and income group, although this support was less concentrated than other efforts to improve colleges' leadership and research capacity. For instance, equity was an important focus of the annual Strategy Institutes and was discussed in numerous publications documenting the initiative's efforts. However, rather than provide coaching or facilitation to support colleges' development of an equity-based agenda, the initiative tended to rely on the colleges' own capacity for and interest in pursuing those efforts. As such, colleges were free to set their own priorities for their Achieving the Dream work, which may or may not have focused on particular racial, ethnic, or income achievement gaps. ${ }^{15}$

Regardless of the goals they developed, all Achieving the Dream colleges were asked to try to "move the needle" on five measures of student success. These measures included (1) completion of developmental courses and progression to credit-bearing courses; (2) completion of so-called gatekeeper courses, including introductory college courses in English and math; (3) completion of attempted courses with a grade of "C" or better; (4) persistence from semester to semester and from year to year; and (5) attainment of college credentials. Colleges were

\footnotetext{
${ }^{14}$ Achieving the Dream demonstration colleges in later rounds sometimes received smaller amounts of money over a shorter time period, depending on the funders that supported them. The majority received the same amount as did the Round 1 institutions.

${ }^{15}$ From 2008 through 2010, Achieving the Dream created more tools and supports to enhance colleges' efforts to reduce achievement gaps, including an online portal called the Equity Resource Center as well other publications and tools.
} 
expected to track these outcomes for each fall cohort of entering students and to make comparisons with past cohorts to determine whether the outcomes improved over time. As noted above, colleges were also expected to break down the results for subgroups of students defined by race or ethnicity and by income. Lumina and the partners theorized that colleges that followed the Achieving the Dream five-step process would detect quantifiable gains on the five measures and would reduce gaps in achievement between subgroups.

Throughout the history of Achieving the Dream, there was some tension between those who believed that gains in student outcomes should come quickly and those who believed that achieving gains was a long-term process. The Integrated Action Plan was vague on this point, indicating that colleges should see "measurable improvement in success rates" after four years and should have "achieved their long-term targets for student success" after eight years. ${ }^{16}$ What was clear was that the five-step process was iterative, so any improvements in student outcomes depended on the colleges' ability to master the initial steps. Even if colleges did all that was asked of them, it could still take time for improvements to show up in the data, given the longitudinal nature of the measures. The oft-used metaphor of turning a ship was invoked by some of the partners to describe the work of Achieving the Dream. On the one hand, they firmly believed that the initiative would set community colleges on a better course; on the other hand, they recognized that changes would likely occur only gradually and might not be fully apparent for several years' time.

\section{Characteristics of Students at the Achieving the Dream Colleges at Baseline}

Table 1.3 shows averages across the Round 1 colleges on a variety of student characteristics in fall 2002, two years before Achieving the Dream was launched. As explained later in this report, the data capture first-time students who were enrolling full time or part time. The top panel shows that as a group, the Round 1 colleges served more women than men and roughly equal proportions of younger and older students. A little more than 40 percent were white, 28 percent were Hispanic, and 17 percent were black. The standard deviation - a measure of spread around the average - and the minimum and maximum values show that there is a high degree of variability across the Round 1 institutions. While a number of institutions served primarily students of color, most served a majority of white students.

The second panel of the table presents baseline institutional averages for the major outcomes that Achieving the Dream is tracking and makes clear why improvement is so desperately needed. For example, the table shows that a sizeable number of matriculating students in fall

\footnotetext{
${ }^{16} \mathrm{MDC}$, Inc. (2008), Part 1-B, p. 1.
} 


\section{Achieving the Dream: Community Colleges Count}

Table 1.3

Average Characteristics of Entering Students at the 26 Round 1 Colleges in Achieving the Dream, Fall 2002

\begin{tabular}{|c|c|c|c|c|}
\hline Characteristics & $\begin{array}{r}\text { Average for } \\
\text { All Colleges } \\
\end{array}$ & $\begin{array}{l}\text { Standard } \\
\text { Deviation } \\
\end{array}$ & $\begin{array}{r}\text { Minimum } \\
\text { Value } \\
\end{array}$ & $\begin{array}{r}\text { Maximum } \\
\text { Value } \\
\end{array}$ \\
\hline \multicolumn{5}{|l|}{ Entering student characteristics } \\
\hline \multicolumn{5}{|l|}{ Gender $(\%)$} \\
\hline Male & 40.4 & 5.3 & 24.2 & 52.2 \\
\hline Female & 59.6 & 5.3 & 47.8 & 75.8 \\
\hline \multicolumn{5}{|l|}{ Age $(\%)$} \\
\hline $18-20$ years & 50.5 & 9.0 & 30.6 & 65.7 \\
\hline $21-25$ years & 18.6 & 4.2 & 10.6 & 25.4 \\
\hline $26-30$ years & 9.3 & 2.4 & 4.9 & 15.2 \\
\hline 31 years and above & 19.8 & 6.4 & 7.5 & 37.7 \\
\hline Average age (years) & 24.6 & 1.7 & 21.5 & 28.7 \\
\hline \multicolumn{5}{|l|}{ Race/ethnicity ${ }^{\mathrm{a}}(\%)$} \\
\hline Hispanic & 28.3 & 29.7 & 0.0 & 94.8 \\
\hline White & 42.0 & 22.7 & 0.0 & 97.9 \\
\hline Black & 17.1 & 15.5 & 0.0 & 52.5 \\
\hline Other & 12.6 & 23.8 & 0.5 & 100.0 \\
\hline \multicolumn{5}{|l|}{ Baseline indicators of the fall 2002 cohort (\%) } \\
\hline Referred to any developmental math course & 61.8 & 15.2 & 25.0 & 81.3 \\
\hline Referred to any developmental English course & 32.7 & 15.8 & 7.5 & 64.2 \\
\hline Referred to any developmental reading course & 33.0 & 10.7 & 7.8 & 54.0 \\
\hline $\begin{array}{l}\text { Referred to one or more developmental courses } \\
\text { in any subject }\end{array}$ & 66.8 & 13.0 & 32.9 & 82.4 \\
\hline $\begin{array}{l}\text { Completed a developmental course (any subject) } \\
\text { within first } 2 \text { years }\end{array}$ & 40.1 & 9.5 & 18.6 & 61.1 \\
\hline $\begin{array}{l}\text { Successful completion of gatekeeper math } \\
\text { course within first } 2 \text { years }\end{array}$ & 15.1 & 5.4 & 6.8 & 24.9 \\
\hline Successful completion of gatekeeper English & & & & \\
\hline course within first 2 years & 26.4 & 8.6 & 15.0 & 52.1 \\
\hline $\begin{array}{l}\text { Completed } 80 \text { percent or more of attempted } \\
\text { credits within first } 2 \text { years }\end{array}$ & 52.2 & 15.3 & 21.8 & 87.3 \\
\hline Enrolled in fall of second year & 47.9 & 6.2 & 32.6 & 59.7 \\
\hline $\begin{array}{l}\text { Awarded an associate's degree or certificate } \\
\text { within } 2 \text { years }\end{array}$ & 3.5 & 3.1 & 0.0 & 12.3 \\
\hline Sample size & & & & 26 \\
\hline
\end{tabular}


Table 1.3 (continued)

SOURCE: MDRC calculations using the Achieving the Dream database maintained by JBL Associates.

NOTES: Calculations for this table used institutional means from all available data for the sample members in the Round 12002 cohort of the "student general" files from JBL. While Alamo Community College District is considered one site for the Achieving the Dream initiative, it has 4 colleges that report data separately to the database, bringing the total number of data-reporting institutions from 26 to 29. Because 2 of these colleges (Central New Mexico Community College and New Mexico State University-Dona Ana) did not submit 2008 data to JBL, they are not included in the analysis. Data for the fall 2002 cohort at Guilford Technical Community College were also not submitted, bringing the sample size for this table to 26 .

The standard deviation is a calculated measure of the tendency of data to be spread out around the mean.

Missing values are not included in individual variable distributions.

Distributions may not add to 100 percent because of rounding.

${ }^{a}$ Respondents who said they are Hispanic and chose a race are included only in the Hispanic category. Respondents who said they are not Hispanic and chose more than one race are only in the multiracial category. Southwestern Indian Polytechnic Institute reported all students as American Indian/Alaskan Native, which falls in the "Other" category.

2002 required developmental (remedial) education in at least one subject, with over half requiring developmental coursework in math. While this average is alarmingly high, there is wide variation across the Round 1 colleges. At one extreme, 81 percent of students at one institution were referred to developmental math; at another institution, the figure was 25 percent. On average, about 40 percent of students who were referred to a developmental course in any subject completed it within two years - a fairly low indicator of success. Once again, these values represent baseline measures that the colleges tried to improve upon in subsequent years.

Gatekeeper math and English courses refer to the first college-level or credit-granting courses in these subjects. As shown near the bottom of the table, students taking gatekeeper courses also had fairly low average completion rates after two years. For example, only 15 percent of students completed a gatekeeper math course within the first two years, and only about 26 percent completed a gatekeeper English course. Similarly, just under half of these students were still enrolled in college one year later, while fewer than 5 percent of students were awarded an associate's degree or certificate during this same time period.

\section{Research Methods and Data Sources}

To answer the research questions posed at the beginning of this chapter, a research team comprising MDRC and Community College Research Center (CCRC) staff studied the Round 1 colleges over a period of several years. The team visited each of the 26 colleges two times: once during the first year of implementation, in spring 2006; and again during the last year of implementation, either in fall 2008 or spring 2009. The visits lasted two to three days and included interviews with the college president, vice presidents and deans of instruction, institutional research staff, the Achieving the Dream coordinator, and faculty members involved in the 
initiative. Researchers followed a standard protocol to make sure that similar questions were asked of people in comparable positions at each institution.

In addition to the field visits, the research team conducted a survey of college administrators and faculty at 23 colleges in 2007, about midway through their involvement in Achieving the Dream. The survey contained questions about the respondents' involvement in the initiative and how often and in what ways they used data to make decisions in their jobs. At smaller institutions, all administrators and faculty members received the survey; at larger institutions, a random sample was surveyed. The response rate to the survey averaged 73 percent among administrators and 60 percent among faculty. A more detailed explanation of the survey methodology and the questions that were asked of respondents is included in Appendix A. ${ }^{17}$

Not surprisingly, an initiative of the size and complexity of Achieving the Dream also generated considerable documentation. The research team reviewed annual reports that the colleges submitted to MDC, Inc., describing how they used their grants and detailing their accomplishments and challenges. These reports included information on the specific strategies that colleges developed to improve student outcomes on their campuses. The research team also reviewed annual reports that the coaches and data facilitators submitted on the work they performed with the colleges and their assessments of the colleges' progress.

Finally, the research team analyzed student records data that the colleges submitted to the Achieving the Dream database, managed by JBL Associates (a higher education consulting firm) under contract with CCRC. The database contains information on full- and part-time students entering the colleges each fall and allows researchers to track student performance over time on the measures listed above: completion of developmental courses and progression to credit-bearing courses, completion of gatekeeper courses, completion of attempted courses with a grade of " $\mathrm{C}$ " or better, persistence from semester to semester and year to year, and attainment of credentials. More information about those data and the methods used in this study is provided in Chapter 8.

\section{Organization of the Report}

As noted earlier, Lumina Foundation and the partner organizations that were responsible for the initiative recognized that the process of building a culture of evidence would be ongoing and that improvements in student outcomes would likely take several years. For that reason, this report focuses mainly on implementation and is organized according to the five-step process described earlier. Chapter 2 delves into the issue of leadership: what Achieving the Dream hoped to accomplish, what assistance it offered, and what success it had in engaging

\footnotetext{
${ }^{17}$ See, also, Jenkins and Kerrigan (2008).
} 
presidents and other senior officials at the colleges. Chapter 3 describes the colleges' experiences in collecting and using data to diagnose problems and develop strategies for improvement. Chapter 4 explains the efforts that colleges made to engage faculty, staff, and external stakeholders in the initiative. Chapter 5 details the intervention strategies that the colleges developed to improve student outcomes. Chapter 6 describes the colleges' efforts to institutionalize Achieving the Dream and establish a culture of continuous improvement. Chapter 7 provides an overall perspective on colleges' development of a culture of evidence and the influence of Achieving the Dream on their progress.

An analysis of trends in student achievement is presented in Chapter 8. This analysis represents a "first look" at student outcomes and will be updated in a final report, which is scheduled for release in 2012. Chapter 9 concludes with reflections on challenges and successes in Achieving the Dream and provides recommendations for the continuous improvement of the initiative. 



\section{Chapter 2}

\section{Leadership Commitment}

Of central importance to the implementation of any institutional reform is strong and committed leadership. Much of the literature on institutional change has posited that visionary leadership is critical for creating and maintaining momentum in large-scale reform efforts. ${ }^{1}$ School leaders often set the tone for an institution's work and hold critical leverage over the school's development and growth. This is particularly true in community college systems, where presidents and chief executive officers have a relatively high level of authority over the everyday practices in their institutions. ${ }^{2}$

Achieving the Dream has long advocated that community colleges seeking to improve their students' achievement focus first on developing their leaders' commitment to student success. As noted in the Achieving the Dream "framing paper" detailing the conceptual framework of the initiative:

Presidential leadership is essential to bring about institutional change that will improve student outcomes. The president or chancellor must have a vision for student success and equity and must be able to mobilize broad support for that vision throughout the college and community. ${ }^{3}$

As the initiative has developed, it has articulated the need for strong leadership commitment in even more concrete terms that are detailed in its key practices and theory of change. Leadership commitment now makes up Step 1 of Achieving the Dream's five-step process for improving student success (see Figure 1.2 in Chapter 1), with colleges' senior leadership urged to commit "to making changes in policy and resource allocation necessary to improve student outcomes." In 2009, the initiative also published a number of practices that it had long advocated as essential components in colleges' leadership commitment (see Box 2.1). These practices include bringing other leaders, such as colleges' senior administrators, boards of trustees, and faculty and staff leaders, into the colleges' institutional improvement work and garnering the commitment of those individuals to make "changes in policies, procedures, and resource allocations to improve student success." ${ }^{5}$

\footnotetext{
${ }^{1}$ Evans (1996); Heifetz (1994); Senge (1990).

${ }^{2}$ Tyree, Milliron, and de la Santo (2004).

${ }^{3} \mathrm{MDC}$, Inc. (2006).

${ }^{4}$ Achieving the Dream (2009), p. 10.

${ }^{5}$ Achieving the Dream (2009), p. 15.
} 


\section{Box 2.1 \\ Principles and Practices for Increasing Student Success Through Institutional Improvement: Practices Associated with Principle 1, Committed Leadership}

\section{Vision and Values}

- President/chancellor and leadership team support efforts to improve student learning and college completion, not just increase enrollments.

- President/chancellor and other senior leaders make an explicit policy commitment to improve performance for all students and achieve equity in student outcomes across racial/ethnic and income groups. This policy is communicated to faculty, staff, students, and the community.

- Institutional communications, including news releases, the college's Web site, appropriate print publications, and so forth, address the student success agenda.

\section{Commitment}

- College's board expects, and the president/chancellor provides, regular reports on student outcomes and the impact of institutional efforts to improve success rates across all student groups.

- Senior leaders demonstrate willingness to support changes in policies, procedures, and resource allocation to improve student success.

- Faculty leaders actively support a culture of inquiry and evidence and a broadbased student success agenda.

SOURCE: Field Guide for Improving Student Success (2009), from the Achieving the Dream: Community Colleges Count initiative. Available online at www.achievingthedream.org/docs/Field_Guide_for_Improving_Student_Success.pdf. 
In addition to advocating for a general student success agenda, senior leaders are expected to make an explicit commitment to reducing achievement gaps across different racial, ethnic, and income groups. Since its inception, Achieving the Dream has placed a high priority on improving the outcomes of low-income students and students of color. At first, the initiative focused only on those colleges with large proportions of African American, Hispanic, Native American, or low-income students, and the Round 1 colleges were expected to commit to overcoming the achievement gaps between these students and the rest of the student body. ${ }^{6}$ This commitment was expected to begin with the president and other senior leaders at the college, who were then charged with spreading that commitment to other faculty and staff at the school. However, as discussed below, Achieving the Dream's efforts to help colleges focus on overcoming these achievement gaps varied, leading some colleges to direct their energies to other areas.

Although Achieving the Dream has codified a number of its practices and supports, this report focuses on the Round 1 colleges, which began their work while Achieving the Dream was still under development. Thus, although Box 2.1 emphasizes a number of practices that colleges are expected to emulate, these practices were not presented in such an iterative form until the final years of the Round 1 colleges' implementation efforts. Similarly, while coaching has been with the initiative since its early beginnings, other supports, such as Trustee Institutes and other leadership meetings, were under development while the Round 1 colleges were implementing their reforms. As such, this chapter offers a look at the initiative's early development, when its practices and supports were still being solidified.

The sections that follow describe the extent to which the 26 Round 1 colleges developed broad-based leadership commitment within their institutions. The implementation research revealed that presidents, senior administrators, and faculty leaders demonstrated considerable support for improving students' success at these colleges, and that Achieving the Dream had some influence on increasing the commitment of these leaders. College presidents were generally aware and supportive of their colleges' Achieving the Dream agendas, even if they tended to be less involved than other staff in the leadership of the initiative. College leaders also tended to be aware of the racial, ethnic, and income achievement gaps at their schools, although closing these gaps was not the main goal of most schools' Achieving the Dream work. Finally, many leaders emphasized the important role that their Achieving the Dream coaches had played in helping them develop their student success agendas.

\footnotetext{
${ }^{6}$ Brock et al. (2007).
} 


\section{Levers for Change in Achieving the Dream}

To facilitate leaders' commitment to student success, the initiative partners recommend that colleges develop several key leadership committees charged with moving their student success agendas forward. First, colleges are expected to develop a core team, which includes the president, chief academic officer, chief student services officer, institutional research (IR) director, and faculty leaders. This core team of leaders is expected to head up the college's institutional change agenda and plan out tactics for increasing students' success. Achieving the Dream also recommends that a second team, called the data team, be formed to engage the IR director, faculty, and staff in analyses of the college's performance and student outcomes, with special attention to low-income students and students of color. ${ }^{7}$

Achieving the Dream also provides a number of supports to participating colleges to spur their efforts to develop leadership commitment. First and foremost among these supports are the "coaches" whom the initiative has employed to work with college leaders. Leadership coaches were allotted 12 days to work with the Round 1 colleges (one coach per college) during their first two years in Achieving the Dream, followed by nine, six, and three days of coaching in their final three years of implementation, respectively. ${ }^{8}$ Coaches are expected to assist colleges' core teams in three broad areas, including (1) advising colleges on how to address priority issues and manage the politics of change; (2) strengthening the teams' communication and openness to using data to confront and solve difficult issues; and (3) fostering continual reflection on the teams' and the colleges' performance and effectiveness. ${ }^{9}$ In preparation for this work, each Achieving the Dream coach receives an initial two-day training and attends a twoday coach retreat once per year.

In addition to assigning coaches, Achieving the Dream provides several forums and resources to support college leaders' commitment to improving students' success. Upon joining Achieving the Dream, each college is expected to send senior leaders, including the college's president, to a four-day Kick-off Institute to begin planning for the first year of work. The initiative also hosts an annual, week-long Strategy Institute, where all of the Achieving the Dream colleges gather and share their implementation plans and interventions aimed at increasing students' success. During the Strategy Institute sessions, particular forums are directed toward senior leaders, including a three-hour President and CEO Roundtable, which allow for further communication among senior administrators across the colleges. Some college leaders may also participate in other Achieving the Dream events, such as a Trustee Institute held

\footnotetext{
${ }^{7} \mathrm{MDC}$, Inc. (2008).

${ }^{8} \mathrm{MDC}$, Inc. (2008).

${ }^{9} \mathrm{MDC}$, Inc. (2008).
} 
annually for the Gulf Coast (Texas) colleges, or ad-hoc trainings or institutes focused on issues such as strategy development or increasing institutional research capacity. ${ }^{10}$

Finally, Achieving the Dream saw improving the outcomes of low-income students and students of color as an important leadership effort. Through the encouragement of senior leaders, colleges were expected to disaggregate their student outcomes data in order to examine and compare the achievement of differing racial, ethnic, and income groups. Equity was also featured as a topic at the initiative's yearly Strategy Institutes, and colleges were asked to report on any equity initiatives they developed. However, while this commitment existed, a racial-, ethnic-, or income-equity focus was not a required part of colleges' Achieving the Dream work, nor did the initiative develop specific supports, such as coaching or facilitation, to help colleges develop a more equity-focused agenda. Instead, colleges were encouraged to develop their own goals for their Achieving the Dream work and had the option to focus their efforts on other student groups. Additionally, the initiative and its coaches tended to encourage colleges to develop interventions aimed at large groups of students rather than boutique programs for certain groups. Therefore, while racial, ethnic, and income equity was an important part of Achieving the Dream, the initiative did not always make this agenda the centerpiece of its support efforts, choosing instead to depend on colleges' own internal capacity to promote this work. ${ }^{11}$

\section{Leadership Commitment to Student Success}

\section{Early Commitment}

As noted in the 2007 baseline report on Achieving the Dream, by MDRC and the Community College Research Center (CCRC), ${ }^{12}$ most Round 1 colleges began Achieving the Dream with strong leadership support for improving student outcomes. In spring 2006, all Round 1 college presidents vocalized a need to improve student outcomes and to eliminate achievement gaps across different student subgroups. Many also saw synergies between Achieving the Dream's goal of building a culture of evidence and state, federal, and accreditation agencies' focus on tracking student outcomes. However, while voicing strong support for

\footnotetext{
${ }^{10}$ In the summer of 2009, Achieving the Dream also produced a series of practical guides to help colleges plan better for implementing Achieving the Dream within their schools; however, these guides were released after the Round 1 colleges had completed their five-year demonstration phase in the initiative and thus were less relevant for this period of study.

${ }^{11}$ As noted in Chapter 1, from 2008 through 2010, Achieving the Dream created more tools and supports to enhance colleges' efforts to reduce achievement gaps, including an online portal called the Equity Resource Center as well other publications and tools.

${ }^{12}$ Brock et al. (2007).
} 
the initiative's goals, most presidents were not as involved in leading their colleges' Achieving the Dream efforts as the initiative had hoped. Many presidents had delegated responsibility for implementing the initiative to other college personnel, with nearly half of the colleges appointing senior administrators to lead this work while others designated faculty, staff, or outside consultants to lead the charge. Additionally, leadership turnover complicated the Achieving the Dream implementation process at about one-third of the colleges, making it difficult for a number of schools to quickly ramp up their plans. ${ }^{13}$ Therefore, while presidents tended to voice strong support for Achieving the Dream's goals in the early years of implementation, their onthe-ground leadership of the initiative at their institutions often differed from Achieving the Dream's recommended structure.

\section{Commitment After Five Years in Achieving the Dream}

\section{Presidents, Senior Administrators, and Faculty Leaders}

Given leaders' early commitment to student achievement in 2006, it is not surprising that many still voiced a strong commitment in spring 2009, when the Round 1 colleges were in their fourth and final year of implementing their Achieving the Dream reforms. As in their early years in the initiative, the majority of the Round 1 presidents, senior administrators, and faculty leaders expressed a strong commitment to improving student success (see Figure 2.1). Just over one-third of the presidents at these schools were strong drivers of the colleges' overall student success agendas (not shown), with faculty and staff often noting that their presidents had a "passion" for student success or that they were "clearly driving the agenda" for improving students' achievement. Tidewater Community College's president exemplified these leaders' strong commitment to student success: "I want us to be a benchmark for student success in much the same way that we are a benchmark in recruitment [and] entrepreneurialism... At the end of the day, all of the glitz in the world falls shallow...if it doesn't have [student success] as its base."

A large majority of senior administrators and faculty leaders also voiced a strong commitment to improving students' achievement, with many observing that Achieving the Dream had a positive influence on their commitment (see Figure 2.2). In the words of one student support services administrator, Achieving the Dream has allowed college personnel to access data in "real time" and made them "more focused" on improving students' success. A coordinator at another school noted that Achieving the Dream "wasn't about just one program or service. It was transformational and groundbreaking for the entire institution."

\footnotetext{
${ }^{13}$ Brock et al. (2007).
} 


\section{Achieving the Dream: Community Colleges Count}

Figure 2.1

\section{Leadership Commitment to Improving Student Success Among Presidents, Senior Administrators, and Faculty Leaders in Achieving the Dream Colleges, Spring 2009}

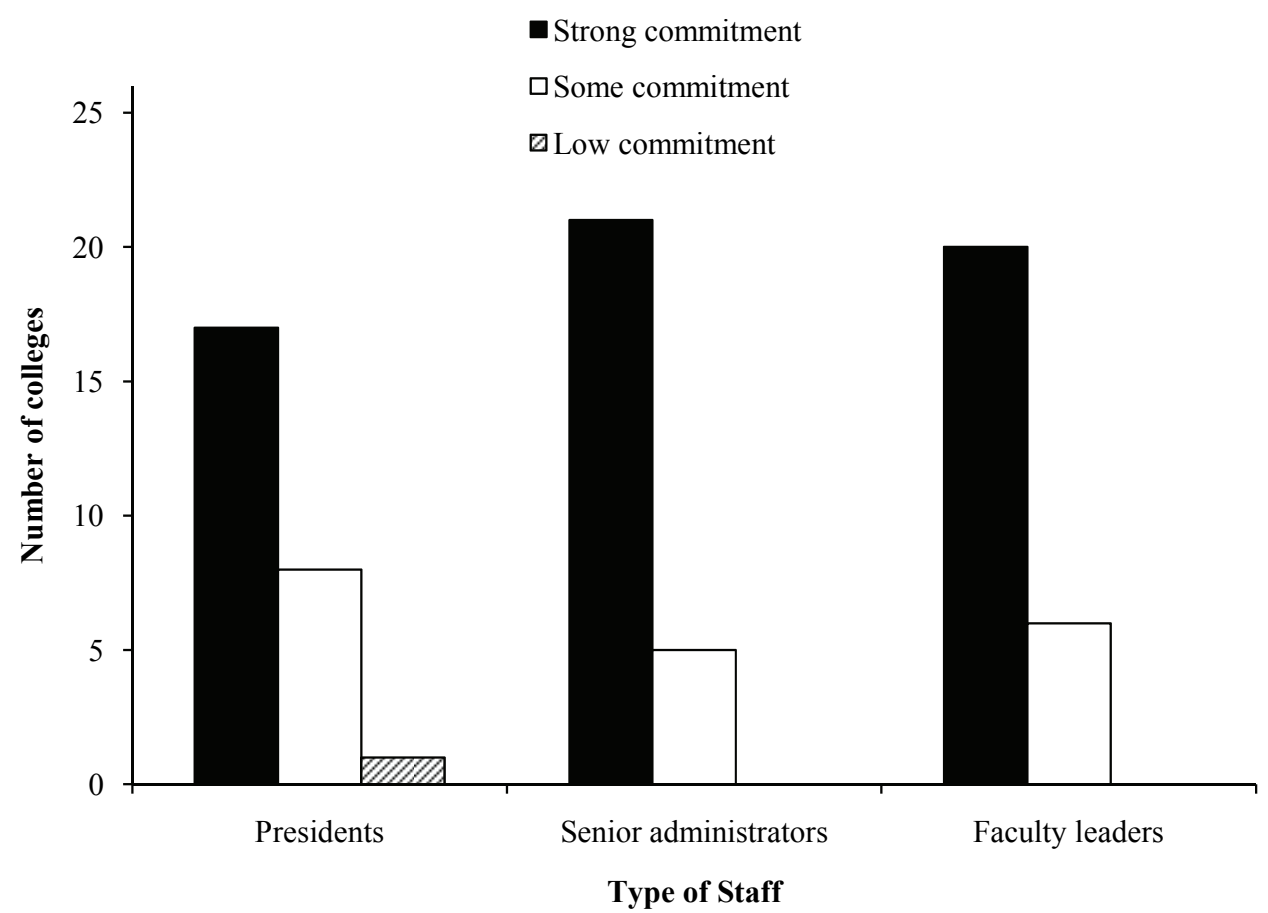

SOURCE: Information collected from faculty, staff, and administrators during two rounds of implementation research across all 26 Round 1 colleges, cross-referenced against reports submitted by college representatives, Achieving the Dream coaches, and data facilitators.

Achieving the Dream's influence on senior administrators and faculty leaders may have been in part a result of the high level of involvement these individuals had in their colleges' Achieving the Dream agendas. Senior administrators and faculty leaders were moderately to highly involved in implementing their colleges' Achieving the Dream plans at nearly all of the Round 1 colleges (see Figure 2.3). Higher- and lower-level administrators were most often the head of colleges' core teams (69 percent of the Round 1 colleges) and leading colleges' Achieving the Dream work. While faculty led a few colleges' core teams, they tended to be most often involved in the development and implementation of colleges' strategies, rather than serving on colleges' higher-level decision-making committees (discussed in Chapter 4). 


\section{Achieving the Dream: Community Colleges Count}

Figure 2.2

\section{Influence of Achieving the Dream on College Presidents', Senior Administrators', and Faculty Leaders' Self-Reported Commitment to Improving Student Success, Spring 2009}

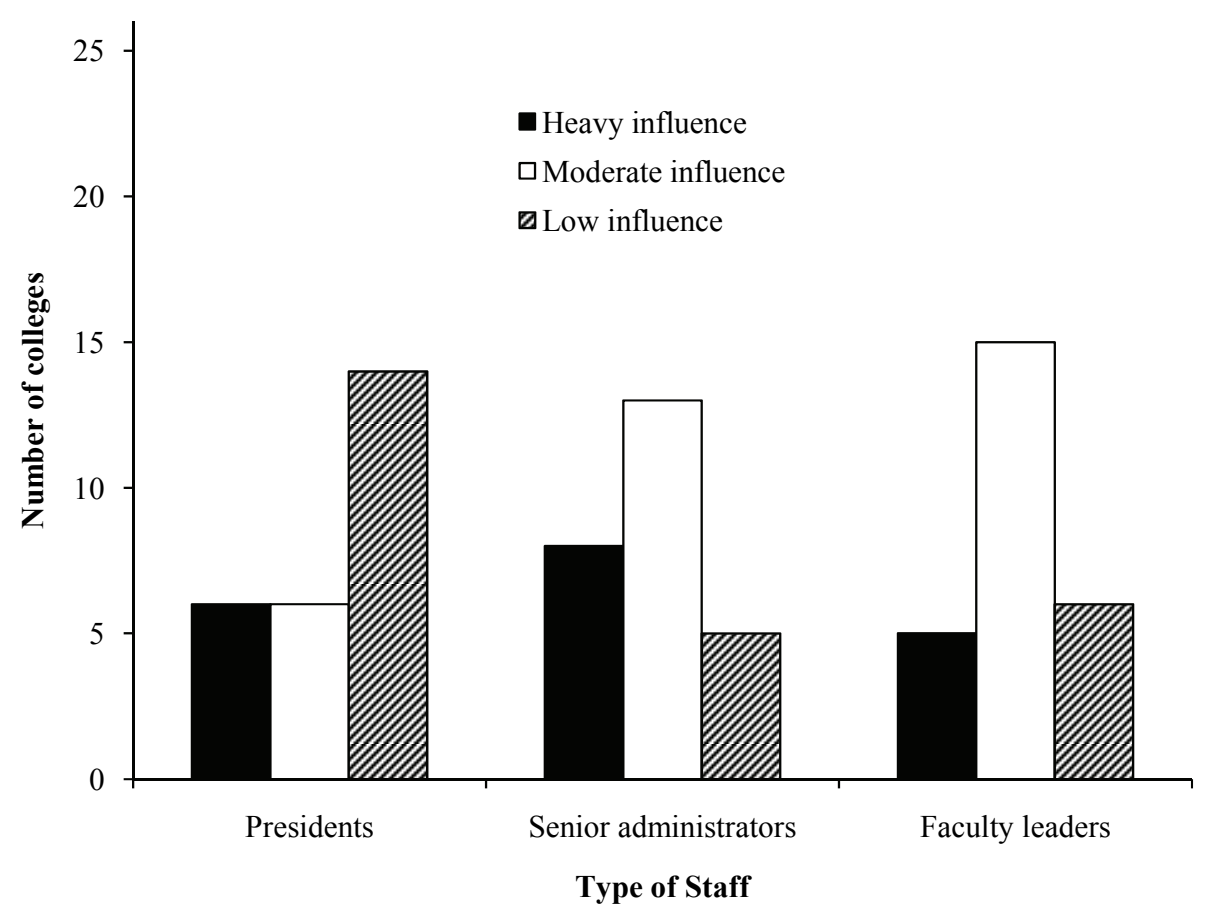

SOURCE: Information collected from faculty, staff, and administrators during two rounds of implementation research across all 26 Round 1 colleges, cross-referenced against reports submitted by college representatives, Achieving the Dream coaches, and data facilitators.

While senior administrators and faculty leaders played key roles in Achieving the Dream, fewer Round 1 presidents were actively involved in colleges' Achieving the Dream efforts. Only four Round 1 presidents were leading their college's core team, while most college presidents delegated this work to other administrators or faculty (see Figure 2.3). Similarly, presidents were split as to the influence of Achieving the Dream on their visions for student success. While nearly half said that Achieving the Dream played at least a moderate role in shaping their agendas, over half did not see the initiative as a primary motivator of their work (see Figure 2.2). The initiative's lesser influence on these individuals was the result of several different factors, including presidents' focus on other pressing issues at the college (such as 


\section{Achieving the Dream: Community Colleges Count}

Figure 2.3

\section{Involvement of Presidents, Senior Administrators, and Faculty Leaders in Student Success Reforms at the Round 1 Colleges in Achieving the Dream, Spring 2009}
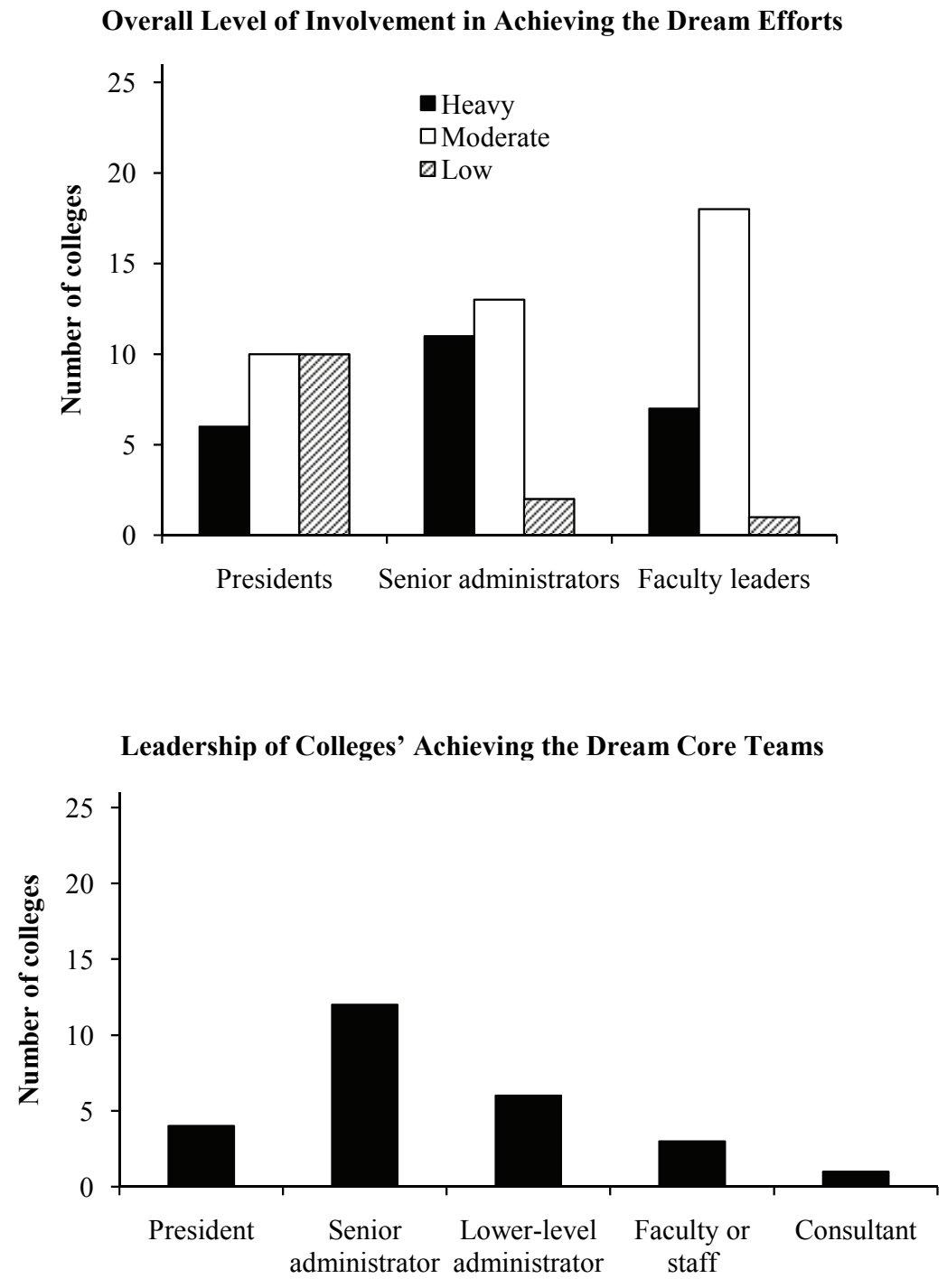

Type of Personnel Leading Core Team

SOURCE: Information collected from faculty, staff, and administrators during two rounds of implementation research across all 26 Round 1 colleges, cross-referenced against reports submitted by college representatives, Achieving the Dream coaches, and data facilitators. 
precarious financial situations, accreditation process requirements, presidents' own personal visions, and leadership turnover).

Given college presidents' busy schedules and the multiple agendas that inform their work, Achieving the Dream's lower level of influence on these individuals may not be surprising. Despite the fact that the initiative was not the primary driving force behind many presidents' visions, most appreciated Achieving the Dream for the systematic focus it brought to student success. A majority of colleges noted that the initiative helped them develop a more focused message about student success and coordinate their efforts to improve students' achievement. For instance, while one president remarked that her vision has "always been about student success," she felt that Achieving the Dream had been "remarkable" in "focusing their efforts." Similarly, a number of multicampus colleges noted that the initiative had helped them develop a clear, cross-campus message and had helped with coordinating the work across their different institutions.

\section{Board of Trustees}

The Achieving the Dream model holds that colleges' boards of trustees, which are generally responsible for helping colleges develop their mission and work, should regularly receive reports on students' achievement and colleges' efforts to improve their success. Most Round 1 colleges' boards demonstrated an awareness and support of the colleges' efforts to improve student achievement, even if they did not necessarily know about the colleges' participation in Achieving the Dream. Virtually all boards reviewed at least some reports on students' success. The boards at five Round 1 colleges were particularly active and credited Achieving the Dream with their heightened awareness of students' outcomes. For instance, at Tallahassee Community College, the board had "workshops before every board meeting...[to] focus on [their] strategic plan data and evidence on how we are doing." Similarly, South Texas College provided regular updates to its board, which led the board to become more interested in performance data as opposed to enrollment or budgetary data. However, as might be expected, most colleges' boards were far less knowledgeable about the goals of Achieving the Dream or how their colleges' student success strategies were directly connected to their Achieving the Dream work.

\section{Leadership Commitment to Reducing Achievement Gaps}

As noted previously, a focus on improving equity across racial, ethnic, and income groups was an important focus of Achieving the Dream from its inception. In line with this focus, most of the leaders at the Round 1 colleges tended to have an awareness of achievement gaps at their schools. For instance, a large majority of the Round 1 colleges disaggregated their student outcomes data by race, ethnicity, or income (or some combination of all three); only four colleges did not analyze these subgroups or stated that analyses by race, ethnicity, or 
income were less important than looking at other student subgroups. Many college leaders noted that an analysis of these disaggregated data had increased their overall awareness of achievement gaps, and many credited Achieving the Dream for this heightened sensitivity.

While most colleges disaggregated their data for different racial and income groups, these analyses did not always translate into a specific focus on achievement gaps. Some leaders acknowledged that race or income was a big issue for their campus, and just over half of the colleges developed at least one strategy that was aimed at improving the success of these students. As described in Box 2.2, the leaders at some colleges, such as Valencia Community College and Durham Technical Community College, saw promising improvements in the achievement gaps among these students. Several of these leaders were quite passionate about this agenda and strongly supported Achieving the Dream's focus on these issues. As one college president mentioned, "I get embarrassed when my friends talk about [not having] the courage to have those [race] discussions. That is what we signed up to do to help students... [Race] is the fault line in America. Lumina provides a huge cover for us to be able to [address racial disparities]... I hope they never walk away from that focus."

However, despite these promising actions, overcoming racial, ethnic, and income achievement gaps was not a key goal at the majority of Round 1 colleges. Only eight leaders made explicit attempts to raise awareness about those issues. Most of these schools focused on either race and ethnicity or income (rather than both), with the majority of schools focusing on the gaps between students of color and white students. The colleges that did not make race, ethnicity, or income equity issues their main focus gave several reasons for their choice. First, the population at some of the schools comprised mostly students of color or low-income students, making it less meaningful to separate out these students from the general student population. Additionally, some schools found few achievement gaps along different racial, ethnic, or income lines, and one school found that students of color were outperforming their white peers. A majority of colleges also explained that they were more interested in helping all students succeed rather than just one specific subset, arguing that nearly all of their students were disadvantaged in some way. A couple of these schools purposely shied away from an explicit focus on race, noting that such conversations were too contentious for their college communities. Others chose to focus their efforts on other student subgroups, such as developmental education students, whose need for additional services was, they felt, greater. Finally, a couple of colleges noted some confusion about Achieving the Dream's equity agenda, with one college noting that its coach and data facilitator had pointed the college away from equityfocused strategies in favor of those aimed at larger groups of students.

Other outside factors may have influenced colleges' timid response to Achieving the Dream's equity agenda. First, in the early part of the twenty-first century, several high-profile cases were being tried in the U.S. Supreme Court, which brought into question the legality of 


\section{Box 2.2}

\section{Spearheading a Focus on Equity: Case Studies of Four Colleges}

While few colleges developed overarching mechanisms for addressing racial, ethnic, and income achievement gaps, many schools designed select strategies to improve the performance of their low-income students or students of color. The stories below represent several different models upon which colleges based their pursuit of this goal.

\section{Valencia Community College: Early Successes in Closing Gaps}

Honored as the first recipient of the Leah Meyer Austin Institutional Student Success Leader Award, ${ }^{\text {a }}$ Valencia made promising strides from 2004 to 2008 in narrowing the achievement gap between its African American and Caucasian students (from 13 percent to 4 percent) in gatekeeper courses, as well as reversing the gap between Hispanic and Caucasian students in gateway courses.

When reviewing internal data on student enrollment and achievement, Valencia noted that students of color, developmental education students, and students who were taking math courses were performing poorly. In order to address these challenges, the college chose to focus its intervention strategies on six gateway courses, including four mathematics courses, an English composition course, and a United States government course. The college used a combination of supplemental learning, learning communities, and a mandatory student life skills course as strategies to close gaps in student achievement in its gateway courses.

As a result of this work, Valencia stands out among the Round 1 colleges for creating a systematic, collegewide approach to improving equity under Achieving the Dream. By 2009, more than 29,000 Valencia students had taken at least one of the six gateway courses, and students' performance improved in each of these courses.

\section{Durham Technical Community College: “Visions" Minority Male Leadership Initiative}

After discovering that persistence and graduation rates among its African American male students were lower than those of other student groups, Durham Tech decided to implement a minority male leadership initiative to help these students overcome their obstacles and succeed in college.

This initiative, entitled the "Visions" program, provided a variety of supports and engagement activities for men with lower-level academic skills. This multifaceted approach included mentoring, intensive academic advising in a weekly discussion group, artistic development through a jazz ensemble, financial support through scholarships and job placement services, leadership opportunities to serve as tutors for children at a local elementary school, and expanded academic opportunities through visits to local universities.

(continued) 


\section{Box 2.2 (continued)}

Durham Tech observed promising increases in Visions students' persistence rates, which were higher than the average persistence rate of other African American male students. With this program at the forefront, Durham Tech has made equity and overcoming achievement gaps a central focus of its Achieving the Dream work. For example, the college has completed a structural inequity audit to identify and address any barriers to success that its existing policies and procedures might create for low-income students and students of color.

\section{Tallahassee Community College: Black Male Achievers Program}

Tallahassee Community College also noted gaps in the persistence, attendance, and grades of its African American male students. It responded by establishing a Black Male Achievers program, which offered a variety of academic and student services to help African American males stay in college and graduate. The program has also promoted personal enrichment and social activities, such as visits from the Tuskegee Airmen and service projects in the community, to advance students' intellectual growth and social connections. This strategy represents an important step in Tallahassee's effort to explicitly and directly engage its campus on the topic of reducing achievement gaps across racial groups.

\section{Santa Fe Community College: Diversity Initiative}

As a traditionally Hispanic-serving institution, Santa Fe Community College became more aware of its students' needs after disaggregating student outcomes data as part of its work under Achieving the Dream. To propel the college's commitment to equity, the president has spearheaded a diversity initiative focused on tackling Hispanic and Native American students' performance issues and hiring staff that better represent the college's student population. The diversity initiative aims to refine the college's mission, vision, and core values to reflect a commitment to equity and student success.

${ }^{a}$ The Leah Meyer Austin Award, sponsored by Lumina Foundation for Education and administered by the American Association of Community Colleges, recognizes outstanding institutional achievement in creating excellence and equity through (1) committed leadership; (2) documented student success strategies; (3) broad engagement; (4) use of evidence to improve programs, policies, and practices; and (5) systemic institutional improvement.

using race in college admissions decisions. ${ }^{14}$ Such actions arguably created a less welcoming environment for a focus on particular racial and ethnic groups, leading some college leaders to move away from such an agenda. ${ }^{15}$ Additionally, as noted above, though Achieving the Dream encouraged an equity-based focus, it did not provide substantial support for helping colleges

\footnotetext{
${ }^{14}$ Grutter versus Bollinger (2003); Gratz vs. Bollinger (2003).

${ }^{15}$ Arenson (2003); Associated Press (2008).
} 
undertake such work. The Round 1 colleges' mixed response suggests that a much more intensive focus, with more external supports, may need to be placed on this equity agenda for colleges to undertake this work.

\section{Senior Leaders' Exposure to Student Outcomes Data}

One of the key tenets of Achieving the Dream is that senior leaders at the college critically review data on their students' achievement and use these findings to develop and revise their plans for increasing students' success. In order to assess administrators' and faculty members' use of data, MDRC and CCRC researchers administered a survey to 23 of the 26 Round 1 colleges. ${ }^{16}$ (See Appendix A for a discussion of the methodology.) The findings from this research revealed that, overall, administrators at a majority of Round 1 colleges tended to review institutional-level student outcomes data, such as information on retention and graduation rates, at least once per year (see Figure 2.4). These leaders typically reviewed other types of data as well, including classroom evaluations and grades (Figure 2.4), outside research including qualitative data, and disaggregated data for different student subgroups (see Figure 2.5). ${ }^{17}$

While administrators reviewed multiple types of data, they did not always analyze these data on a regular basis. With the exception of enrollment data, most administrators at the Round 1 colleges reported that they examined data related to student outcomes and research less than four times per year. Additionally, findings from the survey indicate that the review of these data varied significantly by department, with institutional research and academic affairs administrators analyzing these data more frequently than other departments. Administrators who had a faculty role were also more likely to examine data related to student outcomes or data disaggregated by race, ethnicity, or income, and were more likely to engage in organized discussions about data relating to student achievement gaps. Thus, as might be expected, administrators' review and use of data tended to differ depending on the role they played at the college. ${ }^{18}$

\footnotetext{
${ }^{16}$ Tidewater Community College, Valencia Community College, and Southwestern Indian Polytechnic Institute did not participate in the faculty and administrator survey. For more information on faculty's use of data, see Chapter 4.

${ }^{17}$ For more details on the Achieving the Dream faculty and administrator survey, see Jenkins and Kerrigan (2008).

${ }^{18}$ For more information, see Jenkins and Kerrigan (2008).
} 
Achieving the Dream: Community Colleges Count

Figure 2.4

Frequency with Which Administrators Used Student Outcomes Data, by Type of Data, 2007 to 2008

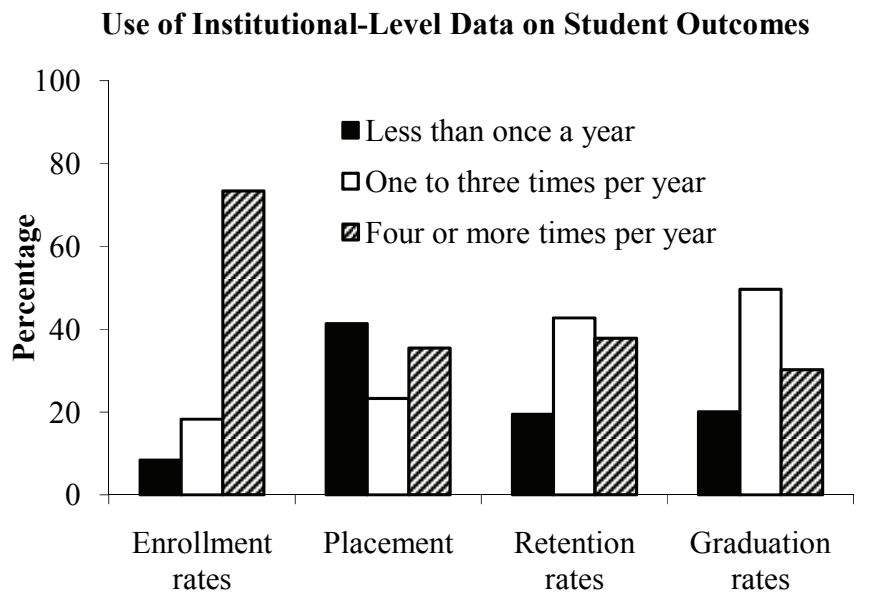

Use of Classroom-Level Data on Student Outcomes

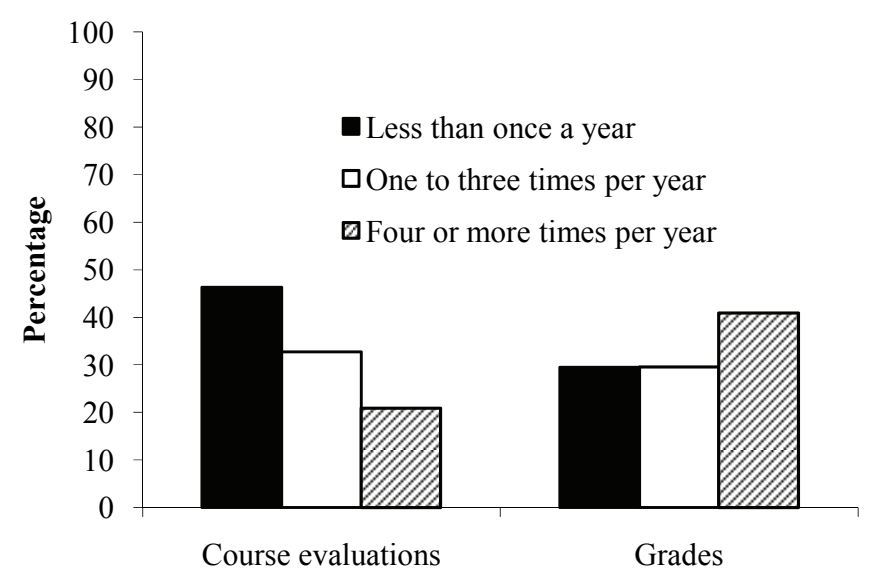

SOURCE: CCRC calculations using survey data collected from faculty and administrators at the Achieving the Dream Round 1 colleges.

NOTE: Faculty and administrator survey data were collected from September 2007 through February 2008, approximately one year before implementation research at the Round 1 colleges. The survey was disseminated at 23 of the 26 colleges. 
Achieving the Dream: Community Colleges Count

Figure 2.5

\section{Frequency with Which Administrators Used Data Disaggregated by Race and Income, 2007 to 2008}

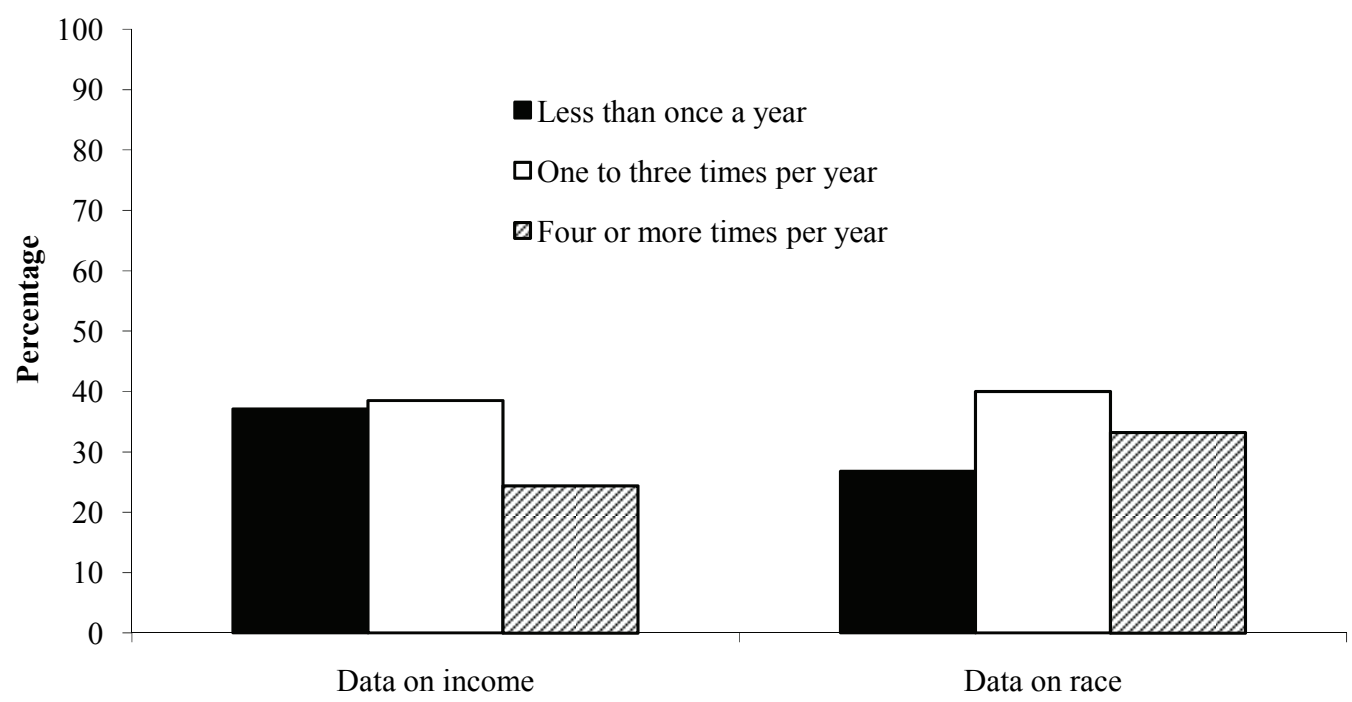

SOURCE: CCRC calculations using survey data collected from faculty and administrators at the Achieving the Dream Round 1 colleges.

NOTE: Faculty and administrator survey data were collected from September 2007 through February 2008, approximately one year before implementation research at the Round 1 colleges. The survey was disseminated at 23 of the 26 colleges.

\section{Usefulness of Achieving the Dream's Inputs}

A large majority of presidents and senior leaders noted that their Achieving the Dream coach was an important guide in helping them develop and advance their student success agenda. While many colleges reported that their coach was a good "cheerleader" for their cause, colleges found coaches most helpful when they provided concrete advice on particular aspects of their institutional improvement plans, such as bringing in new research or ideas for development, helping leaders prioritize program strategies, or providing guidance on how to engage faculty and staff in the colleges' work. A number of colleges, particularly those that struggled 
with their improvement plans, also noted that their coach was very important in helping them "keep on track," confront challenging issues at their schools, and frame their message to the college community and beyond. Finally, a few colleges noted that it was helpful to have an outside perspective on their work and that their coach helped bring legitimacy to their focus on student success.

While few schools had any problems with their coach, those negative sentiments that did arise tended to center around colleges' desire for more guidance or more information about Achieving the Dream's expectations for their work. A handful of colleges noted that they wished their coach had spent more time "in the trenches," including demonstrating a better understanding of their own specific community college environment. While a few of these colleges requested and received new coaches whom they felt were a better fit for their schools, a couple of colleges continued to struggle with their coaches throughout the duration of the initiative. Most of the colleges that had trouble with their coaches tended to be smaller, rural colleges, who felt that their coaches did not have a great understanding of the challenges facing their communities.

A few other Achieving the Dream resources were identified as important supports for leadership commitment. A couple of colleges observed that their leaders had attended a Trustee Institute, which had been very useful in helping board members and trustees become more aware of Achieving the Dream's goals and mission. Others noted the utility of the Strategy Institute and some state-level meetings in helping them connect with and learn from other likeminded leaders. In general, however, few colleges discussed other Achieving the Dream inputs that helped shape their leaders' commitment to or interest in the initiative or student success.

\section{Summary}

In general, the leaders of the Round 1 colleges tended to be committed to improving the success of their students and engaged in reviewing data on their students' achievement. While most colleges did not develop a forthright agenda centered upon reducing achievement gaps along racial, ethnic, and income-level lines, many of these schools were aware of the challenges these students faced, often as a result of their participation in Achieving the Dream. Additionally, many colleges were sharing reports on student outcomes with their boards and actively engaging in plans for improving their students' achievement.

While many colleges had well-defined leadership throughout Achieving the Dream, one challenge that colleges continued to face was turnover among their presidential and senior administrator positions. Just under half of the Round 1 colleges continued to experience change in their high-level leadership, with 12 of the 26 Round 1 colleges hiring a new president from spring 2006 to spring 2009. Presidential turnover was an issue even at schools with leaders who 
had a strong commitment to student success, although those schools had been able to maintain their focus through strong leadership from senior administrators or by hiring highly committed new presidents. However, at some colleges, leadership turnover was a debilitating event, which set back their student success agendas for months or years.

Given these challenges, Achieving the Dream might consider ways to support a more diversified set of leaders at each college who can be distributed through a number of different networks when colleges inevitably experience leadership turnover. Active involvement from a number of senior administrators other than the president also seems to be an important attribute for colleges' implementation of Achieving the Dream, as those schools that did not have senior leaders involved tended to have difficulty implementing their reforms. Therefore, having one or more senior leaders who are continuously involved in the implementation of the college's improvement plans also appears to be important in helping colleges get their student success plans off the ground. 


\section{Chapter 3}

\section{Use of Data to Prioritize Actions}

While leadership commitment to student success is key in the Achieving the Dream model, colleges' development of their data capacity is the backbone of the initiative's push toward creating evidence-based programs and policies. Traditionally, community colleges have tended to focus more on meeting the reporting requirements of government agencies and private funders and less on capturing the internal trends in students' achievement. ${ }^{1}$ Additionally, community colleges tend to have few staff to handle such tasks, making it challenging to focus on other types of data analysis. ${ }^{2}$ As a result, the institutional research (IR) departments at these institutions have generally been less focused on the student success-oriented data analyses promoted by Achieving the Dream.

Given their limited data capacity, many colleges that join Achieving the Dream face a steep hurdle in gearing up their research departments to handle the types of data that the initiative finds most important. The ability of colleges to collect and analyze student and program data, as well as to use those data to inform institutional decisions, are of key importance to Achieving the Dream's vision of evidence-based decision-making. Without strong data systems and skilled research personnel, colleges may be unable to identify student outcomes of interest, to analyze where gaps exist in student achievement, or to track the progress of their programs. As a result, they may be unable to disseminate information about their overall performance or to make evidence-based decisions about their priorities for reform. Therefore, at many schools, Achieving the Dream's call for a strengthened culture of evidence entailed a substantial expansion in their IR staffing and technology.

As Step 2 of Achieving the Dream's institutional improvement model, colleges' use of data to prioritize actions is based on several key premises. First, colleges are expected to analyze longitudinal data on students' achievement, as well as other evidence of students' success, and to identify particular gaps in students' outcomes. The initiative expects that most colleges will discover that students are performing below their expectations, and that these findings will motivate college faculty and staff to develop solutions for their improvement. Additionally, to make sure that they are targeting their resources appropriately, colleges are encouraged to evaluate a limited set of priorities and strategies aimed at increasing students' success.

\footnotetext{
${ }^{1}$ Morest and Jenkins (2007).

${ }^{2}$ Morest and Jenkins (2007).
} 
Such work also requires that colleges have the necessary staffing and technological capacity. As detailed by the initiative in Principle 2 of its "Principles and Practices for Increasing Student Success Through Institutional Improvement" (see Box 3.1), colleges must develop stable informational technology (IT) systems to manage information on student outcomes and support the tracking of students' longitudinal progress across multiple semesters and years. Additionally, they must have capable IR staff with the skills to analyze a number of indicators of student success. Achieving the Dream also recommends that colleges routinely disaggregate their data for students of different races, ethnicities, and income levels as well as other student characteristics to see what achievement gaps may exist among these groups. Furthermore, colleges are encouraged to collect qualitative data on their students through methods such as surveys and focus groups. Finally, Achieving the Dream expects that colleges will evaluate their strategies and interventions, using the results of their analyses to improve programming and policy.

The initiative has now documented an extensive list of practices for participating colleges, some of which are described in Box 3.1; however, it is important to note that the Round 1 colleges began their work in Achieving the Dream while the initiative was still articulating this vision. While longitudinal data analysis and the disaggregation of data for different student subgroups have been priorities of the initiative since the beginning, the full codification of these practices evolved over the course of the initiative's development, after the Round 1 colleges had already begun implementing their reforms. As a result, the Round 1 colleges had fewer resources when they began their work than many of the colleges that joined the initiative later.

This chapter thus provides a look at how an early cohort of colleges progressed in developing their data capacity while the initiative was still building its own infrastructure. Overall, the implementation research found that most of the 26 Round 1 colleges made at least some progress in building their data capacity by increasing their IR staff, providing more data training, or bolstering their IT infrastructures. Most colleges had also made at least some progress in collecting diverse types of data, including longitudinal data on student outcomes, data disaggregated by different subgroups, and qualitative or descriptive data from surveys and focus groups. Despite these advances, many colleges had yet to fully incorporate data analyses and findings into their decision-making about strategy development or institutional policy changes. While some colleges reported that the supports provided by Achieving the Dream, such as data facilitators, helped encourage their progress, others provided mixed reviews of those services. 


\title{
Box 3.1
}

\section{Principles and Practices for Increasing Student Success Through Institutional Improvement: Practices Associated with Principle 2, Use of Evidence to Improve Policies, Programs, and Services}

\author{
Information Technology (IT) and Institutional Research (IR) Capacity
}

- IT capacity is adequate to meet the demand for data and institutional research.

- Policies and procedures are in place to ensure the integrity of the data collected.

- IR staff capacity is adequate to meet demand for data analysis and research.

- IR staff effectively educates and assists college personnel to use data and research to improve programs and services.

\section{Process for Identifying Achievement Gaps}

- College routinely collects, analyzes, and reports longitudinal data on cohorts of students to track student progression and outcomes.

- College routinely disaggregates student cohort data by age, race, gender, income, and other factors to identify gaps in achievement among students.

- College regularly conducts surveys and focus groups with students, faculty, and staff to identify strengths and weaknesses in programs and services, as well as opportunities for improvement.

\section{Process for Formulating and Evaluating Solutions}

- College routinely engages faculty, staff, and others across the campus community to review data on student achievement and help develop and refine strategies for addressing priority problems.

- College routinely evaluates the effectiveness of efforts to improve student success and uses the results to improve policy and practice.

SOURCE: Field Guide for Improving Student Success (2009), from the Achieving the Dream: Community Colleges Count initiative. Available online at www.achievingthedream.org/docs/Field_Guide_for_Improving_Student_Success.pdf. 


\section{Levers for Change in Achieving the Dream}

In order to help colleges strengthen their evidence-based decision-making, Achieving the Dream has instituted a number of supports aimed at increasing colleges' capacity to collect, analyze, and interpret data. First, the initiative employs a data facilitator who has expertise in institutional research and helps guide colleges in developing new systems for data usage. The data facilitator helps colleges decide what questions they should be asking about student achievement, what data they should collect to answer those questions, and how they should present those data to various stakeholders at the college. As explained in Chapter 1, each data facilitator is allotted 12 days to work with the colleges during their first two years in Achieving the Dream, followed by nine, six, and three days in each of the following years, respectively. Each data facilitator also initially attends a two-day training, as well as a twoday retreat each year. ${ }^{3}$

In addition to data facilitators, Achieving the Dream has created a national database to track students' longitudinal progress at participating colleges. Each year, colleges are asked to submit individual-level data on their entering students' achievement around Achieving the Dream's five key indicators of student success, ${ }^{4}$ as well as pertinent information about students' characteristics, such as race, ethnicity, gender, and income status. ${ }^{5}$ These student cohorts are then tracked over subsequent years through colleges' continued data submission. Each college receives a detailed data submission manual, which provides guidance on how to set up its data files. In addition, colleges receive assistance from JBL Associates, the data management organization that manages the database.

JBL Associates subsequently cleans and checks colleges' data and provides individualized reports to each participating institution. These reports summarize students' progress along measures such as the number of credits attempted and completed; referrals to and success in developmental reading, English, and math; persistence; and credential attainment. These reports also break down student outcomes for different student subgroups, as defined by race, ethnicity, income, age, Pell Grant eligibility, and gender. Since its beginning, Achieving the Dream has upgraded this system so that colleges can access this information through the initiative's Web site and can build reports of their own with a new data management tool. In addition, JBL

\footnotetext{
${ }^{3} \mathrm{MDC}$, Inc. (2008).

${ }^{4}$ As described in Chapter 1, the five key indicators are completion of developmental education courses and progression to credit-bearing courses; completion of gatekeeper courses, particularly first college-level or degree-credit courses in math and English; completion of attempted courses with a grade of "C" or better; persistence from term to term and year to year; and attainment of credentials.

${ }^{5}$ Income status is inferred from students' eligibility for Pell Grants, a federal need-based aid program for low-income students.
} 
Associates produces a bimonthly report, which summarizes trends in student outcomes based on an overall analysis of the data provided by all Achieving the Dream colleges.

\section{Colleges' Data Capacity}

\section{Early Data Capacity}

As might be expected from the challenges noted above, a number of Round 1 colleges were struggling to undertake the data analyses recommended by Achieving the Dream during their first year of implementation. In spring 2006, only 8 of the original 27 colleges (30 percent) were considered to have the data capacity needed to develop a culture of evidence. ${ }^{6}$ At that time, most of the colleges described their resources for conducting institutional research as limited, with IR staff at some colleges working hard just to fulfill their basic federal and state compliance reporting requirements. More than a third of the colleges reported having too few IR staff to meet their institution's demand for the higher level of research required to support broad-based, data-informed decision-making. Moreover, many of the colleges were considered to have antiquated or barely operational IT systems at that time, and nearly half reported having insufficient IT staff available to respond to their data requests. Finally, only half of the Round 1 colleges were tracking students' progress longitudinally, while only a handful were using data to guide their program efforts. ${ }^{7}$

Given such challenges, it is perhaps not surprising that so few of the Round 1 colleges were using data to guide their program and strategy development efforts. Instead, most colleges reported that their decisions to develop or expand programs and services were based primarily on administrator experience or intuition, even if their institutions had well-developed IR departments and data that were readily available. ${ }^{8}$

\section{Data Capacity and Use of Data After Five Years in Achieving the Dream}

\section{Colleges' Respect for Data Use}

Early in the initiative, a number of faculty and staff at the Round 1 colleges shied away from their schools' data analysis, expressing concerns that data would be used to scrutinize their

\footnotetext{
${ }^{6}$ Originally, 27 Round 1 colleges joined Achieving the Dream, but one college subsequently dropped out.

${ }^{7}$ Brock et al. (2007).

${ }^{8}$ Brock et al. (2007).
} 
individual teaching methods or work ethic. ${ }^{9}$ However, by the fourth year of the initiative, all but three colleges reported an increased respect for data analysis at their institutions, with many attributing this improvement to their work in Achieving the Dream. Through their colleges' involvement with Achieving the Dream, many faculty and staff learned that data from their IR departments could provide useful information on their students' performance. As one faculty member acknowledged, "I know who [our IR director] is now, and I know what her office does. I know that she's accessible; I know that if I want data, all I have to do is...explain what kind of data I'm looking for."

\section{Development of Data Capacity}

By spring 2009, most colleges had made noticeable progress in developing their data capacity. All but eight of the Round 1 colleges (69 percent) had improved their data capacities or reported an improved ability to meet their basic data needs. As shown in Figure 3.1, half of the colleges reported increasing IR staffing, either by hiring new staff or by reassigning current staff to work on data collection and analysis efforts. That increase in staffing allowed those schools to diversify their data collection and networking with other faculty and staff. For example, a number of colleges were able to assign individual staff members to specialized tasks, such as developing data codebooks, managing data warehouses, conducting focus groups, or running advanced statistical analyses to help predict student trends. Increased staffing has also freed up IR directors' time at some schools, allowing them to dedicate more time to conducting higher-level research, making data-related presentations on campus, or spearheading collegewide decision-making committees and taskforces.

A number of colleges also focused on improving their IR staff's level of expertise. Just over one-fourth of the Round 1 colleges provided further training for their IR staff so that they could undertake more sophisticated data tasks (Figure 3.1). For instance, when expanding its IR department from two to four staff members, Broward College (formerly Broward Community College) provided statistical training in SAS (a widely used data management software program) to all of these individuals. Several other colleges noted that expanding the number of staff with training in data and research helped them avoid overburdening other IR staff. Most often, this training focused on helping IR staff manage large databases more efficiently, quality-check the data to ensure its integrity, or consolidate data from various institutional sources, such as from academic departments and student service centers.

\footnotetext{
${ }^{9}$ Brock et al. (2007).
} 


\section{Achieving the Dream: Community Colleges Count}

Figure 3.1

\section{Progress of Achieving the Dream Round 1 Colleges in Developing Data and Research Capacity, Spring 2006 to Spring 2009}

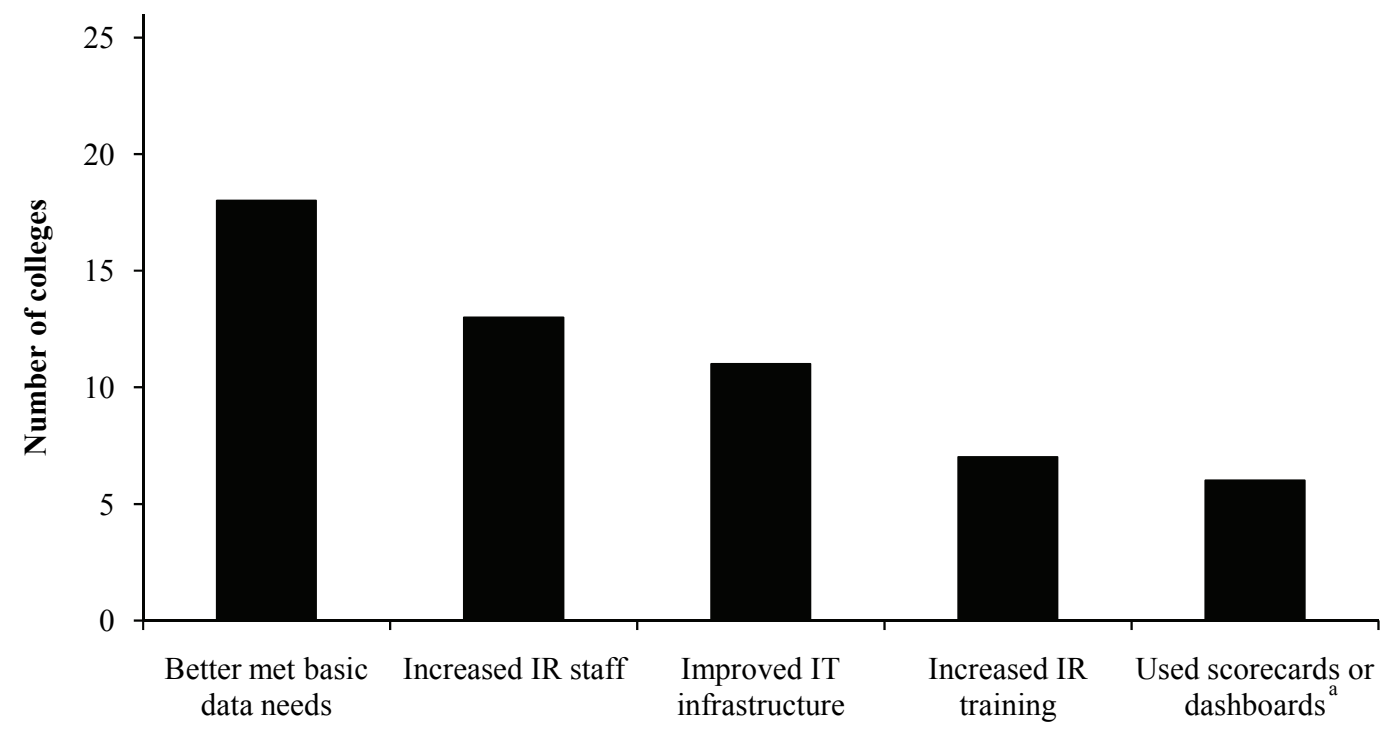

Type of Institutional Research or Data Improvements

SOURCE: Information collected from faculty, staff, and administrators during two rounds of implementation research across all 26 Round 1 colleges, cross-referenced against reports submitted by college representatives, Achieving the Dream coaches, and data facilitators.

NOTES: "IR" stands for institutional research; "IT" stands for information technology.

${ }^{a}$ Data scorecards and dashboards are tools used by colleges to provide streamlined, user-friendly information about key performance outcomes.

Another way in which colleges increased their capacity to use data was by improving their IT infrastructures. Just under half of the Round 1 colleges reported investing resources in their IT infrastructures in order to facilitate their data collection, analysis, and dissemination efforts (Figure 3.1). For some colleges, this effort involved the development of large data warehouses or databases to store various forms of institutional and student data submitted from academic departments, student service centers, or other campus offices. Other colleges focused on upgrading statistical software and Web portals in order to allow the campus community to access "real-time" data from their own desktops or more easily submit data requests. Some colleges also created "scorecards" and "data dashboards" to involve more faculty and staff by 
providing streamlined, up-to-date information about key outcomes of interest (Figure 3.1). As one IR director explained, "Instead of having to create a PowerPoint each time, [data are] all collected on the scorecard," which provided more accessible data. Finally, a few colleges created cross-functional, cross-departmental data systems to leverage IT resources for data management and reporting while sharing the responsibilities of research, assessment, and datadriven programming across areas. For example, South Texas College and Tallahassee Community College both reorganized their IR departments to make data collection and analysis more accessible and functional for faculty and staff.

Though fewer in number, some Round 1 colleges continued to have substantial problems with data analysis after five years in the initiative. In total, just over one-fourth of the Round 1 colleges still had very weak IR capacity. Some simply did not have the proper personnel or resources in place to develop an IR department. These schools tended to employ only one IR staff member to handle all aspects of data and research, often without any clerical or technical support. Other colleges could not upgrade their archaic data systems, thus limiting their data collection and analysis. One college — with a lack of both personnel and technology — was only able to provide raw data for administrators who requested data reports. Even with the assistance and training provided by Achieving the Dream, the difficulties of hiring, retaining, and training the proper personnel at some of the smaller, underfunded colleges proved to be an insurmountable impediment to further developing a culture of evidence.

\section{Colleges' Data Collection and Analysis Activities}

While few Round 1 colleges employed sophisticated data analyses early on in the initiative, ${ }^{10}$ a number of them had developed the capability to undertake this work after five years in Achieving the Dream. By spring 2009, more than three-fourths of the Round 1 colleges had collected longitudinal data, and over half had attempted some type of analysis on these data (see Figure 3.2). Furthermore, approximately half of the colleges were making use of longitudinal data as part of their collegewide discussions around practice and policy development. Many of these schools had the capability to compare and track different cohorts of students from semester to semester, and they used this information to assess whether a particular intervention made any difference in student outcomes such as performance and persistence. Other colleges utilized their longitudinal data to determine student behavioral trends across time, such as any declines in course loads, grade point average, or retention rates across various student groups.

Additionally, most colleges ( 85 percent) collected data disaggregated by race, and over half (69 percent) reported using their disaggregated data to identify where achievement gaps existed (Figure 3.2). A few colleges noted that these disaggregated data helped them see

\footnotetext{
${ }^{10}$ Brock et al. (2007).
} 


\section{Achieving the Dream: Community Colleges Count}

Figure 3.2

\section{Development of Diversified Data Activities at Achieving the Dream Round 1 Colleges, Spring 2009}

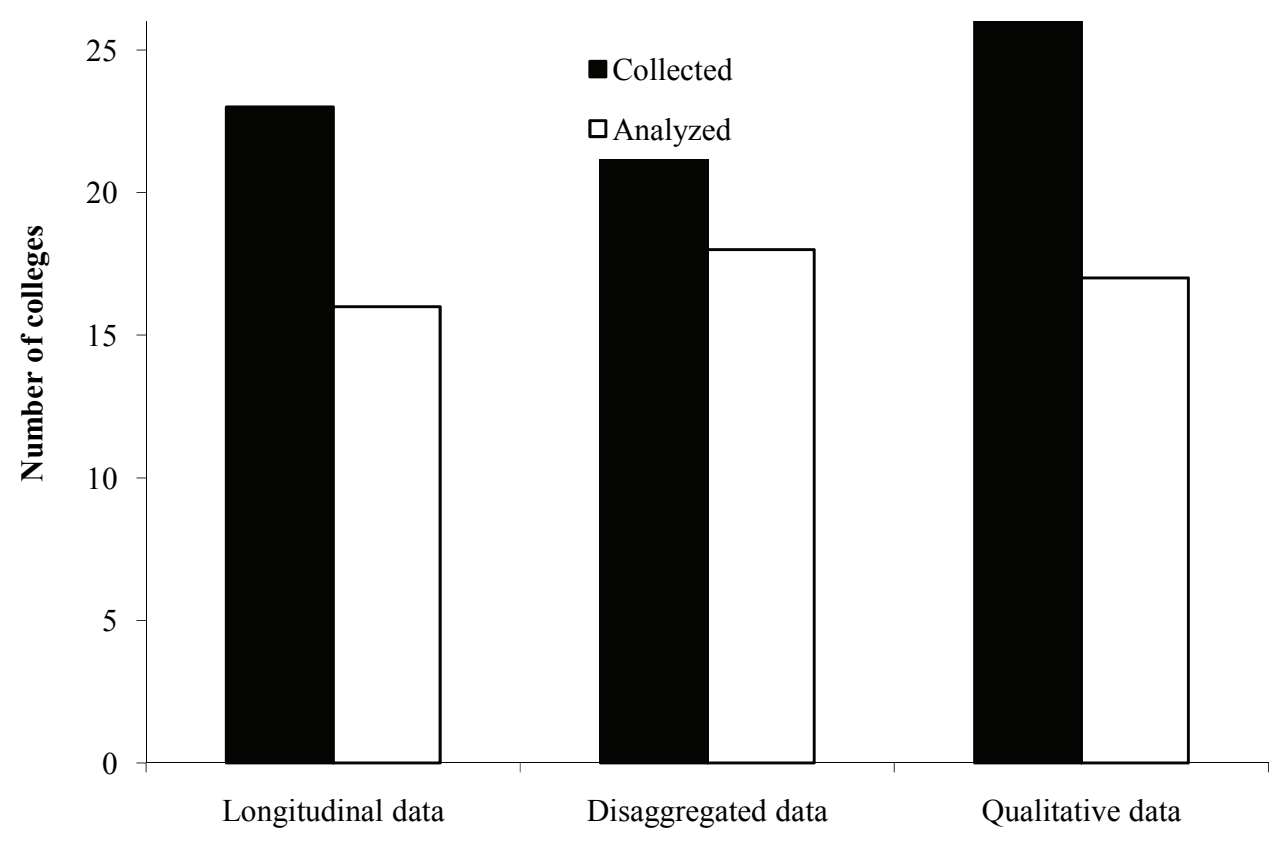

Type of Data Activity

SOURCE: Information collected from faculty, staff, and administrators during two rounds of implementation research across all 26 Round 1 colleges, cross-referenced against reports submitted by college representatives, Achieving the Dream coaches, and data facilitators.

noticeable demographic shifts in their student populations over recent years, which led them to reconsider their existing programs and services for these student constituencies. Other colleges, however, did not seem to find much use for data disaggregated by race or income, because their student populations were more homogenous. Instead, some decided to disaggregate data by other categories of interest, such as level of college preparedness (for example, developmental education status) and student status (for example, first-year students). 
Finally, all of the colleges were also conducting some form of qualitative data analysis by the fifth year of the initiative. Most of the colleges used surveys or focus groups to gather the perspectives of students, faculty, staff, or external stakeholders. (See Chapter 4 for more information.) Some schools undertook more intensive qualitative efforts, such as Santa $\mathrm{Fe}$ Community College's qualitative study on Hispanic men and Danville Community College's efforts to conduct focus groups with its African American male students to better understand what they wanted and needed in college.

\section{Colleges' Use of Data to Make Decisions About Programs and Policies}

After five years in Achieving the Dream, a majority of the colleges still had difficulty using their evaluations of their programs to advance more effective, evidenced-based strategies. Just over 40 percent of the Round 1 colleges reported conducting regular evaluations of their Achieving the Dream strategies and monitoring how those interventions affected student outcomes (see Figure 3.3). While most of the other colleges attempted to evaluate some of their strategies, their efforts were generally hampered by difficulties with their data systems or limited IR staff time. A number of colleges described the challenge of balancing their responsibilities to meet the increased demand for data reports with the need to make time for quality assessments of new programs. Other stumbling blocks included delays or changes to strategy implementation plans, which limited the type of evaluations that could be undertaken.

Despite this, a few of the colleges with stronger data systems did establish data-driven guidelines and procedures for developing their program strategies. For example, some of these colleges established standard procedures for faculty and staff to generate a program idea, explain its rationale, provide evidence to support that rationale (usually based on institutional data), and describe how data could be used to determine the effectiveness of the proposed program. In some instances, this required interested faculty and staff to work with IR staff as part of a task force to track the success of a program and make recommendations for necessary changes. In other cases, college staff worked with local community or K-12 partners, sharing data on students' performance across institutions.

Finally, some colleges used strategy evaluation data to make decisions about program scale-up. Often using simple comparisons between students who participated in a strategy and those who did not, these colleges generally sought to expand strategies that were more successful and revise those that were less promising. For instance, Houston Community College pointed to pilot data indicating that students in its Guided Studies "student success" course showed noticeable increases in retention and engagement over peers who did not participate in the course during their first semester. These promising pilot findings led administrators to scale up the course districtwide to all students who were in college for the first time. On the flip side, another strategy that Houston attempted — which focused on providing financial aid 


\section{Achieving the Dream: Community Colleges Count}

Figure 3.3

\section{Evaluation of Strategies for Improving Student Success at Achieving the Dream Round 1 Colleges, Spring 2009}

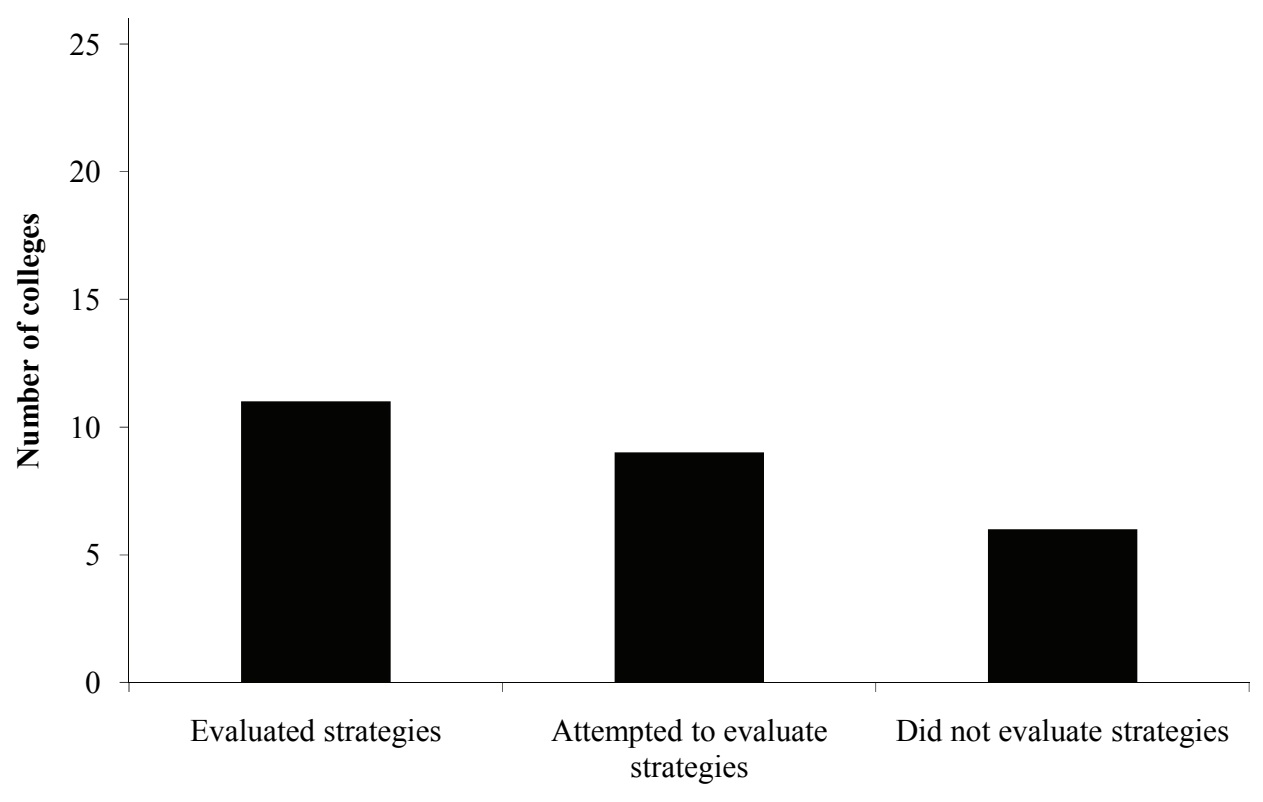

Success with Evaluating Strategies

SOURCE: Information collected from faculty, staff, and administrators during two rounds of implementation research across all 26 Round 1 colleges, cross-referenced against reports submitted by college representatives, Achieving the Dream coaches, and data facilitators.

information to the local, non-college-going community - was discontinued as a result of less promising results. Box 3.2 provides additional examples of strategy evaluations in Achieving the Dream colleges.

\section{Usefulness of Achieving the Dream's Inputs}

Many of the Round 1 colleges noted that their participation in Achieving the Dream had improved their knowledge of, respect for, and use of student outcomes data. Nearly all of these schools said that Achieving the Dream had improved their respect for data analysis and its utility for understanding more about their students' challenges. Additionally, the initiative had 
Box 3.2

\section{Using Data to Build Interventions: Case Studies of Three Colleges}

Colleges' evaluation efforts are a key component of the data-informed decision-making process prescribed by Achieving the Dream. The initiative partners recommend that colleges use both quantitative and qualitative data to create evaluation plans for their strategies. These plans are designed to assess the extent to which a particular intervention has improved student success and to inform decision-making around current and future strategies. However, numerous colleges struggled with the development and enactment of evaluation plans. The examples below suggest several ways in which colleges have used strategy evaluations to further their work.

First, several colleges have used student outcomes data to identify problem areas and target groups, and then conducted focus groups to determine which policies and programs should be introduced. For example, in analyzing its developmental education students, El Paso Community College discovered that 98 percent of its incoming students needed remedial math education. In response to these data, the college began to hold public meetings with representatives from local school districts and the University of Texas at El Paso. These public meetings led to the launch of a College Readiness Consortium, which established a six-step assessment protocol that included comprehensive orientation, preparation, and testing of high school students, followed by post-test interventions, retesting, and "summer bridge" programs (programs for high school graduates to prepare them for college) to help students place at college level on the ACCUPLACER college placement test (a computerized placement tool designed to provide placement and advising information for students entering college). Evaluation results indicated an increase in the number of students placing into college-level math, reading, and writing. ${ }^{\text {a }}$

Other colleges used data derived from intervention pilots to determine the potential effectiveness of these strategies and which ones should be implemented at full scale. For example, Tidewater Community College piloted its FOCUS orientation program to determine whether it was successful at increasing the number of students enrolling in the college's student success courses during their first semester. The FOCUS orientation was piloted with students who were the first in their family to attend college, targeting those who were most in need of college-level skills. Tidewater's evaluation of this pilot revealed promising improvements in the persistence of students who participated in the FOCUS orientation program. As a result, the college chose to fully scale up the orientation program to reach larger numbers of entering students.

To address ongoing evaluation needs, several colleges have created permanent committees to monitor and direct their student success efforts. For example, Hillsborough Community College established the Student Success, Retention, and Placement Committee, a faculty-led body that uses data and research to examine issues related to student success. As part of its work, this committee noted that students who enrolled late and missed the first day of classes tended to have lower success rates than those who began the semester on time. As a result, the college chose to revise its late enrollment procedures.

${ }^{\mathrm{a}}$ Kerrigan and Slater (2010). 
an important influence on a number of colleges' research capacity, with over one-third of these institutions noting that they used their Achieving the Dream grants to increase their IR staffing. Others found that Achieving the Dream had improved the collaboration between their IR and IT staff and encouraged them to collect more diversified types of information about their student populations. For instance, nearly 40 percent of these schools attributed their increased use of qualitative research to their participation in Achieving the Dream.

While Achieving the Dream appeared to have a positive influence on colleges' overall data capacity, the initiative's specific inputs were more mixed. For instance, a majority of the Round 1 colleges (16 colleges) found their data facilitators to be helpful in guiding their research practices; however, a substantial number (10 colleges) had complications with these individuals that made their journeys through the initiative more challenging (see Figure 3.4). The data facilitators at colleges with successful experiences were seen as making important contributions to colleges' understanding of new systems or tools to improve their data analysis. Data facilitators were seen as particularly helpful in sharing new tools for communicating about data, such as institutional scorecards or dashboards, or in helping colleges to develop more sophisticated data analyses. A couple of colleges also noted that their data facilitators helped them to develop analyses for their accreditation reports. Moreover, some colleges reported learning from their data facilitators about how to effectively use data from focus groups and surveys to complement information in their quantitative analyses of student outcomes.

Virtually all of the schools that had difficulty with their data facilitators noted that they were not a "good fit" for their data needs. Several colleges that began the initiative with fairly weak data capacities noted that their data facilitators assumed that they knew more than they did, and consequently did not provide enough concrete assistance in furthering their data knowledge. Other colleges noted that their data facilitators were overly prescriptive or critical or insufficiently available, all of which made their data work more challenging. While five of these colleges requested and received new data facilitators who were more helpful than those who were assigned originally, others continued to muddle through with their original data facilitators. Unfortunately, nearly all of the colleges that struggled with their data facilitators also had weaker IR departments at the outset of Achieving the Dream, which may have further exacerbated their challenges. While a majority of these schools were able to overcome their difficulties and build strong IR systems, a few continued to struggle with building their data capacities.

Achieving the Dream's database, which was intended in part to help support colleges' longitudinal data analysis, received more critical reviews (Figure 3.4). Most colleges (88 percent) reported that they did not find data from the Achieving the Dream database to be helpful, nor did they view the process of submitting these data as "useful" for developing their knowledge (85 percent). First, colleges noted a number of challenges with the "long, arduous" process for submitting these data, which several characterized as "frustrating," "demeaning," 


\section{Achieving the Dream: Community Colleges Count}

Figure 3.4

\section{Contributions of Achieving the Dream Inputs to Use of Data Among Round 1 Colleges, Spring 2009}

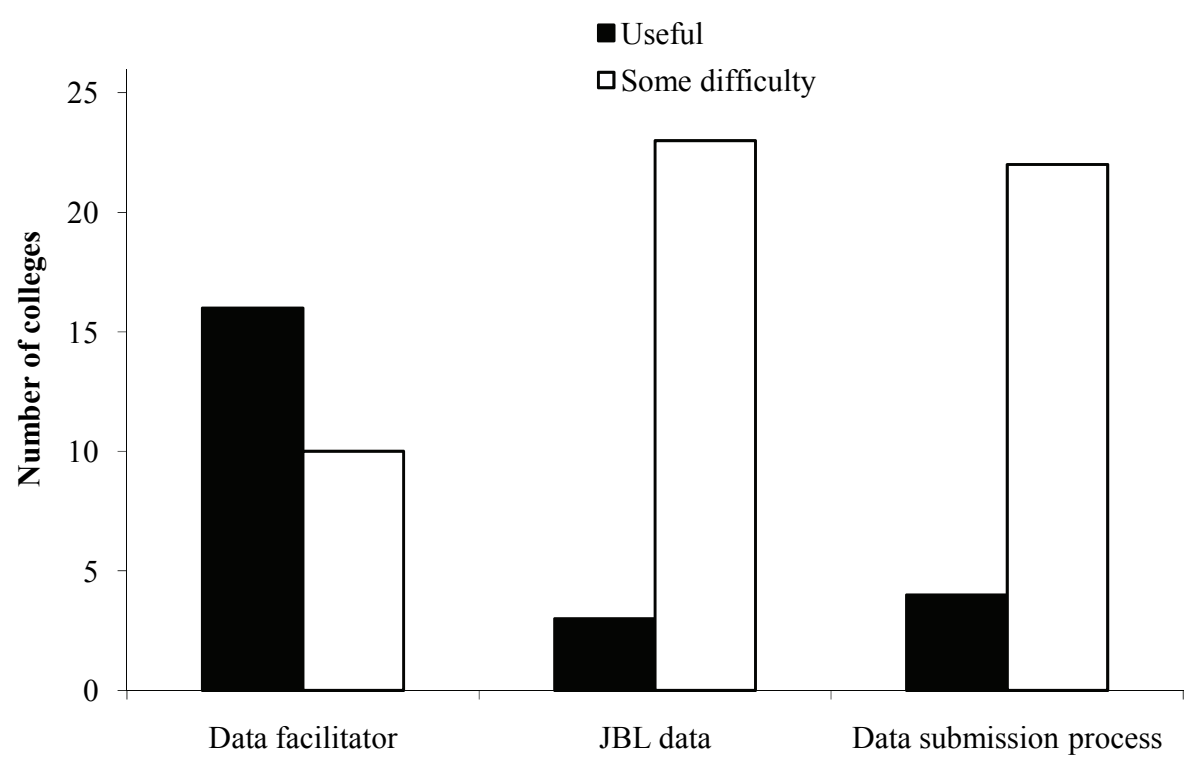

Achieving the Dream Inputs

SOURCE: Information collected from faculty, staff, and administrators during two rounds of implementation research across all 26 Round 1 colleges, cross-referenced against reports submitted by college representatives, Achieving the Dream coaches, and data facilitators.

and "burdensome." Several IR staff emphasized that the differences between the templates for the Achieving the Dream database and their own data systems required them to expend extensive staff time and cost to align the two systems. They also explained that annual changes made to these templates created an extra burden, as they had to continually revise their programming and submissions.

Additionally, most colleges found that the database itself proved less useful for tracking their institutional progress than their own internal data. For instance, a number of schools noted that information from the Achieving the Dream database was not as detailed or relevant as their own institutional data in helping them understand their problem areas. Additionally, because Achieving the Dream only collected data on new students who entered in the fall semester and 
did not specify students' participation in intervention strategies, many colleges felt that the data presented an inaccurate picture of their achievement and progress, particularly when compared with their own internal tracking. Such challenges made it difficult for most colleges to utilize these data to support their reform efforts.

\section{Summary}

As part of Achieving the Dream, the Round 1 colleges were expected to build a culture of evidence by making use of student success and institutional progress data. For some of these colleges, this effort entailed dedicating more staff and resources to their IR departments. For others, it meant enhancing their already well-established IR departments by increasing the skill sets of their staff to undertake new methods for collecting and analyzing data, or by updating IT functions and capabilities to better facilitate data activities. Many colleges also moved beyond basic data collection and analysis to focus on using data to learn about achievement gaps and the success of their programs and strategies. This requirement meant that colleges often had to track student performance and persistence outcomes from semester to semester in order to pinpoint when they needed to provide more support to prevent students from dropping out or failing.

While the Round 1 colleges achieved noticeable success in increasing their data collection and analysis activities, a number of colleges continued to be hampered by ineffective data systems or a lack of IR personnel to undertake the data analyses required of them. While some strong colleges got stronger, a number of colleges with weaker data capacities failed to institute large-scale systems for acquiring and managing data. Given this situation, Achieving the Dream might wish to consider what additional supports it can provide to colleges in these areas. For instance, Achieving the Dream might wish to assign its strongest data facilitators to colleges with weaker data capacity and provide more structured training to help those coaches deal with their schools' unique challenges.

Additionally, Achieving the Dream might consider providing specialized help to those colleges that are unable to hire sufficient staff to manage their data needs. This approach may be particularly valuable for colleges that are located in rural areas, as these schools, in particular, noted challenges with hiring skilled IR staff. Finally, Achieving the Dream might wish to offer more advice to financially strapped schools on how to support the often high costs associated with hiring new staff or obtaining new data systems. 



\section{Chapter 4}

\section{Broad Engagement}

While leadership commitment and data analysis are key steps in community colleges' efforts to increase student success, broadly engaging faculty and staff in an institutionwide improvement process is critical for changing students' achievement levels. Faculty, who are responsible for teaching the content knowledge that students need to master their college courses, and student services staff, who provide the counseling and advising that helps students navigate their college careers, both play key roles in fostering students' success in college. Indeed, many education reform movements have focused centrally upon improving these individuals' practice as the most concrete way of increasing students' achievement. ${ }^{1}$

In addition to full-time faculty and staff, other stakeholders can play an important role in students' achievement. At community colleges, adjunct, or part-time, ${ }^{2}$ faculty play a particularly important role in students' success, as these personnel generally teach the majority of the developmental and entry-level classes that students are most likely to take when they enter college. ${ }^{3}$ Additionally, community colleges often have strong ties with their surrounding neighborhoods and districts, and changes in their local environment can have an important effect on these colleges' work. ${ }^{4}$ For instance, community colleges can play an important role in training workers when new industries move into the area or in providing additional education to laid-off workers in a depressed economy. Finally, the students who attend community colleges, and their experiences and challenges, can also play a key role in shaping colleges' efforts to improve their skills.

Achieving the Dream has long noted the critical role that these internal and external stakeholders play in colleges' institutional improvement process. From early in its development, the initiative has pushed for faculty and staff to play a central part in improving student achievement, noting that,

[A] college cannot work intensively to raise student outcomes without buy-in from faculty and staff. Institutional change means changing the behavior of

\footnotetext{
${ }^{1}$ Elmore and Burney (1996); Datnow and Castellano (2001); Meier (2002); Murnane and Levy (1996).

${ }^{2}$ The terms "adjunct" and "part-time" are used interchangeably in this report to describe individuals who are not employed as full-time faculty at the colleges.

${ }^{3}$ Wallin (2005).

${ }^{4}$ Chen (2009); McClure (2010).
} 
people across the institution, and their support will come most readily when they share responsibility for diagnosing the problems and crafting solutions. ${ }^{5}$

The initiative has also focused on bringing the perspectives of students and outside community members into this change process as well, arguing that colleges must "understand the obstacles their students face in order to design appropriate solutions" for increasing their success. ${ }^{6}$ As such, the engagement of faculty, staff, students, and external stakeholders is highlighted in the third step of Achieving the Dream's model for institutional improvement (see Figure 1.2 in Chapter 1). Additionally, in 2009, the initiative delineated a number of important practices associated with "broad engagement" that colleges should seek to emulate as they develop and implement their reforms (see Box 4.1). Key among those practices are faculty and staff members' regular use of student outcomes data and outside research on effective practices; intentional collaboration between faculty and staff in developing new strategies for improving student success; and the inclusion of part-time faculty, students, and external stakeholders in the colleges' change process.

While a focus on broad engagement has long been a part of Achieving the Dream, the initiative has only recently codified these practices and supports into a framework comprising four principles and thirty-four practices. ${ }^{7}$ As such, the Round 1 colleges have been aware of Achieving the Dream's theory of broad engagement during their time in the initiative but have had more limited exposure to the specified practices outlined in the initiative's four-principle model. Thus, while this chapter discusses colleges' development of engagement practices, it offers a look at the initiative's early influence, before all of its practices and supports had fully solidified.

The sections that follow outline the progress of the 26 Round 1 colleges in engaging both internal and external stakeholders in their efforts to improve students' achievement. In general, most of the Round 1 colleges tended to involve their faculty and staff in the development and implementation of strategies aimed at improving student success. Many colleges also engaged faculty and staff in committees tasked with leading the colleges' reform process; however, their involvement in these leadership committees tended to be limited. Most faculty and staff at the Round 1 colleges also had at least some exposure to student outcomes data, with many using institutional-level data, such as enrollment or graduation rates, and classroom measures, such as grades and course evaluations, at least once per year. However, fewer faculty and staff used student outcomes data regularly in their everyday practice or analyzed students' achievement disaggregated by race, ethnicity, and income.

\footnotetext{
${ }^{5} \mathrm{MDC}$, Inc. (2006), p. 9.

${ }^{6} \mathrm{MDC}$, Inc. (2006), p. 9.

${ }^{7}$ Achieving the Dream (2009).
} 


\section{Box 4.1}

\section{Principles and Practices for Increasing Student Success Through Institutional Improvement: Practices Associated with Principle 3, Broad Engagement}

\section{Faculty and Staff}

- Faculty meets regularly to examine course and program outcomes and develop strategies for addressing achievement gaps and improving student success.

- Faculty routinely assesses academic programs and teaching strategies from the perspective of current research on effective practice.

- Part-time or adjunct faculty are actively engaged in institutional efforts to improve student success.

- Student services staff routinely assess student success strategies from the perspective of current research on effective practice.

- Efforts to improve student success involve alignment and extensive collaboration between academic/instructional units and student services.

\section{Students and External Stakeholders}

- College secures active student participation in efforts to improve student outcomes.

- College secures input from external stakeholders to identify causes of achievement gaps and inform the development of strategies for improving student success.

SOURCE: Field Guide for Improving Student Success (2009), from the Achieving the Dream: Community Colleges Count initiative. Available online at www.achievingthedream.org/docs/Field_Guide_for_Improving_Student_Success.pdf

The involvement of other stakeholders in the Round 1 colleges' institutional improvement process tended to be mixed. Many Round 1 colleges involved students and external stakeholders in multiple aspects of their work. However, the involvement of adjunct faculty was a particular weakness for these schools, with only a handful of schools reaching out to those professionals.

\section{Levers for Change in Achieving the Dream}

Achieving the Dream has provided several supports to help colleges foster the engagement of their faculty, staff, students, and community members in their student success work. First, Achieving the Dream encourages colleges to involve their faculty, staff, and students on 
committees and leadership teams, including the members of both the core and data teams who are involved in implementing the colleges' Achieving the Dream plans. The core team, which is charged with leading the college's institutional change agenda, is expected to include the president, chief academic officer, chief student services officer, institutional research (IR) director, and faculty leaders. The data team, which is charged with conducting analyses of the college's performance and student outcomes, is expected to include the IR director, faculty, and staff. ${ }^{8}$ Additionally, the coaches and data facilitators, whom the initiative employs as consultants for the colleges, are expected to assist colleges in developing plans to actively involve those players in the colleges' reform process. As described earlier, Achieving the Dream also provides several different opportunities for participating colleges to convene so they can share their ideas and improvement strategies, such as a beginning Kick-off Institute and an annual Strategy Institute, and encourages colleges to send faculty and staff to those events. ${ }^{9}$

The initiative has also provided some formal structures to help colleges engage community members, primarily through the assistance of Public Agenda, a national organization with expertise in community engagement. Throughout the course of the initiative, six Round 1 colleges collaborated with Public Agenda to gather the perspectives of both internal and external stakeholders and integrate their views into their improvement process. Additionally, in 2007, Public Agenda developed a tool to assist colleges in holding conversations with external stakeholders, ${ }^{10}$ which includes guidance on techniques such as focus groups, stakeholder dialogues, and community conversations. ${ }^{11}$

While Achieving the Dream has provided some formal and informal processes for involving internal and external stakeholders in colleges' institutional improvement efforts, the initiative generally did not provide formal coaching for faculty, staff, or other stakeholders. The initiative also did not tend to prescribe what colleges should do in the areas of professional development for faculty, data analysis training, or outreach to adjuncts. Instead, higher-level college administrators, with guidance from their Achieving the Dream coaches, were primarily responsible for communicating the college's institutional improvement plan to faculty, staff, students, and external stakeholders and devising plans to involve them in those efforts.

\footnotetext{
${ }^{8} \mathrm{MDC}$, Inc. (2008).

${ }^{9} \mathrm{MDC}$, Inc. (2008).

${ }^{10}$ Freidman (2007).

${ }^{11}$ Other tools and guides were created in mid-2009 to assist community colleges with engaging internal and external stakeholders; however, those guides were produced after the Round 1 colleges' demonstration phase and thus were not available during the years covered in this report.
} 


\section{Engagement of Faculty and Staff}

Like the higher-level administrators at their colleges, a large majority of the faculty and staff leaders at the Round 1 Achieving the Dream colleges believed strongly that their students could succeed, as described in Chapter 2. However, faculty and staff tended to be more involved in certain aspects of their colleges' improvement agendas than others.

\section{Involvement of Faculty and Staff: Strategy Development}

Overall, faculty and staff tended to be more heavily involved in developing and implementing their colleges' interventions and strategies aimed at improving students' achievement than in any other part of their colleges' Achieving the Dream work. The overwhelming majority of colleges (over 80 percent) involved at least a moderate number of full-time faculty and staff in developing their intervention strategies (see Figure 4.1). Although some colleges involved faculty in a multitude of interventions, most colleges tended to have a handful of faculty engaged in implementing a select group of strategies. Student services staff tended to be even more heavily involved in colleges' efforts than faculty, so much so that some staff noted feeling "overburdened" by their colleges' Achieving the Dream efforts. Most colleges with high or moderate staff involvement tended to engage student services staff in two or more interventions, which generally included a mixture of intensive advising, student success courses, revised or new orientations, or new registration procedures.

In general, smaller colleges tended to be better at involving their faculty in strategy development than were larger colleges. For instance, four of the colleges with the heaviest faculty involvement had fewer than 2,500 students. In contrast, staff involvement in strategy development tended to be unrelated to college size, with many mid-sized and large colleges having staff members who were heavily involved in strategy implementation. ${ }^{12}$ While only two larger colleges were able to effectively engage large numbers of faculty, certain attributes of colleges' strategy development helped facilitate their involvement (see Box 4.2). Very few colleges reported low levels of faculty and staff involvement in strategy development. Those that did tended to center on faculty or staff resistance to Achieving the Dream, a focus on instructional strategies, or the limited scale or scope of their college's strategies as reasons for staff's and faculty's limited involvement.

\footnotetext{
${ }^{12}$ The colleges tend to employ fewer student services staff than faculty, which may explain why services staff had higher levels of engagement in the colleges' reform efforts.
} 


\section{Achieving the Dream: Community Colleges Count}

Figure 4.1

Faculty and Staff Involvement in Student Success Reforms at the Achieving the Dream Round 1 Colleges, Spring 2009

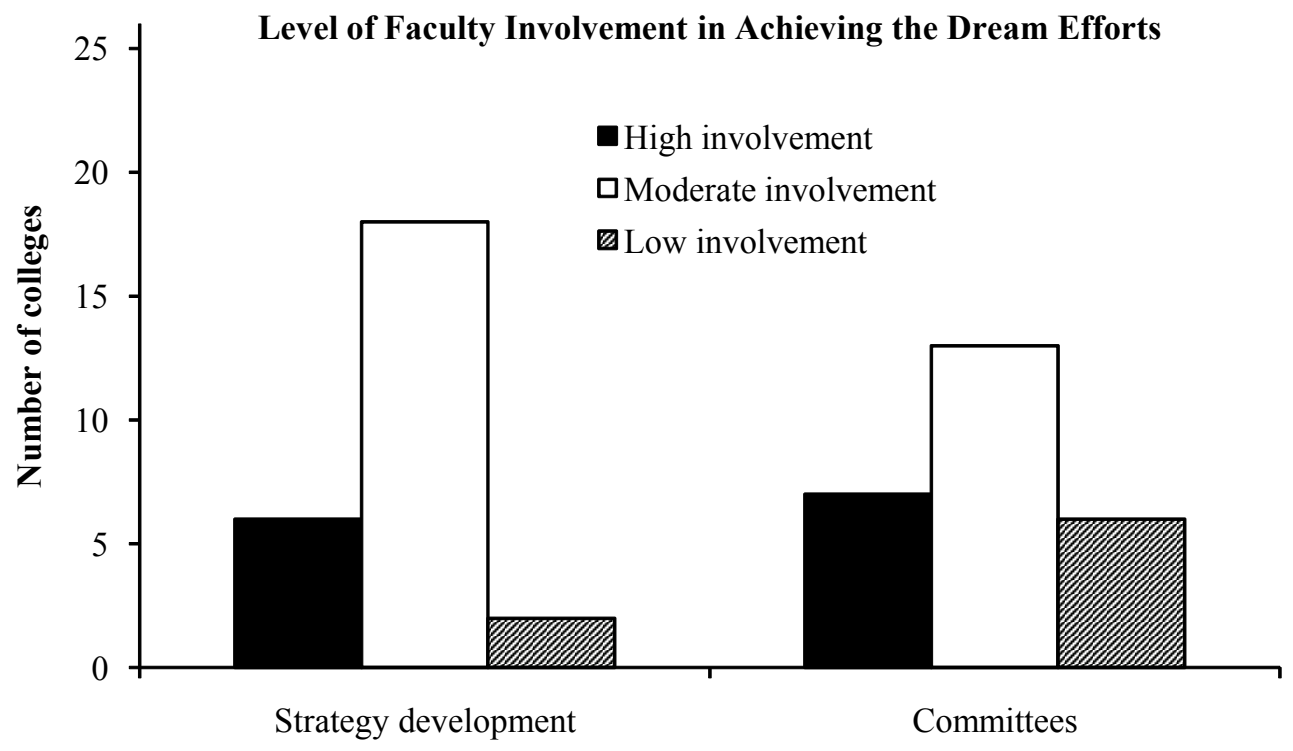

Type of Activity

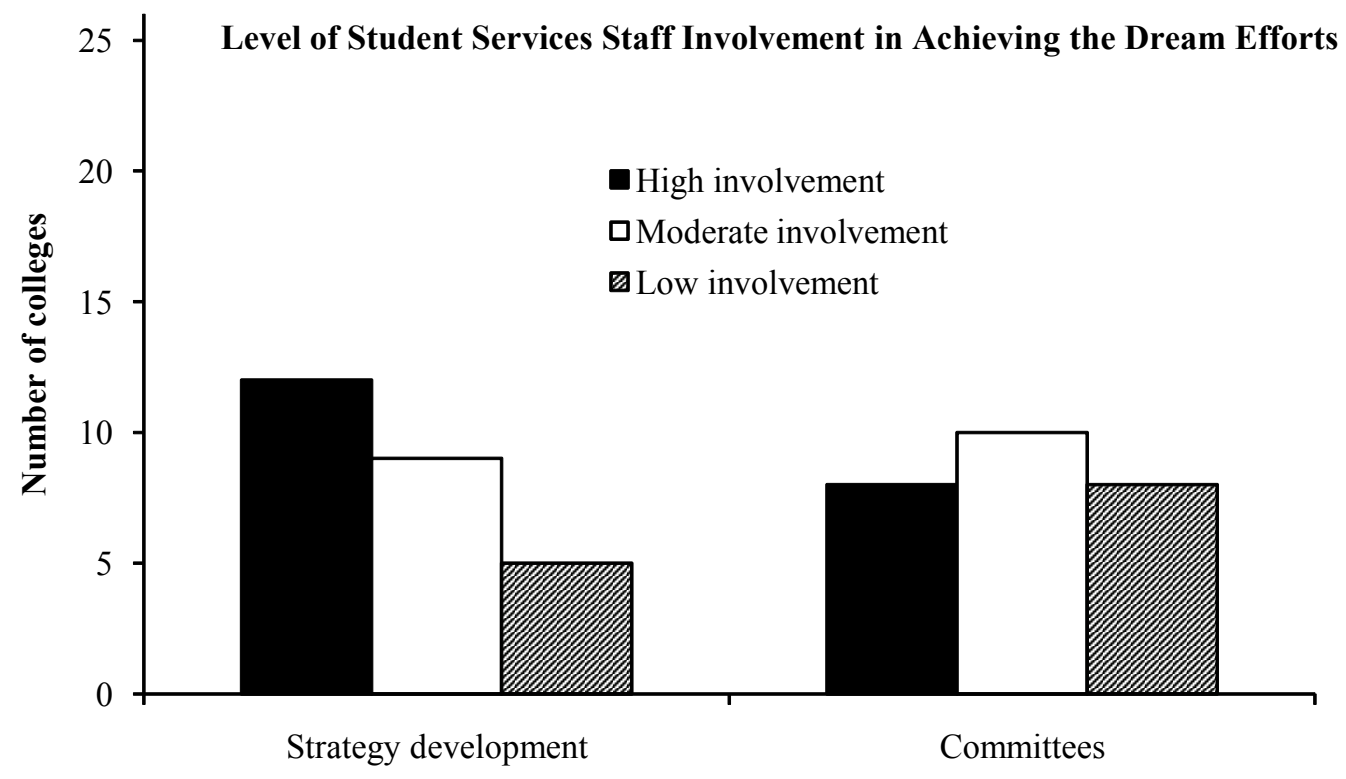

Type of Activity

SOURCE: Information collected from faculty, staff, and administrators during two rounds of implementation research across all 26 Round 1 colleges, cross-referenced against reports submitted by college representatives, Achieving the Dream coaches, and data facilitators. 


\section{Box 4.2}

\section{Promising Practices for Promoting Faculty and Staff Engagement}

While faculty engagement is a core component of Achieving the Dream, some colleges had challenges with engaging large numbers of faculty and staff in their reform efforts. However, several colleges were able to overcome these difficulties by creating more systematic ways to facilitate faculty and staff involvement in the development of their strategies, committee structures, and data analyses.

While most colleges involved faculty and staff in implementing their strategies, larger colleges tended to have greater difficulties involving substantial proportions of their faculty in these efforts. One of the most successful ways that a few colleges engaged greater numbers of faculty in strategy development was by implementing large-scale interventions that touched a number of different academic areas. For instance, Houston Community College developed a success course for its first-time students, which involved a sizeable group of faculty and staff teaching student success courses. Because it was such a large-scale strategy, Houston's success courses required more faculty and staff involvement than many other smaller-scale strategies, which touched only certain subsets of students.

In order to increase faculty and staff involvement in decision-making, a number of the Round 1 colleges developed integrated committee systems focused on student success. For example, Hillsborough Community College created the Student Success, Retention, and Placement Committee, which brought faculty together to analyze data on the college's programs and determine future actions to further student success. This committee would then make recommendations about the continuation or revision of the college's interventions. Another college, Guilford Technical Community College, created a similar committee, which was also tasked with monitoring and revising the college's student success efforts using evaluation data. Guilford rotated membership on this committee every two years in order to facilitate greater faculty and staff involvement.

Other types of strategies for involving faculty and staff in data analysis emerged from the colleges that had high levels of engagement. One of the most common practices was the creation of scorecards or data dashboards, which summarized students' achievement in particular departments or subject areas. Rather than focus solely on institutional-level measures, colleges that developed these tools were able to clearly present student success data, such as course pass rates and persistence, on a departmental level. This more individualized approach provided a readily accessible way for faculty and staff to understand how their students were doing. Another strategy for involving faculty and staff in data analysis was to provide more intensive training in data programming, such as training in how to use data software packages or how to access student outcomes data that were stored in an institutional data warehouse. For instance, at Valencia Community College, training in the SAS software package was undertaken to decrease the data requests that the college's institutional research department received by empowering individual faculty and staff to access the data they needed on their students' achievement. 


\section{Involvement of Faculty and Staff: Committees}

The involvement of faculty and staff in the leadership of a college's change agenda is also an important aspect of Achieving the Dream's vision for change. Most Round 1 colleges took this advice to heart and were successful at engaging at least some of their faculty and staff in committees charged with making critical decisions about the colleges' reforms (Figure 4.1). Colleges with high levels of faculty and staff involvement often restructured their committee systems, creating a number of smaller task forces that allowed for greater faculty and staff input (see Box 4.2 for examples). These task forces tended to make recommendations on specific policies and programs and were integrated with the colleges' broader leadership teams, which in some cases included faculty and staff representatives.

In general, however, at a plurality of Round 1 colleges, a select group of faculty and staff tended to be involved in lower-level committees, such as task forces dedicated to strategy development. While a few colleges had faculty and staff on higher-level, policymaking committees, most colleges tended to limit these committees to administrators, giving faculty and staff a smaller voice in the colleges' decision-making processes. Another 20 to 30 percent of the Round 1 colleges had low faculty and staff involvement, primarily because of faculty and staff resistance to Achieving the Dream, difficulties with the colleges' leadership, or colleges' greater focus on strategy development.

\section{Involvement of Faculty and Staff: Data Analysis}

One of the most critical aspects of Achieving the Dream's framework is the wide dissemination of student outcomes data to the larger campus community and the training of faculty and staff in the use of data and research in their everyday practice (see Box 4.1). In general, most Round 1 colleges tended to heed these suggestions, with the majority of faculty and staff at these institutions having at least some exposure to data on student outcomes. Data from the implementation visits, as well as a survey of full-time faculty and administrators at 23 of the 26 Round 1 colleges, ${ }^{13}$ revealed that the overwhelming majority of faculty and staff reviewed some type of institutional-level data, such as enrollment and graduation rates, and classroom-level data, such as grades and course evaluations, at least once per year (see Figure 4.2). Faculty tended to review classroom-level data more often than institutional-level data, perhaps because this information was more relevant for their classroom practice. However, they also reviewed other types of information, such as data related to course placements, retention, and graduation, as well as outside research.

\footnotetext{
${ }^{13}$ Three colleges — Tidewater Community College, Valencia Community College, and Southwestern Indian Polytechnic Institute — did not participate in the survey.
} 


\section{Achieving the Dream: Community Colleges Count}

Figure 4.2

\section{Frequency with Which Faculty Members Used Student Outcomes Data, by Type of Data, 2007 to 2008}
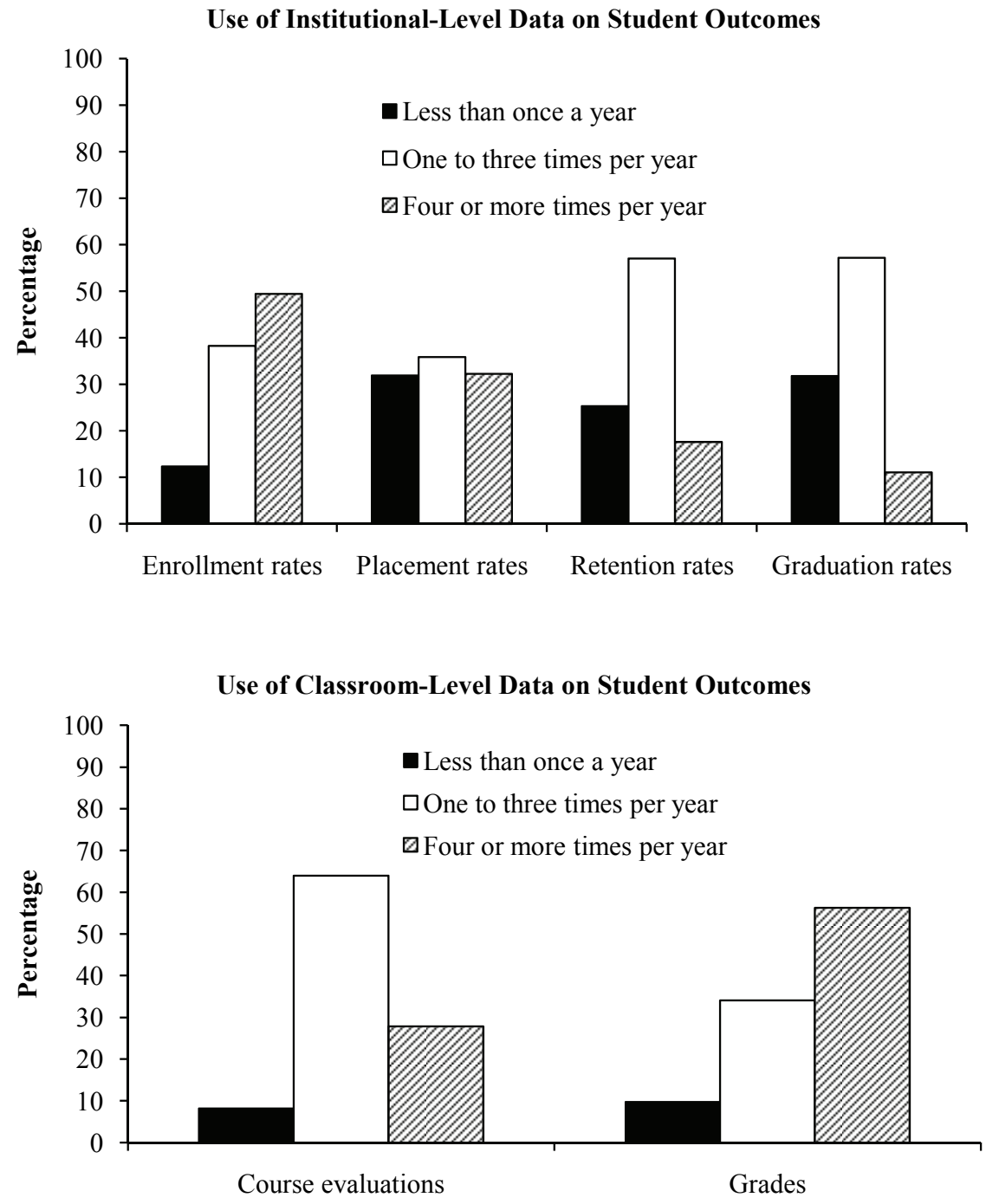

SOURCE: CCRC calculations using survey data collected from faculty and administrators at the Achieving the Dream Round 1 colleges.

NOTE: Faculty and administrator survey data were collected from September 2007 through February 2008, approximately one year before implementation research at the Round 1 colleges. The survey was disseminated at 23 of the 26 colleges. 


\section{Achieving the Dream: Community Colleges Count}

Figure 4.3

\section{Frequency with Which Faculty Members Used Data Disaggregated by Race and Income, 2007 to 2008}

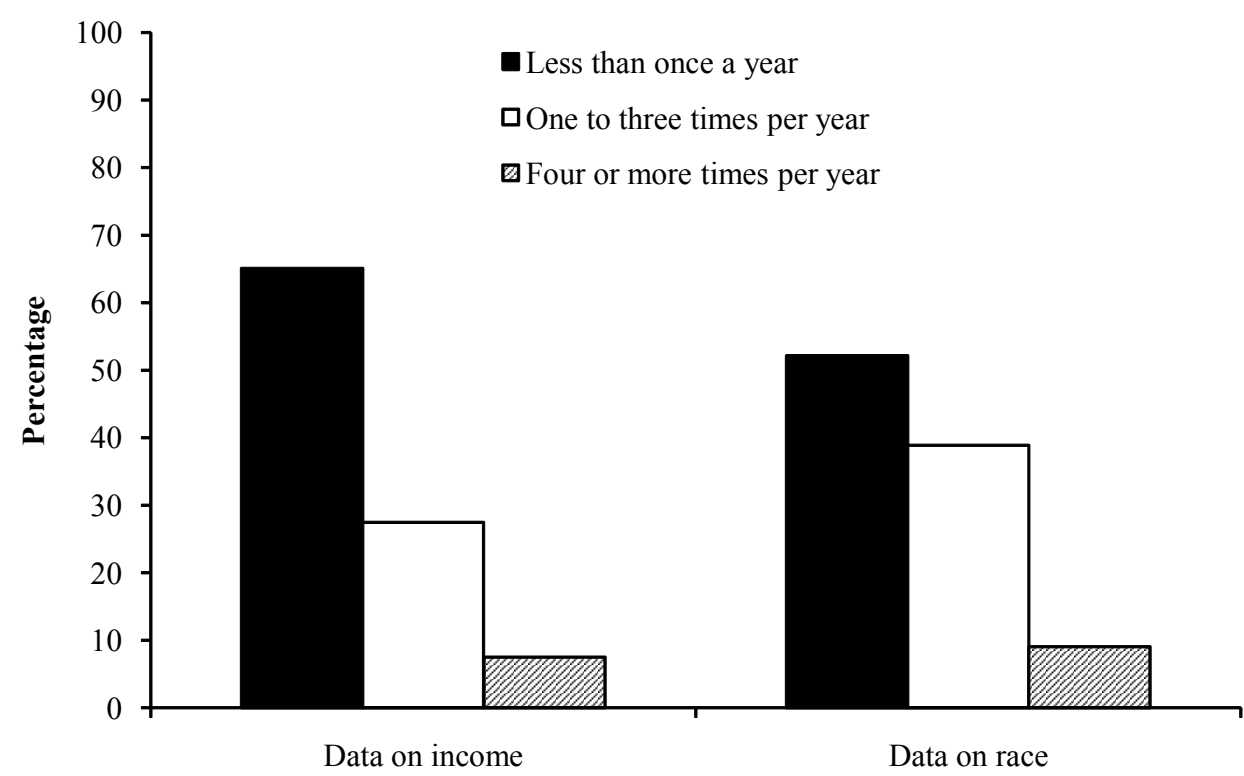

SOURCE: CCRC calculations using survey data collected from faculty and administrators at the Achieving the Dream Round 1 colleges.

NOTE: Faculty and administrator survey data were collected from September 2007 through February 2008, approximately one year before implementation research at the Round 1 colleges. The survey was disseminated at 23 of the 26 colleges.

While most faculty and staff had some exposure to student outcomes data, the type of data that were analyzed and the regularity of their review were mixed. For instance, most faculty and staff had limited exposure to the institutional-level measures that are most important to Achieving the Dream, such as graduation and retention rates, with most faculty reviewing these data less often than four times a year. Similarly, few faculty and staff regularly reviewed data that were disaggregated by race or income, with over 50 percent analyzing these data less often than once a year (see Figure 4.3). However, faculty did review other types of data much more regularly. For instance, approximately half of the faculty at the Round 1 colleges analyzed information on course grades and enrollment rates four or more times per year. Similarly, a number of faculty noted using data and research to some extent when thinking about their advising practices, curriculum, and teaching. 
Perhaps some of this variability in data use stemmed from the fact that very few colleges brought faculty and staff into the data analysis process. Only seven colleges offered some form of training on data analysis to faculty and staff or had institutional research departments that were regularly involved in teaching faculty and staff how to use data. Several other colleges noted that their faculty members were involved in some form of learning outcomes assessment; however, these analyses tended to be driven by colleges' accreditation processes more than by their Achieving the Dream efforts. While most colleges delegated data analysis work to their institutional research departments, a number of key practices helped facilitate faculty's and staff's understanding and use of student outcomes data, providing a good model for better faculty engagement (see Box 4.2).

\section{Collaboration Between Faculty and Staff}

Achieving the Dream's model for institutional improvement also emphasizes the need for greater collaboration between faculty and student services staff when implementing colleges' reforms (see Box 4.1). Overall, Achieving the Dream appears to have positively influenced faculty and staff collaboration at the Round 1 colleges, with the majority of the Round 1 colleges noting an increase in the collaboration between their faculty and staff as a result of their participation in the initiative. There were only a few exceptions to this trend, generally resulting from the college's focus on one specific area (either instruction or student services), or from a lack of involvement of one of these parties in the Achieving the Dream process. Colleges' higher levels of collaboration were generally attributable to an increased number of faculty and

staff working together on one or more of the colleges' strategies or on leadership and planning committees. Particular types of strategies, such as student success courses, orientations, learning communities, in-class advising, or tutoring and supplemental instruction, tended to foster these interactions, primarily because they blended instruction and student support. One college even rearranged its departmental structure in order to better facilitate this collaboration.

\section{Adjunct Faculty Involvement}

Achieving the Dream also recommends that colleges seeking to improve student success involve their adjunct, or part-time, faculty in the colleges' reform efforts (Box 4.1). Adjunct faculty are typically instructors who are employed part time by a college to teach one or two classes. As such, these instructors tend to be less connected to the college environment than fulltime faculty, as they are on campus for only a short period of time each week. However, adjunct 
faculty play a central role in community college teaching, as they tend to teach the majority of developmental and gatekeeper classes that students take when first entering college. ${ }^{14}$

Unfortunately, the involvement of part-time faculty was one of the Round 1 colleges' key weaknesses. Only eight of the Achieving the Dream colleges made attempts to include parttimers in their improvement process, with most of these colleges offering only minimal, onetime professional development sessions or unpaid invitations to participate in the college's projects. Few colleges provided paid time for adjuncts to be involved in professional development or strategy implementation, and over two-thirds of Round 1 colleges made no concerted efforts to engage their adjunct faculty. Colleges noted a couple of reasons for the limited involvement of adjunct faculty, including a lack of funding to pay adjuncts for additional work and difficulty forming partnerships with adjuncts because of their limited time on campus.

Despite these challenges, a few Round 1 colleges developed some useful tactics for involving adjunct faculty in their reform work. For instance, Patrick Henry Community College developed a uniquely comprehensive model for bringing its adjunct faculty into a schoolwide effort to implement collaborative learning in the classroom. As described in Box 4.3, Patrick Henry not only supported initial training for these faculty members, but also provided modest pay increases and ongoing support to trained faculty to ensure that they used collaborative learning techniques in their classrooms. While somewhat less intensive, other colleges made similar efforts to involve these instructors through trainings and meetings around particular interventions. For instance, Valencia Community College allowed adjunct faculty to teach their Learning in Community (LinC) linked courses and opened their trainings to both adjunct and full-time faculty.

\section{Engagement of Students}

While involving faculty and staff is important, Achieving the Dream also recommends that colleges engage students in the institutional improvement process, as they may provide a unique perspective on the colleges' programs and services (Box 4.1). This effort was one of the most successful that the colleges undertook, as all of the Round 1 colleges brought student perspectives into their agenda in some form (see Figure 4.4). The most popular way to garner students' perspectives was through the dissemination of surveys; all of the Round 1 colleges participated in this activity. The most popular survey was the Community College Survey of Student Engagement (CCSSE), which gathers information on students' perspectives on college, use of campus services, and challenges to attendance. All of the Round 1 colleges delivered the

\footnotetext{
${ }^{14}$ Boylan, Bonham, Jackson, and Saxon (1994); Boylan, Bonham, and Bliss (1994); Gerstein (2009); Schuetz (2002).
} 


\section{Box 4.3}

\section{Bringing Adjunct Faculty on Board: Promising Models from Two Round 1 Colleges}

Most of the Round 1 Achieving the Dream colleges struggled to engage adjunct, or parttime, faculty in their student success reform efforts. However, two colleges provided innovative models for involving these individuals in their work. In scaling up one of its promising Achieving the Dream strategies, collaborative learning, Patrick Henry Community College provided extensive supports for adjuncts to learn about and implement this teaching practice. First, Patrick Henry paid adjunct faculty to attend a training session to learn about collaborative learning and how to develop it in their classrooms. Additionally, the college offered supplementary pay to adjunct faculty who incorporated this pedagogy into their classrooms. Finally, it provided ongoing trainings, peer mentoring, and monthly meetings to both full-time and adjunct faculty to support their implementation of this new model of teaching. While the increased pay for adjuncts was relatively small, Patrick Henry represented one of the few colleges that developed a fully integrated professional development system to support both full-time and adjunct faculty in developing a new teaching method.

Paul D. Camp Community College also focused heavily on adjunct faculty through the creation of an adjunct academy that brought part-time faculty members together for trainings and other opportunities. The college found this center to be so effective that it ultimately extended its services to full-time faculty as well. This center provided monthly offerings to adjunct faculty to help them learn about the college's new reforms. For instance, in one session, adjunct faculty learned about the new Blackboard technology, which allowed for online interaction and collaboration among students and instructors, that Paul D. Camp was integrating across its course offerings to help support students' classroom learning and management. Another session focused on a review of the college's findings from the LASSI (Learning and Study Strategies Inventory) survey and a training event focused on students' different learning styles. Paul D. Camp also charged a number of its adjunct faculty with leading some of its student success interventions. While training for these personnel was less systematic than at Patrick Henry, Paul D. Camp's work helped adjunct faculty feel that there was "no separation" between full-time and part-time faculty, and that they were "not made to feel like adjunct faculty."

CCSSE to their students at least once during their participation in Achieving the Dream, with many colleges disseminating this survey multiple times. Some colleges also used other surveys to gather information about students' thoughts, engagement, and learning styles, including the Learning and Study Strategies Inventory (LASSI), Noel-Levitz Student Satisfaction Inventory, Survey of Entering Student Engagement (SENSE), and Visual, Aural, Read/write, Kinesthetic (VARK) inventory of learning styles. Some colleges also took pains to develop their own surveys 


\section{Achieving the Dream: Community Colleges Count}

Figure 4.4

\section{Number of Achieving the Dream Round 1 Colleges with at Least Some Involvement from Students in the Institutional Improvement Process, Spring 2009}

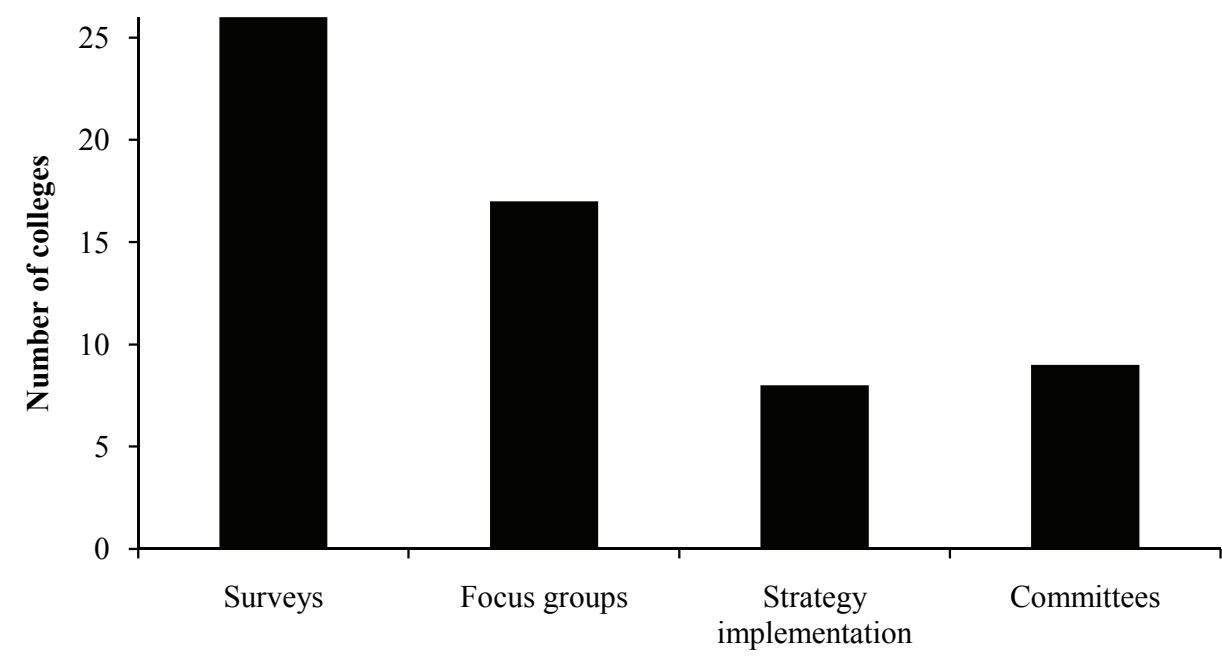

Activity

SOURCE: Information collected from faculty, staff, and administrators during two rounds of implementation research across all 26 Round 1 colleges, cross-referenced against reports submitted by college representatives, Achieving the Dream coaches, and data facilitators.

for students to gather information about their perspectives on specific offerings at the college, such as campus services, courses, or a new strategy that they were piloting.

Another popular strategy for learning about student perspectives was to conduct focus groups. Over 60 percent of the 26 Round 1 colleges discussed their efforts to meet with students through small group discussions. Focus groups were sometimes used to get students' perspectives on the strategies and interventions that colleges were testing. However, more often, colleges held focus group sessions to understand students' concerns and challenges more generally. A few colleges made mention of how student perspectives had changed their reform efforts. For instance, Santa Fe Community College discussed how their students' challenges led them to increase their student support services and create an Office of Student Development Center that coordinates student activities and support. 
Some colleges sought out ways to foster students' more active participation in planning and implementing their college reform agendas. For instance, some colleges involved students directly in helping to implement a particular strategy by serving as a peer mentor, tutor, or student advisor. Additionally, one-third of the colleges had student representatives on their leadership or decision-making committees, such as the board of trustees or the president's council. Therefore, in addition to learning about students' perspectives, a select group of Round 1 colleges also allowed students a real voice in the changes that their institutions were pursuing.

About two-thirds of the colleges reported that Achieving the Dream had an important effect on student engagement. The increased outreach at most of these schools centered primarily on gathering information about student perspectives through surveys and focus groups or involving students in the implementation of a strategy. However, a few colleges discussed important ways that Achieving the Dream had helped them use student perspectives to revise their improvement agenda. For instance, at Durham Technical Community College, students participating in the "Visions" program (which, as described in Chapter 2, aimed to help lowincome African American male students overcome obstacles to succeeding in college) led the movement to shift the program's focus on students' academic performance. Similarly, at Martin Community College, students' requests for more interaction in the classroom led to Martin's focus on collaborative learning and a restructuring of its accreditation plan to integrate a more collaborative teaching approach.

\section{Engagement of External Stakeholders}

Achieving the Dream also recommends that colleges bring external stakeholders, such as K-12 school districts, universities, community members, parents, and businesses, into their student success efforts (Box 4.1). Most of the Round 1 colleges succeeded at bringing some of these external stakeholders into their work (see Figure 4.5). High school districts and universities were common external partners. A majority of the Round 1 colleges were collaborating with these institutions through activities such as "early college" high schools, dual enrollment programs, high school-to-college "bridge programs," early college placement assessments, or articulation agreements with four-year colleges and universities. ${ }^{15}$ Perhaps the best example of these partnerships, El Paso Community College worked intensively with multiple K-12 school districts to develop a multifaceted College Readiness Initiative, which provided early college assessments, advising,

\footnotetext{
${ }^{15}$ Early college high schools combine high school and college curricula, allowing students to earn a high school diploma and an associate's degree in a compressed period of time. High school-to-college bridge programs are generally summer preparation programs for recent high school graduates that focus on increasing graduates' academic skills and making them more college-ready.
} 


\section{Achieving the Dream: Community Colleges Count}

Figure 4.5

\section{Number of Achieving the Dream Round 1 Colleges with at Least Some Involvement from External Stakeholders in the Institutional Improvement Process, Spring 2009}

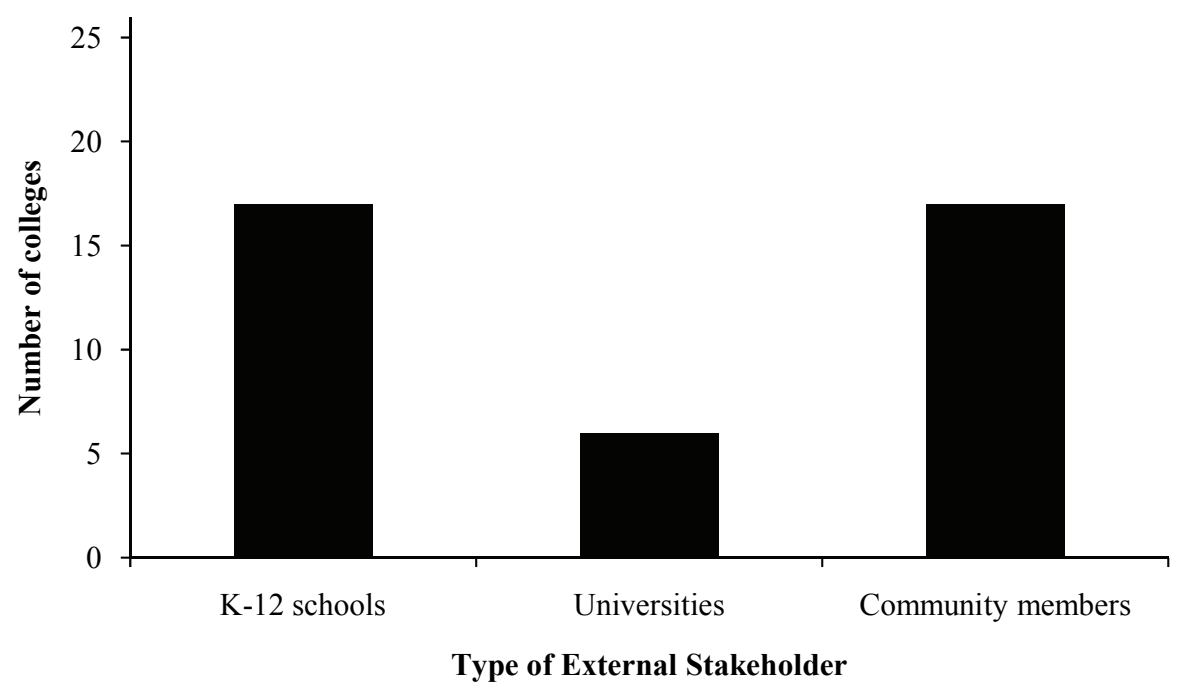

SOURCE: Information collected from faculty, staff, and administrators during two rounds of implementation research across all 26 Round 1 colleges, cross-referenced against reports submitted by college representatives, Achieving the Dream coaches, and data facilitators.

NOTE: Community members include businesses, nonprofits, community-based organizations, and local residents.

and preparation to high school students. ${ }^{16}$ Other colleges, such as Martin Community College, University of New Mexico-Gallup, South Texas College, and Tallahassee Community College, also had multiple avenues for students to begin preparing for college and earn college credits while they were still enrolled in high school.

Many Round 1 colleges also sought input from local community members, businesses, nonprofit organizations, and other interested parties. As described earlier, some schools worked with Public Agenda, an Achieving the Dream partner with expertise in community engagement, to develop "community conversations," through which they brought a number of community members and parents into the colleges to hear their hopes and desires for their programs and

\footnotetext{
${ }^{16}$ For more information, see the case study on El Paso Community College in Kerrigan and Slater (2010).
} 
their students. Although a number of colleges had been working with community and business leaders for several years, Achieving the Dream had at least a moderate influence on nearly half of the Round 1 colleges' external engagement activities.

\section{Summary}

The Round 1 Achieving the Dream colleges, as a whole, were able to moderately engage a number of internal and external stakeholders in their efforts to improve students' achievement. Colleges were most successful at engaging faculty and staff in developing strategies that were aimed at improving students' achievement, and a majority of schools engaged at least some of these personnel in committees tasked with leading the colleges' efforts. Faculty and staff also had at least some exposure to data on student outcomes, although the type of data that were reviewed and the regularity of their use varied across institutions. The Round 1 colleges were also successful at garnering the participation of students and external stakeholders in their work, with some playing a particularly active role in the colleges' reform efforts.

While the Round 1 colleges had many successes engaging faculty and staff, a few limitations were apparent in their work. Most important, adjunct faculty, who are typically responsible for teaching many of the developmental and entry-level classes that students take upon entering college, tended to be absent from the colleges' reform efforts. This disconnect means that many of the classroom reforms with which colleges experimented may not have reached many of the students who could have benefited the most from the colleges' work. Additionally, while faculty and staff had some exposure to data, they did not make regular use of the institutional-level data on which Achieving the Dream has been most focused. Instead, faculty tended to focus on data that were closest to their classroom practice, such as grades and course evaluations. Finally, faculty and staff tended to have less of a voice in colleges' leadership and policymaking committees, meaning that their influence on colleges' reform agendas tended to be more limited.

Given these findings, Achieving the Dream might wish to consider additional ways to help colleges engage faculty and staff in the leadership and management of colleges' reform efforts. In particular, colleges seem to need more support in engaging adjunct faculty and staff in their work. Additionally, colleges may need more guidance on developing concrete ways to involve faculty leaders, such as deans and department chairs, in data analysis, as well as in the leadership and management of colleges' reforms. Several colleges have provided strong models for involving faculty and staff more broadly in their efforts, which provide good examples for the initiative to follow. A more defined approach for bringing faculty and staff into colleges' efforts may help further strengthen their already good work in this area. 



\section{Chapter 5}

\section{Intervention Strategies}

The preceding chapters have discussed colleges' efforts to develop a culture of evidence by fostering committed leadership, increasing data usage, and engaging a broad spectrum of stakeholders. In Step 4 of the Achieving the Dream model, "Implement, Evaluate, and Improve" (see Figure 1.2 in Chapter 1), colleges build upon these foundations by implementing new strategies to help students remain in school, improve their performance, and ultimately graduate with certificates or degrees. These intervention strategies play a crucial role in Achieving the Dream's theory of action as the principal pathway through which colleges' institutional efforts affect what students experience on the ground. As such, the initiative's success at improving student outcomes is contingent upon colleges' ability to implement substantially improved programs that reach sufficient numbers of students.

Overall, the Round 1 colleges implemented a large number of strategies under the auspices of Achieving the Dream. The majority of those strategies were direct programs and services designed to improve students' college success. While the strategies ranged widely, from "light-touch" orientation activities to more intensive curricular reforms, several common themes emerged across the 26 colleges:

- A large majority of strategies were designed to increase academic and social support systems for students, while only about one-fourth changed the content and delivery of classroom instruction itself.

- Nearly half of the colleges' strategies targeted developmental education students, and one-third focused on students in their first year of college. Very few strategies targeted students based on their race, ethnicity, or economic status, though some colleges indirectly addressed achievement gaps along those lines through programs aimed at wider groups of students.

- Despite the colleges' notable efforts to scale up their programs and services, the majority of strategies reached less than 10 percent of their intended target populations. Intensive strategies - defined by longer periods of contact time with students - were particularly unlikely to reach large numbers of students, suggesting that colleges faced a trade-off between the intensity and scale of their interventions.

Most colleges had several additional strategies that did not reach students through direct contact hours, but rather through (1) changes in college policies; (2) improvements in profes- 
sional development opportunities for faculty and staff; and (3) collaborative relationships with external stakeholders, including local school districts and community members. This chapter provides an overview of Achieving the Dream's theory for strategy development, explores major findings from each category of intervention strategies, and concludes with a discussion of the colleges' overall experiences with strategy implementation under the initiative.

\section{Achieving the Dream Framework for Strategy Implementation}

Step 4 in the Achieving the Dream theory of action represents an ongoing process that colleges are expected to follow in order to improve the programs and services that are available to their students. During the initial planning year, colleges identify priority areas for improvement, draw upon available evidence and research to select strategies that show promise of improving outcomes in these areas, and design a plan for strategy roll-out. This planning lays the foundation for colleges' work under Step 4 (summarized in Figure 5.1), which includes the following actions:

- Implement selected strategies, beginning with small-scale pilots when possible and engaging broad segments of faculty and staff.

- Evaluate strategies to assess their success at improving student outcomes.

- Use evaluation results to inform strategy refinement, scaling up interventions that yield promising trends in student success, while modifying or eliminating those that do not. ${ }^{1}$

Implementing strategies is also one of the primary vehicles through which colleges can act to reduce achievement gaps for low-income students and students of color, whether by explicitly targeting interventions to particular student subgroups or by incorporating concerns about equity into the development and implementation of strategies that reach across student populations.

While Achieving the Dream's theory of action for strategy development is now well defined, the Round 1 colleges did not always have such definitive direction for strategy implementation. The development of interventions that are aimed at increasing students' success has been a central goal of Achieving the Dream from the beginning, and, with its focus on data-driven decision-making, the initiative has also emphasized the importance of monitoring and tracking

\footnotetext{
${ }^{1}$ Achieving the Dream (2009).
} 


\section{Achieving the Dream: Community Colleges Count}

Figure 5.1

\section{Step 4 of the Achieving the Dream Institutional Improvement Process: Implement, Evaluate, and Improve Strategies}

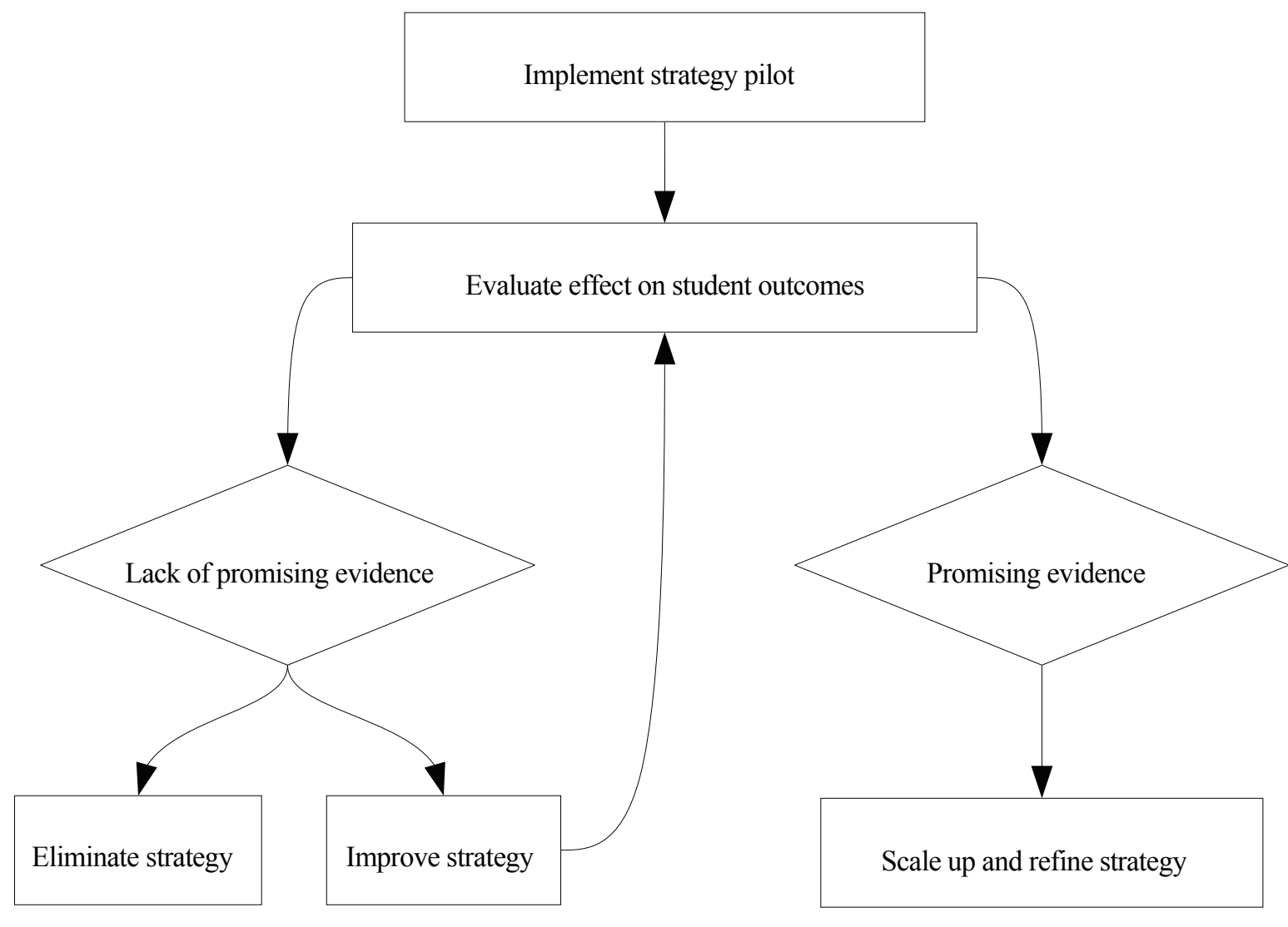

SOURCE: Diagram created based on information from Field Guide for Improving Student Success (2009), p. 11, from the Achieving the Dream: Community Colleges Count initiative. Available online at www.achievingthedream.org/docs/Field_Guide_for_Improving_Student_Success.pdf.

students' progress. However, the initiative did not develop a more codified policy for colleges' evaluation practices until $2008,{ }^{2}$ nor did it publish a more detailed statement of the five-step process for institutional improvement until 2009. ${ }^{3}$ Therefore, while this chapter discusses the

\footnotetext{
${ }^{2}$ Achieving the Dream (2008).

${ }^{3}$ Achieving the Dream (2009).
} 
Round 1 colleges' process for developing strategies, it is important to keep in mind (as was the case in the preceding chapters) that these schools were implementing these interventions while the initiative itself was still under development.

\section{Levers for Change in Achieving the Dream}

The Achieving the Dream partners have provided a number of inputs to support colleges through the rigorous process outlined above. One of the most noteworthy among these is an annual conference - known as the Strategy Institute - that brings together teams of presidents, administrators, faculty, and staff from all cohorts of Achieving the Dream colleges. The Strategy Institute fosters communication and collaboration across colleges as they give presentations on their experiences with strategy development and implementation, network with one another around common interests or interventions, and learn from the initiative partners about their respective areas of expertise. Several of the initiative partners - including MDRC, the Community College Research Center (CCRC), and Jobs for the Future - have also produced written materials designed to inform colleges about specific interventions and policies. For example, Jobs for the Future has released a number of briefs designed to help colleges navigate and influence state policy as they adopt new institutional practices, ${ }^{4}$ while MDRC published two experimental studies of promising strategies during the early years of Round 1 colleges' participation in Achieving the Dream. ${ }^{5}$ MDRC has subsequently partnered with four of the Round 1 colleges to undertake rigorous evaluations of specific Achieving the Dream interventions (discussed in Chapter 8), though the findings from these studies were not released in time to influence the initial selection of strategies at the Round 1 colleges.

Outside of conferences and publications, the initiative partners have also developed a national database for tracking colleges' intervention strategies. While this database was not available when the Round 1 colleges first joined the initiative, it is now accessible to all Achieving the Dream colleges, both seasoned and new. Finally, a subset of the Round 1 colleges have received support from Public Agenda, another Achieving the Dream partner organization, in their efforts to engage stakeholders from their local communities in their student success efforts.

\footnotetext{
${ }^{4}$ Biswas (2007); Collins (2009).

${ }^{5}$ Bloom and Sommo (2005); Brock and Richburg-Hayes (2006).
} 


\section{Type and Reach of Strategies}

\section{Scope of This Analysis}

This analysis is not intended to represent the entirety of colleges' student success efforts. Many colleges had initiated student success agendas before joining Achieving the Dream, while others pursued important activities during the course of their participation that they did not associate with the initiative itself. Rather than capturing the full scope of colleges' student success efforts, this chapter focuses specifically on those strategies that were implemented under the auspices of Achieving the Dream. Disentangling colleges' Achieving the Dream strategies from efforts that were undertaken independently of the initiative was a challenge, particularly when colleges made conscious efforts to align their Achieving the Dream activities with work under other grants and initiatives. As such, researchers from MDRC and CCRC have relied heavily on colleges' own reports about which activities were shaped or significantly influenced by their participation in the initiative.

\section{Direct Programs and Services}

One of the preeminent findings from this analysis is the sheer quantity of new programs and services that colleges implemented under Achieving the Dream. In total, the 26 Round 1 colleges undertook nearly 200 direct interventions in the realms of student services and instruction. Though colleges ranged significantly in the number of direct strategies they implemented (from three to twelve), the average college implemented seven different interventions.

\section{Types of Direct Strategies}

Despite the variety of their strategies, the Round 1 colleges also showed striking commonalities in the types of programs and services they pursued. Figure 5.2 illustrates the relative popularity of various types of interventions, each of which has been classified as a student support service (in light gray), an instructional support (in dark gray), or a change in classroom instruction (in white). Overall, it is apparent that a large majority of direct strategies focused on the former two categories, providing additional support for students inside or beyond the classroom rather than changing the content and delivery of classroom instruction. Examples of popular support strategies include Southwestern Indian Polytechnic Institute's one-stop student support center, which offers tutoring and a number of other services to students, and Mountain Empire's Freshman Orientation Experience, which sought to introduce entering students to the college before enrollment. More specifically, programs that were related to tutoring or supplemental instruction emerged as the most popular type of intervention, including 42 strategies across 21 colleges. Three types of student support services were also implemented at a majority of the Round 1 colleges: advising interventions, student success courses (which provide 


\section{Achieving the Dream: Community Colleges Count}

Figure 5.2

\section{Popularity of Direct Program and Service Strategies: Percentage of Round 1 Colleges That Implemented Each Type of Strategy Under Achieving the Dream}

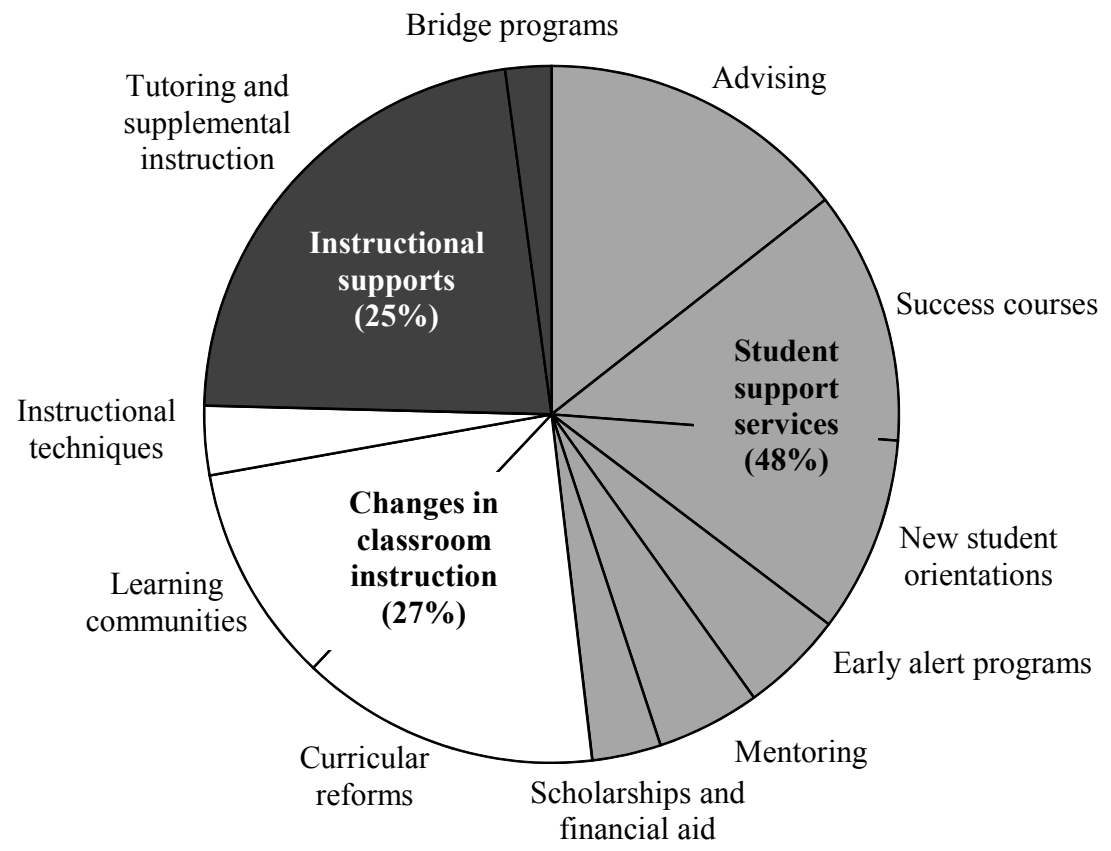

SOURCES: Information collected from faculty, staff, and administrators during two rounds of implementation visits across all 26 Round 1 colleges, cross-referenced against intervention reports submitted by colleges to the Achieving the Dream partners.

NOTES: All 187 direct intervention strategies from the Round 1 colleges are classified according to 11 mutually exclusive strategy types. These types each correspond to one of three broad categories of strategies: student support services, instructional supports, or changes in classroom instruction.

students with fundamental tools for doing well in college, such as time management skills and information about campus support services), and new student orientation programs.

In contrast with the prevalence of student support strategies, only about one-fourth of direct strategies aimed to change classroom instruction itself. The relative scarcity of classroombased reforms is consistent with the challenge of engaging broad segments of faculty in colleg- 
es' Achieving the Dream work (discussed in Chapter 4). ${ }^{6}$ A number of factors might help to explain this general trend. At the institutional level, shared governance models at the community colleges often require time-intensive approval procedures before interventions that require faculty buy-in can be implemented, thus making it difficult for administrators to make timely changes on the instructional side. Initiative-level factors might also have contributed to the distribution of strategies presented in Figure 5.2. For instance, the Achieving the Dream theory of action takes an expansive view of institutional reform, focusing heavily on the role of senior leadership and defining success in terms of broad performance measures such as student progression and completion. While these measures are undoubtedly of interest to most faculty, they do not provide concrete measures of student learning in the classroom, such as grades and student learning outcomes. ${ }^{7}$ The latter is an expanding area of work for faculty nationwide, as well as a central focus of reviews by all of the regional accreditation agencies. ${ }^{8}$ In fact, faculty at several of the Achieving the Dream colleges have become involved in setting and assessing student learning outcomes, but those activities have taken place largely outside the scope of the initiative. It is possible that faculty would engage in Achieving the Dream more quickly if the initiative were to incorporate classroom-level measures, such as student learning outcomes, along with institutional performance indicators.

In spite of these challenges, a handful of strategies were designed to influence instructional practices - especially with the goal of fostering active and collaborative learning techniques - while a larger set focused on changes in course curricula. In particular, learning communities stood out as the only type of curricular reform to gain broad popularity across the Round 1 colleges, with 15 of the 26 colleges trying this strategy in some form. ${ }^{9}$ This widespread emergence likely reflects the increased spotlight that was placed on learning communities during the early years of Achieving the Dream. For example, MDRC released its report on promising findings from learning communities during the summer of $2005,{ }^{10}$ just as the Round

\footnotetext{
${ }^{6}$ Only six of the Round 1 colleges achieved a high level of faculty involvement in strategy development, while twice as many colleges had a high level of involvement from student services staff.

${ }^{7}$ In a survey of student data usage across 41 Round 1 and Round 3 colleges, 90 percent of faculty reported reviewing grades at least once per year, and 85 percent considered grades to be a useful source of information. By contrast, the percentages of faculty who used information about institutional retention and graduation rates hovered at 72 and 65 percent, respectively, and faculty tended to view this information as less useful in their work (Jenkins and Kerrigan, 2009).

${ }^{8}$ Manning (2009).

${ }^{9}$ Learning communities reflect an intervention that is designed to strengthen classroom engagement by fostering peer relationships and building thematic connections across subject areas. A small group of students enrolls in two or more classes together as a "community," while the instructors of these "linked" courses work together to build integrated syllabi and develop mutually reinforcing themes (Visher, Wathington, RichburgHayes, and Schneider, 2008). Figure 5.2 presents learning communities separately from other curricular reform interventions in order to highlight their relative popularity.

${ }^{10}$ Bloom and Sommo (2005).
} 
1 colleges were completing their initial planning year and preparing for their first year of implementation under the initiative. Learning communities were also featured at multiple Achieving the Dream Strategy Institutes and conferences, ${ }^{11}$ as well as at specialized training opportunities, including an intensive institute at the Washington Center at Evergreen State College. The popularity of this strategy, however, does not imply that it is easy to implement; nearly all of the learning communities at the Round 1 colleges have remained limited in scale because of the manifold administrative, pedagogical, and financial demands of the program.

\section{Target Populations for Direct Strategies}

Defining a target population is one of the most important aspects of a college's strategy development efforts, as similar interventions can produce markedly different results, depending upon whom they reach. As such, the Achieving the Dream model encourages colleges to specify and justify which student group(s) they intend to target with a particular strategy. Figure 5.3 illustrates that developmental education students were by far the most popular target population. Spanning across colleges and strategy types, nearly half of all direct strategies focused on developmental education students, with a significant subset targeted specifically to developmental students in their first year of college. Furthermore, each of the 26 colleges had at least one strategy targeted to developmental education, and three focused all of their direct strategies in this area. Some interventions were extended broadly to all students enrolled in any developmental course, while others were tailored specifically to students with more remedial needs. For example, several colleges, such as Brookhaven Community College, mandated student success courses for those students who placed into developmental courses. The dominance of developmental education as a focus for strategic interventions is reflective of a broader national movement to improve services for underprepared students in community colleges. In fact, eight of the 26 Round 1 colleges have already begun their participation in the Developmental Education Initiative that is funded by the Bill \& Melinda Gates Foundation and was launched in 2009.

First-year students were the next most popular target group after developmental-level students. Approximately one-third of all direct strategies were focused on first-year students, ${ }^{12}$ including at least one such strategy at all but three of the 26 colleges. Colleges hoped that by reaching students early with targeted interventions - such as new student orientation programs and student success courses - they could better prepare students to persist through the challenges of their first few semesters.

\footnotetext{
${ }^{11}$ Brock et al. (2007).

${ }^{12}$ This percentage includes 10 percent of direct strategies that simultaneously targeted developmental and first-year students.
} 


\section{Achieving the Dream: Community Colleges Count}

Figure 5.3

\section{Popularity of Direct Program and Service Strategies: Percentage of Achieving the Dream Strategies Focused on Each Type of Target Population}

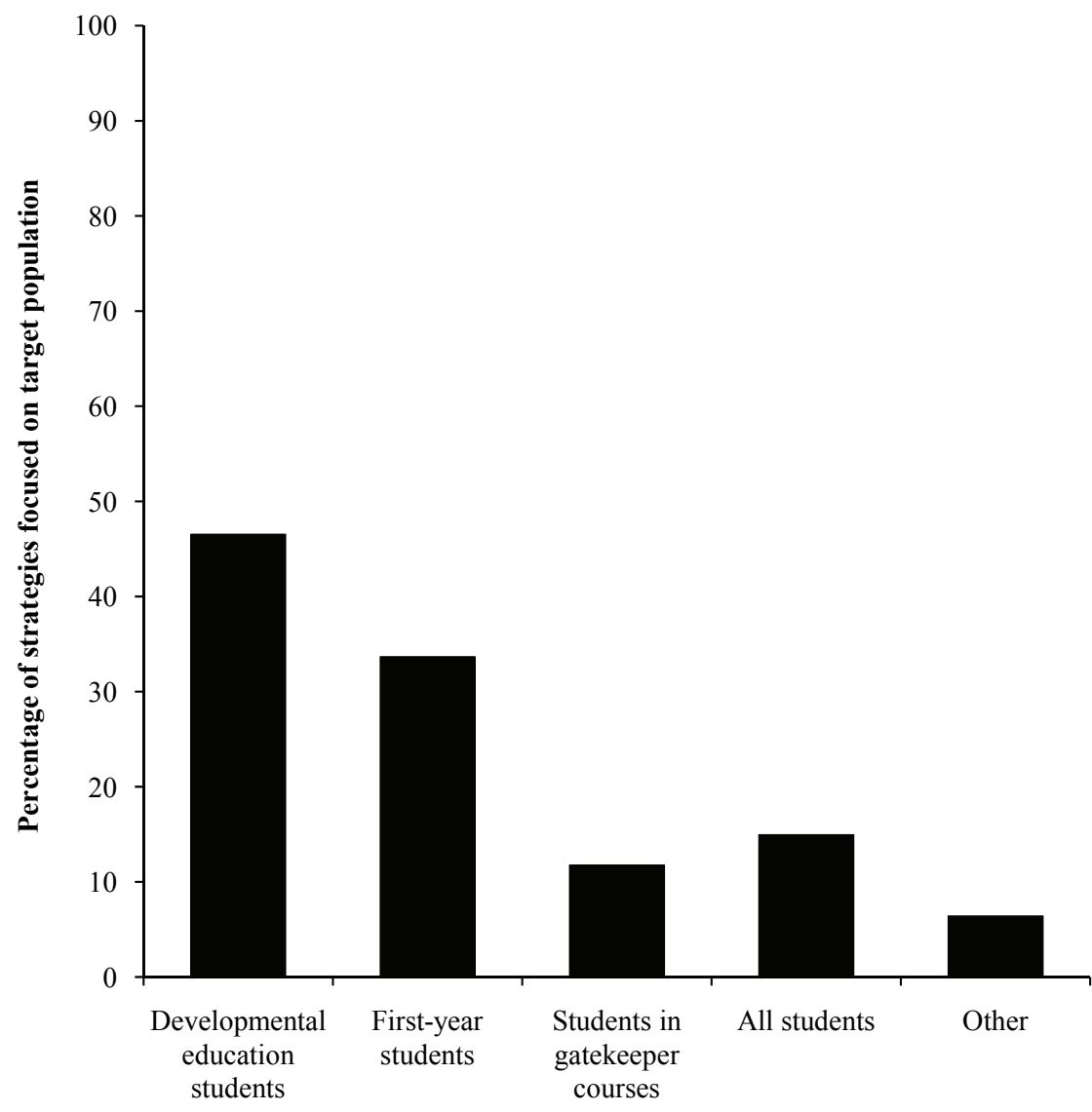

Target Population of Students

SOURCES: Information collected from faculty, staff, and administrators during two rounds of implementation visits across all 26 Round 1 colleges, cross-referenced against intervention reports submitted by colleges to the Achieving the Dream partners.

NOTES: Percentages add to more than 100 because some strategies target more than one student group and are thus included in more than one category. More specifically, 10 percent of strategies target both first-year students and developmental education students (for example, a success course for first-year students with developmental placements), and 4 percent of strategies target both developmental education and gatekeeper students (for example, a learning community linking a developmental course with an entry-level college course).

The "Other" category includes a handful of strategies targeting students of color, low-income students, students planning to transfer to four-year institutions, or students with English as a Second Language. 


\section{Direct Strategies and Achievement Gaps}

While colleges focused their strategies on developmental education and first-year student populations, they generally avoided publicly targeting interventions to specific racial, ethnic, or economic groups. The handful of exceptions included a small group of colleges that implemented mentoring programs specifically for men of color. Twelve schools in total also participated in Lumina Foundation's Dreamkeepers (11 schools) and Angel Fund Emergency Aid (1 school) programs ${ }^{13}$ - which offered emergency grants or loans to students who faced financial difficulties that could lead them to drop out of school — but outside of those programs, only a couple of colleges reported interventions tailored to students' financial needs. ${ }^{14}$ College leaders specified a number of reasons for their decisions not to focus strategies on specific racial or economic subgroups. Several felt that other factors, such as developmental education placement, were more meaningful indicators of student need; others argued that racial and economic divisions were not useful given the composition of their particular student bodies (especially at institutions where a large majority of students come from low-income families or are students of color). Some colleges also reported that they wanted to focus on improving outcomes for all students, not just those with certain demographic characteristics.

Rather than target students based explicitly on race, ethnicity, or income level, some colleges favored subtler approaches, focusing or tailoring strategies to better meet the needs of particular student groups within the entire student body. For example, in Alamo Community College District, personnel noted that male students of color were not using tutoring services to the same extent as other students. The college responded by convening a focus group of African American male students to share their thoughts about tutoring. Based on feedback from the focus group that some students felt uncomfortable attending tutoring in a centralized location, the college expanded its tutoring services online and in various, less formalized locations. In a similar vein, most of the Round 1 colleges disaggregated program data, and some actively used these data to identify the differential impacts that their strategies might have on subgroups of interest.

\section{Scale of Direct Strategies}

The ultimate goal of the Achieving the Dream initiative is to improve student outcomes institutionwide, but the needle on student achievement cannot be moved through small-scale

\footnotetext{
${ }^{13}$ Though funding from Dreamkeepers was contingent upon participation in Achieving the Dream (Geckeler, 2008), most of the 11 colleges that participated in Dreamkeepers considered this project to be outside the scope of Achieving the Dream.

${ }^{14}$ Santa Fe Community College implemented an innovative scholarship strategy by piloting three alternative models of scholarship delivery, while South Texas College focused its efforts on developing labs and workshops to improve students' understanding of financial aid opportunities.
} 
pilot projects alone. Instead, colleges must extend promising interventions to a substantial percentage of their target populations. For the purpose of this analysis, strategy scale was calculated using estimates from college personnel about the approximate number of students reached in a given semester (generally fall 2008, depending upon available data), as well as the total size of the target population for a given intervention. Strategies were designated "large scale" if they reached over 25 percent of their intended target populations, "medium scale" if they reached between 10 percent and 25 percent, and "small scale" if they reached under 10 percent of their target populations.

While the Round 1 colleges were generally able to commit the resources needed to expand a small number of interventions (a majority had either one or two large-scale strategies), some found that the reach of their strategy implementation exceeded their capacity for scale-up. Figure 5.4 illustrates that even by spring 2009, over half of all direct strategies remained small in scale, while less than a third were large scale. This is particularly noteworthy in light of the low threshold (25 percent) used to define "large scale," suggesting that far fewer strategies actually reached a majority of targeted students. Large-scale strategies were even less common at the subset of colleges with student enrollment over $15,000 .^{15}$ The percentage of direct strategies reaching large scale at those seven colleges (18 percent) was less than half of that at schools with enrollment under 2,000 (41 percent). These findings are not surprising given that larger colleges had to expand much further in order to reach a given percentage of their student populations.

\section{The Trade-off Between Intensity and Scale}

One of the most important findings to emerge from this analysis is the relationship between strategy "intensity" - or the amount of contact time students had with a particular program or service - and scale-up. Direct strategies were classified as "high intensity" if they reached students for 10 or more hours per semester, "medium intensity" if they reached students for between 5 and 10 hours, and "low intensity" if they reached students for 5 or fewer hours. Intensity is of particular relevance to this analysis in light of the expectation that more intensive strategies are more likely to meaningfully affect students' experiences, and thus are more likely to improve their outcomes in observable ways.

Overall, patterns of implementation across the Round 1 colleges suggest a trade-off between the intensity and scale of direct student services and instructional strategies. Figure 5.5 illustrates that only 31 percent of high-intensity strategies were large scale, compared with 38 percent of low-intensity strategies. On the flip side, high-intensity strategies were nearly twice as likely as low-intensity strategies to remain small scale, with 63 percent of all high-intensity interventions reaching under 10 percent of their target populations. These findings highlight a

\footnotetext{
${ }^{15}$ National Center for Education Statistics (2010).
} 


\section{Achieving the Dream: Community Colleges Count}

Figure 5.4

\section{Proportion of Direct Program and Service Strategies Operating at Small, Medium, and Large Scale at the Round 1 Achieving the Dream Colleges, Spring 2009}

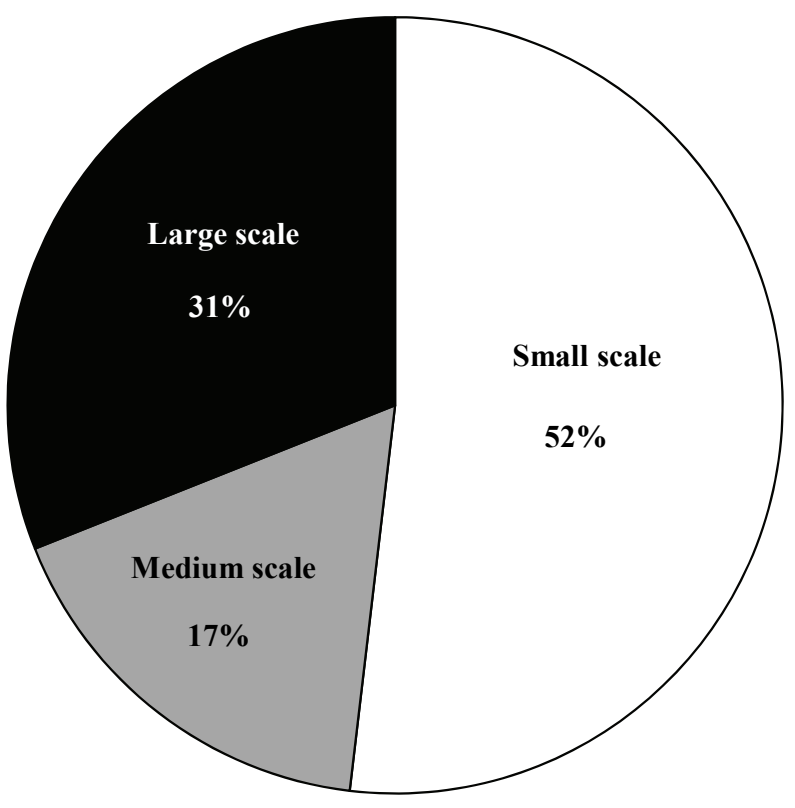

SOURCE: Estimates of strategy scale are based on information collected from faculty, staff, and administrators during implementation visits in fall 2008 through spring 2009, as well as from the Achieving the Dream intervention reports submitted by colleges.

NOTES: Strategy scale is defined as a percentage of an intervention's intended target population that is reached in a given semester (usually fall 2008, depending upon available data). Strategies are characterized as "small scale" if they reached under 10 percent of the students in their target population, "medium scale" if they reached between 10 percent and 25 percent, and "large scale" if they reached over 25 percent of their target population. A total of 187 direct program and service strategies at all 26 Round 1 colleges were analyzed.

more widespread dilemma for community colleges that are seeking to maximize the impact of their programs in the face of tight resource constraints: "heavy-touch" interventions allow for more contact time with students, but they also tend to be more expensive and difficult to implement at scale. 


\section{Achieving the Dream: Community Colleges Count}

Figure 5.5

\section{Proportion of Direct Program and Service Strategies Operating at Small, Medium, and Large Scale at the Round 1 Achieving the Dream Colleges, by Strategy Intensity, \\ Spring 2009}

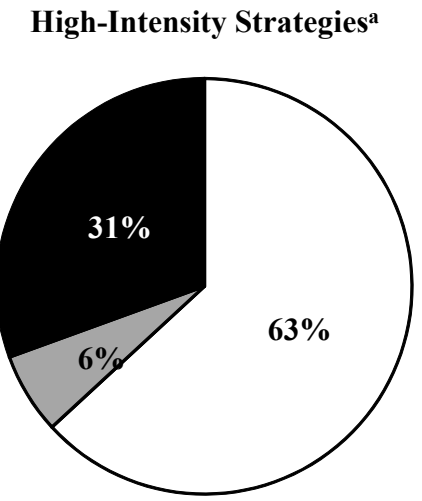

Small scale

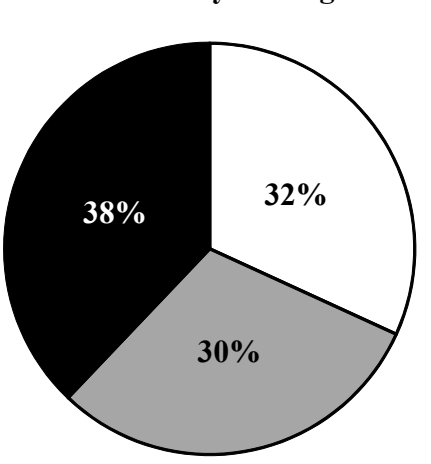

Large scale

SOURCE: Estimates of strategy scale are based on information collected from faculty, staff, and administrators during implementation visits in fall 2008 through spring 2009, as well as from the Achieving the Dream intervention reports submitted by colleges.

NOTES: Strategy scale is defined as a percentage of an intervention's intended target population that is reached in a given semester (usually fall 2008, depending upon available data). Strategies are characterized as "small scale" if they reached under 10 percent of the students in their target population, "medium scale" if they reached between 10 percent and 25 percent, and "large scale" if they reached over 25 percent of their target population.

aThe "High-Intensity" pie on the left represents 95 direct strategies that reached students for more than 10 hours per semester.

'The "Low-Intensity" pie on the right represents 66 direct strategies that reached students for 5 or fewer hours per semester.

This trade-off is supported by findings from a recent study of the costs of implementing Achieving the Dream at five of the Round 1 colleges. ${ }^{16}$ This study revealed that intervention strategies were a major area of investment under the initiative, representing an average expenditure of $\$ 2$ million per college. Those costs were driven primarily by the faculty and staff time invested in strategy development and implementation, and they were concentrated in the final three years of the initiative, when colleges were directing their efforts toward strategy scale-up. Thus, more intensive interventions - which generally involve longer faculty or staff contact

\footnotetext{
${ }^{16}$ Zachry and Coghlan (2010).
} 
with students and frequently require more advanced planning — also tend to demand more staff resources, increase costs, and consequently pose challenges for scale-up.

The trade-off between intensity and scale can be further illustrated by examining the types of strategies that were most likely to be scaled up. In particular, orientation programs and "light-touch" advising programs were the most popular types of low-intensity, large-scale strategies across the Round 1 colleges. In fact, nearly half of these colleges had orientation programs reaching at least one-fourth of their first-year students. This finding is in keeping with the preceding discussion of intensity and affordability, as most orientation programs were short, one-time events that could reach large groups of students simultaneously. Moreover, a substantial number were built upon existing programs rather than designed and planned from scratch. These factors all serve to explain the relatively low per-student cost of planning, implementing, and scaling up new student orientations. ${ }^{17}$ Similarly, while advising interventions varied significantly in their intensity and scale, over a third of them were classified as low intensity and large scale.

Curricular reform and instructional strategies tended to be more intensive and less likely to reach large numbers of students. In fact, interventions that focused on changes in classroom instruction, which reflected only about one-fourth of all direct strategies, accounted for over half of the high-intensity, small-scale interventions. More specifically, 18 of 19 learning community programs fell into this group, along with approximately half of the 26 curricular reform interventions. These patterns provide further evidence for the hypothesis that in-classroom reforms typically present additional challenges for implementation and scale-up.

Despite the manifold challenges of scaling up high-intensity strategies, all but four of the Round 1 colleges succeeded in bringing at least one such strategy to scale, contributing to a total of 29 "high-intensity, large-scale" strategies. This group of strategies was driven overwhelmingly by student success course interventions, which emerged as the only type of highintensity intervention to reach large numbers of students at a majority of colleges. In fact, 17 of 22 student success courses were large scale, while an additional 3 reached moderate numbers of students. Several colleges ensured the broad reach of these strategies by enacting mandates for students to take their success courses. While a few homed in on specific groups of students, such as those with multiple developmental needs, others required the course for new students.

The scale-up of other types of intensive interventions was far less consistent. However, as described in Box 5.1, a substantial minority of colleges achieved pockets of success scaling up curricular reform strategies, supplemental instruction programs, and instructional

\footnotetext{
${ }^{17}$ Two additional factors also facilitated the scale-up of orientation programs at a subset of the Round 1 colleges. The first is that some colleges actually generated money through their orientation programs, as increased student enrollments led to higher rates of funding. The second is that a handful of colleges introduced mandates for students to attend orientation, thus substantially increasing the reach of these programs.
} 


\section{Box 5.1}

\section{Promising Approaches for Scaling Up Strategies}

Community colleges face a number of challenges in scaling up intensive intervention strategies, including high per-student costs, staffing shortages, space limitations, scheduling demands, and difficulties in recruiting sufficient numbers of faculty, staff, and students to participate. Some of the Round 1 colleges surmounted these challenges by relying on innovative approaches to effectively scale up promising strategies. These approaches include:

- Addressing student recruitment concerns by enacting mandates for participation. For example, Valencia Community College made student success courses mandatory for all students placing into three areas of developmental education, while several other colleges required all first-year students to take the course.

- Addressing staffing shortages by using administrators and student services staff as success course instructors. When success course scale-up and mandates created the need for additional sections, a number of colleges turned to administrators and student services staff to teach these courses. With Achieving the Dream funding, some colleges were able to provide training to all student success course instructors to ensure consistency in curriculum coverage and delivery. Using a broader array of instructors offers the dual benefits of providing students with an extra opportunity to connect with administrators and staff, as well as fostering greater buy-in from administrators and staff to a student-centered vision of instruction.

- Addressing cost limitations by obtaining state funding, as well as developing technology and hybrid course approaches. A number of colleges were able to obtain state and tuition funding for student success courses by aligning the course name and number with those of courses already recognized by the state. In the realm of math curricular reform, a few colleges sought scalable change by adding a software component to their courses. For example, Galveston College used MyMathLab software to address the need for supplemental learning assistance in its developmental math courses. This software allows students to complete math assignments while receiving help from both the software and the professor while professors are able to monitor student progress and address challenges that students are facing with the material. In a similar vein, Coastal Bend College initiated computer-assisted math labs to increase the number of students passing and progressing through its math courses. Strategies such as these are often described as "hybrid" approaches because they combine technology, hands-on assistance, and access to an instructor or tutor. In order to provide their students with sufficient numbers of qualified tutors, some colleges, such as Hillsborough Community College and Wayne Community College, have combined their computer lab with their tutoring centers, while others, such as Martin Community College and Tallahassee Community College, have created systems for faculty to spend some of their office hours in the computer lab. 
reforms as well. One promising approach to scalable curricular reform was to enhance math instruction through the use of computer aids. Doña Ana Community College, Coastal Bend College, and Galveston Community College each made use of different computer systems EducoSoft, Hawkes, and MyMathLab, respectively - to enhance instruction in their developmental math courses. Each of these interventions was based on the pairing of regular classroom materials with computer-assisted math labs, resulting in substantial curricular changes for all students in the affected courses. Outside of computer-based instruction, a small group of colleges undertook other curricular reforms designed to improve articulation and alignment across course levels or reinforce critical skills such as reading and practical reasoning. Finally, a couple of colleges achieved intensive, widespread changes in the classroom by focusing on active and collaborative learning approaches. For example, Patrick Henry Community College has adopted an intensive cooperative learning program, which is described further in the section on professional development strategies below.

\section{Policy Change Strategies}

Though they do not generally involve direct contact among faculty, staff, and students, institutional policies are nonetheless an important factor influencing students' college experiences and chances of achieving success. Well-formulated policies can ensure that students are placed into courses that reflect their abilities and interests, directed toward an efficient pathway for meeting their goals, and supported with academic and financial resources. By contrast, misguided policies can present unnecessary obstacles that impede or delay students' progress. Many of the Achieving the Dream colleges have recognized the importance of strong institutional policy as a lever for improving student success across large numbers of students. Approximately two-thirds of the Round 1 colleges undertook at least one policy reform strategy, for a total of 30 strategies across the 26 colleges. (See Box 5.2 for examples.)

\section{Types of Policy Change Strategies}

By a wide margin, the most common policy reforms were designed to improve assessment and placement procedures to match students with the courses that best served their needs. For example, University of Mexico-Gallup mandated that all first-year students scoring below a certain level on its placement exam be assigned to developmental courses; this college was also one of several to adjust its placement test cut-off scores as part of its work under Achieving the Dream. Another handful of colleges focused on adopting new placement tools or improving existing ones to better assess student preparedness.

Outside of assessment and placement, the next most popular areas for policy reform were in registration and course sequencing. Registration strategies ranged from providing priority 
Box 5.2

\section{Types of Policy Change Strategies Implemented Under the Auspices of Achieving the Dream}

\section{Assessment and Placement}

- Improvement of assessment tools for incoming students

- Review and revision of placement test cut-off scores

- Adoption of mandatory placement for developmental education students

\section{Registration}

- Priority registration for developmental education students

- Elimination of late registration based on evidence from data analysis

- Provision of online registration option

\section{Course Sequencing and Prerequisites}

- Resequencing of developmental education courses

- Adoption of prerequisites or mandatory course sequences based on data

- Reorganization of courses across levels and departments

\section{Identification and Removal of Barriers to Success}

- Initiative to streamline graduation process and requirements

- Simplification and improvement of financial aid procedures

- Adoption or revision of attendance policies

SOURCE: Information collected from faculty, staff, and administrators during two rounds of implementation visits across all 26 Round 1 colleges, cross-referenced against intervention reports submitted by colleges to the Achieving the Dream partners.

registration opportunities for targeted groups of developmental education students to eliminating late registration based on evidence that students suffered academically when they missed the first few sessions of a course. In course sequencing, a handful of colleges implemented new policies governing students' progression through their developmental and credit- bearing coursework. Some have also initiated cross-institutional efforts with their local high schools and universities to improve curricular alignment across the K-16 spectrum. 


\section{Target Populations for Policy Change Strategies}

Not surprisingly, developmental education again emerged as the dominant target area for policy reforms. Over half of all policy change strategies were focused specifically on developmental education, with an emphasis on changes in assessment and placement processes. Many of the remaining policy strategies were directed broadly to all students or to those in their first year. However, a small but noteworthy handful of policy reforms were designed with an eye to reducing achievement gaps across racial and income groups. For example, Central New Mexico Community College developed a strategy to improve graduation rates, with a particular focus on its Hispanic male students. Its multipronged Graduation Initiative strategy included policy reforms to remove structural barriers to graduation, streamline graduation requirements, and better identify students who were nearing graduation. South Texas College also aimed to improve its achievement gaps, though it took a different approach to equity-driven policy reforms, focusing instead on improving its processes for delivering financial aid to low-income students.

\section{Professional Development Strategies}

Besides improving upon the programs, services, and policies that affect students, Achieving the Dream colleges are expected to leverage faculty and staff engagement to improve student success. Indeed, the initiative highlights the importance of professional development in creating more systemic changes in community colleges' improvement efforts (discussed in Chapter 6). Professional development proved to be an important area of college activity under Achieving the Dream; every college reported at least one strategy in this area, while a handful considered it an important focus of their work under the initiative. Some colleges created new centers dedicated to faculty and staff training, while others, such as Southwestern Texas Junior College, increased their funding for professional development and hired new directors to oversee this work. Findings from an MDRC cost study of Achieving the Dream further highlight the centrality of this work: investments in professional development, which averaged $\$ 654,000$ across the five colleges in that study, represented an important share of colleges' spending on activities related to the initiative. ${ }^{18}$ Box 5.3 captures some of the wide variety of professional development strategies that were implemented at the Round 1 colleges under the auspices of Achieving the Dream. However, rather than enumerate each of these strategies, this section focuses specifically on those professional development strategies that were explicitly linked to colleges' direct strategies under the initiative. ${ }^{19}$

\footnotetext{
${ }^{18}$ Zachry and Coghlan (2010).

${ }^{19}$ Other types of professional development are discussed in Chapter 3 (in reference to training in data analysis) and Chapter 4 (in reference to broad engagement).
} 


\section{Box 5.3}

\section{Types of Professional Development Strategies Implemented Under the Auspices of Achieving the Dream}

\section{One-Time Events on Campus}

- Campus-wide in-services and retreats focused on student success

- Guest speakers with expertise in specific strategies or institutional reforms

\section{Conferences}

- Achieving the Dream Strategy Institutes

- State and regional community college conferences

- Conferences devoted to developmental instruction or to specific subject areas

- General funding for faculty and staff to pursue conferences of interest

\section{Other Travel Opportunities}

- Visits to other colleges to learn about key strategies and accomplishments

- Evergreen Institute for faculty and staff participating in learning communities ${ }^{\mathrm{a}}$

\section{Workshops}

- Sporadic training on select pedagogical approaches

- Weekly lunch events for faculty and staff

- Customer service and diversity training for student services staff

- Advising workshops, particularly for faculty

- Training for faculty and staff in data collection, analysis, or usage ${ }^{b}$

\section{Orientation Programs}

- Student success-focused orientation events for new faculty and staff

\section{Ongoing Development Series}

- Ongoing training related to specific direct strategies or instructional techniques

- Train-the-trainer models for self-perpetuating professional development

- Professional development centers hosting ongoing training series

- Intensive leadership development programs and academies 


\section{Box 5.3 (continued)}

\section{Support for Faculty Research}

- Mini-grants for independent classroom research projects

- Data analysis training for pockets of interested faculty ${ }^{\mathrm{b}}$

\section{Print and Electronic Resources}

- Resource centers with information about effective approaches to serving students

- Webinars and podcasts on specific topics of interest

- Faculty handbooks

SOURCE: Information collected from faculty, staff, and administrators during two rounds of implementation visits across all 26 Round 1 colleges, cross-referenced against intervention reports submitted by colleges to the Achieving the Dream partners.

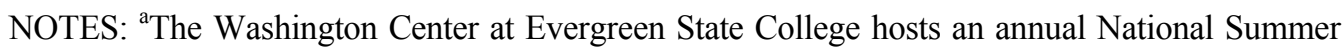
Institute on learning communities, drawing on research and practitioner experience to help colleges initiate or improve upon their learning communities programs.

${ }^{b}$ Professional development related to data analysis and usage is addressed in Chapter 3.

\section{Professional Development Supporting Direct Strategies}

Over one-third of all professional development strategies under Achieving the Dream were designed to improve the implementation of colleges' direct interventions. For example, the majority of those 15 colleges that implemented learning communities also reported some form of accompanying training for faculty and staff. Professional development related to advising, related to advising, instructional techniques, curricular reform, and tutoring was also reported at a number of colleges. Some colleges sent faculty and staff to off-campus training events, such as the multi-day learning community institute at Evergreen State College. Others drew upon the expertise of their peers, funding teams of faculty and staff to visit other institutions that had excelled in the implementation of a particular strategy. For example, in preparation for restructuring its own advising system, Coastal Bend College sent members of its advising task force to learn about the models being employed at other institutions. Other colleges took similar approaches to empower cadres of faculty and staff to become experts in a particular strategy, with the expectation that they would share their knowledge and enthusiasm with other faculty and staff upon their return. 
In addition to off-site visits, on-campus "train the trainer" models were employed at a handful of the Round 1 colleges. One prominent example of this approach was at Patrick Henry Community College, which began by funding a small group of faculty to become certified "collaborative learning" trainers who could lead professional development for their peers on campus. This model was reinforced by small stipends provided to all faculty, both full time and adjunct, who were willing to go through an intensive professional development program. Through this approach, Patrick Henry has now provided collaborative learning training to 80 percent of its faculty. Furthermore, the college has developed a self-sustaining training center called the Southern Center on Active Learning Excellence, or SCALE - to extend collaborative learning training to faculty from community colleges across the state and beyond (described in more detail in Chapter 6).

In sum, the relative popularity of strategy-specific professional development reflects a promising trend: college leaders sought to leverage faculty and staff training in order to fortify the implementation of their direct strategies. Not all colleges pursued this type of alignment, nor were most direct interventions associated with specialized professional development. However, the synergy that emerged between professional development and direct strategy implementation at many colleges suggests that college leaders recognized the importance of training personnel as a crucial step in improving programs and services.

\section{Recipients of Professional Development}

Professional development under Achieving the Dream tended to be fairly evenly distributed between strategies that were designed to reach a broad swath of campus personnel including both faculty and staff - and strategies that were targeted specifically to faculty members. Many efforts in the latter category were focused specifically on subgroups of faculty members, such as those in a particular academic department or those teaching developmental education courses. However, in keeping with discussions throughout this report, professional development reaching adjunct faculty was noticeably rare. Furthermore, only a handful of professional development strategies were targeted specifically and exclusively to student services staff. This finding holds in spite of the fact that student support service interventions made up nearly half of all direct strategies implemented at the Round 1 colleges.

\section{Strategies Oriented Toward External Stakeholders}

The final category of strategies presented in this chapter comprises colleges' efforts to engage external stakeholders in their student success agendas. (See Box 5.4 for examples.) While less than half of the Round 1 colleges reported strategies in this area, a couple of colleges had four or five strategies that were focused on external stakeholders. A significant majority of external stakeholder strategies were directed toward strengthening colleges' relationships with 


\section{Box 5.4}

\section{Types of Externally Oriented Strategies Implemented Under the Auspices of Achieving the Dream}

\section{Collaboration with High Schools}

- Forums for dialogue between college and high school personnel

- Cross-institutional task forces focused on articulation and alignment

- Dual enrollment programs and "early college" high schools

- Early placement testing in "feeder" high schools

\section{Engagement of Community Members in Efforts to Promote Equity and Reduce Achievement Gaps}

- Community conversations focused on promoting success among disadvantaged students

- Community input into strategic planning

- Relationship-building between people of color in the community and students

\section{Communication with Parents and Family Members}

- Parent/family orientation programs, including information about academics and financial aid

SOURCE: Information collected from faculty, staff, and administrators during two rounds of implementation visits across all 26 Round 1 colleges, cross-referenced against intervention reports submitted by colleges to the Achieving the Dream partners.

local school districts. Several of the Round 1 colleges used their participation in Achieving the Dream as a platform to initiate conversations with high school administrators about how to help students make the difficult transition into community college. At a subset of these colleges, cross-institutional conversations led to the subsequent implementation of targeted interventions within feeder school districts, ${ }^{20}$ including dual enrollment programs and early placement testing for high school students. Where external engagement efforts were not focused on alignment with high schools, some sought to increase community support for their efforts to narrow

${ }^{20}$ "Feeder" school districts are those K-12 school districts that are located near a community college. As a result, students from these schools often "feed into" the community college population. 
achievement gaps across racial and ethnic subgroups of students. For example, a handful of colleges hosted community discussions centered on academic success among students of color.

\section{Colleges' Use of Data to Inform Strategy Development and Refinement}

During their initial year of exploration and planning, Achieving the Dream colleges are expected to select intervention strategies based on their analyses of student outcomes data. The ideal is that colleges adopt strategies that show promise of addressing priority problems and narrowing achievement gaps, and that they draw upon available research to develop wellinformed plans for implementation. Furthermore, once these strategies have been piloted and evaluated (see Chapter 3 for a discussion of strategy evaluation), colleges are expected to make informed decisions about their continuation, refining and scaling up those strategies that yield promising outcomes while improving or eliminating those that do not. The following discussion reveals that the Round 1 colleges made good strides in being more deliberative in their strategy development, but most still have work ahead of them to fully utilize data to make decisions about these interventions.

\section{Data and Strategy Development}

MDRC's baseline research in spring 2006, during the Round 1 colleges' first year of implementation following their planning year, revealed that colleges had mixed success using data to develop strategies. On the one hand, they tended to honor the spirit of Achieving the Dream by reflecting broadly on priority problems in student performance. About half of the Round 1 colleges conducted some form of review of their longitudinal student data to identify priority areas for reform, and a majority drew from qualitative focus group data to home in on students' perceived barriers to success. ${ }^{21}$ Furthermore, as illustrated by the high proportion of strategies that were targeted intentionally toward developmental education students and firstyear students, colleges frequently chose broadly defined focus areas for their strategies that related in some way to the problems they identified.

On the other hand, only about one-third of the colleges were able to draw direct ties between their analysis of outcomes data and their selection of specific strategies at baseline. This finding is not surprising in light of the fact that most of the Round 1 colleges were still very early in their development of a culture of evidence when they began their planning years in fall $2004 .^{22}$ They generally did not have the data capacity to undertake quantitative analyses that

\footnotetext{
${ }^{21}$ Brock et al. (2007).

${ }^{22}$ As cited in Chapter 3, only 8 of the original 27 colleges had the data capacity needed to develop a culture of evidence when they began in Achieving the Dream.
} 
would be sufficiently sophisticated and specialized to yield meaningful information for strategy selection. Instead, a few colleges conducted literature reviews during their planning year, but they were confronted with a paucity of experimental research documenting effective intervention strategies at community colleges. ${ }^{23}$ The result was that much of the Round 1 colleges' early strategy selection was based on qualitative knowledge of "best practices" gleaned from Achieving the Dream conferences, as well as ideas for intervention strategies that predated colleges' participation in the initiative. ${ }^{24}$ In addition, as presented in the discussions of conference attendance and professional development in Chapter 4 and this chapter, many colleges relied upon the faculty and staff who were charged with leading their interventions to gather knowledge about how to design and implement them. This knowledge generally came from the Strategy Institutes, site visits to other colleges, and strategy-specific conferences and trainings.

\section{Data and Strategy Refinement}

By spring 2009, over one-third of the Round 1 colleges were making effective use of student outcomes data to refine strategies. These colleges tended to be above average in their institutional research capacities and in the strength of their strategy evaluations, both of which facilitated their efforts to gather reliable, strategy-specific data that could be used to improve their interventions. For example, one college developed a formal system in which task forces continuously reviewed data and made improvements to select strategies. Another achieved a similar process of continuous, data-based improvements through its evaluation of a new student orientation program. After distributing surveys during the pilot year of this strategy, college personnel responded to student feedback by integrating registration activities into the orientation sessions. They subsequently expanded and mandated this program based on promising patterns of persistence among orientation attendees. A third example of applied strategy evaluation occurred when a supplemental instruction program was refined and expanded based on promising findings from a simple comparison evaluation.

Though some colleges had notable accomplishments in strategy evaluation and refinement - which they attributed in large part to their participation in Achieving the Dream most still demonstrated significant room for improvement. Half of the Round 1 colleges made some strategic use of data but fell short in the consistency and rigor of their data usage. For example, few reported making decisions about strategy scale-up that were explicitly guided by their evaluations. Furthermore, a small handful of colleges showed little or no evidence of

\footnotetext{
${ }^{23}$ Scrivener and Weiss (2009), p. ix. It was this need for high-quality evidence about strategy effectiveness that motivated MDRC's four random assignment studies under Achieving the Dream. Unfortunately, though, the results of these studies were not available to the Round 1 colleges during their early years of participation in the initiative.

${ }^{24}$ Brock et al. (2007).
} 
applying their evaluation results to strategy refinements, which is not surprising given that all of them continued to struggle with the evaluation process itself (as discussed at greater length in Chapter 3).

\section{Summary}

Colleges can expect real changes in student outcomes only when they extend meaningfully improved programs and services to significant numbers of students. In other words, a strategy will make an observable impact on institutional performance only if it (1) raises academic outcomes among the students who are served, and (2) reaches enough students to "move the needle" on collegewide measures.

The analysis in this chapter reveals that colleges implemented a large number of strategies representing an enormous investment of time and work by college personnel — an average of seven strategies at each college and a total of more than 200 strategies at all 26 colleges. They also made noteworthy progress toward scale-up, as nearly all succeeded in expanding at least one direct strategy to reach at least 25 percent of its intended target population. However, a majority of strategies across the Round 1 colleges remained small in scale, particularly when they involved the kind of intensive contact that might be expected to meaningfully influence students' performance. The result is that the benefits of promising interventions were frequently extended only to small pockets of students.

The difficulty that colleges experienced in scaling up strategies raises two important questions for the initiative. First, would Achieving the Dream institutions be better served if they aimed to implement fewer strategies? The Achieving the Dream model encourages colleges to pilot new ideas before evaluating and selecting those that prove to be most effective. However, some colleges may have overextended themselves in their planning stages, making it difficult for them to improve and expand even their most promising interventions. In the words of one Round 1 college president, "Part of the reason we have not accomplished as much as we could is that from the beginning, we set out to do too many things." The college in question made important progress in implementing over a dozen direct strategies for policy change and professional development, but even those strategies represented only a fraction of the vast number of interventions it had envisioned under Achieving the Dream. Overreaching was a common experience among the Round 1 colleges, with many that were unable to continue with all of their planned strategies throughout their participation in the initiative. They found that both staffing and funding were stretched too thin across the multitude of interventions they wanted to pursue.

The second question is focused not on colleges' approach, but rather on the initiative's

model itself: how can the Achieving the Dream partners help colleges to identify effective 
strategies that can be scaled up at low cost, or else to locate supplemental funding for scale-up? The level of funding provided by the initiative was instrumental in jump-starting colleges' strategic work, but it was rarely sufficient to bring their ideas to scale. It will be important for the initiative partners and colleges to work together to identify practical approaches and funding streams to support this work.

In conclusion, the colleges' challenges with strategy scale-up underline the manifold demands of Achieving the Dream's theory of improvement. While the Round 1 colleges have made important advances in strategy development and implementation, their struggles with scale-up have important implications for their ability to make headway on the institutional performance measures presented in Chapter 8 . 


\section{Chapter 6}

\section{Establishing a Culture of Continuous Improvement}

While strengthening their leadership, data analysis, engagement, and strategy development can provide important levers for improving students' success, colleges' ability to institutionalize such practices is key to creating lasting change. Encapsulating Achieving the Dream's fifth step of the institutional improvement process (see Figure 1.2 in Chapter 1), establishing a culture of continuous improvement focuses on helping colleges develop strong management and accountability systems to support their multiple efforts to improve students' achievement. In the view of Achieving the Dream, these systems include standing committees to monitor colleges' improvement work and processes for making policy and planning decisions based on evidence of students' achievement (see Box 6.1). Colleges are expected to draft and implement a strong strategic plan, which will guide their vision for improving student success and set specific benchmarks for monitoring their improvement. The initiative also encourages colleges to integrate their student success work with other institutional efforts such as fund-raising, accreditation, and budgetary allocations to create more systemic processes for increasing students' achievement. Finally, Achieving the Dream encourages colleges to invest in improving the skills of their faculty and staff through professional development opportunities that reinforce their efforts to strengthen students' performance.

From Achieving the Dream's perspective, it is this centralization of the change agenda that brings a college's efforts to increase student achievement to full fruition. While other steps in the improvement process allow colleges to revise individual practices and programs, this final step pushes colleges to develop an integrated system for supporting and managing these changes institutionwide. This chapter analyzes how successful the 26 Round 1 colleges were at developing such systems and establishing an organizational process to support the integration of their vision throughout the college.

Overall, the implementation findings reveal that the majority of Round 1 colleges had at least some institutional systems in place that monitored and used data on student outcomes, although the strength of those systems varied across schools. A number of colleges used at least some form of data analysis in their strategic planning and budgeting processes, and many tied their external grants and accreditation activities to their work under Achieving the Dream. Additionally, while the extent of their reach and influence varied, a number of colleges had task forces or committees that monitored their efforts to improve student outcomes. Finally, nearly all of the Round 1 colleges provided professional development activities to their faculty and staff, with just over half providing more intensive professional development services to promote their faculty and staff skill-building. 


\section{Box 6.1}

\section{Principles and Practices for Increasing Student Success Through Institutional Improvement: Practices Associated with Principle 4, Systemic Institutional Improvement}

\section{Institutional Management}

- College has established a strategic planning process that relies on data to set goals for student success and to measure goal attainment.

- Plans for a given year are driven by a limited set of strategic priorities that have a focus on student success.

- College regularly evaluates its academic programs and student services to determine how well they promote student success and how they can be improved.

- Decisions about budget allocations are based on evidence of program effectiveness and linked to plans to increase student success rates.

- College uses external grant funds strategically to support systemic efforts to improve outcomes for students broadly, not just for isolated projects that benefit small numbers of students.

- College works actively to enlarge and sustain pilot programs or practices that prove to be effective.

- Student success agenda is integrated with ongoing accreditation activity, reviews, and self-study.

\section{Organization}

- College has a standing committee or committees that are responsible for guiding and monitoring efforts to improve student outcomes.

- Major meetings, organizational units, and work groups focus regularly on the student success agenda.

\section{Professional Development}

- College offers faculty and staff professional development opportunities that reinforce efforts to improve student success and close achievement gaps.

- College's induction and orientation activities for new faculty and staff, including adjunct and contingent faculty, foster a commitment to student success.

- College provides training to faculty and staff on using data and research to improve programs and services.

SOURCE: Field Guide for Improving Student Success (2009), from the Achieving the Dream: Community Colleges Count initiative. Available online at www.achievingthedream.org/docs/Field_Guide_for_Improving_Student_Success.pdf. 


\section{Colleges' Development of a Systemic Institutional Improvement Process}

Key to Achieving the Dream's vision for continuous improvement is colleges' establishment of strategic planning and management systems to monitor and coordinate their student success efforts (see Box 6.1). In order to institutionalize their earlier efforts, colleges are expected to develop a number of committees, task forces, and policies aimed at strengthening their reforms and making their changes more concrete. For example, colleges are expected to develop standing committees that guide their work toward improving student outcomes, as well as a strategic planning process that uses data to set goals for students' achievement and measure their progress. As part of this process, colleges are asked to evaluate their programs and services regularly to determine how they can be improved and to make budget allocations to support those policies and practices that are most beneficial for increasing students' success.

As noted earlier, though Achieving the Dream has codified a number of its practices and supports, the Round 1 colleges began their work while the initiative was still under development. Thus, although Box 6.1 emphasizes a number of practices that colleges are expected to emulate, those practices were presented in this iterative form only during the final years of the Round 1 colleges' implementation. Therefore, while this chapter summarizes the Round 1 colleges' progress with those tasks, it provides a look (like the chapters before it) at the initiative's early influence as it was still being developed.

\section{Strategic Planning}

Developing a strong strategic plan that sets clear goals for institutions' reforms and benchmarks for measuring their progress is a key element of Achieving the Dream's vision for institutionalizing colleges' improvement efforts. Nearly half of the Round 1 colleges had a strong strategic plan that clearly used data to set goals for student success and allowed colleges to measure their attainment of those goals (see Figure 6.1). Many of these colleges also developed strong mechanisms for communicating their goals to the college community. For instance, a number of schools created institutional scorecards that delineated particular student achievement goals (such as targets for student persistence or course pass rates), which the college then used to regularly track their progress. Several also had faculty and staff play an active role in defining the colleges' goals each year, either through an integrated committee system that made recommendations to the higher-level planning committee or by having faculty submit recommendations for new programs and policies each year. These efforts helped publicize the colleges' commitment to improve students' achievement while also integrating the larger campus community into this work.

A little less than half of the Round 1 colleges also had partially developed strategic planning systems in place. These systems tended to be less well articulated, and they monitored 


\section{Achieving the Dream: Community Colleges Count}

Figure 6.1

\section{Aspects of Systemic Institutional Improvement Processes in Place at the Achieving the Dream Round 1 Colleges, Spring 2009}

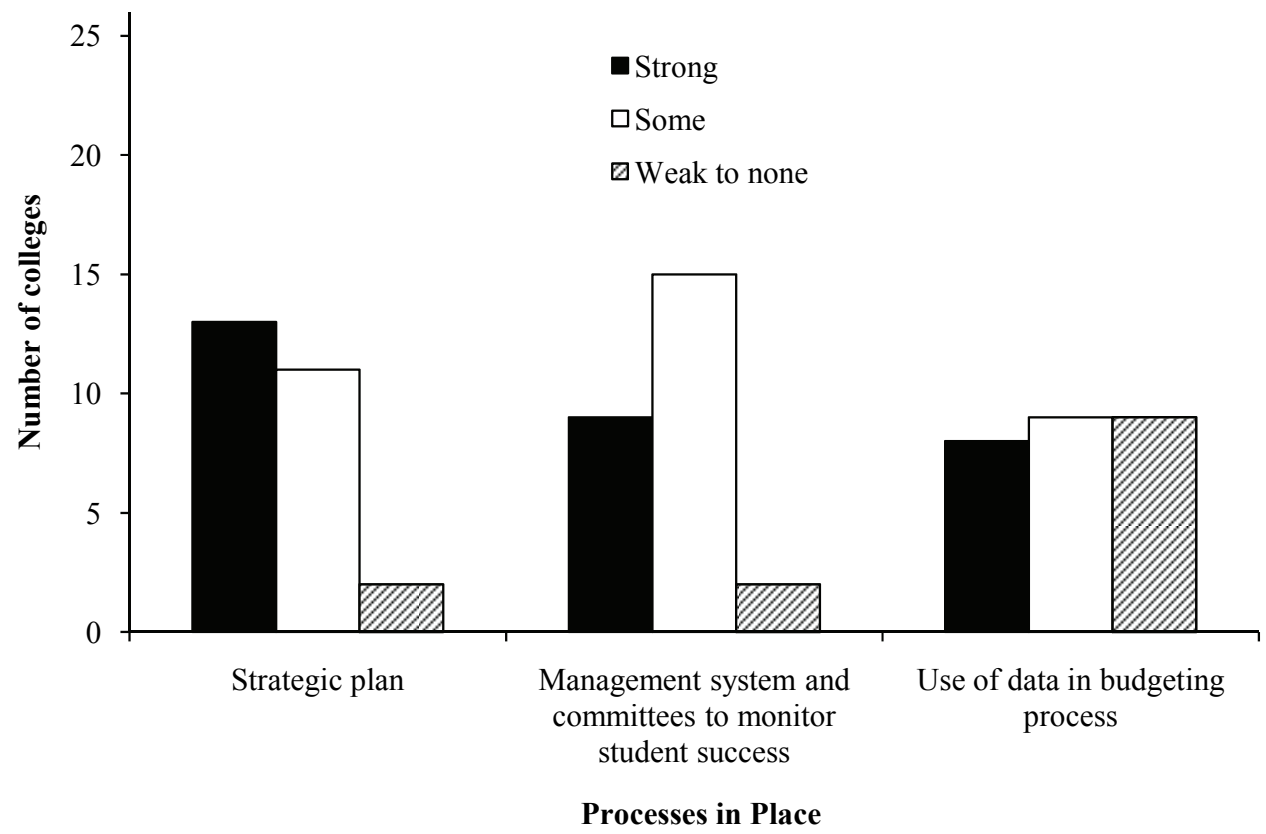

SOURCE: Information collected from faculty, staff, and administrators during two rounds of implementation research across all 26 Round 1 colleges, cross-referenced against reports submitted by college representatives, Achieving the Dream coaches, and data facilitators.

colleges' progress against specific standards for student success less frequently than those with a strong strategic plan. For instance, some colleges had general goals, such as improving developmental education, but had not yet attached specific achievement benchmarks to those goals. Others did not have well developed data and evaluation processes in place by which to set specific targets for student success and measure their progress. Additionally, most of these colleges tended to involve higher-level administrators in their strategic planning, and involved faculty and staff less often in the process. Only two colleges had no clear strategic plan in place, primarily because of a high level of administrator turnover. These findings reveal that most Round 1 colleges had made important strides in developing an overall plan to monitor their institutional progress, even if a majority of colleges needed to strengthen their efforts further. 


\section{Organization and Management of Student Success Efforts}

In addition to creating an institutionalized plan for improving students' achievement, colleges in Achieving the Dream were expected to develop mechanisms for carrying out that plan. In particular, the initiative argued that colleges should develop committees and task forces to oversee their improvement efforts and make decisions about resource allocations that would support their reform work (see Box 6.1). As the initiative had hoped, nearly all of the Round 1 colleges had either existing or newly developed committees tasked with monitoring their efforts to improve students' achievement. In fact, findings from the Achieving the Dream cost study, which highlighted the investments of five Round 1 colleges in the initiative, reveal that colleges generally invested heavily in their broad institutional reform process (see Box 6.2). Committee work, in particular, tended to be a key driver of costs. ${ }^{1}$

Just over one-third of the Round 1 colleges had particularly strong management systems in place, marked by a sophisticated committee system (as shown in the second set of bars in Figure 6.1), which involved numerous faculty and staff at the college and allowed these individuals considerable leverage in the colleges' decision-making. In general, each of these schools tended to have several lower-level committees that were charged with monitoring specific aspects of the success agenda, such as tracking a subset of the college's strategies or monitoring the college's overall institutional improvement. These committees then made specific programming or policy recommendations to each college's executive committee and thus played a substantial role in moving the college's agenda forward. Each college's higherlevel administrative staff also tended to have standing roles in these committees and vice versa (for example, faculty on the executive council) so that ideas and recommendations could be translated easily across these different groups.

About 60 percent of the Round 1 colleges had more limited strategic management systems in place. Most of the schools had at least one committee that monitored one or more aspects of their student success agenda, such as improving developmental education or tracking the success of one or more of their strategies. However, unlike the schools with strong management systems, these schools tended not to have an overarching network of committees that brought these ideas together, leaving many of these small management groups out of the institution's broader decision-making process. Similarly, most of these schools did not have committees that

used data regularly to make decisions about programming, and even fewer had functioning

${ }^{1}$ Zachry and Coghlan (2010). 
Box 6.2

\section{The Costs of Undertaking Institutional Reform}

Improving colleges' commitment to student success, data analysis, and broad engagement can provide an important impetus for increased student achievement. However, substantial costs may also be incurred in pursuit of these endeavors. In 2010, MDRC published a case study of the investments that five colleges made in Achieving the Dream's institutional improvement process. Through an analysis of these schools' expenses over their five-year participation in the initiative, this study revealed that the colleges took Achieving the Dream's recommendations seriously and made substantial investments in their institutional research, leadership, and strategies. In addition, it revealed that the key principles of Achieving the Dream were consistent drivers of colleges' overall reform expenses.

Colleges' activities and expenditures have particular relevance for considering how policymakers might support these schools' continued improvement. Summarized below are some key findings that provide a context for colleges' expenditures on institutional reform.

- The five colleges spent an average of $\$ 6.3$ million on their broad institutional reform process. While these monies represented less than 5 percent of their overall institutional revenues, they reflect the substantial efforts that colleges made to improve their institutions. In general, colleges tended to support much of their work through the reallocation of existing employee time. These findings reveal that colleges can support many of their reforms internally; however, such choices may present opportunity costs as colleges reassign faculty and staff to new positions.

- The grant of $\$ 450,000$ that each college received from Lumina provided an important impetus for change at all five colleges and was used to leverage investments of their own funds and external grants. While colleges supported much of their work internally, the flexible monies provided by Lumina helped them invest in important aspects of their work, most notably professional development. However, colleges spent significantly more in implementing their changes, using their own staff resources, internal funds, and external grants to continue their work.

- Investments across the five colleges revealed that heavier spending is likely to occur later in colleges' institutional improvement process. Colleges tended to spend few funds early in their institutional reform process, instead investing most of their monies in the final few years of their implementation of Achieving the Dream. Such findings reveal that colleges' scale-up of their institutional changes requires additional resources and careful planning.

- Committee work and professional development tended to be key drivers of expenditures in leadership management at these five schools, while institutional research costs tended to be driven by data analysis and staffing. Colleges that focused on faculty and staff more heavily also tended to have higher levels of spending. This finding reveals that efforts to broadly engage faculty and staff also come with a significant price tag and should be considered carefully in colleges' reform efforts.

SOURCE: Zachry and Coghlan (2010). 
data teams to analyze program outcomes on a regular basis. ${ }^{2}$ Leadership turnover also seemed to stall the decision-making process at a number of these schools. Indeed, frequent turnover in leadership was a substantial factor at the two colleges that lacked real committee oversight of their student success efforts.

Therefore, in addition to developing strategic planning systems, most Round 1 colleges had mechanisms in place for bringing these plans to fruition. However, the majority of Round 1 schools still needed to establish connections among the numerous, individualized task forces that were monitoring their efforts, as this work had not yet become the fully functioning system that the initiative had envisioned.

\section{Use of Data in Budgeting}

As part of their strategic management systems, colleges participating in Achieving the Dream were also expected to use the findings from their data analyses and evaluations to make decisions about programmatic funding (Box 6.1). Ideally, the initiative hoped that colleges would use this research to scale up practices that proved to be most promising while diverting funds away from programs that showed little effect on students' achievement. Findings from the implementation research at the 26 Round 1 colleges revealed that nearly 60 percent of them used data to at least a moderate degree when making decisions about programming and policies (see the third set of bars in Figure 6.1). Just over 30 percent of the Round 1 colleges had excelled at this work, developing strong links between their budget allocations process and their larger institutional decision-making, often as part of their strategic plan. For instance, Hillsborough Community College established a sophisticated online strategic planning process requiring each academic area to set measureable goals and provide evidence of students' achievement to support their budget requests. Many other colleges with evidence-based budgeting systems had similar leanings, regularly using data on improved student achievement to make higherlevel decisions about programming and policy.

Another 35 percent of the Round 1 colleges also used some aspects of data analysis in their budgeting process; however, their use of evidence tended to be limited to a particular set of programs or strategies rather than being integrated with the colleges' larger financial decisionmaking. For instance, some colleges made decisions about funding special projects or strategies based on evidence of student success, but these decisions were generally divorced from the colleges' overall budgeting process. In many cases, colleges had not yet developed their data capacity enough to be able to make regular decisions based on evidence of students' achieve-

\footnotetext{
${ }^{2}$ Achieving the Dream recommends that all colleges participating in the initiative develop a data team, consisting of institutional researchers, administrators, faculty, and staff, who are tasked with collecting and analyzing data on student outcomes.
} 
ment. Finally, a few colleges had a high level of staff turnover, making it difficult for them to establish more systematic procedures for budgetary decision-making.

Just over one-third of the Round 1 colleges rarely used evidence of student success in their budgeting processes. The primary limitation for most of these schools was difficulty with data analysis, as many had limited institutional research departments that had trouble managing the colleges' multiple data tasks. These issues made it especially challenging for them to adeptly use data on students' achievement to guide their budgeting process.

Therefore, while many institutions had made important strides in connecting their budgeting to program effectiveness, most Round 1 schools still had only limited mechanisms in place to bring promising programs to scale. These findings, together with the challenges that colleges had with evaluating and scaling up their strategies, suggest that colleges encountered real difficulties in establishing effective mechanisms for validating program effectiveness that could be used to guide budgetary decisions. Given these challenges, Achieving the Dream may need to identify the key roadblocks that inhibit colleges' ability to link these efforts and provide additional supports to help schools overcome these difficulties.

\section{Integration with Other Institutional Activities}

As part of colleges' push to establish their reform efforts institutionwide, the initiative has also encouraged participating schools to integrate their Achieving the Dream work with other institutional efforts, such as accreditation or endeavors to secure external grants (Box 6.1). Nearly all of the Round 1 colleges were successful in bringing together these different strands of their work. For instance, a majority of the Round 1 schools tied their Achieving the Dream work in with their accreditation activities. In many cases, colleges used Achieving the Dream as a framework for establishing the benchmarks and accountability systems that their accreditation agencies required for their continued support. For many schools, this work centered around a particular Achieving the Dream strategy or activity, which the college sought to further expand and monitor as part of its accreditation plans. For instance, Paul D. Camp Community College sought to expand its Achieving the Dream work on "distance learning" (courses taken online) as it renewed its accreditation through the Southern Association of Colleges and Schools (SACS). Similarly, Houston Community College focused on increasing its use of data in institutional decision-making when developing its proposal for SACS approval.

In addition to their accreditation work, virtually all of the Round 1 colleges were also successful in obtaining external grants that they then used to support the student success endeavors that they had started under Achieving the Dream. Most colleges tended to have one or more federal grants that supported their efforts, most commonly Title III, Title V, and TRIO grants. However, a number of schools also had grants from other sources, such as foundations 
or local or state governments. Many of these schools used this supplemental funding to further scale up their Achieving the Dream strategies or to sustain other practices that were seen as effective in improving students' success.

These findings underscore how colleges' Achieving the Dream efforts can be used to interconnect their diverse strategies for institutional improvement. While some colleges may have struggled with other aspects of systemic reform, their ability to integrate accreditation and grant-seeking activities with their Achieving the Dream planning and activities reveals a promising mechanism for furthering colleges' institutionalization of their Achieving the Dream work.

\section{Professional Development}

In order to support the continuous improvement of faculty and staff knowledge, Achieving the Dream also recommends that colleges offer ample professional development opportunities to hone and increase the skills of faculty and staff (Box 6.1). In particular, the initiative hopes that participating colleges will offer professional development activities that reinforce their efforts to increase student success and help them learn how to use data effectively to improve programs and services.

Overall, most of the Round 1 colleges took seriously the call to provide training to their faculty and staff. As noted in Chapter 5, all of the colleges provided at least some sort of professional development for their faculty and staff, with those activities being a key focus for half of the colleges. Similarly, findings from the Achieving the Dream cost study revealed that professional development was a key area of expenditure in the five case study colleges (see Box 6.2). This was particularly the case for colleges that involved large numbers of faculty and staff in such activities. ${ }^{3}$

At schools with more intensive professional developmental offerings, these opportunities tended to be directed more concretely toward the colleges' student success efforts and provided continuous support for faculty and staff growth throughout the school year. Typically, these schools established semester- or year-long growth plans (as described for Tallahassee and Central New Mexico community colleges in Box. 6.3), on-site learning centers for faculty and staff, or ongoing training related to specific strategies or interventions (as described for Patrick Henry's program in Box 6.3). While these schools also provided other, more sporadic opportunities for professional growth, such as one-time workshops or speaker presentations, the key practice that set these schools apart was their focus on providing continuous support to their

\footnotetext{
${ }^{3}$ Zachry and Coghlan (2010).
} 


\section{Box 6.3 Intensive Professional Development}

While many colleges offered only sporadic training or workshops for faculty and staff, a number of institutions developed model programs to continuously support the development of their faculty and staff. A few of the most promising programs are highlighted here.

\section{Patrick Henry Community College}

In order to support the scale-up of its collaborative learning strategy, Patrick Henry developed an ongoing training center, called the Southern Center for Active Learning Excellence, or SCALE. SCALE provides training in collaborative learning to both full-time and part-time college faculty, including introductory training for novices as well as ongoing support for faculty who have already been trained. The center provides a number of supports to promote collaborative learning in the classroom, such as free courses for faculty and staff to learn about different elements of active learning, coaching and mentoring opportunities, examples of classroom lessons, surveys for students, and training institutes for other colleges to learn about collaborative learning. Faculty leaders direct the center and have been certified as collaborative learning trainers through the Cooperative Learning Center at the University of Minnesota. This "train-the-trainer" model allows Patrick Henry to train increasing numbers of faculty each year while controlling the costs for these services. To date, 85 percent of Patrick Henry's full-time and 60 percent of its adjunct faculty have been trained in the use of collaborative learning in the classroom.

\section{Tallahassee Community College}

Tallahassee operates a systematic, year-long professional development program for its faculty. New faculty members participate in ongoing New Faculty Seminars through the institution's Center for Teaching Excellence while seasoned faculty members are responsible for completing Professional Growth Plans, in which they list goals for increasing student success inside the classroom and propose methods for building their own skills and knowledge to make these targets a reality. In addition, faculty members monitor their students' performance outcomes, examine whether and how their target goals have been met, and provide justification for their work at the end of each year. Though not always directly related to its work in Achieving the Dream, Tallahassee's ongoing system for faculty development represents a key avenue for colleges' further development of their faculty's skills and integration of new reforms.

\section{Central New Mexico Community College}

Like Tallahassee, Central New Mexico also provides ongoing support to its faculty, through a semester-long instructor development course. This course offers faculty an opportunity to focus on topics such as student success, classroom management, and learning styles. It teaches faculty members how to recognize students who have disengaged and how to apply learning techniques to reintegrate them into the classroom. In addition, this semester-long course familiarizes faculty with institutional resources that are available to support their instruction, thereby helping new faculty to become acquainted with the college. While this professional development course tended to be separate from the college's student success initiatives, it could easily be modeled to provide more sustained training and reflection for faculty as part of colleges' implementation of new reforms. 
faculty and staff to learn a new skill, pedagogy, or practice that was directly linked with their efforts to improve student achievement.

At the remaining half of Round 1 colleges, professional development tended to be more sporadic. While these colleges had some professional development opportunities, they tended to be limited to a small subset of strategies, sporadic speakers, or occasional visits to conferences or workshops. However, only a few Round 1 colleges did not see professional development as an important priority. The reasons for their decreased attention tended to center around budget issues or a lack of focus on their Achieving the Dream work in general.

\section{The Influence of Achieving the Dream on Colleges' Systemic Institutional Improvement Processes}

Achieving the Dream had an important influence on most of the Round 1 colleges' systemic institutional improvement processes, with the initiative influencing over 80 percent of these schools to at least a moderate degree (see Figure 6.2). For some schools, Achieving the Dream brought about a strong shift in focus, moving them more toward an evidence-based, student success-driven management process. Achieving the Dream also helped a number of colleges refine their systems for monitoring student success, such as developing institutional scorecards for measuring progress toward their institutional goals or further focusing their strategic planning on evidence-based practices for increasing student success. Additionally, a number of colleges attributed their revised committee structures to their work in Achieving the Dream. Indeed, only four colleges felt no real effects from Achieving the Dream on their strategic planning and management. These schools tended to have weaker strategic management systems in general, and were continuing to work at developing more coordinated systems to oversee their various projects.

Similarly, over two-thirds of the Round 1 colleges noted that they devoted a significant proportion of their Achieving the Dream funding to their professional development activities. Many reported that their Achieving the Dream grants were integral to this work, with several colleges using this grant as their central mechanism for funding professional development. Those that depended most heavily on their Achieving the Dream grants tended to be smaller colleges with limited financial supports. While larger colleges also found the grant helpful, they were also able to use their institutional funds to support faculty and staff professional development.

While Achieving the Dream had an important influence on nearly all of the Round 1 colleges, the initiative was only one of a multitude of forces pushing many colleges toward more systematic management and monitoring. For instance, a majority of schools discussed their accreditation process or their presidents' own vision as driving forces behind their management and planning systems. Others noted that they had made only modest changes to their 


\section{Achieving the Dream: Community Colleges Count}

Figure 6.2

\section{Influence of Achieving the Dream on Systemic Institutional Improvement Processes in Round 1 Colleges}

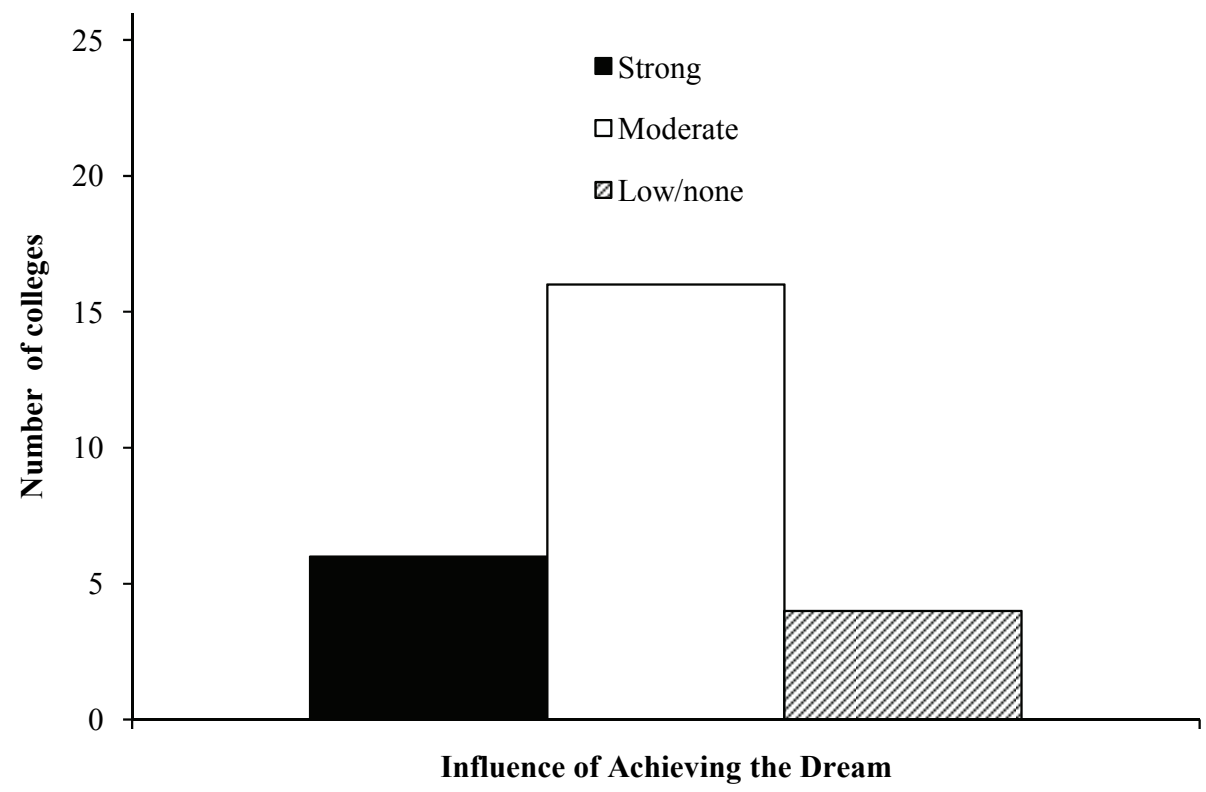

SOURCE: Information collected from faculty, staff, and administrators during two rounds of implementation research across all 26 Round 1 colleges, cross-referenced against reports submitted by college representatives, Achieving the Dream coaches, and data facilitators.

management structures as a result of Achieving the Dream, reporting that some of those changes were already in progress when they began in the initiative. Such comments reveal that Achieving the Dream was one of a number of factors pushing colleges to monitor and improve their students' achievement.

\section{Summary}

Overall, the Round 1 colleges made important strides in developing more systemic efforts to increase students' achievement. A majority of the Round 1 colleges had strategic planning mechanisms in place, which established goals for their work, and had established task forces to monitor those efforts and take actionable steps to realize their goals. Similarly, most schools offered some form of professional development for their faculty and staff, and they had 
integrated their Achieving the Dream work with other institutional reform efforts, such as accreditation and fund-raising. However, these systems needed further strengthening at a number of schools, as they were limited in their development of actionable goals and benchmarks for student improvement, and in their use of data to monitor their efforts. Additionally, they had yet to effectively connect their funding strategies with evidence of program effectiveness, making it more difficult to successfully scale up promising programmatic interventions. Such findings reveal that Achieving the Dream schools may need additional time to institutionalize their reform practices.

Given these challenges, Achieving the Dream might need to give participating colleges more time to fully integrate their reforms within the larger structure of the college and strengthen those capacities that may be hindering the development of more data-driven systems. As noted in previous chapters, most colleges were still heavily engaged in strategy development and learning how to evaluate the effects of their reforms on students' achievement. Similarly, a number of schools were still struggling to ramp up their institutional research capacity to meet the demands of the initiative. As such, Achieving the Dream might look toward helping colleges take on more sophisticated data analyses that would allow them to build the infrastructure to use data regularly within their strategic management and budgeting processes.

Achieving the Dream might also encourage colleges to develop more systematized professional development opportunities for their faculty and staff that support their efforts to continuously improve student achievement. While conferences and workshops may help expose faculty and staff to new ideas, more concrete efforts are needed to help these individuals bring such reforms into their everyday practice. The systems developed by Patrick Henry, Tallahassee, and Central New Mexico community colleges represent three models for providing more sustained growth and development of faculty and staff skills. Achieving the Dream might look to efforts such as these to further encourage these individuals' engagement in colleges' reforms and provide an even stronger foundation for colleges' efforts to improve students' achievement.

Finally, as colleges seek to implement these broader changes, they are also likely to spend greater amounts of institutional funds. Findings from the Achieving the Dream cost study reveal that colleges are much more likely to spend high levels of institutional funds should they seek to develop the types of intensive professional development and engagement structures recommended by the initiative. Given the likelihood that colleges will invest heavily in this work, Achieving the Dream might wish to help them consider how to balance these expenses with their other existing commitments and priorities. Providing sound advice that allows colleges to plan for their investments and consider the longer-term impact of their reforms may help these schools to sustain the changes that they are making on the ground today. 



\section{Chapter 7}

\section{Institutionalizing Change: Progress in Building a Culture of Evidence}

Colleges' ability to adopt strong leadership, data analysis, and engagement practices that are aimed at improving students' success and their ability to integrate those efforts into their institutional work are considered cornerstones of Achieving the Dream's vision for building a culture of evidence. Colleges that are able to build systems "in which data and inquiry drive broad-based institutional efforts to close achievement gaps and improve student outcomes" are considered to have excelled at these tasks. ${ }^{1}$ Thus, while the previous chapters have emphasized colleges' development of particular sets of practices, Achieving the Dream's model focuses on colleges' integration of those practices into a coherent and continuous system for institutional improvement aimed at increasing students' achievement.

Given Achieving the Dream's relentless focus on strengthening colleges' data-based decision-making, this chapter provides a concluding, summative look at the Round 1 colleges' success in building an overall culture of evidence during their five-year implementation of Achieving the Dream. The colleges' progress in building a culture of evidence is based on the strength of their implementation of each of the five steps in the initiative's continuous improvement model: (1) securing leadership commitment; (2) using data to prioritize actions; (3) engaging stakeholders; (4) implementing, evaluating, and improving intervention strategies; and (5) establishing a culture of continuous improvement. Thus, each of these factors is taken into consideration when evaluating the strength of colleges' evidence-based decision-making.

When examining colleges' overall development of a culture of evidence, the implementation research revealed that many schools had made substantial progress in building a culture of evidence during their five-year participation in Achieving the Dream. Approximately 81 percent ( 21 of 26) of the Round 1 colleges had improved their data-based decision-making by spring 2009, nearly double the number of schools that were making progress in spring 2006. Only five colleges (19 percent) continued to have major challenges implementing Achieving the Dream's model for institutional improvement, which represents an important decrease from the 15 colleges (56 percent) that were struggling in 2006. Overall, most of the Round 1 colleges made improvements in their data analyses and institutional research capacities while also developing a number of interventions to improve students' achievement. However, areas of improvement remained for a number of schools, including the broad engagement of both full-

\footnotetext{
${ }^{1}$ Achieving the Dream (2009), p. 3.
} 
time and part-time faculty and the strengthening of colleges' use of data to make broad-based decisions about institutional policies and programming.

\section{Colleges' Overall Progress in Developing a Culture of Evidence}

As noted in the previous chapters, a number of colleges made great improvements to their data analysis, faculty engagement, strategies, and strategic management practices during the course of their participation in Achieving the Dream. As a result, many also made great strides in building a culture of evidence during their five years in the initiative.

\section{Strong Colleges: Colleges with an Institutionalized Culture of Evidence}

As Table 7.1 reveals, 42 percent (11) of the Round 1 colleges had implemented most of the practices associated with a strong culture of evidence by the end of their five-year participation in Achieving the Dream. These colleges had excelled at building or further strengthening all five aspects of Achieving the Dream's institutional improvement model and (1) had strong leadership systems committed to improving student success; (2) had well-developed institutional research departments that conducted intensive, in-depth analyses of their students' achievement; (3) involved faculty, staff, students, and external stakeholders in multiple aspects of their reform agenda; (4) had well-developed strategies, with one or more strategies reaching a large proportion of their target population; and (5) had instituted multiple processes for strategic planning, program review, and professional development, and had made financial and programmatic decisions based on evidence of improved student achievement.

While each of these colleges was strong, many had begun Achieving the Dream with well-developed data analysis systems and a strong focus on improving student success. As can be seen in Table 7.1, just over half (six) of these strong colleges had exhibited these traits early on in the Achieving the Dream process. Despite this trend, a number of these schools credited the initiative with helping them develop even better systems for improving student success (see Table 7.2). For instance, Valencia Community College, which had started Achieving the Dream with a stellar institutional research department and highly engaged faculty and staff, used the initiative to catalyze its reform agenda and bring together the college's four campuses to create an institutionwide movement. Similarly, South Texas College, which began the initiative with a strong institutional research department, chose to further develop and expand its data analysis capacity, hiring three additional institutional researchers and breaking its department into smaller divisions to make it easier to share the results of data analyses throughout the school.

Achieving the Dream had a particularly dramatic influence on helping four of the remaining strong colleges build more evidence-based systems (see Table 7.2 and Box 7.1). These "star" schools began Achieving the Dream with a weak or very weak culture of evidence, with 
Achieving the Dream: Community Colleges Count

Table 7.1

\section{Culture of Evidence at Achieving the Dream Round 1 Colleges, Spring 2006 and Spring 2009}

\begin{tabular}{lrrrrr}
\hline & \multicolumn{2}{c}{ Spring 2006 } & & \multicolumn{2}{c}{ Spring 2009 } \\
\cline { 2 - 3 } \cline { 5 - 5 } Culture of Evidence Rating & $\begin{array}{r}\text { Number of } \\
\text { Round 1 Colleges }\end{array}$ & $\begin{array}{r}\text { Percentage of } \\
\text { Round 1 Colleges }\end{array}$ & $\begin{array}{r}\text { Number of } \\
\text { Round 1 Colleges }\end{array}$ & $\begin{array}{r}\text { Percentage of } \\
\text { Round 1 Colleges }\end{array}$ \\
\hline $\begin{array}{l}\text { Strong or very strong } \\
\text { culture of evidence }\end{array}$ & 6 & 23 & 11 & 42 \\
$\begin{array}{l}\text { Some culture of evidence } \\
\begin{array}{l}\text { Weak or very weak } \\
\text { culture of evidence }\end{array}\end{array}$ & 5 & 19 & 10 & 38 \\
\hline Total & 15 & 58 & 5 & 19 \\
\hline
\end{tabular}

SOURCE: Information collected from faculty, staff, and administrators during two rounds of implementation research across all 26 Round 1 colleges, cross-referenced against reports submitted by college representatives, Achieving the Dream coaches, and data facilitators.

NOTE: Percentages may not add to 100 because of rounding.

few data systems in place and less organized processes for making decisions about student success. As such, these colleges tended not to make planning, programmatic, or budgetary decisions based on evidence of what works for students, and relied instead on anecdotes or hunches when implementing reforms. However, all of these schools noted that Achieving the Dream had "made possible a...paradigm shift" that allowed them to "transform" their institutional research capabilities, "reshape" their strategic planning processes, and focus on "data that tells about student success." These colleges developed in a number of similar ways, including making strides in incorporating their faculty, staff, and other stakeholders into their student success work and focusing strongly on professional development, which helped integrate their faculty and staff into their reform agenda.

While Achieving the Dream played an important role in these colleges' development and provided some integral supports for their work, these schools seemed to focus more often on how the initiative's theory had helped them build upon the already strong passion for helping students that their faculty, staff, and administrators exhibited. Achieving the Dream data facilitators played an important role at a few of these colleges, helping them develop systemized ways of analyzing and sharing data institutionwide. Additionally, coaches and the Achieving the Dream meetings, such as the Strategy Institute, were generally viewed as "very helpful." However, what seemed to make the most difference for development at these colleges were strong, visionary leaders at multiple levels of the institution (for example, administrators as well 


\section{Achieving the Dream: Community Colleges Count}

Table 7.2

\section{Influence of Achieving the Dream on the Culture of Evidence at Round 1 Colleges and Progress Made from Spring 2006 to Spring 2009}

\begin{tabular}{lrrr}
\hline Number of Colleges & $\begin{array}{r}\text { Spring 2006 } \\
\text { Culture of } \\
\text { Evidence }\end{array}$ & $\begin{array}{r}\text { Spring 2009 } \\
\text { Culture of } \\
\text { Evidence }\end{array}$ & $\begin{array}{r}\text { Progress Made } \\
\text { from Spring 2006 } \\
\text { to Spring 2009 }\end{array}$ \\
\hline Heavy influence: $\mathbf{8}$ colleges & Strong & Very strong & +1 \\
\hline 3 colleges & Some & Strong & +1 \\
3 college & Weak & Strong & +2 \\
1 college & Very weak & Strong & +3 \\
Some influence: $\mathbf{1 1}$ colleges & Strong & Very strong & +1 \\
2 colleges & Very weak & Some & +2 \\
1 college & Weak & Some & +1 \\
6 colleges & Very weak & Weak & +1 \\
2 colleges & & & +1 \\
Little influence: 7 colleges & Strong & Very strong & +1 \\
1 college & Weak & Some & 0 \\
1 college & Some & Some & 0 \\
2 colleges & Very weak & Very weak & -1 \\
2 college & Some & Weak & \\
\hline
\end{tabular}

SOURCE: Information collected from faculty, staff, and administrators during two rounds of implementation research across all 26 Round 1 colleges, cross-referenced against reports submitted by college representatives, Achieving the Dream coaches, and data facilitators.

NOTES: While some of the colleges in the "Little influence" category made progress in developing their cultures of evidence, they did not consider Achieving the Dream to be a primary motivator for these changes.

${ }^{\text {aSpring }} 2006$ culture of evidence ratings are based on implementation findings from MDRC and CCRC's baseline report on the Round 1 Achieving the Dream colleges (Brock et al., 2007, pp. 9697).

'Progress ratings reflect changes in colleges' cultures of evidence between spring 2006 and spring 2009, as measured by movement across the following rating scale: very weak, weak, some, strong, very strong. For example, a college that received a "very weak" rating in spring 2006 and a "very strong" rating in spring 2009 would receive a progress rating of "+4," indicating that it had progressed 4 levels in the rating scale. 


\section{Box 7.1}

\section{"Star" Colleges in Achieving the Dream: Institutions that Made Solid Progress in Building a Culture of Evidence}

Four of the 26 Round 1 colleges stood out because they had a weak culture of evidence at the start of the initiative and made great strides in building up their culture over five years. These colleges made changes that set them apart from the other colleges that made less progress, including:

- Multiple senior administrators who were deeply involved in the colleges' reforms. Each college had a cadre of senior leaders, including the vice presidents of instruction and student services and the head of institutional research (IR), leading its Achieving the Dream work. Two colleges also had presidents who were very involved.

- Active IR departments that produced accessible reports on students' achievement. Each school focused sharply on increasing IR capacity by hiring new IR staff and upgrading its data management system, which allowed it to better manage multiple IR demands. Each school also produced institutional- or department-specific reports on students' success, with clearly delineated target goals for students' achievement.

- Regular evaluations of their interventions to improve student success. Each college systematically tracked its interventions, often comparing students who were participating in a particular program with nonparticipants. These findings were disseminated widely throughout the school, with a number of faculty and staff commenting on the results.

- Strong faculty and staff leaders who played an active role in leading the colleges' reforms and interventions. Each of the four colleges had strong participation from faculty and staff, who were involved in leadership and policymaking committees at their colleges and led the implementation of numerous strategies that were aimed at improving students' success.

- Integrated committee structures that allowed for regular communication among administrators, faculty, and staff. Each of the four schools developed numerous standing committees to monitor its reform efforts. These committees brought faculty, staff, and administrators together through regular communication, providing a clear and consistent voice in their colleges' larger policy- and institutional decision-making.

- Consistent attention to financial supports for strategy scale-up and numerous strategies operating at scale. Each of these colleges developed systematic ways to support broad-scale reforms, often by using federal or state grants to support the additional costs. All four colleges had strategies that were reaching substantial proportions of their remedial students or students who were in college for the first time.

- Heavy investment in professional development. Each of the four schools dedicated significant funds to training faculty and staff. 
as faculty and other staff) who were able to build well-integrated, multidimensional processes for developing and making decisions about their programs and policies. While Achieving the Dream was a "galvanizing effort" to help them focus on students' success, all of these schools used Achieving the Dream's process to actualize the existing strengths within their schools and identify the weaknesses, which they then focused on improving. Therefore, while Achieving the Dream's services were useful, a strong, broad-based effort that focused on increasing student success on the ground at these colleges was what allowed their Achieving the Dream-inspired reforms to take root.

\section{Colleges with Some Culture of Evidence}

While several colleges made outstanding progress in building a culture of evidence over their five years in Achieving the Dream, a number of other schools had also made important strides in furthering their evidence-based decision-making. As can be seen in Table 7.1, 38 percent (10) of the Round 1 colleges had instituted some of the aspects of Achieving the Dream's suggested improvement process in their schools after five years in the initiative. All had built (or started with) relatively capable institutional research departments, and most schools undertook longitudinal analyses of student outcomes and tracked the success of at least some of their student success interventions. Other stakeholders, such as faculty and staff, also reported increased awareness of student achievement or had some exposure to reports on students' success in particular interventions. Faculty and staff were also generally involved in some aspects of the reform agenda at many of these schools, most often around implementing the colleges' student success strategies, although several were also involved in larger leadership committees. Finally, most colleges had some form of strategic planning process in place, which at times used student achievement data to inform decision-making.

Although these colleges had made important strides in engaging with data, several issues hindered their ability to develop a more broad-based culture of evidence. While most had increased their institutional research departments, half of these schools still suffered from a lack of capacity to undertake analyses that are important for documenting students' progress and had challenges with managing the increased requests for student outcomes data. Colleges with very small institutional research departments, staffed with only one or two people, had a particularly difficult time getting data out to their faculty and staff, often because they were charged with conducting multiple analyses at once. ${ }^{2}$ In addition, some colleges were unable to pursue longitudinal analyses of their students' achievement because their information technology (IT) systems were limited or weak. For example, one college had no way of tracking its students' progress

\footnotetext{
${ }^{2}$ In comparison, colleges with a strong culture of evidence tended to have five or more well-trained researchers leading their data analyses.
} 
over multiple years and had no plans for developing such a system, arguing that the cost of managing this type of data warehouse was "prohibitive" for a larger institution of its size.

These colleges also faced important challenges with sustaining the leadership and momentum of their work over the course of five years. For instance, more than half of these schools faced issues with leadership turnover, which made it difficult to systematically advance their improvement agendas. Additionally, the majority of these colleges had leadership teams that either didn't share data across the campus or did not systematically use data to make programming and policy decisions. Finally, nearly all of the colleges had faculty or staff who were resistant to using student outcomes data or who were not sure how these data should affect or inform their everyday practice. Indeed, more than half of these colleges had entire academic or student services departments that were either not involved in the college's Achieving the Dream agenda or were far less involved than other personnel.

While many schools still struggled with important aspects of Achieving the Dream's model, most of them had made progress since spring 2006, with many attributing their development to their work in Achieving the Dream. As can be seen in Table 7.2, 11 out of 26 (42 percent) of the Round 1 colleges said that Achieving the Dream had some influence on their development of a culture of evidence. Some of these efforts were centered on an increase in their data capacity, through the addition of new staff, upgraded IT systems, or more sophisticated analyses of their students' achievement. However, more often Achieving the Dream had supported the colleges' implementation of student success strategies. Many of these schools noted that the grant of $\$ 450,000$ from Achieving the Dream played an important role in this process, with some of these colleges observing that the grant was one of the most important contributions Achieving the Dream made to their schools. ${ }^{3}$ Nearly all of these schools used the grant to support key aspects of their reform agendas, including the implementation of strategies, professional development for faculty and staff, and increasing their IR capacities.

While most of the colleges with some culture of evidence attributed a number of their modifications to Achieving the Dream, most also noted other factors that were important in their development. For instance, many of the schools discussed how their accreditation processes or grants other than the one provided by Achieving the Dream, such as federal Title V or TRIO grants, were the main drivers of the reforms at their colleges. Achieving the Dream was seen as "complementing" or "reinforcing" this agenda, but not necessarily as the primary inspiration behind the colleges' efforts to improve student achievement or to use data. Additionally, a few colleges said that the motivation for their reforms stemmed from an internal push to increase student achievement. Similar to colleges with a strong culture of evidence, this internal

\footnotetext{
${ }^{3}$ All of the schools that saw the grant as very important were smaller schools with fewer than 5,000 students.
} 
push came more often than not from a strong leader who had a pre-existing commitment to improving student success. Thus, while Achieving the Dream had some effect on the culture of evidence at these schools, this influence tended to be balanced with other internal or external forces pushing these institutions in this same direction.

\section{Colleges with a Weak Culture of Evidence}

Relatively few colleges were still having major problems developing a culture of evidence at their schools by the end of their demonstration phase in Achieving the Dream. As can be seen in Table 7.1, only five (19 percent) of the Round 1 colleges were still struggling to implement a number of Achieving the Dream's recommended practices by spring 2009. Very weak institutional research departments were the primary difficulty hindering most of these schools' ability to institute a broad, data-driven culture. Most of these schools did not employ an institutional researcher continuously during their time in the initiative, relying instead on outside consultants or other, less well-trained staff to fill these positions. Sometimes these challenges were the result of a poor economic situation, which kept the college from being able to attract good technical support. Some schools also had difficulty implementing Achieving the Dream across multiple campuses and providing sustained leadership to bring these disparate groups together.

Without strong institutional research capacity, most of these schools were unable to undertake even the most basic data analyses during much of their time in the initiative. For instance, most lacked sophisticated IT systems to manage large quantities of data and thus were unable to extract information on student outcomes efficiently. Perhaps as a result of these difficulties, few undertook longitudinal data analyses during their time in Achieving the Dream, with some colleges hiring outside consultants to develop and submit their data to Achieving the Dream's database. Those that did analyze longitudinal data tended to rely on the reports they received from JBL Associates, which provided schools with individual analyses of the student outcomes data they submitted to the Achieving the Dream database. Given these challenges, it is perhaps not surprising that none of these schools systematically engaged faculty and staff in data analysis, nor did they have strategic planning systems that regularly used data on students' success. Furthermore, few of these schools systematically evaluated their strategy interventions and made decisions about their improvements based on evidence of promising trends in student achievement.

The challenges facing colleges with a weak culture of evidence tended to be the result of forces outside of Achieving the Dream. For instance, all five colleges that still had a weak culture of evidence by spring 2009 had experienced a high level of turnover in their leadership and administration, making it difficult to sustain any reform efforts at their schools. Additionally, some of these schools were located in economically challenged areas, making it difficult to 
attract and pay high-quality institutional research staff. However, at times, these colleges were also limited by their interest in, engagement with, or even understanding of Achieving the Dream. For instance, a few of these schools initially misunderstood the purpose of Achieving the Dream and had focused primarily on strategy implementation. Additionally, some had faculty or staff who were resistant to using data or engaging with Achieving the Dream altogether.

While these colleges struggled with many aspects of Achieving the Dream's model, all had also seen some positive results from their involvement in the initiative. Nearly all of the schools reported that Achieving the Dream had made them more aware of the importance of data, and most had made modest strides in building up their data analysis processes. For instance, a few of these schools collected qualitative data regularly through surveys or focus groups and used the results to better understand how their students were experiencing college. Additionally, a few of the schools were focused on analyzing data (often from JBL's analyses of the Achieving the Dream database) for different student subgroups and noted how those data had informed the focus of some of their strategies. Finally, all of these schools had developed at least one strategy aimed at increased student success, and some had successfully brought those strategies to scale within their institutions.

While these schools had experienced some positive results from their participation in Achieving the Dream, important questions remained about whether they would sustain their efforts after completing the demonstration phase of the initiative. Several of these schools noted that their Achieving the Dream grants had played an important role in helping them implement their student success reforms and that they did not have a plan for how these reforms would be sustained after the grant period ended. Unfortunately, it appears that the tenuous culture of evidence at some of these schools was built upon funding from the initiative and had not been integrated fully within their institutions. Thus, it remains to be seen how much of their momentum can be sustained after this funding ends.

\section{Summary}

Many colleges made encouraging progress in further developing institutionalized systems for improving student success and improving their culture of evidence during their five years in Achieving the Dream. Most Round 1 colleges had developed systems that used data on student outcomes to help guide their planning and policy decisions. The majority of colleges also had task forces overseeing their institutional improvement efforts. Additionally, many had tied their Achieving the Dream work in with other external grants and accreditation activities to create a more wide-ranging student success effort. Finally, most colleges had devoted substantial resources to the training and professional development of their faculty and staff. 
In addition, nearly all of the Round 1 colleges strengthened their overall culture of evidence by making substantial upgrades to their data capacity and communication about students' achievement. Twenty-one ( 81 percent) of the 26 Round 1 colleges had made important progress in building a stronger culture of evidence by spring 2009, with only five colleges (19 percent) continuing to have major challenges implementing Achieving the Dream's model for institutional improvement. However, areas of improvement remained for a number of schools, including the broad engagement of both full-time and part-time faculty and the strengthening of colleges' management systems for improving student success. Additionally, few schools were using data systematically to monitor the effect of their strategies or their overall institutional performance, thus falling short of the initiative's hope for institutionalized evidence-based decision-making.

While many of the Round 1 colleges made good progress in strengthening their culture of evidence, a crucial aspect of the Achieving the Dream model is the improvement of students' achievement. The initiative expects that colleges' institutional changes and reforms will lead to improvements in overall student performance, such as students' progress through developmental education, completion of gatekeeper courses, and their persistence from term to term and year to year. Also important is whether or not colleges were able to reduce the achievement gaps among various student subgroups. The next chapter of this report turns to examining these trends in student performance and what changes can be seen across Achieving the Dream's five key indicators of student performance. 


\section{Chapter 8}

\section{Trends in Academic Performance}

The previous chapters examined how well the Round 1 colleges implemented the Achieving the Dream model for institutional improvement. The initiative expects that colleges' rigorous implementation of the five-step model that is illustrated in Chapter 1 will ultimately lead to measureable improvements in students' academic achievement. That is, the initiative anticipates that colleges' increased attention to student outcomes data and changes to policies and practices will lead in turn to measurable improvements in the rates in which students: ${ }^{1}$

1. Complete remedial or developmental courses and progress to credit-bearing courses.

2. Enroll in and complete college-level "gatekeeper" courses.

3. Complete courses, with a grade of "C" or higher. ${ }^{2}$

4. Reenroll term-to-term and year-to-year.

5. Earn certificates or degrees.

As noted in the previous chapters, Achieving the Dream helped many colleges build a stronger foundation for accomplishing these goals. College leaders tended to have a strong commitment to changing programs and policies to increase students' achievement, and a number of Round 1 colleges made improvements to their data capacity and the dissemination of student outcomes data, both of which helped colleges strengthen their culture of evidence. Finally, most colleges developed multiple strategies aimed at increasing students' achievement and involved at least some faculty and staff in this reform process.

While Achieving the Dream can count these changes as successes, many of the Round 1 institutions were still facing important challenges in 2009 in scaling up those reforms that might directly affect students' achievement. For instance, many colleges struggled to undertake certain forms of data analysis, such as strategy evaluations, making it difficult to know whether and how their strategies might be influencing students' success. The majority of colleges' strategies also tended to remain small in scale, affecting only selected pockets of the student

\footnotetext{
${ }^{1}$ Achieving the Dream (2009).

${ }^{2}$ While the benchmark specifies passing with a grade of "C" or higher, Achieving the Dream colleges did not start submitting data on course grades with this limitation until 2007. As a result, all of the course completion measures in this report are based on passing courses with a grade of " $\mathrm{D}$ " or higher. Completion of developmental and gatekeeper courses are measured with a grade of "C" or higher.
} 
body. Finally, many colleges had difficulties involving broad segments of faculty and staff in the types of leadership and development opportunities that might ultimately lead to a change in practice.

This chapter describes changes over time in the five key benchmarks listed above for the Round 1 colleges in the initiative, providing a preliminary look at the student outcomes at these colleges over the course of their five years of planning and implementing Achieving the Dream. The analysis suggests that the average trends in the five indicators across the 26 institutions remained unchanged over time, with a few exceptions. Specifically, the average rates for completion of gatekeeper English and coursework completion within two years both improved modestly over time. In contrast, the average rates for completion of developmental math, developmental English, developmental reading, and gatekeeper math courses remained substantially the same throughout the period, as did persistence and completion of a degree or certificate. When the data are examined for individual institutions, some show improvements on the five indicators. Other institutions, however, show declines on some indicators, and the modal pattern is one of no change.

While these descriptive trends may seem to suggest that Achieving the Dream had few positive effects on student outcomes, the results must be interpreted cautiously. First, as noted above, many of the strategies directly affecting students remained small in scale during the period under study, making it questionable how much they might have affected student outcomes during this time. Second, the primary data used in these analyses focus on all entering students who were in college for the first time, independent of whether these students were targeted by their college to participate in a specific strategy. That is, the analyses use outcomes for everyone, not just those targeted by interventions. Given these limitations, it is reasonable to expect to see little change in student outcomes at this juncture.

It is also important to remember that these findings are not causal, but rather simply describe movements in student outcomes over time. In order to determine whether the initiative caused the patterns that are described above, it is necessary to estimate what would have happened in the absence of Achieving the Dream and compare that estimate to what actually happened. The best way to determine whether a causal relationship existed between Achieving the Dream and changes in student outcomes would be to set up an experimental study that randomly assigned colleges to a program group that participated in Achieving the Dream and a control group that did not. A random assignment process was not used to select the participating colleges, so this method cannot be used for the analysis of the effect of Achieving the Dream on student outcomes. However, MDRC did implement a series of random assignment studies of particular interventions at several colleges in order to assess how these individual programs affected students' achievement. The results of those studies are summarized in Box 8.1. 


\section{Box 8.1}

\section{MDRC's Achieving the Dream Impact Studies}

MDRC conducted impact studies at four Round 1 colleges to measure the effects of student success strategies on academic performance and persistence outcomes. These studies investigated the impact of three different strategies on student outcomes: (1) learning communities at Hillsborough Community College in Florida and Houston Community College in Texas; (2) a college success course at Guilford Technical Community College in North Carolina; and (3) a classroom-based mentoring program at South Texas College. All four impact studies were conducted using a random assignment methodology.

\section{The Beacon Mentoring Program — South Texas College}

In order to address low completion and persistence rates in courses with high enrollment, South Texas College administrators established a low-cost, "personal touch" mentoring program. Focused on helping students pass math courses that were characterized by high enrollment and failure rates, South Texas's Beacon Mentoring Program assigned trained "Beacon Mentors" (volunteer South Texas staff) to a college algebra or developmental math course, in which they made brief in-class presentations about student services and academic skills building and worked with class instructors to reach struggling or absentee students. Mentors also encouraged students to visit them outside of class for additional academic support.

The program was evaluated by MDRC during the spring 2008 semester, with over 2,100 students enrolled in 83 math classes participating in the study. Overall, the program did not significantly affect students' academic performances or persistence, though it did increase the number of students who accessed tutoring and reduced their withdrawal rates from the math class in which they were registered. Some positive academic results were also found among certain student subgroups. For instance, part-time students who had a Beacon Mentor were more likely to complete their math class and earn more credits, and developmental math students earned significantly more credits in their nonmath developmental courses. ${ }^{\text {a }}$

\section{Learning Communities - Houston Community College and Hillsborough Community College}

With the aim of improving developmental education students' academic success and engagement, the learning communities programs at Houston and Hillsborough linked a developmental education reading (Hillsborough) or math (Houston) course with a college success course. Both colleges implemented fairly basic learning communities' models that strengthened over the course of the demonstration, as faculty collaborated more frequently to integrate the curriculum of the two courses with each other. The student cohorts created by co-enrollment were the most salient feature of each program, with students and faculty reporting the development of increased academic and personal support networks. ${ }^{b}$

(continued) 


\section{Box 8.1 (continued)}

The effect of these learning communities on students' outcomes varied by institution. Overall, Hillsborough's program did not have a meaningful impact on students' academic success (that is, there was no difference in student outcomes between those who participated in the program and those who did not), though some positive impacts may be seen on the educational outcomes for students in the third cohort as faculty collaboration and curricular integration increased. ${ }^{\mathrm{c}}$ Houston's learning communities, however, had large positive effects on students' completion of developmental math. Students in learning communities also progressed through their developmental education course sequence more rapidly. ${ }^{\mathrm{d}}$

\section{Guilford Technical Community College — "On Course"}

Guilford Tech implemented a one-semester, three-credit student success course based on Skip Downing's On Course ${ }^{\mathrm{TM}}$ curriculum, which focuses on fostering students' academic and socioemotional skills. ${ }^{\text {e }}$ The college targeted both new and continuing developmental education students to take the course and aimed to improve students' academic achievement, retention, and campus involvement. Three cohorts of students participated in the study from spring 2008 through spring 2009, and follow-up data are being collected on their academic progress. Results from this study will be available in 2011.

${ }^{\mathrm{a}}$ Visher, Butcher, and Cerna (2010).

${ }^{\mathrm{b}}$ Visher, Schneider, Wathington, and Collado (2010).

${ }^{c}$ Weiss, Visher, and Wathington (2010).

${ }^{\mathrm{d}}$ Weissman et al. (forthcoming).

${ }^{\mathrm{e}}$ Downing (2008).

The next section outlines the methodology used in this chapter, followed by three sections that discuss the trends in student outcomes in detail, examine whether changes in student outcomes occur around the start of the initiative, and provide results for two student subgroups. The final section summarizes the overall lessons gained through this work.

\section{Methodology}

Data on the Round 1 colleges obtained from the Achieving the Dream database maintained by JBL Associates are used in the analysis of student indicators. ${ }^{3}$ The statistics presented

\footnotetext{
${ }^{3}$ The Achieving the Dream database consists of student-level cohort data that the initiative requires participating colleges to submit annually for six years (Achieving the Dream, 2009). The database consists of

(continued)
} 
in the figures and tables are based on averages of the institutional rates on each measure so that colleges with large enrollments are weighted equally to colleges with small enrollments. The data consist of average college-level indicators three years before the initiative began (2002 to 2004, or the "pre-initiative period") and three years after its implementation (2005 to 2007, or the "post-initiative period"). ${ }^{4}$ Outcomes for each cohort are examined for two years from the time students entered college. For example, outcomes for the 2007 cohort are analyzed through 2009. Since the Round 1 colleges are a diverse group, variation in outcomes are also examined. Tests are applied to determine whether the differences in the rates between periods are statistically significant, ${ }^{5}$ and significance levels are adjusted for multiple comparisons. ${ }^{6}$

\section{Trends in Student Outcomes Among the Round 1 Colleges}

The descriptive analysis of trends looks initially at the rates of indicators over time after accounting for possible changes in student composition and differences across states. ${ }^{7}$ The top panel of Figure 8.1 shows the change over time in developmental math completion for students requiring remediation. The solid line in the top panel of the figure shows that about 25 percent of students in each cohort completed the developmental math sequence within their first two years of college.

While the average trend over time is fairly flat, outcomes at some colleges were much higher or lower. The dotted line shows the pattern in developmental course completion over time for colleges with student outcomes at the top of the distribution (the ninety-fifth percentile) of all Round 1 colleges, while the dashed line shows the outcomes for colleges at the bottom of the distribution (the fifth percentile). In 2002, close to 45 percent of students in institutions at the top of the distribution completed the developmental math sequence within two years compared with 7 percent of students in institutions at the bottom of the distribution. The spread between the institutions at the extremes declined somewhat by 2007, with 42 percent of students at institutions in the ninety-fifth percentile completing developmental math compared with about 6 percent of students at institutions in the bottom fifth percentile.

student-level outcomes of all degree/certificate-seeking undergraduate students (full and part time) entering an institution for the first time either during the fall term or during the 12-month period.

${ }^{4}$ The 2007 cohort is used to represent the post-initiative period in most analyses, as that cohort represents the fourth year of participation in Achieving the Dream and reflects the latest year for which data are available. (See Appendix B for details.)

${ }^{5}$ Results that are statistically significant are unlikely to have arisen by chance.

${ }^{6}$ The multiple comparison adjustments follow the guidelines in Schochet (2008).

${ }^{7}$ To address the possibility that compositional changes in the student population are likely to occur over time, all means are adjusted for gender, age at cohort entry, race/ethnicity, nonresident alien status, and state fixed effects. For more detail on the model, see Appendix B. 


\section{Achieving the Dream: Community Colleges Count}

\section{Figure 8.1}

Trends in Developmental Math and Developmental English Completions Among Students Referred to Any Developmental English or Math Course, 2002-2007:

Two-Year Outcomes for Achieving the Dream Round 1 Colleges
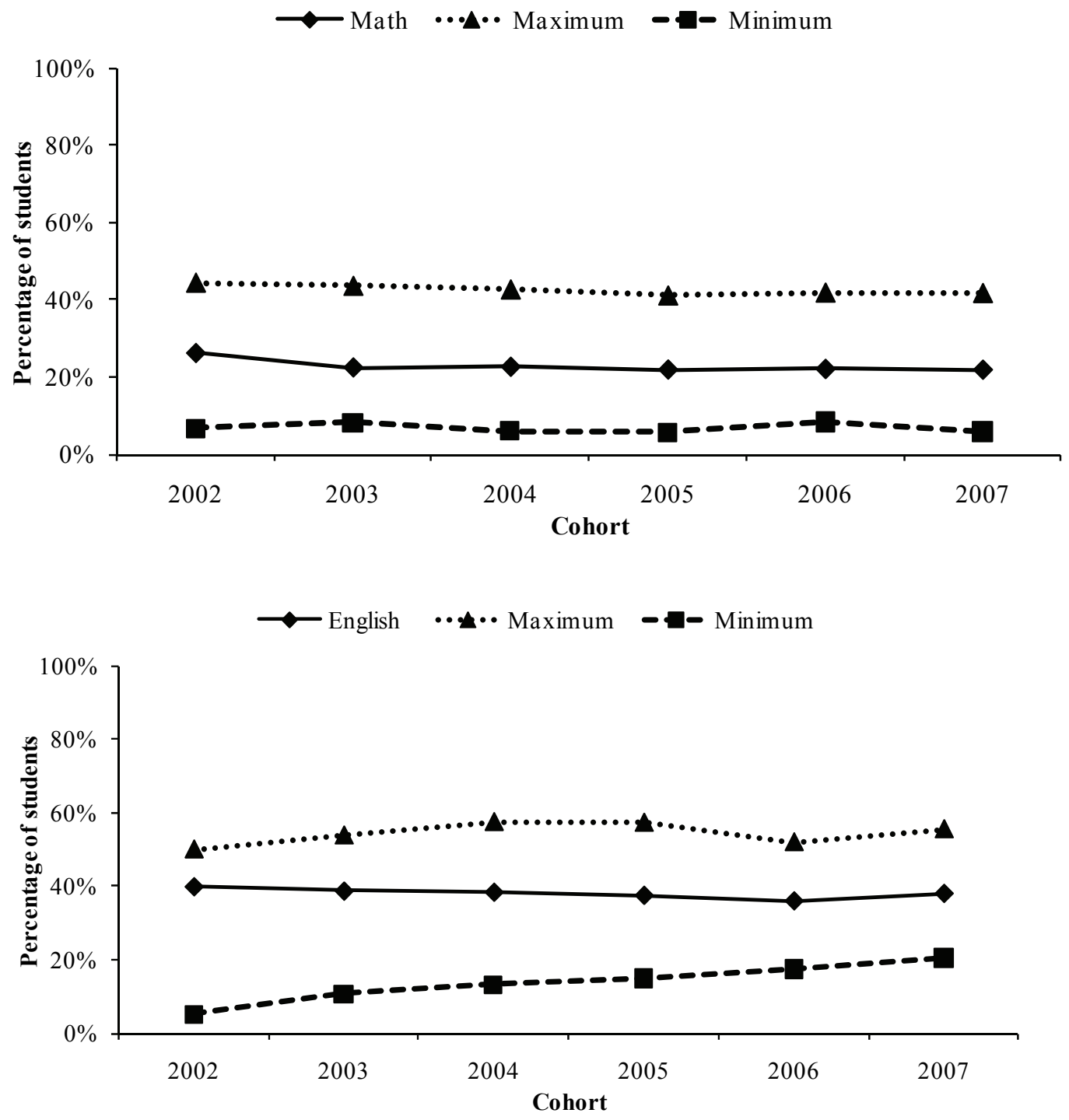

(continued) 


\section{Figure 8.1 (continued)}

SOURCE: MDRC calculations using the Achieving the Dream database maintained by JBL Associates.

NOTES: Calculations for these figures used institutional means for all available data for sample members in the fall 2002 through fall 2007 cohorts at Achieving the Dream Round 1 colleges. The solid line shows averages adjusted for gender, race/ethnicity, and state fixed effects. To illustrate the variability in these outcomes among institutions, the dotted lines show the trend over time among those institutions with student outcomes among the highest (the ninety-fifth percentile) of all colleges in Round 1. The dashed lines show the trend among institutions with the lowest student outcomes (the fifth percentile) of all colleges in Round 1.

The bottom panel of Figure 8.1 shows the change over time in developmental English completion. The solid line shows that average completion rates have remained steady over time at around 40 percent. Again, there is substantial variation among institutions, as illustrated by institutions at the ninety-fifth and fifth percentiles of the outcomes distribution. The figure suggests that there was considerable variation among institutions in the early period and a decline in variation toward the end of the period. In fact, the figure suggests a that completion rates had converged slightly by 2007 , with those institutions at the top of the distribution having student completion rates at around 55 percent by the end of the period, while those at the bottom of the distribution increased their developmental English completion rates to around 20 percent by the end of the period.

Similar to developmental course completion, trends in "gatekeeper" math - the first college-level course in math - show little change over time. The top panel of Figure 8.2 reveals that only about 15 percent of students completed the gatekeeper math course within their first two years - a very small percentage. This is disconcerting given that many colleges require a college-level math course before degree attainment. In contrast, the average gatekeeper English completion rate appears to increase by about 5 percentage points over time, as shown in the bottom panel of Figure 8.2. The figure shows that around 30 percent of students in the 2002 to 2004 cohorts completed a gatekeeper English course within their first two years; the completion rate increased to 34 percent among the 2007 cohort.

Figure 8.3 shows changes in course completion over time. The figure shows that approximately half of students across all cohorts completed 80 percent or more of the courses they attempted, although there is some suggestion of a decline in completion among the early cohorts. The figure shows that there is a large amount of variation in course completion, with around 86 percent of students completing at least 80 percent of their attempted courses in institutions at the top of the distribution, compared with around 32 percent of students in institutions at the fifth percentile of the distribution in 2002. The average rate for completing courses seems to decline somewhat among the 2004 cohorts for the institutions at the extremes of the distribution. The rates for the later cohorts then appear to stabilize among institutions at the ninety-fifth percentile and increase among institutions at the fifth percentile of the distribution. 


\section{Achieving the Dream: Community Colleges Count}

Figure 8.2

\section{Trends in Completion of Gatekeeper Math and English Courses Among All Students, 2002-2007: Two-Year Outcomes for Achieving the Dream Round 1 Colleges}
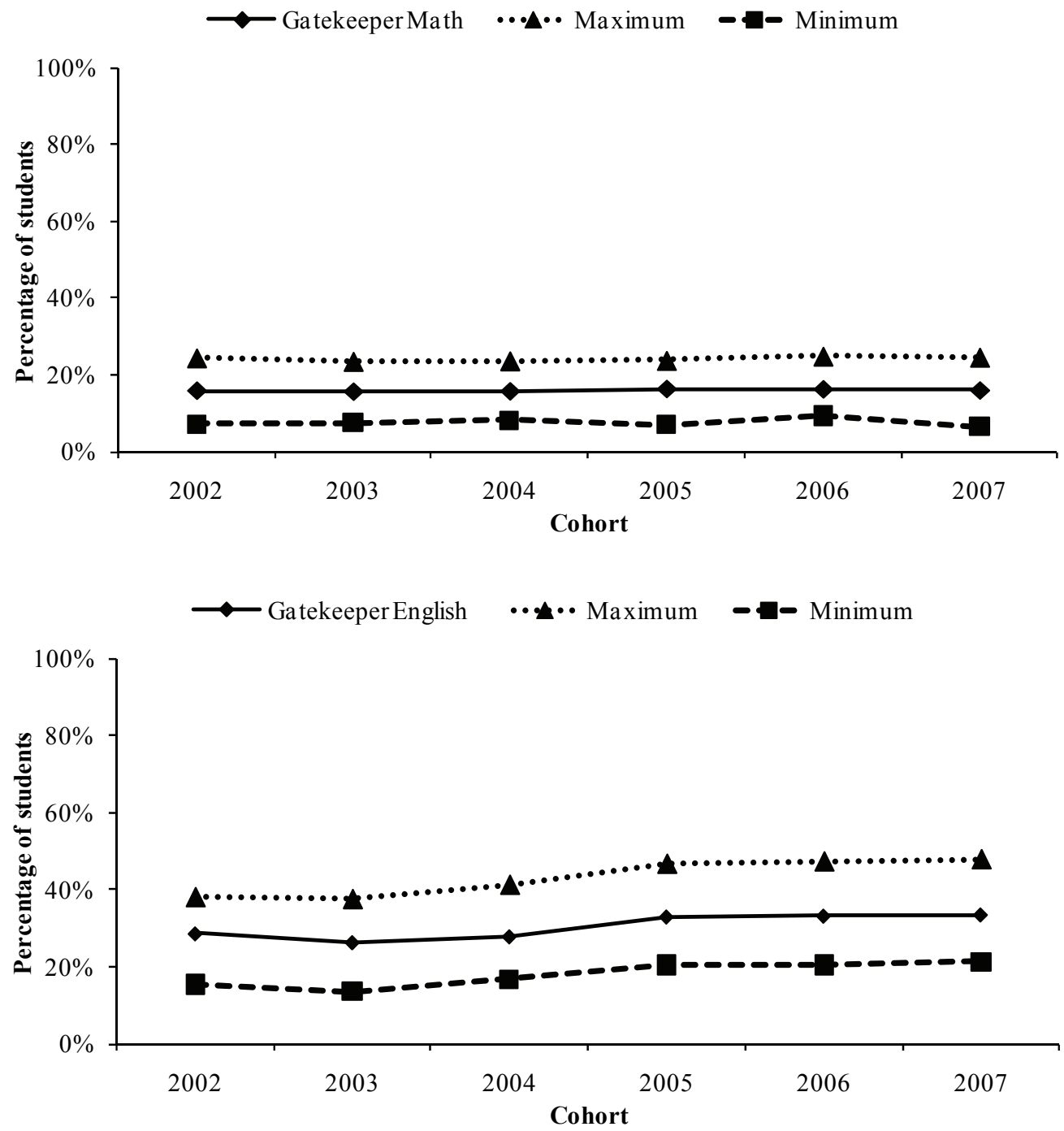

SOURCE: MDRC calculations using Achieving the Dream database maintained by JBL Associates.

NOTES: Calculations for these figures used institutional means for all available data for sample members in the fall 2002 through fall 2007 cohorts at Achieving the Dream Round 1 colleges. The solid line shows averages adjusted for gender, race/ethnicity, and state fixed effects. To illustrate the variability in these outcomes among institutions, the dotted lines show the trend over time among those institutions with student outcomes among the highest (the ninety-fifth percentile) of all colleges in Round 1 . The dashed lines show the trend among institutions with the lowest student outcomes (the fifth percentile) of all colleges in Round 1. 


\section{Achieving the Dream: Community Colleges Count}

\section{Figure 8.3}

Trends in Course Completion, 2002-2007:

Two-Year Outcomes for Achieving the Dream Round 1 Colleges

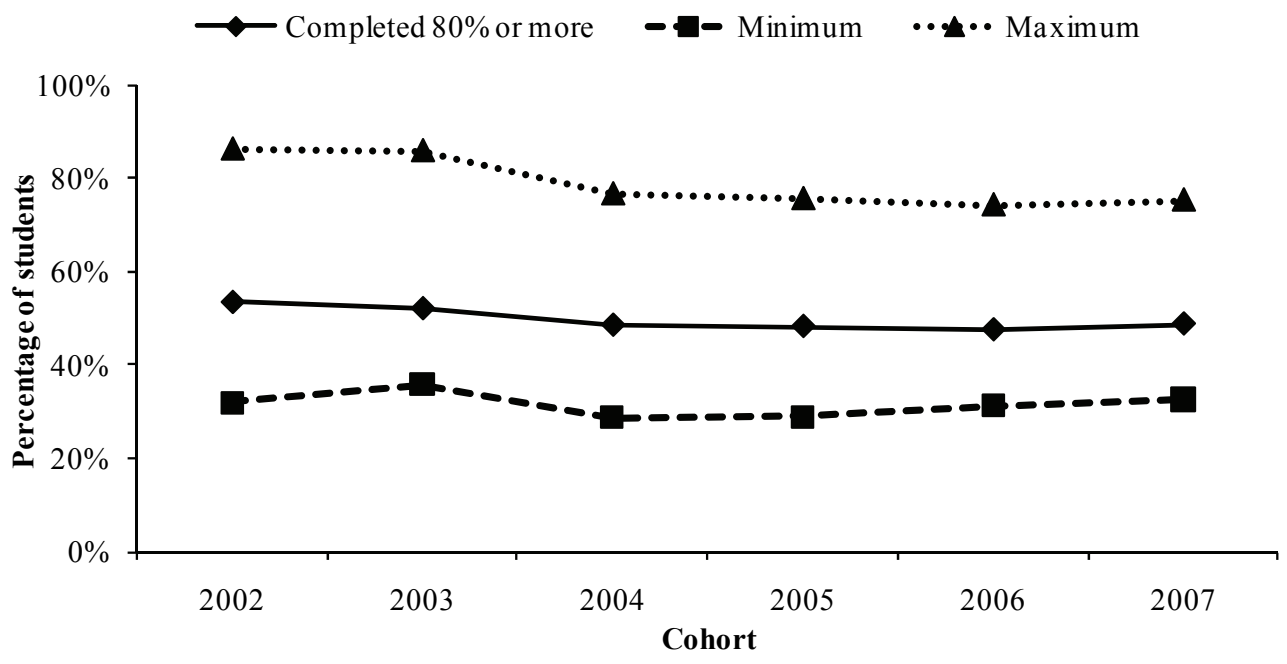

SOURCE: MDRC calculations using the Achieving the Dream database maintained by JBL Associates.

NOTES: The figure shows the percentage of students completing 80 percent or more of the courses they attempted. Calculations for this figure used institutional means for all available data for sample members in the fall 2002 through fall 2007 cohorts at Achieving the Dream Round 1 colleges. The solid line shows averages adjusted for gender, race/ethnicity, and state fixed effects. To illustrate the variability in this outcome among institutions, the dotted lines show the trend over time among those institutions with student outcomes among the highest (the ninety-fifth percentile) of all colleges in Round 1. The dashed lines show the trend among institutions with the lowest student outcomes (the fifth percentile) of all colleges in Round 1.

Overall, this descriptive analysis suggests that the average trend for most indicators is fairly stable over time, although there is a considerable amount of variation in rates among the Round 1 institutions. This variation is not surprising given the differences among institutions' enrollments, student composition, and student preparation for college, as discussed in Chapter 1. Nonetheless, the trend in outcomes among institutions at the extremes of the distribution often follows the same pattern of change over time as the average, suggesting that the trend pattern was relatively the same across colleges regardless of whether they were at the low or high end of the distribution. The next section discusses whether these patterns of change in student outcomes are related to participation in the Achieving the Dream initiative. 


\section{Changes in Trends and Achieving the Dream}

While the analysis above provides useful visuals of change over time, it does not indicate whether average changes in outcomes between the pre-initiative and post-initiative periods are statistically different. This section provides more information about the differences in student outcomes during these periods. Box 8.2 explains how to read the tables in this chapter that show statistically significant changes. ${ }^{8}$ The first column of Table 8.1 reports adjusted averages for the 2002-2004 cohorts (representing the pre-initiative period), and the second column reports adjusted averages for the 2007 cohort (representing the post-initiative period). The third column reports the difference between the two periods and the fourth column translates the percentage point difference into the percentage change over the two periods.

The first panel of the table shows that developmental math completion rates increased by about 4.2 percentage points. The absence of asterisks in the far-right column indicates that this difference is not statistically significant, meaning that there is more than a 10 percent likelihood that it occurred by chance. The second panel shows the results for gatekeeper math and English. As illustrated in Figure 8.2, there is no difference in gatekeeper math completion rates between the two periods, but gatekeeper English completion rates increased by 6.4 percentage points (or 23.7 percent).

The course completion panel of the table shows that 45.4 percent of students completed 80 percent or more of their courses within their first two years in college during the preinitiative period and 51.0 percent of students completed most courses in the post-initiative period. This finding differs from the slightly declining trend shown in Figure 8.3. The reason for the dissimilarity is that the table means are adjusted to show the effect of credit completion after accounting for the 2002-2004 (or pre-initiative) pattern in completion rates. ${ }^{9}$ After the adjustment, the table shows that the group of students who completed 80 percent or more of their courses in 2007 grew by 5.6 percentage points (for an increase of just over 12 percent). The next two panels show that persistence (enrollment from semester to semester) and completion of a credential remain largely unchanged.

\footnotetext{
${ }^{8}$ As in the figures, all means in the tables in this chapter are adjusted for gender, age at cohort entry, race/ethnicity, nonresident alien status, and state fixed effects. In contrast to the figures, means reported in all tables in this chapter are also adjusted for a time trend. Details on the model are provided in Appendix B.

${ }^{9}$ The pre-initiative trend obscures the relationship between student outcomes and the initiative because it represents a systematic increase or decrease that was in place prior to the implementation of Achieving the Dream. Since the goal of this analysis is to isolate whether changes are related to the implementation of the initiative, a time-trend is employed in the model. See Appendix B for details.
} 


\section{Box 8.2}

\section{How to Read the Tables in This Chapter}

Most tables in this chapter use a similar format, illustrated below. The abbreviated table shows some average student indicators for the 2002-2004 cohorts (which represent the pre-initiative period) and the 2007 cohort (which represents the post-initiative period). The first row, for example, shows that 21.0 percent of students in the 2002-2004 cohorts and 25.2 percent of students in the 2007 cohort completed developmental math within two years of starting college.

The "Difference" column in the table shows the differences between the two cohorts' outcomes - that is, the change in outcomes over time. For example, the change in developmental math completion can be calculated by subtracting 21.0 percent from 25.2 percent, yielding an increase of 4.2 percentage points. The percentage change is derived by dividing the difference by the average outcome of the 2002-2004 cohort. For example, 4.2 divided by 21.0 equals 0.201 , which yields a 20.1 percent increase.

In the row that displays asterisks, the difference is "statistically significant," meaning that there is only a small probability that it occurred by chance. The number of asterisks indicates the p-value, or the likelihood of this chance (that is, the likelihood that the difference is not distinguishable from zero). One asterisk corresponds to the 10 percent level, meaning that there is less than a 10 percent chance that the difference is really zero; two asterisks, less than a 5 percent chance; and three asterisks, less than a 1 percent chance. For example, as the third row below shows, the change in gatekeeper English completion is 6.4 percentage points, a difference that is statistically significant at the 1 percent level, indicating that there is less than a 1 percent chance that the difference is really zero.

\begin{tabular}{|c|c|c|c|c|c|}
\hline \multirow[b]{2}{*}{ Performance Indicators } & \multicolumn{2}{|c|}{ Cohort } & \multirow[b]{2}{*}{ Difference } & \multirow{2}{*}{$\begin{array}{r}\text { Percentage } \\
\text { Change } \\
\end{array}$} & \multirow{2}{*}{$\begin{array}{r}\text { P- } \\
\text { Value }\end{array}$} \\
\hline & 2002-2004 & 2007 & & & \\
\hline \multicolumn{6}{|l|}{ Developmental courses } \\
\hline $\begin{array}{l}\text { Completion of developmental math } \\
\text { requirement within two years (\%) }\end{array}$ & 21.0 & 25.2 & 4.2 & 20.1 & \\
\hline $\begin{array}{l}\text { Completion of developmental English } \\
\text { requirement within two years }(\%)\end{array}$ & 37.8 & 38.7 & 0.9 & 2.3 & \\
\hline $\begin{array}{l}\text { Completion of gatekeeper } \\
\text { English course within first two years (\%) }\end{array}$ & 27.2 & 33.6 & 6.4 & 23.7 & $* * *$ \\
\hline
\end{tabular}




\section{Achieving the Dream: Community Colleges Count}

Table 8.1

\section{Change in Average Two-Year Performance Indicators at Achieving the Dream Round 1 Colleges, 2002-2004 Cohorts Compared with 2007 Cohort}

\begin{tabular}{|c|c|c|c|c|c|}
\hline Performance Indicators & $\begin{array}{r}2002-2004 \\
\text { Cohorts } \\
\end{array}$ & $\begin{array}{r}2007 \\
\text { Cohort } \\
\end{array}$ & Difference & $\begin{array}{r}\text { Percentage } \\
\text { Change } \\
\end{array}$ & Sig. \\
\hline \multicolumn{6}{|l|}{ Referred to any developmental courses ${ }^{\mathrm{a}}(\%)$} \\
\hline$\overline{\text { Developmental math }}$ & 61.1 & 60.9 & -0.2 & -0.3 & \\
\hline Attempted course within first 2 years & 75.8 & 70.1 & -5.8 & -7.6 & \\
\hline Completed requirement within first 2 years & 21.0 & 25.2 & 4.2 & 20.1 & \\
\hline Developmental English & 31.7 & 35.4 & 3.7 & 11.7 & \\
\hline Attempted course within first 2 years & 71.3 & 64.9 & -6.4 & -9.0 & \\
\hline Completed requirement within first 2 years & 37.8 & 38.7 & 0.9 & 2.3 & \\
\hline Developmental reading & 32.1 & 32.8 & 0.7 & 2.1 & \\
\hline Attempted course within first 2 years & 69.7 & 69.8 & 0.1 & 0.1 & \\
\hline Completed requirement within first 2 years & 37.7 & 41.3 & 3.5 & 9.4 & \\
\hline \multicolumn{6}{|l|}{ Successfully completed gatekeeper $\operatorname{courses}^{\mathrm{a}, \mathrm{b}}(\%)$} \\
\hline Gatekeeper math within first 2 years & 15.9 & 15.5 & -0.4 & -2.4 & \\
\hline Gatekeeper English within first 2 years & 27.2 & 33.6 & 6.4 & 23.7 & $* * *$ \\
\hline $\begin{array}{l}\text { Gatekeeper math within first } 2 \text { years, among students } \\
\text { referred to developmental math }\end{array}$ & 14.3 & 12.2 & -2.1 & -14.5 & \\
\hline $\begin{array}{l}\text { Gatekeeper English within first } 2 \text { years, among } \\
\text { students referred to developmental English }\end{array}$ & 25.1 & 28.2 & 3.1 & 12.4 & \\
\hline \multicolumn{6}{|l|}{$\underline{\text { Course completion }}^{\mathrm{d}}$} \\
\hline Attempted credits within first 2 years & 30.0 & 31.0 & 1.0 & 3.2 & \\
\hline Completed credits within first 2 years & 22.0 & 24.5 & 2.5 & 11.5 & $* *$ \\
\hline $\begin{array}{l}\text { Ratio of completed credits to attempted credits within } \\
\text { first } 2 \text { years }(\%)\end{array}$ & 66.2 & 72.4 & 6.1 & 9.2 & $* *$ \\
\hline $\begin{array}{l}\text { Completed } 80 \text { percent or more of attempted credits } \\
\text { within first } 2 \text { years }(\%)\end{array}$ & 45.4 & 51.0 & 5.6 & 12.3 & $* *$ \\
\hline Achieved 20 credit hour milestone within 2 years $(\%)$ & 47.4 & 55.6 & 8.2 & 17.3 & $* *$ \\
\hline \multicolumn{6}{|l|}{ Persistence (\%) } \\
\hline Enrolled in fall of second year & 46.2 & 49.5 & 3.3 & 7.2 & \\
\hline Enrolled in at least one semester in second year & 51.4 & 54.2 & 2.8 & 5.4 & \\
\hline \multicolumn{6}{|l|}{ Completions (\%) } \\
\hline Completed a credential by the end of the second year & 5.2 & 7.6 & 2.4 & 45.4 & \\
\hline Completed an associate's degree & 3.2 & 4.1 & 1.0 & 31.0 & \\
\hline Completed a certificate or diploma & 2.1 & 3.5 & 1.4 & 64.7 & \\
\hline
\end{tabular}




\section{Table 8.1 (continued)}

SOURCE: MDRC calculations using the Achieving the Dream database maintained by JBL Associates.

NOTES: Calculations for this table used institutional means for all available data for sample members in the fall 2002 through fall 2007 cohorts at the Achieving the Dream Round 1 colleges. While Alamo Community College District is considered one site for the Achieving the Dream initiative, it has 4 colleges that report data separately to the database, bringing the total number of data-reporting institutions from 26 to 29. Because 2 of these 29 colleges (Central New Mexico Community College and New Mexico State University-Dona Ana) did not submit 2008 data to JBL, the total sample size for this table is 27 colleges.

Data for the fall 2002 cohort at Guilford Technical Community College were not submitted.

Entries show estimated difference in probabilities from a linear regression that controls for gender, race/ethnicity, a time trend, and state fixed effects. Statistical significance levels, shown in the Sig. column, are indicated as: $* * *=1$ percent; $* *=5$ percent; and $*=10$ percent.

To control for spurious findings resulting from multiple comparisons, significance levels for individual variables are shown only if the aggregate domain measure was statistically significant with a p-value below the Benjamini-Hochberg maximum (Schochet, 2008).

Standard errors are clustered by institution.

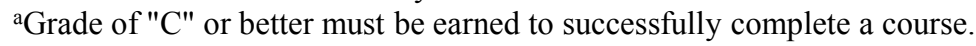

${ }^{b}$ Gatekeeper math is the first college-level math course at the college; gatekeeper English is the first college-level English course at the college.

${ }^{\mathrm{c} C a l c u l a t i o n s}$ used data for sample members who have developmental referral data.

${ }^{\mathrm{d}}$ Completion with a grade of "D" or better is reported for this block of outcomes. Credits completed with a grade of "C" or better was not introduced as a variable until the $2007 \mathrm{JBL}$ submission guide was released.

\section{Variation in Differences Over Time}

Although differences for most outcomes are small (and positive) or show no change, the averages could mask variation across the institutions. Figure 8.4 examines variation across Round 1 institutions in the change in gatekeeper English completion rates over the two periods, and shows a moderate amount of variation across institutions. For example, the largest increase in gatekeeper English completion was 18.6 percentage points (a 65 percent increase for this institution) and the largest decrease in gatekeeper English completion was 14.6 percentage points (a 32.5 percent decrease for this institution). Of the 27 institutions examined, 11 of the institutional-level differences were statistically significant (indicated by the black bars in the figure). ${ }^{10}$

There is less variation in the distribution of differences over time in fall-to-fall persistence, as shown in Figure 8.5. The largest (statistically significant) increase in this measure of persistence was 10.3 percentage points (representing a 22 percent increase at this institution), and the largest (statistically significant) decrease in this measure was 12.0 percentage points

\footnotetext{
${ }^{10}$ While 26 institutions participated in Achieving the Dream, Alamo Community College District has four colleges that report data separately to the database, bringing the total number of data-reporting institutions from 26 to 29. Because two of these 29 colleges (Central New Mexico Community College and New Mexico StateDona Ana) did not submit 2008 data to JBL, the total number of institutions in this analysis is 27 colleges.
} 


\section{Achieving the Dream: Community Colleges Count}

Figure 8.4

\section{Distribution of Pre-Initiative and Post-Initiative Differences in Completion of Gatekeeper English at Achieving the Dream Round 1 Colleges, 2002-2007}

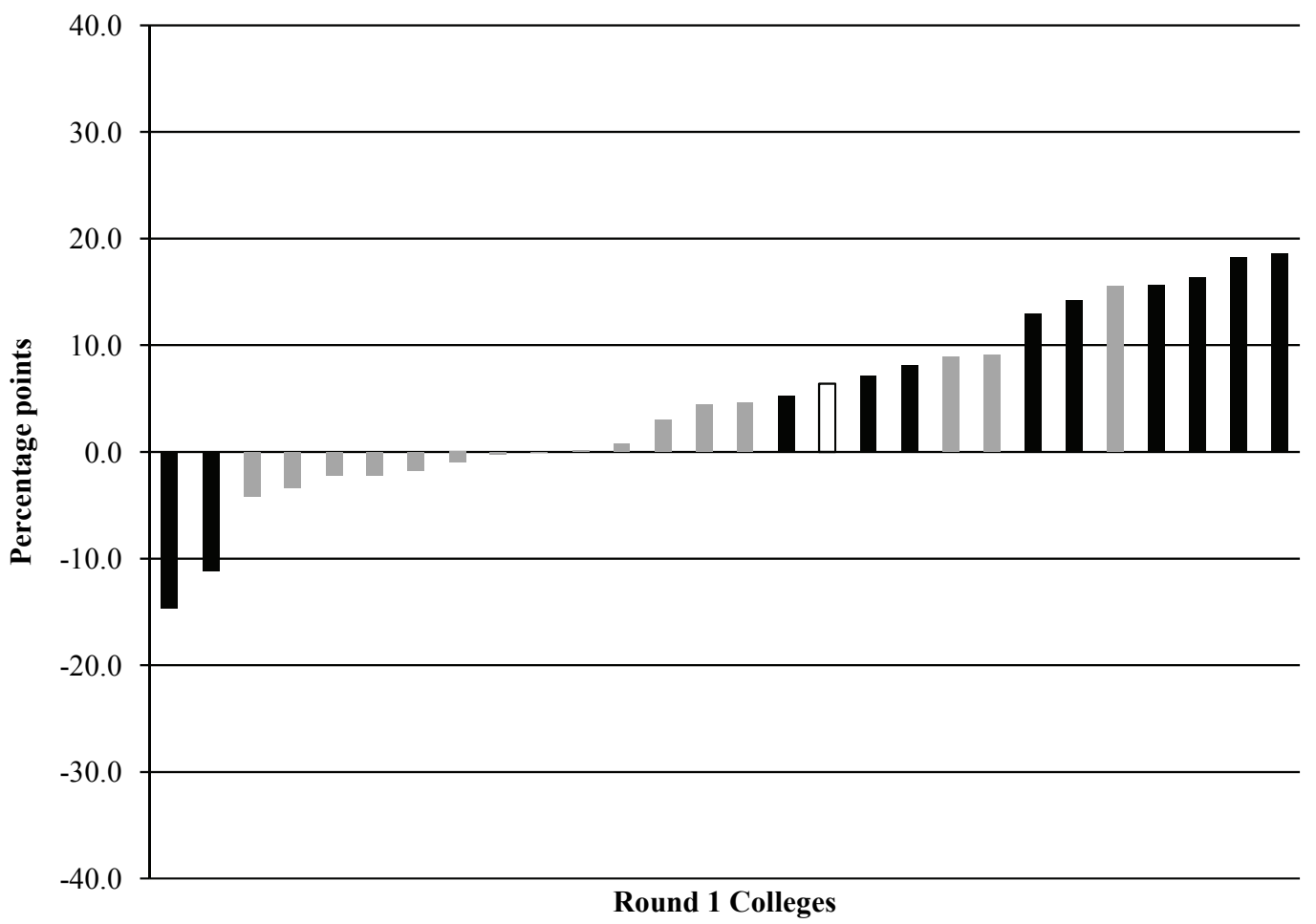

SOURCE: MDRC calculations using the Achieving the Dream database maintained by JBL Associates.

NOTES: The figure shows the percentage point difference in the completion of gatekeeper English within two years between the averages for the 2002-2004 cohorts and the 2007 cohort. The Benjamini-Hochberg correction for multiple hypothesis testing was applied. The black bars indicate differences that are statistically significant at the corrected p-value or lower (Schochet, 2008). The white bar shows the overall average difference of 6.4 percentage points presented in Table 8.1 , which is statistically significant at the 1 percent level. Calculations for this figure used institutional means for all available data for sample members in the fall 2002 through fall 2007 cohorts at Achieving the Dream Round 1 colleges. The averages that generated the differences were adjusted for gender, race/ethnicity, state fixed effects, and a linear time trend.

(representing a 28 percent decrease at this institution). The results of an analysis of variation in other outcomes are shown in Figure 8.6. Most outcomes vary substantially across institutions, with most institutions falling into the category of having no change in student outcomes over time. 
Achieving the Dream: Community Colleges Count

Figure 8.5

\section{Distribution of Pre-Initiative and Post-Initiative Differences in Fall-to-Fall Persistence at Achieving the Dream Round 1 Colleges, 2002-2007}

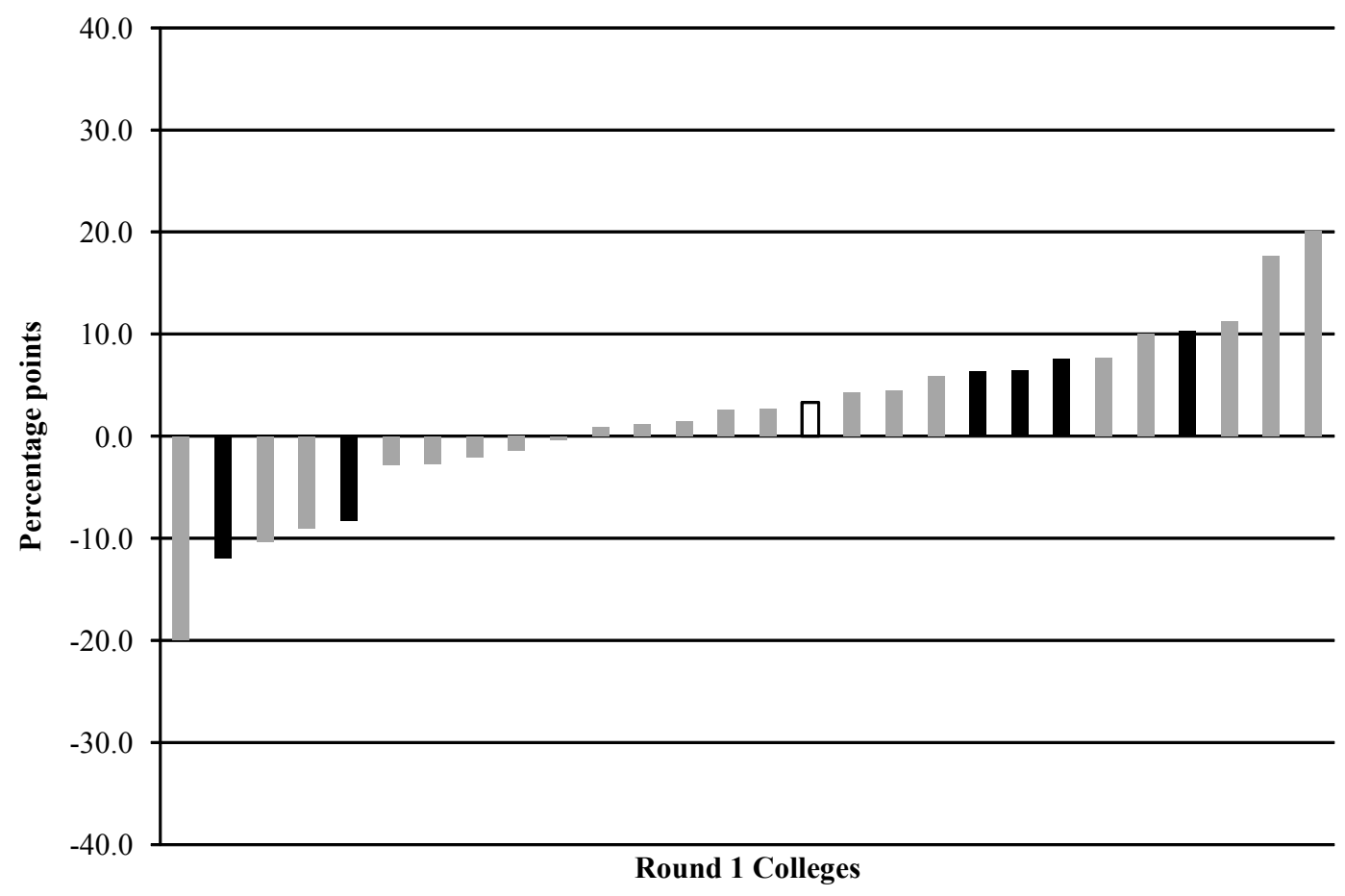

SOURCE: MDRC calculations using the Achieving the Dream database maintained by JBL Associates.

NOTES: The figure shows the percentage point difference between the averages for the 2002-2004 cohorts and the 2007 cohort in fall-to-fall persistence. The Benjamini-Hochberg correction for multiple hypothesis testing was applied. The black bars indicate differences that are statistically significant at the corrected p-value or lower (Schochet, 2008). The white bar shows the overall average difference of 3.3 percentage points presented in Table 8.1. Calculations for this figure used institutional means for all available data for sample members in the fall 2002 through fall 2007 cohorts at Achieving the Dream Round 1 colleges. The averages that generated the differences were adjusted for gender, race/ethnicity, state fixed effects, and a linear time trend.

In addition to the foregoing analysis, an exploratory analysis was conducted to examine whether the student outcomes at colleges with more dramatic changes in their culture of evidence may have differed from the overall group. As discussed in Chapter 7, field research of the initiative revealed some unevenness in the Round 1 colleges' adoption of practices associated with a culture of evidence. Of all of the colleges examined, four institutions were found to have 


\section{Achieving the Dream: Community Colleges Count}

Figure 8.6

\section{Distribution of Institution-Level Changes in Two-Year, Interim Performance Indicators at Achieving the Dream Round 1 Colleges, 2002-2004 Compared with 2007}

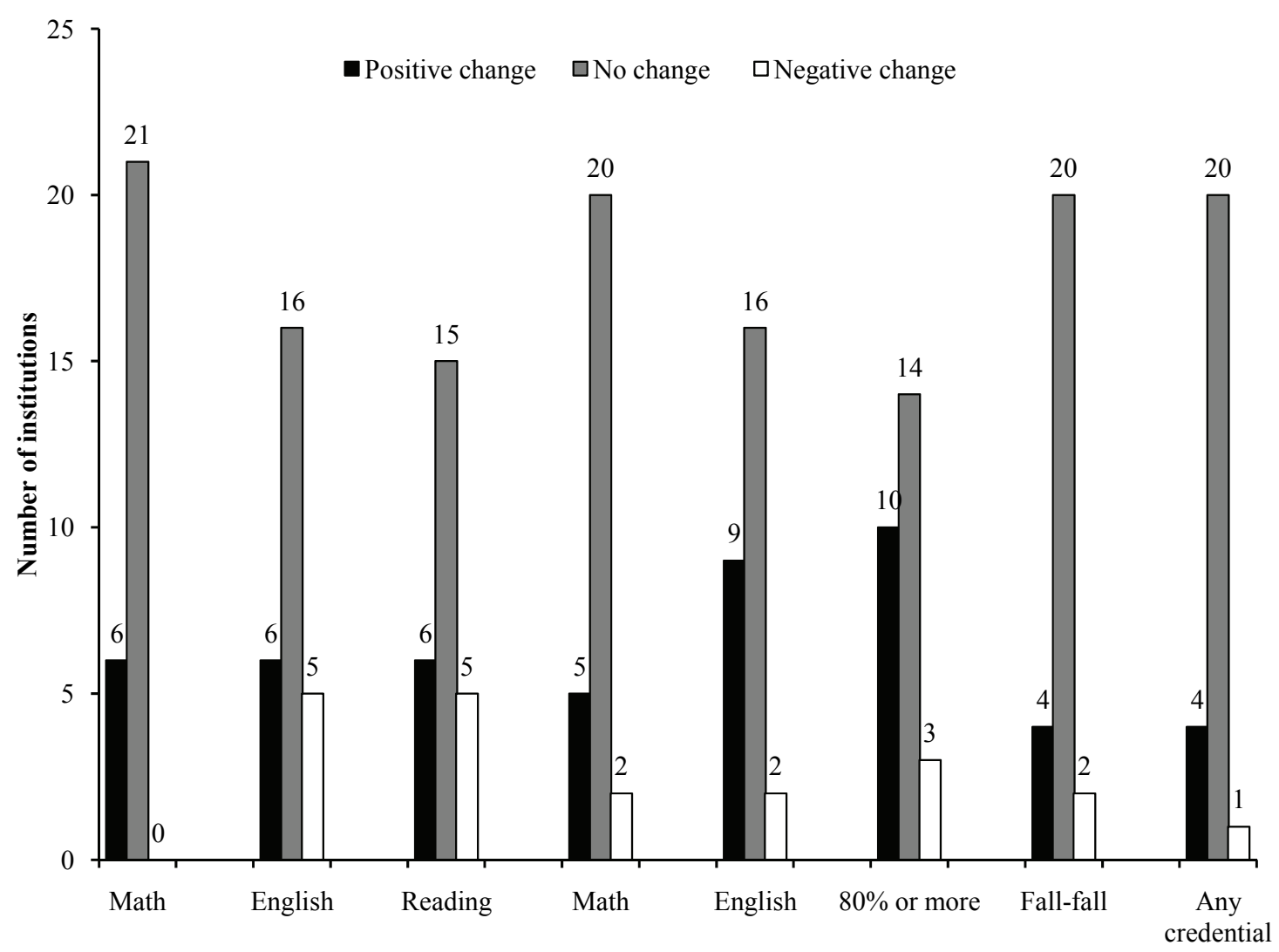

SOURCE: MDRC calculations using the Achieving the Dream database maintained by JBL Associates.

NOTES: Calculations for this figure used institutional means for all available data for sample members in the fall 2002 through fall 2007 cohorts at Achieving the Dream Round 1 colleges.

Some colleges did not report into the database on some measures.

Bars show the number of differences that are positive and statistically significant ("Positive Change"), not significant ("No Change"), or negative and statistically significant ("Negative Change"). The Benjamini-Hochberg correction for multiple hypothesis testing was applied. Statistical significance is characterized as p-values below the corrected maximum (Schochet, 2008).

For the measures of "developmental requirement completion" and "gatekeeper course completion," a grade of "C" or better must be earned to successfully complete a course. Gatekeeper math is the first college-level math course at the college; gatekeeper English is the first college-level English course.

For the " $80 \%$ or more course completion" measure, completion with a grade of " $\mathrm{D}$ " or better is reported. Credits completed with a grade of "C" or better was not introduced as a variable until the 2007 JBL submission guide was released. 
a weak culture of evidence one year after the initiative began, but a strong culture of evidence three years later. These "star" institutions thus showed the greatest level of progress during their time in Achieving the Dream and, in interviews and focus groups, attributed many of their changes to their work in Achieving the Dream. Given their high level of progress, these colleges might be expected to have different student outcome trends from other Round 1 colleges. However, the results of the exploratory analyses of these star colleges suggest that the distribution of outcomes at these colleges is no different from those of other Round 1 institutions. ${ }^{11}$ That is, these continuously improving colleges also experienced increases, decreases, and lack of change across the various indicators of student outcomes. This finding suggests that the trends in student outcomes did not vary based on improvements to the practices associated with a strong culture of evidence, at least not during the time period covered in this report.

\section{Variation in Differences by Student Subgroups}

As noted in previous chapters, improving student outcomes and closing the gap in achievement by income and race or ethnicity are major goals of the initiative. As such, this section explores whether the income, racial, and ethnic gaps in achievement that are apparent early in the initiative decreased during the colleges' participation in Achieving the Dream.

\section{Differences by Pell Grant Receipt Status}

Numerous studies have shown that low-income students enroll in college at lower rates, are more likely to "stop out" (that is, interrupt their studies) or drop out of college, and take significantly longer to complete a degree or certificate if they do remain in school. ${ }^{12}$ Therefore, improving outcomes among this group may have lasting effects. Table 8.2 shows changes in student outcomes over time by Pell Grant receipt status, a proxy for low-income status. The first set of three columns reports outcomes for students who did not receive a Pell Grant. The differences shown in the third column reveal no statistically significant change over time in the Achieving the Dream indicators - that is, from the pre-initiative period (cohorts 2002-2004) to the postinitiative period (cohort 2007).

The next set of three columns shows the changes in student outcomes for Pell Grant recipients. When comparing Pell Grant recipients with those who did not receive a Pell Grant in the pre-initiative period, on average, the grant recipients are referred more often to developmental coursework and are less likely to complete gatekeeper math and the credits they attempted within their first two years, but are more likely to complete gatekeeper English within their first two years. These patterns remained largely the same in the post-initiative period, with some

\footnotetext{
${ }^{11}$ These analyses are not shown in this report.

${ }^{12}$ For example, see Berker, He, and Cataldi (2002); Brock et al. (2007).
} 


\section{Achieving the Dream: Community Colleges Count}

Table 8.2

\section{Change in Average Two-Year Performance Indicators at Achieving the Dream Round 1 Colleges, by Pell Grant Status, 2002-2004 Cohorts Compared with 2007 Cohort}

\begin{tabular}{|c|c|c|c|c|c|c|}
\hline \multirow{2}{*}{ Performance Indicators } & \multicolumn{3}{|c|}{ No Pell Grant Receipt } & \multicolumn{3}{|c|}{ Pell Grant Receipt } \\
\hline & 2002-2004 & $\begin{array}{r}2007 \\
\end{array}$ & Diff & $2002-2004$ & 2007 & Diff \\
\hline \multicolumn{7}{|l|}{ Referred to any developmental courses $^{a}(\%)$} \\
\hline Developmental math & 51.5 & 57.7 & 6.2 & 71.2 & 67.2 & -4.0 \\
\hline Attempted course within first 2 years & 68.4 & 64.0 & -4.4 & 80.7 & 77.7 & -3.0 \\
\hline Completed requirement within first 2 years & 19.2 & 23.8 & 4.6 & 21.9 & 27.3 & 5.3 \\
\hline Developmental English & 24.4 & 33.9 & 9.5 & 39.8 & 41.0 & 1.2 \\
\hline Attempted course within first 2 years & 62.9 & 62.9 & 0.0 & 76.2 & 71.8 & -4.4 \\
\hline Completed requirement within first 2 years & 36.6 & 31.1 & -5.5 & 41.3 & 43.9 & 2.5 \\
\hline Developmental reading & 23.2 & 28.4 & 5.2 & 41.1 & 38.6 & -2.5 \\
\hline Attempted course within first 2 years & 61.4 & 64.8 & 3.4 & 73.9 & 75.4 & 1.5 \\
\hline Completed requirement within first 2 years & 33.5 & 36.7 & 3.2 & 40.4 & 46.7 & 6.3 \\
\hline \multicolumn{7}{|l|}{ Successfully completed gatekeeper } \\
\hline \multicolumn{7}{|l|}{ courses $^{\mathrm{a}, \mathrm{b}}(\%)$} \\
\hline Gatekeeper math within first 2 years & 18.4 & 16.3 & -2.1 & 16.5 & 15.2 & -1.3 \\
\hline Gatekeeper English within first 2 years & 28.7 & 29.4 & 0.8 & 30.7 & 37.4 & $6.8 * *$ \\
\hline Gatekeeper math within first 2 years, among & & & & & & \\
\hline students referred to developmental math ${ }^{\mathrm{c}}$ & 18.6 & 8.7 & -9.9 & 14.2 & 11.7 & -2.5 \\
\hline $\begin{array}{l}\text { Gatekeeper English within first } 2 \text { years, } \\
\text { among students referred to developmental }\end{array}$ & & & & & & \\
\hline English $^{\mathrm{c}}$ & 30.8 & 19.8 & -10.9 & 24.7 & 34.4 & $9.7 *$ \\
\hline \multicolumn{7}{|l|}{ Course completion $^{\mathrm{d}}$} \\
\hline Attempted credits within first 2 years & 28.4 & 27.6 & -0.8 & 33.9 & 35.5 & 1.6 \\
\hline Completed credits within first 2 years & 22.2 & 21.8 & -0.4 & 24.3 & 27.2 & $2.9 * *$ \\
\hline $\begin{array}{l}\text { Ratio of completed credits to attempted } \\
\text { credits within first } 2 \text { years }(\%)\end{array}$ & 71.7 & 70.9 & -0.8 & 64.7 & 69.8 & $5.1 *$ \\
\hline $\begin{array}{l}\text { Completed } 80 \text { percent or more of } \\
\text { attempted credits within first } 2 \text { years }(\%)\end{array}$ & 56.3 & 58.2 & 1.9 & 43.1 & 49.6 & $6.5 *$ \\
\hline Achieved 20 credit hour milestone within & & & & & & \\
\hline 2 years $(\%)$ & 43.7 & 44.7 & 1.0 & 52.5 & 58.2 & $5.7 * *$ \\
\hline \multicolumn{7}{|l|}{ Persistence (\%) } \\
\hline Enrolled in fall of second year & 47.1 & 42.4 & -4.6 & 52.1 & 55.3 & 3.1 \\
\hline $\begin{array}{l}\text { Enrolled in at least one semester in second } \\
\text { year }\end{array}$ & 51.8 & 47.0 & -4.8 & 57.6 & 61.7 & 4.1 \\
\hline \multicolumn{7}{|l|}{ Completions (\%) } \\
\hline Completed a credential by the end of the & 73 & 62 & -11 & 41 & 76 & \\
\hline Completed an associate's degree & 5.0 & $\begin{array}{l}0.2 \\
2.9\end{array}$ & $\begin{array}{l}-1.1 \\
-2.1\end{array}$ & $\begin{array}{l}4.1 \\
2.3\end{array}$ & $\begin{array}{l}1.6 \\
4.1\end{array}$ & $\begin{array}{l}3.5 * 4 \\
1.8 *\end{array}$ \\
\hline Completed a certificate or diploma & 2.3 & 3.4 & 1.1 & 1.8 & 3.6 & $1.8 *$ \\
\hline
\end{tabular}


Table 8.2 (continued)

SOURCE: MDRC calculations using the Achieving the Dream database maintained by JBL Associates.

NOTES: Calculations for this table used institutional means for all available data for sample members in the fall 2002 through fall 2007 cohorts at the Achieving the Dream Round 1 colleges. While Alamo Community College District is considered one site for the Achieving the Dream initiative, it has 4 colleges that report data separately to the database, bringing the total number of data-reporting institutions from 26 to 29. Because 2 of these 29 colleges (Central New Mexico Community College and New Mexico State University-Dona Ana) did not submit 2008 data to JBL, the total sample size for this table is 27 colleges.

Data for the fall 2002 cohort at Guilford Technical Community College were not submitted.

Entries show estimated difference in probabilities from a linear regression that controls for gender, race/ethnicity, a time trend, and state fixed effects. Statistical significance levels are indicated as: *** $=1$ percent; $* *=5$ percent; and $*=10$ percent.

Differences in indicators between Pell recipients and other students were tested for statistical significance; no statistically significant differences were found.

To control for spurious findings resulting from multiple comparisons, significance levels for individual variables are shown only if the aggregate domain measure was statistically significant with a p-value below the Benjamini-Hochberg maximum (Schochet, 2008).

Standard errors are clustered by institution.

${ }^{\text {a }}$ Grade of "C" or better must be earned to successfully complete a course.

${ }^{b}$ Gatekeeper math is the first college-level math course at the college; gatekeeper English is the first collegelevel English course at the college.

${ }^{\mathrm{c} C a l c u l a t i o n s}$ used data for sample members who have developmental referral data.

${ }^{\mathrm{d} C o m p l e t i o n}$ with a grade of "D" or better is reported for this block of outcomes. Credits completed with a grade of "C" or better was not introduced as a variable until the 2007 JBL submission guide was released.

improvements in average indicators for Pell Grant recipients in the post-initiative period. However, when comparing the differences across these two groups (not shown), the changes were not large enough to result in statistically significant reductions in the achievement gap between students who received a Pell Grant and those who did not. ${ }^{13}$

\section{Differences by Race and Ethnicity}

The first set of columns in Table 8.3 reports outcomes for white students, who make up the plurality of the student body at Round 1 colleges, on average. The table shows that white students experienced statistically significant improvement over time in successfully completing gatekeeper English and completing credits attempted. The next three columns show outcomes for black students, which reveal significant increases in course completion. The last set of columns shows outcomes for Hispanic students (who may be of any race). Unlike the previous groups, the indicators show no significant change over time. These findings suggest that there were some improvements in white and black students' course completions, but when looked at on the whole, there were few improvements across most of these indicators for these different student subgroups. Additionally, tests comparing the changes in white, black, and Hispanic students'

\footnotetext{
${ }^{13}$ The p-values from the formal tests of the differences between the two groups exceed conventional levels (that is, the $\mathrm{p}$ value is greater than 0.10 ), indicating that the differences could have occurred by chance.
} 


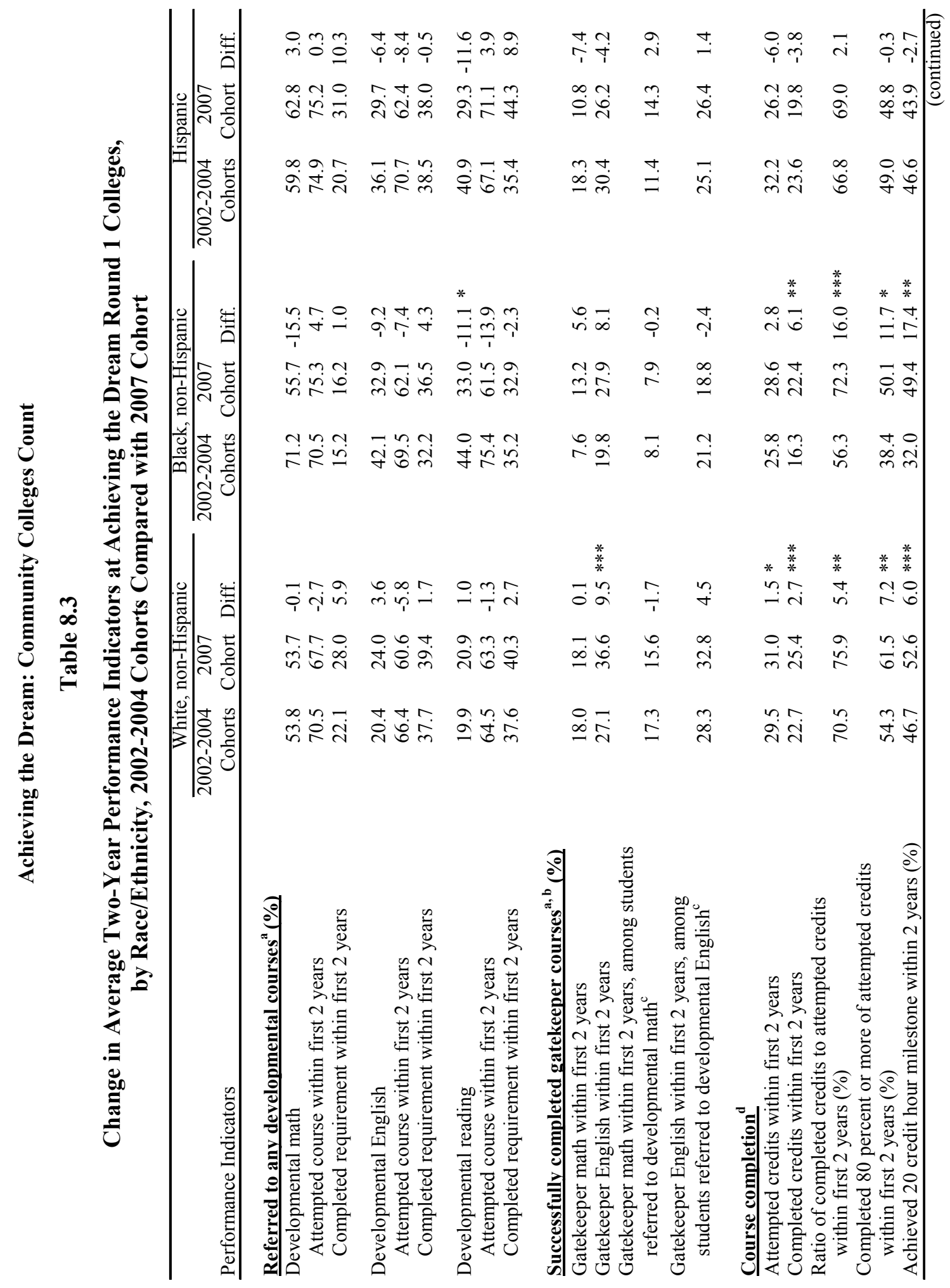




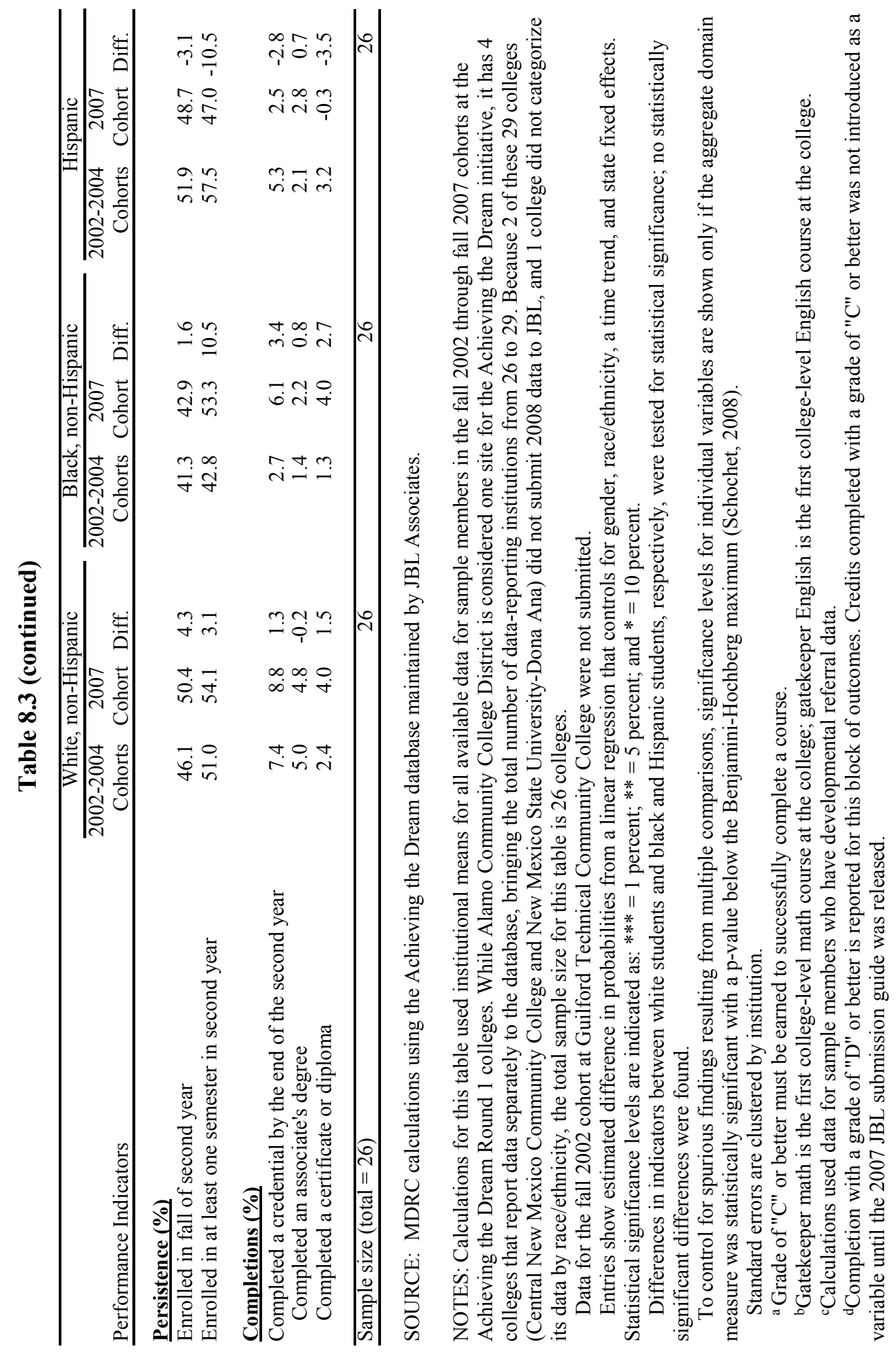


outcomes (not shown) revealed no significant differences, and as a result, the achievement gap remained largely unchanged.

\section{Is There an Association Between Changes in Trends and Achieving the Dream?}

While the descriptive analyses in the figures and Tables 8.1, 8.2, and 8.3 seem to suggest that Achieving the Dream has had positive effects on some student outcomes and no effect on others, it is important to remember that these findings are not causal. That is, since trends in student outcomes may change independently of Achieving the Dream, simple changes in student outcome trends cannot be interpreted as indicating that the initiative had a positive or negative effect on student outcomes. First, the presented measures do not account for other processes that could have been implemented around the same time as Achieving the Dream and that could have affected student outcomes in the absence of the initiative. ${ }^{14}$ Second, these indicators may gradually improve over time as a result of natural processes. For example, a higher proportion of students will pass developmental math in two years than in one year simply because of more time elapsing. ${ }^{15}$

Finally, another reason to avoid drawing a causal inference from these findings is that the participating Achieving the Dream schools were chosen through a selective process that automatically distinguishes them as being different from schools that were not selected or did not apply. Therefore, differences in outcomes at the Achieving the Dream schools may have been lower, the same, or higher independent of the implementation of Achieving the Dream. In order to derive the causal effect of Achieving the Dream, it is necessary to compare the actual outcomes from Achieving the Dream schools with outcomes that represent what would have happened in the absence of the initiative.

\section{Summary}

While Achieving the Dream had many successes with the Round 1 colleges, the colleges varied in their ability to adopt all facets of the five-step model. For instance, many of the

\footnotetext{
${ }^{14}$ For example, the percentage of students who are referred to the lowest levels of developmental math could have declined steadily if the students entering the colleges each year had higher levels of math proficiency. This trend could result in a larger number of students completing the developmental math sequence within the first year. Given that such alternative explanations cannot be ruled out, simple differences in outcomes should be regarded only as a descriptive measure of change over time and not a result of the Achieving the Dream initiative.

${ }^{15}$ These are examples of two particular threats to the internal validity of the analysis. Internal validity refers to the extent to which the independent variable can be proven to have produced the observed effect. The particular threats of history and maturation that are described in the text are common problems in before-andafter comparisons such as the ones presented in this chapter (Cook and Campbell, 1979).
} 
institutions were still facing important challenges in scaling up reforms that might directly affect students' achievement as late as 2008-2009, or the colleges' fourth year of implementation (the end point for this analysis of student outcomes). In addition, many colleges struggled to undertake certain forms of data analysis, such as strategy evaluations, making it difficult to know whether and how their strategies might be influencing students' success. As a result of these and other factors, the majority of colleges' strategies also tended to remain small in scale, affecting only selected pockets of the student body.

Given these issues, much variation existed in the student outcomes across these colleges, and few changes were seen overall in Achieving the Dream's five indicators of student success. Research into organizational change, specifically change that is associated with the delivery of education, has shown repeatedly that time is needed for the organizational restructuring to be manifested in changes in student outcomes. ${ }^{16}$ That research, taken together with the unevenness in colleges' implementation of Achieving the Dream's principles and practices, suggests that more time may be needed to see real changes in students' achievement.

However, some of these findings also imply that Achieving the Dream may need to modify some of its practices to see more substantial changes in student outcomes. For instance, though closing achievement gaps was a stated purpose of the initiative, relatively few changes were seen in achievement gaps among low-income students and students of color. Similarly, the analysis of those colleges that made the most progress in building a culture of evidence suggests that changes to colleges' institutional practices alone may not be enough to influence students' outcomes. Such findings reveal that Achieving the Dream may need to focus greater attention on helping colleges develop more programs and practices that affect students' achievement directly and that aim to reduce the differences in outcomes among students by race, ethnicity, and income level.

Despite these challenges, the positive movement in students' completion of gatekeeper English courses and overall course completion does suggest some room for cautious optimism. Field research at the Round 1 colleges indicated that many colleges had made a substantial shift in how they addressed students' success, even if their efforts had not yet translated into sizeable programs and interventions for students. As a result, colleges may be better poised in the future to develop a more limited set of interventions and focus on scaling up those programs to reach larger numbers of students. Similarly, colleges' increased data capacity may better position them to evaluate the success of such strategies and make modifications to ensure they are resulting in improved student achievement. Perhaps this stronger focus on large-scale student interventions, along with a continued strengthening of the culture of evidence at these colleges, will produce more substantial shifts in student outcomes in the future.

\footnotetext{
${ }^{16}$ Quint (2006); Payzant (2007).
} 



\section{Chapter 9}

\section{Instituting Large-Scale Reform: Achieving the Dream in Context}

As observed throughout this report, many of the Round 1 colleges in Achieving the Dream made substantial progress in developing more evidence-based systems that are aimed at improving students' success rates. Over 75 percent of the Round 1 colleges improved their culture of evidence over the course of their five-year participation in the initiative, and only a handful of colleges made little progress in implementing the initiative's model for institutional improvement. Indeed, a number of colleges had great success with the initiative, with over 40 percent of colleges instituting nearly all of the practices associated with a strong culture of evidence and many attributing their improvements to Achieving the Dream. Overall, most of the Round 1 colleges made a number of enhancements to their institutions, including more sophisticated methods for data analysis, numerous interventions aimed at increasing students' achievement, and more efficient systems for monitoring those efforts.

Lumina Foundation for Education, Achieving the Dream, and the colleges themselves took bold steps to try to improve student achievement, and they have met with a number of successes. While community colleges are a prominent part of the national conversation today about how to improve the academic achievement of low-income populations in particular, few organizations were concentrating on these institutions before 2004, and even fewer were devoting substantial funds to their improvement. In the short time since the initiative began, Lumina, Achieving the Dream, and the participating colleges made substantial strides in bringing community colleges to the forefront.

While Achieving the Dream has made significant progress with community colleges, the initiative, like its participating institutions, also has room for improvement. As reported here, a number of challenges still exist for the community colleges that are participating in Achieving the Dream. For instance, outside of implementing colleges' strategies, the faculty and staff at many of the Round 1 colleges tended to be less involved than administrators in the colleges' overall improvement work. Similarly, only a handful of colleges attempted to engage their parttime faculty and staff, who most often teach the developmental and gatekeeper courses that are so important to students' ultimate success in community colleges. Additionally, while most colleges had expanded at least one strategy, the majority of strategies at these schools remained small in scale, leaving large proportions of students relatively untouched by the colleges' Achieving the Dream work. Finally, Achieving the Dream colleges have seen relatively few changes in their student outcomes over the course of their five years in the initiative, raising a number of questions as to how institutions' reforms are affecting students on the ground. 
These issues represent important challenges to Achieving the Dream's vision for improved student achievement; however, they should also be placed in the context of the overall struggles facing the U.S. education system as a whole. Elementary and secondary schools have long faced an uphill battle in their efforts to improve students' achievement, with only a relative few achieving large-scale reforms that successfully increased students' academic skills or graduation rates. ${ }^{1}$ Far more have been mired in many of the same struggles that Achieving the Dream colleges face, including students with major academic challenges, poor funding streams, difficulties bringing programs to scale, and a lack of faculty or staff engagement in larger school reform efforts. ${ }^{2}$ Additionally, school systems working with adolescent populations, such as middle and high schools, tend to have the greatest struggle with improving student achievement, revealing the key challenge facing community colleges. ${ }^{3}$

Achieving the Dream's four principles and 34 criteria for increasing student success through institutional improvement have provided a broad structure for dealing with many of these challenges. Similarly, the initiative's five-step process for increasing students' achievement, which focuses on honing colleges' leadership commitment, data analysis, engagement of internal and external stakeholders, implementation of interventions, and institutionalization of successful practices, has offered a strong model for this change process. However, lessons from the institutional change and K-12 literature on whole systems reform also provide useful insights into ways in which the Achieving the Dream model might be expanded to have an even greater impact on students' achievement. Drawing from that literature, as well as from the interim findings from the Round 1 colleges presented in this report, this final chapter provides several recommendations for improving Achieving the Dream's model for institutional change.

\section{Improvements to the Leadership Model in Achieving the Dream}

\section{- Broaden the leadership model to include faculty, staff, and lower-level administrators.}

The model for institutional improvement under Achieving the Dream has focused heavily on the commitment and involvement of presidents and senior administrators in colleges' efforts to drive changes. Leadership commitment makes up the first step of the initiative's five-step model for increasing students' success and is the first principle in Achieving the Dream's recommended practices for institutional improvement. The initiative

\footnotetext{
${ }^{1}$ Kemple, Herlihy, and Smith (2005); Snipes, Doolittle, and Herlihy (2002); Bloom, Thompson, and Unterman (2010).

${ }^{2}$ Berends, Kirby, Naftel, and McKelvey (2001); Elmore and Burney (1996); Elmore (2000); Quint (2006).

${ }^{3}$ Snipes and Casserly (2004); Quint (2006); Balfanz and Legters (2005).
} 
has also provided key supports to enhance senior leaders' involvement, including a presidential coach and a number of annual events, such as Trustee Institutes and focused discussions at the annual Strategy Institutes.

While presidential involvement further enhanced a number of colleges' work in Achieving the Dream, the involvement of senior leaders, mid- and lower-level administrators, faculty, and staff in the leadership process was often a stronger determinant of a college's success in achieving broad-based change. For instance, many colleges that built up their databased decision-making capacity had senior, or even lower-level, administrators leading their Achieving the Dream work, with presidents who were only minimally involved. Alternately, several colleges that struggled with Achieving the Dream had presidents who were leading the colleges' work. Finally, while many strong Achieving the Dream colleges had visionary presidents, a number of colleges with less influential leaders also made great progress in building a culture of evidence. Therefore, while presidential leadership may be useful in colleges' efforts to build a culture of evidence, the regular involvement of the college president does not appear to be the defining factor of colleges' success in fostering institutional change.

In contrast, a number of K-12 reform efforts have tended to focus on reforms that change the on-the-ground interactions among faculty, staff, and students, primarily through a revision of classroom practices and curriculum. ${ }^{4}$ Though improving students' academic outcomes remains difficult for many K-12 reforms, schools that have seen some successes with increasing students' achievement or workforce outcomes — such as New York City's "small schools of choice," Talent Development High Schools, and Career Academies - engaged teachers and other front-line staff as the key players in students' educational lives. ${ }^{5}$ These initiatives have tended to focus on the classroom as the primary vehicle for improving students' success, with a heavy focus on professional development and other leadership models that will directly affect instructors' practice and students' learning.

\footnotetext{
${ }^{4}$ Bryk et al. (2009); Stigler and Hiebert (1999); Elmore (2000); Quint, Thompson, and Bald (2008); Corrin et al. (2008); Bryk and Schneider (2002).

${ }^{5}$ New York City's "small schools of choice" are small, academically nonselective, four-year public high schools for students in grades 9 through 12, open to students at all levels of academic achievement and located in historically disadvantaged communities. See Bloom, Thompson, and Unterman (2010).

Talent Development, which targets some of the most troubled schools in the country, seeks to raise the expectations of teachers and students, with the ultimate goal of preparing all students for postsecondary education and employment. See Kemple, Herlihy, and Smith (2005).

The Career Academy approach is a widely established high school reform initiative aimed at improving students' performance in high school and providing them with clearer pathways to postsecondary education and careers. Career Academies are typically organized as schools-within-schools in an effort to create more supportive teaching and learning communities; they have a career theme and attempt to integrate a college preparatory academic curriculum with more applied, occupation-related courses; and they establish partnerships with local employers as a means of increasing students' awareness. See Kemple (2008); Kemple and Rock (1996); Quint, Bloom, Black, and Stephens (2005).
} 
While Achieving the Dream has promoted the inclusion of faculty and staff in colleges' core teams and developed several principles focused on professional development, the initiative to date has provided fewer formalized systems for integrating faculty and staff into the work to bring about change, instead leaving their inclusion largely up to individual college administrators, with variable results. Given the primary role that faculty and staff play in teaching and supporting students' learning, the initiative should focus more attention on directly engaging these personnel as leaders in the colleges' reform process. For instance, the initiative might involve mid-level managers more directly, such as department heads and deans, as a way to better affect faculty and staff practice. College faculty and staff could work with coaches to help amplify their voices in the institutional improvement process. Similarly, the initiative might develop more systematic ways for faculty and staff to share and build upon their knowledge of promising practices for improving student success and employ those individuals as mentors to new Achieving the Dream colleges. Finally, the initiative might designate a leadership team of faculty and staff that would work in tandem with senior administrators in developing the colleges' improvement agenda. Their valuable knowledge of students' successes and challenges would help bring a critical perspective to colleges' efforts to improve students' achievement.

\section{- Focus more directly on improving instruction and student services.}

To date, Achieving the Dream has focused on helping colleges improve student achievement by encouraging faculty, staff, and administrators to analyze data on student outcomes to identify priorities for reform and develop interventions to improve students' achievement. As noted in the preceding chapters, these recommendations have succeeded at increasing college personnel's awareness of their students' poor outcomes; however, they have less often led to the colleges' understanding of what practices they might use to improve these students' achievement. For instance, colleges often used their data analysis to identify broad areas of focus, such as developmental education, but then implemented a smattering of strategies that may or may not have addressed the core challenges these students were facing. While the initiative encourages colleges to use research and data to identify successful practices, in actuality many Round 1 colleges chose instead to implement strategies that were popular at other schools or that they had heard about at the initiative's Strategy Institutes. Additionally, few of those interventions focused on changing the instruction in content courses; instead, most concentrated on offering supplemental supports to students, such as tutoring, additional advising, or student success courses.

This disconnect between colleges' data analysis and choice of interventions highlights a chasm in Achieving the Dream's theory of change, which provides clear methods for colleges to identify their problems but offers less guidance on what practices might help resolve those problems. Recent research on K-12 reforms suggests that data-based decision making may not be enough to improve student achievement and, instead, schools should focus more sharply on 
instruction and the strategies for overcoming students' learning difficulties. ${ }^{6}$ Key to such efforts is focusing on a revision of the classroom practices and instruction that are most likely to change students' academic outcomes. For instance, in efforts to improve students' learning, the First Things First initiative - a comprehensive school reform model that seeks to address the impersonal nature and poor performance of many secondary schools serving disadvantaged students - included the implementation of professional development activities that are geared toward making classroom instruction more rigorous and engaging for students. ${ }^{7}$ Much research has posited that an intensive focus on improving the services and instruction that students receive are key pillars of successful school reform. ${ }^{8}$

Achieving the Dream could benefit from these efforts by helping colleges develop a more systematic approach to identifying promising reforms for improving students' achievement. As in K-12 models, in which principals serve as key instructional leaders, Achieving the Dream could encourage senior administrators to gain a deeper knowledge of their colleges' own classroom practices and build momentum for learning about new and improved ways of promoting students' achievement. Additionally, given the wide network that Achieving the Dream now encompasses, the initiative could encourage broader sharing of successful practices across institutions through professional workgroups or quarterly meetings, with a systematic focus on interventions that improve student learning. Such efforts might result in insights about what practices can actually change students' achievement and help colleges develop more refined methods for choosing their approaches to improve students' success.

\section{- Provide more support to colleges that are experiencing leadership turnover.}

Nearly half of the Round 1 colleges participating in Achieving the Dream experienced turnover in their senior leadership, including both presidents and other senior leaders, during their five years in the initiative. Such turnover created major difficulties for a number of colleges in terms of their progress within the initiative, as they were unable to develop clarity or momentum in their plans for improving student success. In fact, those colleges that had the greatest difficulties with Achieving the Dream tended to have high levels of turnover among their senior administrative staff.

Given that leadership turnover is a common part of the community college experience, Achieving the Dream should look for ways to help support colleges when they confront this experience. ${ }^{9}$ Diversifying colleges' leadership of Achieving the Dream, as suggested above,

\footnotetext{
${ }^{6}$ Wohlstetter, Datnow, and Park (2008); Wagner et al. (2006); Elmore (2000); Quint (2006).

${ }^{7}$ Quint, Bloom, Black, and Stephens (2005).

${ }^{8}$ Quint (2006); Bryk et al. (2009); Elmore (2000).

${ }^{9}$ Brock et al. (2007); Klein and Takeda-Tinker (2009); American Association of Community Colleges (2006).
} 
may help to smooth such transitions, as lower-level administrators, faculty, and staff are able to carry forward the colleges' efforts. Similarly, rather than involving only one or two central players in the colleges' work to implement changes, engaging a cadre of senior administrators and mid-level managers, such as deans and department heads, might help ensure that colleges are able to maintain their momentum if some of their senior leaders leave the institution. Finally, the initiative might look for additional ways to support colleges during these transition periods, such as providing additional coaching or mentoring, or developing more systematized guidelines for how colleges might continue their work during unsteady times.

\section{- Develop clearer guidelines for colleges' efforts to address racial, ethnic, and income achievement gaps.}

Achieving the Dream proposed that reducing racial, ethnic, and income achievement gaps was to be a critical part of colleges' work in the initiative. This message was a clear focus of several of the initiative's Strategy Institutes, and colleges were asked to report on their efforts each year as part of their annual reports. However, while many Round 1 college leaders expressed an interest in improving student success, relatively few colleges articulated a clear plan for closing achievement gaps across different racial, ethnic, and income groups. Colleges gave a number of reasons for this lack of focus, ranging from a desire to focus on other types of achievement issues, such as developmental education students' low success rates, to discomfort talking about race or income issues, to a lack of clarity about how to focus on these groups, particularly when these students made up a majority of a college's student population.

Such findings reveal that Achieving the Dream may need to further clarify its expectations for colleges' efforts to improve equity across racial, ethnic, and income lines and provide better guidance for colleges that are undertaking this work. Given that a number of colleges served highly disadvantaged populations, the initiative might consider how to structure its message with these schools and provide models for developing a more nuanced equity agenda in colleges whose students are mostly nonwhite or low-income.

Additionally, while the initiative encourages colleges to focus on equity, it does not require schools to develop this agenda when they join the initiative. If Achieving the Dream is serious about having colleges undertake this work, it might consider developing a more systematic approach for colleges to focus on these gaps throughout their participation in the initiative. Achieving the Dream might begin requiring colleges to submit a detailed statement of their plans to confront achievement gaps during the Kickoff Institute or during their planning year. Additionally, the initiative could require colleges to examine and report on their annual student outcome trends broken out by race, ethnicity, and income status. Finally, given that a number of colleges continued to be nervous about approaching sensitive issues of race and income, the initiative might consider providing specific coaching or mentoring to help build stronger 
leadership around this issue. Indeed, research suggests that institutions without good supports to tackle these issues are more likely to avoid these discussions. ${ }^{10}$

\section{Improvements to the Data Analysis Model in Achieving the Dream}

\section{- Develop stronger supports for colleges with weak institutional research capacity.}

While Achieving the Dream clearly had an effect on most colleges' data capacity, a group of Round 1 colleges continued to have difficulty collecting and analyzing student outcomes data throughout their five-year participation in the initiative. These schools were hampered by issues such as ineffective data systems, a lack of institutional research (IR) personnel, or insufficient capabilities to track and monitor students' achievement.

Given these colleges' sustained challenges and the centrality of data analysis to Achieving the Dream's framework, the initiative should consider more proactive ways of supporting colleges that enter with very weak data capacity. Several of these schools noted that their smaller sizes, rural locations, or challenging financial situations hindered their ability to improve their IR capacity. Achieving the Dream might, therefore, consider providing additional supports to colleges that have those risk factors. For instance, Achieving the Dream might wish to assign its strongest data facilitators to colleges with weak data capacity and provide more structured training for both the colleges and the coaches who are assisting them. Achieving the Dream might also consider offering more advice to financially strapped schools on how to support the often high costs associated with hiring new staff or obtaining new data systems, particularly the new hardware and software systems that are often used to analyze longitudinal data. Finally, Achieving the Dream might consider providing specialized help to those colleges that are unable to hire sufficient staff to manage their data needs. This may be particularly helpful for colleges that are located in rural areas, as they most often noted challenges with hiring skilled IR staff.

\section{- Incorporate more nuanced measures of student outcomes that relate directly to classroom practices and students' learning and progress.}

While the faculty and staff at the Round 1 colleges analyzed some data on students' achievement, results from the faculty and administrator survey revealed that data were not being used as regularly as the initiative leadership had hoped. Additionally, certain types of data, such

\footnotetext{
${ }^{10}$ Wooldridge and Gooden (2009); Gooden (2010a); Gooden (2010b).
} 
as measures that monitored the effect of classroom teaching on students' learning of specific course content, tended to be used more often than the institutional measures, such as graduation or persistence rates, that are the focus of Achieving the Dream. Finally, a number of faculty and staff noted greater involvement with their colleges' learning outcomes processes, which are designed to establish standards and assessments for what students should learn in particular courses tied to program learning outcomes. In fact, many Round 1 colleges were undertaking student learning outcomes initiatives in concert with their Achieving the Dream work, often in response to their accreditation requirements. However, the fruits of this work were rarely captured in Achieving the Dream's overarching measures of student achievement.

Given faculty and staff's interest in and involvement with student learning outcomes and classroom-level data, Achieving the Dream should consider incorporating such measures into its model for institutional improvement. In addition to being more relevant for faculty and staff, monitoring students' progress and completion of particular course sequences could aid colleges and the initiative in a number of other ways. For instance, these measures could provide a useful means for evaluating colleges' strategies and interventions, as they are able to capture changes in student learning, in addition to persistence and progression. Additionally,

processes for setting, assessing, and using student learning outcomes as a means of monitoring institutional improvement are now key requirements emphasized by all the regional accreditation agencies, providing a strong incentive for colleges to focus on them. Finally, and perhaps most important, student learning outcomes measures could provide interim checks on colleges' progress in improving students' achievement, as they might capture changes in student outcomes that may not be reflected in measures of institutional effectiveness.

\section{Improvements to the Broad Engagement Model in Achieving the Dream}

\section{- Concentrate efforts to involve adjunct faculty and staff.}

One of the most salient weaknesses in the Round 1 colleges' institutional reforms was the integration of adjunct or part-time faculty and staff into the change process. Very few Round 1 colleges found meaningful ways to bring together and support the development of those faculty and staff or to involve them in the strategies they were implementing. This is a critical oversight, particularly in light of the fact that adjunct faculty teach a large majority of students in developmental or gatekeeper introductory courses. If these part-time faculty members are not involved in the colleges' institutional improvement processes, then it is likely that large swaths of the colleges' student bodies will not be touched by their reforms. 
While Achieving the Dream currently recommends the involvement of part-time faculty and staff in the institutional reform process, the initiative should seek out new ways to further encourage colleges to pursue this work. This may be a challenge, given that many colleges noted that neither their budgets nor adjuncts' busy schedules allowed for more concentrated engagement efforts. However, colleges can learn from the few Round 1 colleges, such as Valencia, Patrick Henry, and Paul D. Camp, that found more systematic ways to support the inclusion of adjunct and part-time faculty. Some key aspects of their work included finding ways to give incentives to adjunct faculty to participate in strategy development, such as providing additional stipends or slight pay increases; developing centers devoted to the professional development of these faculty; finding ways to integrate part-time and full-time staff; and giving key leadership roles to adjunct faculty and staff when implementing the colleges' reforms.

\section{- Provide in-depth and meaningful professional development to all college personnel.}

One of the most critical discoveries in school reform research today is how poorly new models of instruction are integrated into classroom practice. Traditionally, most school systems have relied on one- or two-day conferences or trainings to teach faculty and staff about new teaching methods or reforms. ${ }^{11}$ However, studies have revealed that such professional development does little to change these individuals' everyday practice, as they become subsumed in their normal routines with little support for integrating their new learning into their practice. ${ }^{12}$ Instead, school reformers are now urging that institutions develop systematic professional development systems, which include training that is embedded within faculty's and staff's everyday practice and which utilize supports such as peer mentoring and coaching to create a continuous model of improvement. ${ }^{13}$ While professional development reforms alone do not necessarily lead to improved student achievement, ${ }^{14}$ a more systematic approach to training teachers has been a key tool that K-12 reformers have used to modify instructor practices and to gauge the effect that such practices have on students' learning.

Like most K-12 schools, few of the Round 1 Achieving the Dream colleges engaged in the type of systematic professional development that is recommended for truly changing practitioners' work; these colleges tended to focus instead on shorter workshops, conferences,

\footnotetext{
${ }^{11}$ Darling-Hammond et al. (2009); Elmore (2000).

${ }^{12}$ Troen and Boles (2003); Darling-Hammond et al. (2009).

${ }^{13}$ Stigler and Hiebert (1999); Darling-Hammond et al. (2009); Elmore (2000).

${ }^{14}$ Some studies, which have focused on the effects of increased professional development on student outcomes, have had disappointing results (Corrin et al., 2008; Garet et al., 2010). However, systematic professional development and training remains key in other K-12 efforts that have seen some success in increasing students' academic and workforce outcomes (Darling-Hammond et al., 2009).
} 
or presentations by various speakers as a way to influence practitioners' work. While those activities may be useful tools for exposing faculty and staff to new educational research, they are less likely to influence their classroom or support practices. Achieving the Dream may wish to place more emphasis on developing or supporting concrete and systemic professional development in community colleges. The initiative could learn from a few of the Round 1 colleges that implemented these more systematic professional development systems, such as Patrick Henry, with its training in collaborative learning.

\section{Recommendations for Policy Change}

While changes at the institutional level are important, some of the challenges that community colleges face are broader, more systemic issues related to funding and policy. Policymakers may wish to consider the following recommendations to support larger positive changes in community college students' success.

\section{- Continue to strengthen Achieving the Dream's state policy efforts and connect these actions to institution-level reforms.}

Achieving the Dream advocated a broad set of reforms aimed at improving community college students' success, both at the institutional and the state policy levels. While this report has focused primarily on institution-level changes, the initiative's state policy efforts, under the direction of Jobs for the Future (JFF), also met with a number of successes. For instance, the community college system in the state of Virginia has undertaken a broad revamping of its developmental education system, in large part a result of the policy work undertaken in Achieving the Dream. ${ }^{15}$ Texas is undertaking similar work at the state level in an effort to improve the achievement of its developmental education students. ${ }^{16}$

Continuing to strengthen such state-led reforms has a number of advantages for Achieving the Dream's efforts to improve students' success. First, as JFF's work has shown, changes at the state policy level can bring about changes at all colleges in a state, thereby ensuring that new reforms are implemented by a wide group of institutions rather than a select few that may be involved in Achieving the Dream. Second, states represent a major funding source for community colleges, so a focus on improving these institutions at the state level may help facilitate the dissemination of critical funding needed to undertake new reforms. States' economic hold on community colleges might also create greater accountability systems and ensure that colleges are fully enacting newly recommended changes. Finally, states can utilize existing organiza-

\footnotetext{
${ }^{15}$ Mills (2010); The Virginia Community Colleges Developmental Education Taskforce (2009).

${ }^{16}$ The Texas Higher Education Coordinating Board (2009).
} 
tions, such as statewide councils for presidents, faculty, and staff, as vehicles for engaging practitioners in new reforms. Tapping into such systems might also help counteract some of the challenges that the initiative has had in bringing these stakeholders into the work.

Given the important role that state policy reform can have in institutional change, Achieving the Dream should continue to focus its efforts in these areas. One avenue for strengthening this work further is to develop more open communication channels between institutions that are participating in Achieving the Dream and those that are involved in changes at the state policy level. While both parties are actively pursuing initiatives to improve student achievement, they less often have the opportunity to reflect with one another about how such changes are being implemented. Achieving the Dream has a number of avenues for promoting such conversations, including providing facilitated time at the Strategy Institute or coordinated reflections in newsletters or reports.

\section{- Provide targeted resources for community college improvement.}

One the greatest challenges facing community colleges today is severely restricted finances. Most community colleges survive on thin institutional budgets, especially when compared with their richer four-year counterparts. Indeed, community colleges' strapped financial situation is often the reason that they employ large numbers of adjunct faculty, who can be easily hired and fired at will. Community colleges' difficulties have only increased since the onset of the U.S. recession in 2007-2008, which has tightened state budgets and forced many states to make double-digit reductions in their higher education and community college funding. ${ }^{17}$

In order to accomplish the ambitious agenda that policymakers and foundations are encouraging, more funding is needed to support community colleges' endeavors. As can be seen in this report, many Round 1 colleges struggled to employ full-time faculty and staff and support their professional development. Given these challenges and the fact that broad institutional change also requires significant investments in staff and infrastructure, policymakers should continue to pursue ways to strengthen community colleges' financial profiles so that they can afford these endeavors.

\section{- Develop a more systematic approach to evaluating community colleges' strategies and interventions.}

Achieving the Dream and its funders have invested numerous resources in helping colleges pilot and scale new interventions aimed at improving student success. Additionally,

\footnotetext{
${ }^{17}$ Strauss (2009); Blumenstyk, Sander, Schmidt, and Wasley (2008); Davis (2009); Dooley (2009); Gruver (2009); Clark (2009).
} 
through its Strategy Institute and other venues, the initiative has helped colleges network about their efforts, with many schools developing very similar approaches to increasing students' achievement. However, despite the commonality in colleges' interventions, few rigorous analyses have been undertaken comparing the effects of these various interventions on students' achievement.

Given the multitude of colleges now participating in the initiative, Achieving the Dream has a strong platform for helping advance the field's knowledge about how specific reforms might affect students' achievement. With numerous colleges implementing similar strategies, the initiative, and the funders and policymakers who support it, might look to systematically test how variations in these programs might produce different impacts on students' achievement. For instance, analyzing the differences among several colleges' supplemental instruction programs and their effects on student achievement would provide more information about which type of program might work best for improving students' outcomes. A coordinated effort to analyze the differences in colleges' approaches - and the results of their efforts - would provide a substantial boon to both the initiative and community colleges at large given the relative dearth of rigorous research that is available on these programs.

\section{Conclusion}

Achieving the Dream has taken bold steps to improve community college students' achievement, and it has reaped many benefits from the hard work of its partners and participating colleges since it was launched in 2004. Many Round 1 colleges have exited their implementation years with stronger data capacity and a more nuanced understanding of the challenges that their students face. They have also developed a number of strategies to improve students' success and made efforts to move their institutions toward a greater focus on these students' needs. While larger changes in students' achievement may not yet have been realized, Achieving the Dream has begun an unprecedented movement toward helping colleges improve their students' outcomes and develop systems to sustain those efforts over the long term.

Based on the Round 1 colleges' experiences, a number of suggestions have been provided in this report to further strengthen Achieving the Dream's model. Bringing faculty and staff voices more concretely into colleges' reform work and focusing more directly on improvements to classroom instruction and services may have important benefits for the next stage of the initiative's work. Given the successes they have already had, the initiative and its partici-

pating colleges stand poised to move forward with this agenda and to make the changes that are needed to help community college students across the country accomplish their goals. 
Appendix A

Methodology for Survey of Faculty and Administrators at Achieving the Dream Colleges 

To examine patterns of and reasons for data use by faculty and administrators at Achieving the Dream colleges, the research team, comprising staff from MDRC and the Community College Research Center (CCRC), designed a survey to be delivered using selfadministered, online instruments. ${ }^{1}$

The research team developed two survey instruments through a process involving extensive internal review and revision. The instruments were pilot-tested in spring 2007 with faculty and administrators at three second-round Achieving the Dream colleges, ${ }^{2}$ and were further revised based on the responses and feedback from institutional researchers at the pilot colleges.

The administrator instrument contains 100 items, and the faculty instrument contains 101 items, most of which overlap. Both instruments ask questions on three main topics: (1) data accessibility, (2) data use and usefulness, and (3) familiarity with and involvement in Achieving the Dream. Most items use a seven-point Likert scale, ${ }^{3}$ although some are questions requiring only a "yes" or "no" response. Both instruments also ask for demographic information about the respondent and include an open-ended question about both the use of data at the respondent's college and views on Achieving the Dream.

The sampling frame included administrators and full-time faculty members at the colleges who joined the Achieving the Dream initiative in Round 1 (in summer 2004) and in Round 3 (in summer 2006). Three of the Round 1 colleges declined to participate in the survey, leaving 23 Round 1 colleges in five states (Florida, New Mexico, North Carolina, Texas, and Virginia) and 13 Round 3 colleges in two states (Pennsylvania and Washington).

The Human Resources Research Organization (HumRRO) administered the survey. HumRRO also participated in the final stages of questionnaire development. HumRRO staff were responsible for the Web programming to permit online administration of the survey, maintenance of the online survey, and management of the paper versions of the survey and of the telephone administration of the survey, and served as the primary contact for survey questions and technical difficulties. Finally, HumRRO provided CCRC with an interim data set in January 2008, and the final data set in February 2008.

\footnotetext{
${ }^{1}$ The survey methodology and respondent demographics and characteristics described here are from Jenkins and Kerrigan (2008), pp. 9-11.

${ }^{2}$ Colleges participating in the demonstration phase of the initiative joined the Achieving the Dream initiative in four "rounds" - Round 1, summer 2004; Round 2, summer 2005; Round 3, summer 2006; and Round 4, summer 2007.

${ }^{3} \mathrm{~A}$ Likert scale is a psychometric scale, often used in questionnaires and surveys, which allows respondents to express their level of agreement with a particular statement.
} 
The research team asked colleges to provide names, titles, and e-mail addresses for fulltime faculty members and administrators. For the purposes of this survey, "administrator" was defined as anyone at the assistant/associate director level and above, but the colleges were allowed to decide whom to include in this category. In cases where a college provided the team with all nonfaculty positions, the list of administrators was edited based on the job titles that were provided. This process generated a list of 2,209 full-time administrators.

The faculty survey was confined to full-time faculty members, since many colleges do not collect contact information on adjunct faculty at the college level. Because some of the larger colleges had a large number of faculty, a single-stage sampling procedure was used to reduce the number of faculty who were invited to participate in the study. At the colleges with faculties larger than 150, the team randomly selected 150 faculty members by automatically generating random numbers for each individual and then selecting the first 150, the minimum number that the team estimated was needed to ensure statistical rigor. Individuals who were no longer affiliated with a given college or were on leave were deleted, and the next person on the list was selected as a replacement. This process of replacement continued only during the presurvey phase, when e-mail addresses were being tested; once the survey was deployed, no replacements occurred. Through this process, 4,130 full-time faculty members were invited to participate in the study.

The survey was administered beginning in September 2007. To encourage a high response rate, a multiphase administration process was used. It began with a preliminary e-mail message designed to give advance notice of the survey and to test the list of e-mail addresses that the research team had received from the colleges. The next communication, one week later, was an e-mail message with the URL for the survey and a unique password for each respondent. The third e-mail message was sent as a follow-up one week later to everyone who had not yet responded. A fourth e-mail message was sent one month after the initial invitation. One week later, letters with a hard copy of the survey enclosed were mailed to all nonrespondents. The mailing of the hard copy letters coincided with a request to the college presidents to encourage their faculty and administrators to complete the survey. Phone administration of the survey to those who had not yet responded began just over two months after the initial e-mail message was sent. At that time, the colleges were approaching winter break, so efforts to contact the faculty and administrators at the colleges were suspended until after the new year. A final email message went to all nonrespondents, and the survey was concluded with a final one-week phone administration in the week following the February 2008 Achieving the Dream Strategy Institute, which was attended by teams from every participating college.

The survey achieved a response rate of 60 percent from the faculty surveyed and a 73 percent response rate from the administrators. Response rates varied considerably by college. Responses to the faculty survey ranged from a low of 37 percent at one college to a high of 85 
percent at another. College response rates to the administrator survey ranged from 57 percent to 93 percent.

Respondent demographics of faculty and administrators were fairly similar across colleges. Of the faculty respondents, 56 percent were female, and of the administrators, 62 percent were female. The majority of faculty and administrator survey respondents, more than 78 percent, identified themselves as white. The next largest group comprised those who identified themselves as Hispanic/Latino/Spanish; they made up 12 percent of the faculty and 15 percent of the administrators. Black, Asian or Pacific Islander, and American Indian or Alaskan Native faculty accounted for 8 percent, 3 percent, and 2 percent of the faculty respondents, respectively. Black administrators made up 12 percent of the administrator respondents. Asian or Pacific Islanders and American Indian or Alaskan Natives made up 3 percent and 1 percent of administrator respondents, respectively. Ten percent of faculty and 8 percent of administrators identified themselves as "other."

More than 62 percent of the faculty who completed the survey taught in academic transfer/general education areas. Administrators involved in academic affairs and instruction made up 20 percent of the respondents, and those in student affairs/student services accounted for 18 percent of the respondents. The institutional research staff accounted for just over 3 percent of the respondents. 

Appendix B

Technical Appendix 



\section{Data}

JBL Associates, a higher education consulting firm, is compiling the Achieving the Dream database with student-level data from all of the participating colleges. These data, used to measure progress on Achieving the Dream's five student outcome indicators, ${ }^{1}$ include demographic characteristics, transcript information, and associate's degrees and certificates for fall cohorts of credential-seeking students enrolling in college for the first time at each college. The database includes students who are seeking short-term certificates, longer-term certificates, and associate's degrees both full time and part time. This is the population tracked by the Integrated Postsecondary Education Data System (IPEDS), with the addition of part-time students. The colleges have submitted regular updates on each cohort, which make it possible to track the outcomes for the students over the course of the initiative.

\section{Regression Model Used to Estimate Mean Student Outcomes}

Student-level data from the Achieving the Dream database are aggregated to produce institutional averages. Ordinary least squares regression is employed to estimate the following model:

$$
y_{i t}=\alpha+\beta_{1} 2005_{i}+\beta_{2} 2006_{i}+\beta_{3} 2007 i+\gamma T+X_{i t} \Delta+V_{S} \Phi+\varepsilon_{i t},
$$

where

$y_{i t}=$ the average of the two-year student outcome measure for institution $i$

$2005_{i}=1$ if the institutional average $i$ is part of the post-initiative cohort of 2005, and 0 otherwise

$T=$ a time trend employed to account for trends in institutional outcomes established prior to the start of the initiative (so that changes in the postinitiative period are not overshadowed by pre-initiative trends)

\footnotetext{
${ }^{1}$ The five measures of student success in Achieving the Dream are (1) completion of developmental courses and progression to credit-bearing courses; (2) completion of so-called gatekeeper courses, including introductory college courses in English and math; (3) completion of attempted courses with a grade of "C" or better; (4) persistence from semester to semester and from year to year; and (5) attainment of college credentials.
} 


$$
\begin{aligned}
X_{i t}= & \text { a matrix of average institutional student characteristics, including the } \\
& \text { proportion of males, age at cohort entry, the proportion of students in } \\
& \text { several race/ethnicity categories, and the proportion of students who } \\
& \text { have nonresident alien status } \\
V_{s}= & \text { a matrix of state indicator variables } \\
\varepsilon_{i t}= & \text { a random error term for observation } i \text {, which is assumed to vary by col- } \\
& \text { lege - that is, } \varepsilon_{i t}=v_{i}+u_{t} \text {, where } u_{t} \text { is assumed to be independently } \\
& \text { and identically distributed }
\end{aligned}
$$

\section{Alternative Trend Breaks}

Given that Achieving the Dream had a long "ramp-up" phase, it is important to determine when to mark the start of the Achieving the Dream period. While the analyses in Chapter 8 use 2005 to represent the official start of Achieving the Dream, earlier chapters in this report show that the actual implementation of Achieving the Dream varied widely. As a result, the period after 2005 may be too early for many colleges and possibly too late for others (if they had started to implement changes prior to being selected to join the Achieving the Dream initiative). This issue is addressed in two ways:

1. The provision of the Achieving the Dream grants in 2004 is used as a proxy for the start of the Achieving the Dream initiative in 2005, as done in the Achieving the Dream baseline report. ${ }^{2}$

2. Since the precise timing of the start of the initiative is unknown, data on student outcomes were used to identify when a structural break in trend occurs as opposed to imposing a period for the break. ${ }^{3}$ Since implementation of Achieving the Dream varied by college, as indicated by the field research findings in this report, student-level data are examined to indicate when implementation of the Achieving the Dream model may have occurred.

The results from the structural break analysis suggest that the initiative was implemented in 2005 (see Appendix Table B.1). The analyses, therefore, use 2002-2004 as the preinitiative period.

\footnotetext{
${ }^{2}$ Brock et al. (2007).

${ }^{3}$ Piehl, Cooper, Braga, and Kennedy (1999); Andrews (1993).
} 
Achieving the Dream: Community Colleges Count

Appendix Table B.1

Alternative Trend Breaks in Interim Performance Indicators

\begin{tabular}{|c|c|c|}
\hline Performance Indicators & $\begin{array}{r}\text { Maximum } \\
\text { Test Statistic } \\
\end{array}$ & $\begin{array}{r}\text { Year of } \\
\text { Maximum } \\
\end{array}$ \\
\hline \multicolumn{3}{|l|}{ Referred to any developmental courses $^{\mathrm{a}}(\%)$} \\
\hline$\overline{\text { Developmental math }}$ & 1.6 & 2005 \\
\hline Attempted course within first year & 1.3 & 2005 \\
\hline Completed requirement within 1 year & 2.7 & 2006 \\
\hline Developmental English & 1.3 & 2004 \\
\hline Attempted course within first year & 4.1 & 2005 \\
\hline Completed requirement within 1 year & 7.3 & 2005 \\
\hline Developmental reading & 2.3 & 2005 \\
\hline Attempted course within first year & 0.5 & 2006 \\
\hline Completed requirement within 1 year & 1.9 & 2005 \\
\hline \multicolumn{3}{|l|}{ Successfully completed gatekeeper courses $^{\mathrm{a}, \mathrm{b}}(\%)$} \\
\hline \multicolumn{3}{|l|}{ Gatekeeper math course within first year, among students referred to } \\
\hline developmental math ${ }^{\mathrm{c}}$ & 6.2 & 2005 \\
\hline Gatekeeper English course within first year, among students referred to & 10.4 & 2005 \\
\hline \multicolumn{3}{|l|}{$\underline{\text { Course completion }}^{\mathrm{d}}$} \\
\hline Attempted credits within first year & 0.0 & 2005 \\
\hline Completed credits within first year & 7.7 & 2004 \\
\hline Ratio of completed credits to attempted credits within first year (\%) & 5.7 & 2004 \\
\hline Completed 80 percent or more of attempted credits within first year $(\%)$ & 6.1 & 2004 \\
\hline \multicolumn{3}{|l|}{ Persistence (\%) } \\
\hline Enrolled in first semester after initial term of enrollment & 3.8 & 2006 \\
\hline
\end{tabular}

SOURCE: MDRC calculations using the Achieving the Dream database maintained by JBL Associates.

NOTES: Calculations for this table used all available data for sample members in the fall 2002 through fall 2007 cohorts at Achieving the Dream Round 1 colleges to derive averages of the performance indicators. The sample size used in the table is $N=421,202$, years 2002 through 2007. Figures control for student characteristics and state. The chi-squared critical values for testing for a break in trend with appropriate trimming are 5.95 at the 10 percent level of statistical significance, 7.4 at the 5 percent level, and 10.8 at the 1 percent level.

${ }^{\text {a }}$ Grade of "C" or better must be earned to successfully complete a course.

${ }^{b}$ Gatekeeper math is the first college-level math course at the college; gatekeeper English is the first college-level English course at the college.

${ }^{\mathrm{c} C a l c u l a t i o n s}$ used data for sample members who have developmental referral data.

${ }^{\mathrm{d}}$ Completion with a grade of " $\mathrm{D}$ " or better is reported for this block of outcomes. Credits completed with a grade of "C" or better was not introduced as a variable until the 2007 JBL submission guide was released. 



\section{References}

Achieving the Dream. 2008. Evaluation Guidelines for Achieving the Dream Institutions Rounds One through Four. Chapel Hill: MDC, Inc.

Achieving the Dream. 2009. Field Guide for Improving Student Success. Chapel Hill: MDC, Inc.

American Association of Community Colleges (AACC). 2006. Competencies for Community College Leaders. Washington, DC: AACC.

American Association of Community Colleges (AACC). 2009. Community College Enrollment Survey: An Analysis of Estimated Fall 2009 Headcount Enrollments at Community Colleges. Washington, DC: AACC.

Andrews, Donald. 1993. "Tests for Parameter Instability and Structural Change with Unknown Change Point." Econometrica 61, 4: 821-856.

Arenson, Karen W. 2003. "Ballot Measure Seen in Wake of Court Ruling." New York Times (July 10). Web site: http:/www.nytimes.com/2003/07/10/us/ballot-measure-seen-in-wake-of-courtruling.html.

Associated Press. 2008. "Neb. Voters Approve Ban on Affirmative Action." USA Today (November 5). Web site: http://www.usatoday.com/news/politics/2008-11-05-491640836_x.htm.

Balfanz, Robert, and Nettie Legters. 2005. The Graduation Gap: Using Promoting Power to Examine the Number and Characteristics of High Schools with High and Low Graduation Rates in the Nation and Each State. Center for Social Organization of Schools (CSOS) Policy Brief (January). Baltimore: CSOS.

Berends, Mark, Sheila Nataraj Kirby, Scott Naftel, and Christopher McKelvey. 2001. Implementation and Performance in New American Schools: Three Years into Scale-Up. Santa Monica: RAND.

Berkner, Lutz, Shirley He, and Emily Forrest Cataldi. 2002. Descriptive Summary of 1995-96 Beginning Postsecondary Students: Six Years Later. NCES 2003-151. Washington, DC: National Center for Education Statistics, Institute of Education Sciences, U.S. Department of Education.

Biswas, Rhada Roy. 2006. A Supporting Role: How Accreditors Can Help Promote the Success of Community College Students. Boston: Jobs for the Future.

Biswas, Rhada Roy. 2007. Accelerating Remedial Math Education: How Institutional Innovation and State Policy Interact. Boston: Jobs for the Future.

Bloom, Dan, and Colleen Sommo. 2005. Building Learning Communities: Early Results from the Opening Doors Demonstration at Kingsborough Community College. New York: MDRC. 
Bloom, Howard, Saskia Levy Thompson, and Rebecca Unterman. 2010. Transforming the High School Experience: How New York City's New Small Schools Are Boosting Student Achievement and Graduation Rates. New York: MDRC.

Blumenstyk, Goldie, Libby Sander, Peter Schmidt, and Paula Wasley. 2008. "Community College Leaders Grapple with Budget Cuts, Accountability, and Competition." Chronicle of Higher Education (April 18).

Web site: http://chronicle.com/article/community-college-leaders/7576/.

Boylan, Hunter R., Barbara S. Bonham, and Leonard B. Bliss. 1994. "Characteristic Components of Developmental Education Programs.” Research in Developmental Education 11, 1: 1-4.

Boylan, Hunter R., Barbara S. Bonham, James Jackson, and D. Patrick Saxon. 1994. "Staffing Patterns in Developmental Education Programs: Full-Time/Part-Time, Credentials, and Program Placement." Research in Developmental Education 11, 5.

Brock, Thomas, Davis Jenkins, Todd Ellwein, Jennifer Miller, Susan Gooden, Kasey Martin, Casey MacGregor, and Michael Pih with Bethany Miller and Christian Geckeler. 2007. Building $a$ Culture of Evidence for Community College Student Success: Early Progress in the Achieving the Dream Initiative. New York: MDRC.

Brock, Thomas, and Lashawn Richburg-Hayes. 2006. Paying for Persistence: Early Results of a Louisiana Scholarship Program for Low-Income Parents Attending Community College. New York: MDRC.

Bryk, Anthony, and Barbara Schneider. 2002. Trust in Schools: A Core Resource for Improvement. New York: Russell Sage Foundation Publications.

Bryk, Anthony, Penny Sebring, Elaine Allensworth, Stuart Luppescu, and John Easton. 2009. Organizing Schools for Improvement: Lessons from Chicago. Chicago: The University of Chicago Press.

Chen, Grace. 2009. "Community College Curriculum: Drastically Changed by Today's Economy." Community College Review (August 20).

Clark, Kim. 2009. "Budget Cuts Take Toll on Education: Budget Cuts Have Hit Public Colleges Hard, Even as the Demand for a Well-Educated Workforce Soars." U.S. News and World Report (August 19).

Web site: http://www.usnews.com/articles/education/best-colleges/2009/08/19/budget-cuts-taketoll-on-education.html

Collins, Michael Lawrence. 2009. Setting up Success in Developmental Education: How State Policy Can Help Community Colleges to Improve Student Outcomes. Boston: Jobs for the Future.

Cook, Thomas D., and Donald T. Campbell. 1979. Quasi-Experimentation: Design and Analysis for Field Settings. Chicago: Rand McNally. 
Corrin, William, Marie-Andrée Somers, James J. Kemple, Elizabeth Nelson, and Susan Sepanik, with Terry Salinger and Courtney Tanenbaum. 2008. The Enhanced Reading Opportunities Study: Findings from the Second Year of Implementation. New York: MDRC.

Darling-Hammond, Linda, Ruth Chung Wei, Alethea Andree, Nikole Richardson, and Stelios Orphanos. 2009. "State of the Profession: Study Measures Status of Professional Development." Journal of Staff Development 30, 2: 42-44, 46-40.

Datnow, Amanda, and Marisa Castellano. 2001. "Managing and Guiding School Reform: Leadership in Success for All Schools." Educational Administration Quarterly 37, 2: 219-249.

Davis, Gene. 2009. "College Funding Dilemma: Community College Enrollments Up But Budget Cuts Slash Funding." Denver Daily News (August 10).

Web site: http://thedenverdailynews.com/article.php?aID=5259.

Dooley, Sheena. 2009. "Community College District Prepares to Make Budget Cuts." Quad City Times (October 14).

Dougherty, Kevin, and Esther Hong. 2006. "Performance Accountability as Imperfect Panacea." Pages 51-86 in Thomas Bailey and Vanessa Morest Smith (eds.), Defending the Community College Equity Agenda. Baltimore: Johns Hopkins University Press.

Downing, Skip. 2008. On Course: Strategies for Creating Success in College and in Life. 15th Edition. Boston: Houghton Mifflin.

Elmore, Richard F. 2000. Building a New Structure for School Leadership. Washington, DC: The Albert Shanker Institute.

Elmore, Richard, and Deanna Burney. 1996. Professional Development and Instructional Improvement in Community School District \#2, New York City. Philadelphia: University of Pennsylvania, Graduate School of Education, Consortium for Policy Research in Education.

Evans, Robert. 1996. The Human Side of Change. San Francisco: Jossey-Bass.

Friedman, Will. 2007. Strengthening Achieving the Dream Planning through Stakeholder Engagement: A Guide for Community College Leadership Teams. Chapel Hill: MDC, Inc.

Garet, Michael S., Andrew J. Wayne, Fran Stancavage, James Taylor, Kirk Walters, Mengli Song, Seth Brown, Steven Hurlburt, Pei Zhu, Susan Sepanik, and Fred Doolittle. 2010. Middle School Mathematics Professional Development Impact Study: After the First Year of Implementation. Washington, DC: Institute of Education Sciences.

Geckeler, Christian, with Carrie Beach, Michael Pih, and Leo Yan. 2008. Helping Community College Students Cope with Financial Emergencies: Lessons from the Dreamkeepers and Angel Fund Emergency Financial Aid Programs. New York: MDRC.

Gerstein, Amy. 2009. Community College Faculty and Developmental Education: An Opportunity for Growth and Investment. Stanford, CA: The Carnegie Foundation for the Advancement of Teaching. 
Gooden, Susan T. 2010a. “Assessing Agency Performance: The Wisconsin Experience.” In James Svara and Norman Johnson (eds.), Justice for All: Responsibilities and Actions to Promote Social Equity in Public Administration. Armonk, NY: M.E. Sharpe.

Gooden, Susan T. 2010b. "Social Equity in Public Administration: The Need for Fire." In Rosemary O'Leary, David M. VanSlyke, and Soonhee Kim (eds.), The Future of Public Administration, Public Management, and Public Services around the World: The Minnowbrook Perspective. Washington, DC: Georgetown University Press.

Gratz versus Bollinger, 359 U.S. 244 (2003).

Grutter versus Bollinger, 359 U.S. 306 (2003).

Gruver, Mead. 2009. "Wyoming Community College Budget Cuts Outlined." Billings Gazette (August 4).

Web site: http://billingsgazette.com/news/state-and-regional/wyoming/article_eef42b7c-812c11de-b29b-001cc4c03286.html.

Heifetz, Ronald. 1994. Leadership without Easy Answers. Cambridge, MA: Harvard University Press.

Jenkins, Davis, and Monica Reid Kerrigan. 2008. Evidence-Based Decision Making in Community Colleges: Findings from a Survey of Faculty and Administrator Data Use at Achieving the Dream Colleges. New York: Community College Research Center, Columbia University.

Jenkins, Davis, and Monica Reid Kerrigan. 2009. Faculty and Administrator Data Use at Achieving the Dream Colleges: A Summary of Survey Findings. New York: Community College Research Center, Columbia University, and MDRC.

Kemple, James J., with Cynthia J. Willner. 2008. Career Academies: Long-Term Impacts on Labor Market Outcomes, Educational Attainment, and Transitions to Adulthood. New York: MDRC.

Kemple, James J., Corinne M. Herlihy, and Thomas J. Smith. 2005. Making Progress Toward Graduation: Evidence from the Talent Development High School Model. New York: MDRC.

Kemple, James J., and JoAnn Leah Rock. 1996. Career Academies: Early Implementation Lessons from a 10-Site Evaluation. New York: MDRC.

Kerrigan, Monica Reid, and Doug Slater. 2010. Collaborating to Create Change: How El Paso Community College Improved the Readiness of Its Incoming Students Through Achieving the Dream. New York: Community College Research Center, Columbia University, and MDRC.

Klein, Jaime, and Becky Takeda-Tinker. 2009. "The Impact of Leadership on Community College Faculty Job Satisfaction.” Academic Leadership Online Journal 8, 4 (Spring).

Lumina Foundation for Education. 2002. "Community College Initiative Overview." Unpublished document. Indianapolis: Lumina Foundation for Education.

Manning, Terri M. 2009. Using Achieving the Dream to Meet Accreditation Requirements: Principles and Practices of Student Success. Indianapolis: Lumina Foundation for Education. 
McClure, Anne. 2010. "Community Colleges as Economic Saviors.” University Business: Solutions for Higher Education Management.

Web site: http://www.universitybusiness.com/viewarticle.aspx?articleid=1543.

MDC, Inc. 2006. Increasing Student Success at Community Colleges: Institutional Change in Achieving the Dream: Community Colleges Count. Chapel Hill, NC: MDC, Inc.

MDC, Inc. 2008. Integrated Action Plan: Institutional Change in Achieving the Dream: Community Colleges Count. Chapel Hill, NC: MDC, Inc.

Meier, Deborah. 2002. In Schools We Trust: Creating Communities of Learning in an Era of Testing and Standardization. Boston: Beacon Press.

Mills, Kay. 2010. Altered States: How the Virginia Community College System Has Used Achieving the Dream to Improve Student Success. Boston: Jobs for the Future.

Morest, Vanessa Smith, and Davis Jenkins. 2007. Institutional Research and the Culture of Evidence at Community Colleges. New York: Community College Research Center, Columbia University.

Murnane, Richard J., and Frank Levy. 1996. Teaching the New Basic Skills: Principles for Educating Children to Thrive in a Changing Economy. New York: The Free Press.

National Center for Education Statistics. 2002. Descriptive Summary of 1995-96 Beginning Postsecondary Students: Six Years Later. Washington, DC: U.S. Department of Education.

National Center for Education Statistics. 2009. "College Navigator.” Washington, DC: U.S. Department of Education, Institute for Education Sciences, Integrated Postsecondary Education Data System (IPEDS).

Web site: http://nces.ed.gov/collegenavigator.

National Center for Education Statistics. 2010. "IPEDS Data Center." Washington, DC: U.S. Department of Education, Institute for Education Sciences, Integrated Postsecondary Education Data System (IPEDS).

Web site: $h t t p: / / n c e s . e d . g o v / i p e d s / d a t a c e n t e r$.

Payzant, Thomas W., with Christopher M. Horan. 2007. "The Boston Story: Successes and Challenges in Systemic Education Reform. "In Paul Reville and Celine Coggins (eds.), Urban School Reform: Persistence and Progress in the Boston Public Schools. Cambridge, Mass.: Harvard Education Press.

Piehl, Anne Morrison, Suzanne J. Cooper, Anthony A. Braga, and David M. Kennedy. 1999. "Testing for Structural Breaks in the Evaluation of Programs." NBER Working Papers 7226. Washington, DC: National Bureau of Economic Research, Inc.

Provasnik, Stephen, and Michael Planty. 2008. Community Colleges: Special Supplement to the Condition of Education 2008. NCES 2008-033. Washington, DC: National Center for Education Statistics, Institute of Education Sciences, U.S. Department of Education. 
Quint, Janet. 2006. Meeting Five Critical Challenges of High School Reform: Lessons from Research on Three Reform Models. New York: MDRC.

Quint, Janet, Howard S. Bloom, Alison Rebeck Black, and LaFleur Stephens, with Theresa M. Akey. 2005. The Challenge of Scaling Up Educational Reform: Findings and Lessons from First Things First. New York: MDRC.

Quint, Janet, Saskia Levy Thompson, and Margaret Bald. 2008. Relationships, Rigor, and Readiness: Strategies for Improving High Schools. New York: MDRC.

Schochet, Peter. 2008. Technical Methods Report: Guidelines for Multiple Testing in Impact Evaluations. Washington, DC: U.S. Department of Education, Institute for Education Sciences.

Schuetz, Pam. 2002. "Instructional Practices of Part-time and Full-time Faculty." New Directions for Community Colleges 118: 39-46.

Scrivener, Susan, and Michael J. Weiss, with Jedediah J. Teres. 2009. More Guidance, Better Results? Three-Year Effects of an Enhanced Student Services Program at Two Community Colleges. New York: MDRC.

Senge, Peter. 1990. The Fifth Discipline: The Art and Practice of the Learning Organization. New York: Doubleday Currency.

Snipes, Jason, and Michael Casserly. 2004. "Urban School Systems and Education Reform: Key Lessons from a Case Study of Large Urban School Systems." Journal of Education for Students Placed at Risk 9, 2: 127-141.

Snipes, Jason, Fred Doolittle, and Corinne Herlihy. 2002. Foundations for Success: Case Studies of How Urban School Systems Improve Student Achievement. New York: MDRC.

Stigler, James, and James Hiebert. 1999. The Teaching Gap: Best Ideas from the World's Teachers for Improving Education in the Classroom. New York: Free Press.

Strauss, Valerie. 2009. "Community Colleges See Demand Spike, Funding Slip.” Washington Post (July 1).

Web site: http://www.washingtonpost.com/wp-dyn/content/article/2009/06/30/ AR2009063003786.html.

Texas Higher Education Coordinating Board. 2009. Statewide Developmental Education Plan 20102011 Biennium. Austin, TX: Texas Higher Education Coordinating Board.

Troen, Vivian, and Katherine C. Boles. 2003. Who's Teaching Your Children?: Why the Teacher Crisis Is Worse Than You Think and What Can Be Done About It. New Haven: Yale University Press.

Tyree, Lawrence W., Mark David Milliron, and Gerardo E. de la Santo (eds.). 2004. The Leadership Dialogues: Community College Case Studies to Consider. Phoenix, AZ: League for Innovation in the Community College. 
Virginia Community Colleges Developmental Education Taskforce. 2009. Turning Point: Developmental Education in Virginia's Community Colleges. Richmond, VA: Virginia Community College System.

Visher, Mary, Kristin Butcher, and Oscar Cerna, with Dan Cullinan and Emily Schneider. 2010. Guiding Developmental Math Students to Campus Services: An Impact Evaluation of the Beacon Program at South Texas College. New York: MDRC.

Visher, Mary, Emily Schneider, Heather Wathington, and Herbert Collado. 2010. Scaling Up Learning Communities: The Experience of Six Community Colleges. New York: MDRC.

Visher, Mary, Heather Wathington, Lashawn Richburg-Hayes, and Emily Schneider, with Oscar Cerna, Christine Sansone, and Michelle Ware. 2008. The Learning Communities Demonstration: Rationale, Sites, and Research Design. New York: MDRC.

Wagner, Tony, Robert Kegan, Lisa Lahey, Richard W. Lemons, Jude Garnier, Deborah Helsing, Annie Howell, and Harriette Thurber Rasmussen. 2006. Change Leadership: A Practical Guide to Transforming Our Schools. San Francisco, CA: Jossey-Bass.

Wallin, Desna L. (ed.). 2005. Adjunct Faculty in Community Colleges: An Academic Administrator's Guide to Recruiting, Supporting, and Retaining Great Teachers. Bolton, MA: Anker Publishing.

Weiss, Michael, Mary Visher, and Heather Wathington, with Jedediah Teres and Emily Schneider. 2010. Learning Communities for Students in Developmental Reading: An Impact Study at Hillsborough Community College. New York: MDRC.

Weissman, Evan, Kristin F. Butcher, Emily Schneider, Jedediah Teres, Herbert Collado, and David Greenberg, with Rashida Welbeck. Forthcoming. Learning Communities for Students in Developmental Math: Impact Studies at Queensborough and Houston Community Colleges. New York: MDRC.

Wohlstetter, Priscilla, Amanda Datnow, and Vicki Park. 2008. "Creating a System for Data-Driven Decision-Making: Applying the Principal-Agent Framework." School Effectiveness and School Improvement 19, 3: 239-259.

Wooldridge, Blue, and Susan Gooden. 2009. The Epic of Social Equity: Evolution, Essence, and Emergence." Administrative Theory and Praxis 31, 2: 225-237.

Zachry, Elizabeth, and Erin Coghlan, with Rashida Welbeck. 2010. Investing in Change: How Much Do Achieving the Dream Colleges Spend - and from What Resources - to Become DataDriven Institutions? New York: MDRC. 



\section{Earlier Publications on Achieving the Dream}

Investing in Change

How Much Do Achieving the Dream Colleges Spend — and from What Resources - to Become Data-Driven Institutions?

2010. Elizabeth M. Zachry and Erin Coghlan with Rashida Welbeck.

Terms of Engagement

Men of Color Discuss Their Experiences in Community College

2010. Alissa Gardenhire-Crooks, Herbert Collado, Kasey Martin, and Alma Castro with Thomas Brock and Genevieve Orr.

Collaborating to Create Change

How El Paso Community College Improved the Readiness of Its Incoming Students Through

Achieving the Dream

2010. Monica Reid Kerrigan and Doug Slater.

Guiding Developmental Math Students to Campus Services

An Impact Evaluation of the Beacon Program at South Texas College

2010. Mary G. Visher, Kristin F. Butcher, and Oscar S. Cerna with Dan Cullinan and Emily

Schneider.

Building Student Success From the Ground Up

A Case Study of an Achieving the Dream College

2009. Elizabeth Zachry and Genevieve Orr.

Achieving the Dream Colleges in Pennsylvania and Washington State

Early Progress Toward Building a Culture of Evidence

2009. Davis Jenkins, Todd Ellwein, John Wachen, Monica Reid Kerrigan, and Sung-Woo Cho.

Faculty and Administrator Data Use at Achieving the Dream Colleges

A Summary of Survey Findings

2009. Davis Jenkins and Monica Reid Kerrigan.

Promising Instructional Reforms in Developmental Education

A Case Study of Three Achieving the Dream Colleges

2008. Elizabeth M. Zachry with Emily Schneider.

Evidence-Based Decision Making in Community Colleges

Findings from a Survey of Faculty and Administrator Data Use at Achieving the Dream Colleges 2008. Davis Jenkins and Monica Reid Kerrigan.

Building a Culture of Evidence for Community College Student Success

Early Progress in the Achieving the Dream Initiative

2007. Thomas Brock, Davis Jenkins, Todd Ellwein, Jennifer Miller, Susan Gooden, Kasey

Martin, Casey MacGregor, and Michael Pih with Bethany Miller and Christian Geckeler.

NOTE: A complete publications list is available from MDRC and on its Web site (www.mdrc.org), from which copies of reports can also be downloaded. 



\section{About MDRC}

MDRC is a nonprofit, nonpartisan social and education policy research organization dedicated to learning what works to improve the well-being of low-income people. Through its research and the active communication of its findings, MDRC seeks to enhance the effectiveness of social and education policies and programs.

Founded in 1974 and located in New York City and Oakland, California, MDRC is best known for mounting rigorous, large-scale, real-world tests of new and existing policies and programs. Its projects are a mix of demonstrations (field tests of promising new program approaches) and evaluations of ongoing government and community initiatives. MDRC's staff bring an unusual combination of research and organizational experience to their work, providing expertise on the latest in qualitative and quantitative methods and on program design, development, implementation, and management. MDRC seeks to learn not just whether a program is effective but also how and why the program's effects occur. In addition, it tries to place each project's findings in the broader context of related research - in order to build knowledge about what works across the social and education policy fields. MDRC's findings, lessons, and best practices are proactively shared with a broad audience in the policy and practitioner community as well as with the general public and the media.

Over the years, MDRC has brought its unique approach to an ever-growing range of policy areas and target populations. Once known primarily for evaluations of state welfare-to-work programs, today MDRC is also studying public school reforms, employment programs for exoffenders and people with disabilities, and programs to help low-income students succeed in college. MDRC's projects are organized into five areas:

- Promoting Family Well-Being and Children's Development

- Improving Public Education

- Raising Academic Achievement and Persistence in College

- Supporting Low-Wage Workers and Communities

- Overcoming Barriers to Employment

Working in almost every state, all of the nation's largest cities, and Canada and the United Kingdom, MDRC conducts its projects in partnership with national, state, and local governments, public school systems, community organizations, and numerous private philanthropies. 
